\title{
Venous oxygen saturation and oxygen transport in the newborn period : an experimental and clinical study
}

Citation for published version (APA):

van der Hoeven, M. A. H. B. M. (1999). Venous oxygen saturation and oxygen transport in the newborn period : an experimental and clinical study. [Doctoral Thesis, Maastricht University]. Universiteit Maastricht. https://doi.org/10.26481/dis.19990623mh

Document status and date:

Published: 01/01/1999

DOI:

10.26481/dis.19990623mh

Document Version:

Publisher's PDF, also known as Version of record

\section{Please check the document version of this publication:}

- A submitted manuscript is the version of the article upon submission and before peer-review. There can be important differences between the submitted version and the official published version of record.

People interested in the research are advised to contact the author for the final version of the publication, or visit the DOI to the publisher's website.

- The final author version and the galley proof are versions of the publication after peer review.

- The final published version features the final layout of the paper including the volume, issue and page numbers.

Link to publication

\footnotetext{
General rights rights.

- You may freely distribute the URL identifying the publication in the public portal. please follow below link for the End User Agreement:

www.umlib.nl/taverne-license

Take down policy

If you believe that this document breaches copyright please contact us at:

repository@maastrichtuniversity.nl

providing details and we will investigate your claim.
}

Copyright and moral rights for the publications made accessible in the public portal are retained by the authors and/or other copyright owners and it is a condition of accessing publications that users recognise and abide by the legal requirements associated with these

- Users may download and print one copy of any publication from the public portal for the purpose of private study or research.

- You may not further distribute the material or use it for any profit-making activity or commercial gain

If the publication is distributed under the terms of Article $25 \mathrm{fa}$ of the Dutch Copyright Act, indicated by the "Taverne" license above, 
Venous oxygen saturation and oxygen transport in the newborn period An experimental and clinical study 
Copyright ${ }^{\circ} 1999$ M.A.H.B.M.van der Hoeven

All rights reserved. No part of this publication may be reproduced, stored in a retrieval system, or transmitted, in any form or by any means, electronic, mechanical, photocopying, recording or otherwise without the prior written permission of the author.

For information: M.A.H.B.M. van der Hoeven, Hoge Kanaaldijk 13, 6212 XR Maastricht.

Venous oxygen saturation and oxygen transport in the newborn period. An experimental and clinical study.

Thesis University of Maastricht - with ref.- with summary in Dutch

ISBN $90-9012779-8$

Subject headings: venous oxygen saturation; oxygen transport; newborn infants

Production: Datawyse | Universitaire Pers Maastricht 


\section{Venous oxygen saturation and oxygen transport in the newborn period}

An experimental and clinical study

Proefschrift

ter verkrijging van de graad van doctor aan de Universiteit Maastricht, op gezag van de Rector Magnificus, Prof.dr. A.C. Nieuwenhuijzen Kruseman, volgens het besluit van het College van Decanen, in het openbaar te verdedigen op woensdag 23 juni 1999 om 16.00 uur, door

Markus Antonius Henricus Benedictus Maria van der Hoeven 


\section{Promotor}

Prof.dr. C.E. Blanco

\section{Co-promotor}

Dr. W.J. Maertzdorf

\section{Beoordelingscommissie}

Prof.dr. R.A.M.G. Donckerwolcke (voorzitter)

Prof.dr. S. Bambang Oetomo (Rijksuniversiteit Groningen)

Prof.dr. H. Kuipers

Prof.dr. S. de Lange

Prof.dr. D. Tibboel (Erasmus Universiteit, Rotterdam) 
aan Brigitte aan Casper

Lisa Sabine 



\section{Abbreviations}

Chapter 1 Introduction and aims of the study

Chapter 2 Oxygen transport: Review of the literature

Chapter 3 Mixed venous oxygen saturation $\left(\mathrm{SvO}_{2}\right)$ and biochemical parameters of hypoxia during progressive hypoxemia in 10-14 day old piglets.

Pediatric Research 1997,42:878-884

Chapter 4 Relationship between mixed venous oxygen saturation $\left(\mathrm{SvO}_{2}\right)$ and markers of tissue oxygenation in progressive hypoxic hypoxia and in isovolemic anemic hypoxia in 8-12 days old piglets.

Critical Care Medicine: In Press

Chapter 5 Feasibility and accuracy of a fiberoptic catheter for the measurement of venous oxygen saturation $\left(\mathrm{SvO}_{2}\right)$ in newborn infants.

Acta Paediatrica 1995;84:122-127

Chapter 6 Continuous central venous oxygen saturation $\left(\mathrm{ScvO}_{2}\right)$ measurement by a fiberoptic catheter in newborn infants.

Archives Diseases in Childhood; Fetal Neonatal Ed. 1996;74:F177-F188

Chapter 7 Central venous oxygen saturation $\left(\mathrm{ScvO}_{2}\right)$ and derived variables at different ranges of arterial oxygenation in newborn infants with respiratory insufficiency.

Submitted

Chapter 8 Summary and conclusions.

Chapter 9 Samenvatting

Dankwoord 
AH

ARDS

ATP

$\mathrm{CaO}_{2}$

$\mathrm{cvO}_{2}$

$\mathrm{ccvO}_{2}$

$\mathrm{c}(\mathrm{a}-\mathrm{v}) \mathrm{O}_{2}$

$\mathrm{COHb}$

$\mathrm{DO}_{2}$

$\mathrm{DO}_{2}$ enit

2,3-DPG

ECMO

$\mathrm{FiO}_{2}$

F.O.E.

FOE crit

$\mathrm{Hb}$

$\mathrm{HbF}$

$\mathrm{HH}$

$\mathrm{HHb}$

IRDS

$\mathrm{MetHb}$

$\mathrm{O}_{2} \mathrm{Hb}$

$\mathrm{P}_{50}$

$\mathrm{P}_{90}$

$P_{\text {ao }}$

$\mathrm{P}_{\text {pulm }}$

$\mathrm{PaCO}_{2}$

$\mathrm{P}_{\mathrm{Alv}} \mathrm{O}_{2}$

$\mathrm{paO}_{2}$

$\mathrm{pvO}_{2}$

Qt

ROP

$\mathrm{SaO}_{2}$

$\mathrm{ScvO}_{2}$

$\mathrm{SvO}_{2}$

$\mathrm{SvO}_{2}$ crit

$\mathrm{VO}_{2}$ anemic hypoxia

acquired respiratory distress syndrome

adenosine triphosphate

total arterial oxygen content $(\mathrm{ml} / \mathrm{dl})$

mixed venous oxygen content $(\mathrm{ml} / \mathrm{dl})$

central venous oxygen content $(\mathrm{ml} / \mathrm{dl})$

difference between arterial and venous oxygen content $(\mathrm{ml} / \mathrm{dl})$

carboxyhemoglobin

oxygen delivery $\left(\mathrm{ml}^{\mathrm{m}} \mathrm{min}^{-1} \cdot \mathrm{kg}^{-1}\right)$

critical value of oxygen delivery $\left(\mathrm{ml} \cdot \mathrm{min}^{-1} \cdot \mathrm{kg}^{-1}\right)$

2,3-diphosphoglycerate ( $\mathrm{mmol} / \mathrm{l})$

extracorporeal membrane oxygenation

fractional inspiratory oxygen concentration

fractional oxygen extraction

critical value of fractional oxygen extraction

hemoglobin $(\mathrm{mmol} / \mathrm{l})$

fetal hemoglobin (mmol/l)

hypoxic hypoxia

deoxyhemoglobin

idiopathic respiratory distress syndrome

methemoglobin

oxyhemoglobin

partial pressure of oxygen at $50 \%$ oxygen saturation $(\mathrm{kPa}$, torr)

partial pressure of oxygen at $90 \%$ oxygen saturation $(\mathrm{kPa}$, torr)

mean aortal blood pressure $(\mathrm{mmHg})$

mean pulmonary blood pressure $(\mathrm{mmHg})$

arterial partial pressure of carbon dioxide $(\mathrm{kPa}$,torr)

alveolar partial pressure of oxygen $(\mathrm{kPa}$, torr)

arterial partial pressure of oxygen $(\mathrm{kPa}$, torr)

mixed venous partial pressure of oxygen $(\mathrm{kPa}$, torr)

cardiac output $\left(\mathrm{ml} \cdot \mathrm{min}^{-1} \cdot \mathrm{kg}^{-1}\right)$

retinopathy of prematurity

arterial oxygen saturation (\%)

central venous oxygen saturation (\%)

mixed venous oxygen saturation (\%)

critical value of mixed venous oxygen saturation (\%)

oxygen consumption $\left(\mathrm{ml} \cdot \mathrm{min}^{-1} \cdot \mathrm{kg}^{-1}\right)$ 


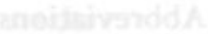


Chapter 1

General introduction and aims of the study 


\section{General introduction and aims of the study}

The transport of oxygen and carbon dioxide to and from the cells is essential for cell integrity. Oxygen is needed as the final electron acceptor to obtain energy coupled to the formation of ATP in the mitochondria. Carbon dioxide is the end product of the aerobic degradation of carbohydrate and fat molecules. In a multicellular organism gas transport constitutes of three main components including 1) gas exchange with the environment (lung), 2) the actual transport from the gas exchange unit to and from the cells (blood and heart) and 3) the gas uptake by the cells from the blood and vice versa. The aim of medical intensive care is to preserve the human organism by maintaining cellular and organ integrity. For this, 1) gas exchange with the environment is supported by oxygen supply and/or mechanical ventilation. 2) Gas transport to the cells is sustained by improving heart function and increasing hemoglobin, the main transport medium for oxygen. 3) Oxygen uptake and cell integrity is monitored by biochemical parameters of hypoxia as lactate and pyruvate.

\section{Venous oxygen saturation}

The measurement of venous oxygen saturation in the pulmonary artery - mixed venous oxygen saturation $\left(\mathrm{SvO}_{2}\right)$ - is the average of all the oxygen saturations of the venous blood from all the different organs. Within this measurement all aspects of the oxygen transport (delivery: hemoglobin, $\mathrm{SaO}_{2}$ and cardiac output) and tissue oxygen uptake are integrated. The fact that $\mathrm{SvO}_{2}$ is an average value and that it is an integrated measurement of different aspects of oxygen transport is at the same time the strength and the weakness of this measurement.

The strength of the integrated measurement is the fact that one is informed about the tissue oxygen uptake together with the oxygen delivery to the tissues, in contrast to other routine measurements in intensive care as hemoglobin, $\mathrm{paO}_{2}, \mathrm{SaO}_{2}$ and cardiac output, which refer only to oxygen delivery to the tissues.

The weakness of the $\mathrm{SvO}_{2}$ measurement as an average value is that a normal value cannot exclude an oxygen restricted metabolism in one or more organs. Another difficulty referring to the integrated aspect of the $\mathrm{SvO}_{2}$ value is how to interpret an abnormal value, since it is dependent on so many different variables. At last, in the case of sepsis or ARDS and "pathologic oxygen supply dependency" a disorder in tissue oxygen uptake has been assumed and questionable normal or high $\mathrm{SvO}_{2}$ values were encountered. In spite of these drawbacks many adult intensive care units have adopted the continuous $\mathrm{SvO}_{2}$ measurement as a standard routine care, since it provides at least a trend of the balance between oxygen delivery and tissue oxygen uptake.

\section{Neonatal intensive care}

In neonatal intensive care the mentioned methods to support the integrity of the organism are as just as important as in adult intensive care.

However, in neonatal medicine several additional problems are encountered: 1) the transition from intra-uterine to extra-uterine environment associated with the switch of the gas exchange unit and with a concomitant increase of $\mathrm{paO}_{2} .2$ ) Gas transport is affected by an increased concentration of fetal hemoglobin with a low amount of 2,3-DPG and 
decreased $p_{s_{0}}$ resulting in a left-warded shift of the oxygen dissociation curve. 3) Gas transport is affected by an increased cardiac output. 4) Oxygen uptake by the cells is increased in the neonatal period compared with adults.

Another aspect of oxygen transport in the neonatal period is the toxic effects of oxygen. Several long term consequences of prematurity as retinopathy of prematurity, bronchopulmonary dysplasia and necrotizing enterocolitis are associated with oxygen toxicity. Considering this, the monitoring of oxygen transport to the tissues has attracted a lot of attention. Oxygen transport is measured intermittently by samples taken of arterial blood to determine $\mathrm{paO}_{2}$ and $\mathrm{SaO}_{2}$. The current continuously measured oxygen parameter is $\mathrm{SaO}_{2}$ by pulse oximetry. However this parameter only assesses the delivery of oxygen to the tissues and not the tissue oxygen uptake or the oxygen extraction.

For this, it was suggested to measure venous oxygen saturation $\left(\mathrm{SvO}_{2}\right)$ to monitor

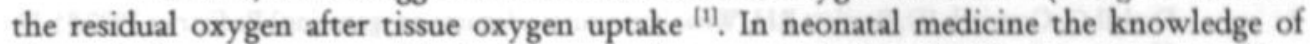
the real tissue oxygen uptake is extremely important, because both, hypoxia as well as hyperoxia have their damaging effects. An umbilical venous catheter positioned into the right atrium with a fiberoptic device should make it possible to measure central venous oxygen saturation $\left(\mathrm{ScvO}_{2}\right)$ continuously.

Five studies were performed to examine the possibilities and limitations of $\mathrm{SvO}_{2}$ measurement in newborn infants and are reported in this thesis.

\section{Outline of the thesis}

Review of the literature. In this thesis four main aspects of oxygen transport will be surveyed. The review will focus on I) physiology of oxygen transport, subdivided into paragraphs describing definitions and terminology, oxygen cascade and venous oxygen saturation.

The consequences and compensatory mechanisms of II) bypoxia at cellular level and at systemic level are reviewed as far as this is related to methods used in our studies. For example, lactate and pyruvate were used in two studies to monitor tissue oxygenation. Consequently, the metabolism of lactate and pyruvate will be discussed in this review, in contrast to, for example, the ventilatory response during hypoxia, which was not related to our studies.

The assessment of the oxygen saturation in the blood as provided by III) oximetry, the cornerstone of the fiberoptic technique to measure $\mathrm{SvO}_{2}$, is reviewed featuring general principles, reliability and accuracy of fiberoptic and pulse oximetry.

IV) The management of improving oxygen transport will be described in two paragraphs containing on one hand the historical and current use of oxygen in neonatal medicine and on the other hand the debate on the $\mathrm{DO}_{2} / \mathrm{VO}_{2}$ relationship and the strategy to optimize $\mathrm{DO}_{2}$ and $\mathrm{SvO}_{2}$ in adult intensive care.

Aims of the study: Since our interest in $\mathrm{SvO}_{2}$ measurement primarily was motivated by the aspect of the tissue oxygen uptake of the integrated $\mathrm{SvO}_{2}$ measurement we addressed the following questions:

1) What is the relation between tissue oxygenation and the $\mathrm{SvO}_{2}$ value?

2) Is this relation between tissue oxygenation and $\mathrm{SvO}_{2}$ different when oxygen delivery to the tissues is reduced by different methods?

To examine the clinical possibilities of the $\mathrm{SvO}_{2}$ measurement in the newborn period, the following questions were addressed: 
3) Is it possible to measure $\mathrm{SvO}_{2}$ continuously in a newborn infant? Where? Are the $\mathrm{SvO}_{2}$ values reliable and accurate?

4) What is the normal range of $\mathrm{SvO}_{2}$ values in stable newborn infants breathing room air? What is the relation between $\mathrm{SaO}_{2}$ and $\mathrm{SvO}_{2}$ values?

5) What is the range of $\mathrm{SvO}_{2}$ values during the acute phase of IRDS during mechanical ventilation and oxygen administration? What is the relation between $\mathrm{SaO}_{2}$ and $\mathrm{SvO}_{2}$ values and derived calculations such as venous admixture and fractional oxygen extraction? What is the value of $\mathrm{ScvO}_{2}$ in clinical neonatal medicine.

1 Dudell G, Cornisch JD, Bartlett RH. What constitutes adequate oxygenation? Pediatrics 1990;85:3941 
Transport: Reviang of the Literature 
Chapter 2

Oxygen Transport: Review of the Literature

I Physiology of Oxygen Transport

II Hypoxia

III Monitoring Oxygen; Oximetry

IV Therapeutic Management to improve Oxygen Transport 61 References 


\section{Physiology of Oxygen Transport}

\section{Definitions and terminology}

Atmosphere, oxygen and evolution

\section{Oxygen Cascade}

Inspired $p \mathrm{O}_{2}$

Alveolar $\mathrm{pO}_{2}$

The alveolar/arterial $p \mathrm{O}_{2}$ difference

Venous admixture or shunt

Ventilation / perfusion (V/Q) scatter

Oxygen transport by bemoglobin

Adult Hemoglobin ( $\mathrm{HbA}$ )

Structure and stereochemistry

Oxygen affinity

Hemoglobin switching

Fetal hemoglobin $(\mathrm{HbF})$

Structure

Oxygen affinity

Modulation of oxygen affinity

Clinical studies on modulating oxygen affinity

Oxygen uptake by the tissues

Tissue vascular geometry

Kinetics of the oxyhemoglobin dissociation

Intracapillary resistance to oxygen

Myoglobin

Constant and uniform oxygen consumption

Oxygen consumption within the cells

Glycolysis

Citric acid cycle

Oxidative phosphorylation

Fat and protein

The mitochondrion: the end-organelle for oxygen consumption

Anatomy and function

Uncoupling the electron transfer from the ATP synthesis.

The genome of mitochondria

The mitochondrion during perinatal development

Venous oxygen saturation 


\section{Definitions and terminology of quantities related to oxygen transport.}

A set of definitions of the different quantities pertaining on the oxygen transport by the blood was described by several authors recently ${ }^{[2,5]}$. Some confusion has arisen about the definition of fundamental quantities as oxygen saturation and fractional oxyhemoglobin. In this chapter a set of definitions is given with the current symbols in relation to their measurement.

1.1 Oxygen tension $\left(\mathrm{pO}_{2}\right)$ is expressed in $\mathrm{kPa}$ or $\mathrm{mmHg}$ (Torr). The oxygen tension of the blood is defined as being equal to the partial pressure of oxygen in the gas mixture with which the blood is in equilibrium. Partial pressure is defined as the substance fraction of oxygen times the total pressure of the gas mixture [1]. The end-capillary $\mathrm{pO}_{2}$ determines the oxygen flow to the tissues.

1.2 Oxygen content or concentration of total oxygen $\left(\mathrm{ctO}_{2}\right)$ is determined by the sum of the concentration of oxygen associated with hemoglobin $\left(\mathrm{cO}_{2}(\mathrm{Hb})\right)$ and the concentration of oxygen dissolved in the blood not associated with a protein $\left(\mathrm{cO}_{2}(\right.$ free $\left.)\right)$.

$$
\mathrm{ctO}_{2}=\mathrm{cO}_{2}(\mathrm{Hb})+\mathrm{cO}_{2}(\text { free })
$$

The freely dissolved oxygen is determined by the solubility constant for oxygen $\left(\alpha \mathrm{O}_{2}\right)$ and oxygen tension.

$$
\mathrm{cO}_{2}(\text { free })=\alpha \mathrm{O}_{2} \cdot \mathrm{pO}_{2}
$$

The solubility constant for oxygen $\left(\alpha \mathrm{O}_{2}\right)=0.01 \mathrm{mmol} / \mathrm{L} \cdot \mathrm{kPa}$ or $0.0031 \mathrm{ml} / \mathrm{dl} . \mathrm{mmHg}$ or $0.0225 \mathrm{ml} / \mathrm{dl} . \mathrm{kPa}$

1.3 Concentration of oxygen associated with hemoglobin $\left(\mathrm{cO}_{2}(\mathrm{Hb})\right)$ is determined by the concentration hemoglobin capable of binding oxygen and by oxygen saturation $\left(\mathrm{SO}_{2}\right)$.

1.4 Concentration of hemoglobin capable of binding oxygen involves only hemoglobin bound to oxygen (oxyhemoglobin, $\mathrm{cO}_{2} \mathrm{Hb}$ ) or that which can bind oxygen (deoxyhemoglobin, $\mathrm{cHHb}$ ).

1.5 Oxygen saturation $\left(\mathrm{SO}_{2}\right)$ is simply the fraction or percentage of hemoglobin bound to oxygen compared with the hemoglobin capable of binding. This quantity can be measured by a spectrophotometric measurement of oxyhemoglobin $\left(\mathrm{cO}_{2} \mathrm{Hb}\right)$ and deoxyhemoglobin $(\mathrm{cHHb})^{[2]}$.

$$
\mathrm{SO}_{2}=\mathrm{cO}_{2} \mathrm{Hb} /\left(\mathrm{cO}_{2} \mathrm{Hb}+\mathrm{cHHb}\right)
$$

1.6 Concentration of total hemoglobin $(\mathrm{ctHb})$ is the sum of all hemoglobin derivates as oxyhemoglobin, $\mathrm{cO}_{2} \mathrm{Hb}$, deoxyhemoglobin, $\mathrm{cHHb}$, and those derivates, not capable of binding oxygen, the dyshemoglobins (cdysHb) including carboxyhemoglobin $(\mathrm{cCOHb})$, methemoglobin $(\mathrm{cMetHb})$, and other unnamed non-oxygen binding hemoglobin derivates.

$$
\mathrm{ctHb}=\mathrm{cO}_{2} \mathrm{Hb}+\mathrm{cHHb}+\mathrm{cCOHb}+\mathrm{cMetHb}+\mathrm{cdysHb}
$$


Since oxygen saturation $\left(\mathrm{SO}_{2}\right)$ involves only oxyhemoglobin and deoxyhemoglobin it can be measured spectrophotometrically without measuring carboxyhemoglobin or methemoglobin by simple spectrophotometers or by pulse oximeters and fiberoptic reflectance spectroscopy. In multiwavelengths spectrophotometers several dyshemoglobins can be determined. Oxygen saturation $\left(\mathrm{SO}_{2}\right)$ can then be determined by application of the subsequent equation ${ }^{[1,2,3]}$ :

$$
\mathrm{SO}_{2}=\mathrm{cO}_{2} \mathrm{Hb} /(\mathrm{ctHb}-\mathrm{cCOHb}-\mathrm{cMetHb}-\mathrm{cdysHb})
$$

1.7 Fractional Oxyhemoglobin $\left(\mathrm{FO}_{2} \mathrm{Hb}\right)$ is the fraction of oxyhemoglobin compared with the concentration of total hemoglobin. This quantity is essentially different from saturation as can be seen when the two equations (5) and (6) are compared.

$$
\mathrm{FO}_{2} \mathrm{Hb}=\mathrm{cO}_{2} \mathrm{Hb} / \mathrm{ctHb}
$$

These two quantities have been frequently confused, since in many subjects there is no or minimal dyshemoglobin present. However, when substantial amounts of dyshemoglobin are present, the results of oximeters, measuring only $\mathrm{cO}_{2} \mathrm{Hb}$ and $\mathrm{cHHb}$ as pulse oximeters and fiberoptic reflectance oximeters, are different to the results of multiwavelengths spectrophotometers. This discrepancy has led to the introduction of new terms as functional and fractional oxygen saturation ${ }^{[+7]}$. Since the terminology and symbols used meet the international standards and recommendations these new terms were called unnecessary and self-contradictory ${ }^{[1,2,4]}$. The use of a special symbol for $\mathrm{SO}_{2}$ as measured by the pulse oximeter $\left(\mathrm{SpO}_{2}\right)$ and the proposal to introduce a symbol for the oxygen saturation value given by a Hewlett Packard, for example, as $\mathrm{S}_{\text {hp }} \mathrm{O}_{2}$ or that of Oximetrix as $\mathrm{S}_{\mathrm{x}} \mathrm{O}_{2}$ was rejected. The symbol for a measured value must be independent of the (limitations of the) method and of the manufacturer ${ }^{[5]}$.

The fraction of each hemoglobin derivate can be defined in the same way as for fractional oxyhemoglobin.

Fractional deoxyhemoglobin $\mathrm{FHHb}=\mathrm{cHHb} / \mathrm{ctHb}$

Fractional carboxyhemoglobin $\mathrm{FCOHb}=\mathrm{cCOHb} / \mathrm{ctHb}$

Fractional methemoglobin $\mathrm{FCOHb}=\mathrm{cMetHb} / \mathrm{ctHb}$

To illustrate the different use of the terms of saturation and fractions two definitions of the total concentrations of oxygen are given:

Firstly as the total concentration of oxygen as defined in equation (1)

$$
\mathrm{ctO}_{2}=\mathrm{cO}_{2}(\mathrm{Hb})+\mathrm{cO}_{2}(\text { free })
$$

which may be rewritten in terms of saturation:

$$
\mathrm{ctO}_{2}=\left(\left(\mathrm{cO}_{2} \mathrm{Hb}+\mathrm{cHHb}\right) \cdot 1.39 \cdot \mathrm{SO}_{2}\right)+\left(\mathrm{pO}_{2} \cdot \alpha \mathrm{O}_{2}\right)
$$

where 1.39 is an oxygen-hemoglobin binding constant based on molecular level studies of hemoglobin expressed as the maximal amount of oxygen $(\mathrm{ml})$ can be bound to hemoglobin (gram). And secondly, as equation (7), which may also be expressed in terms of fractional 
concentrations $^{[2,3]}$ :

$$
\mathrm{ctO}_{2}=\left(\mathrm{ctHb} \cdot 1.39 \cdot \mathrm{FO}_{2} \mathrm{Hb}\right)+\left(\mathrm{pO}_{2} \cdot \alpha \mathrm{O}_{2}\right)
$$




\section{Atmosphere, Oxygen and Evolution}

A discussion about oxygen transport should start with some remarks on the origin of oxygen in the atmosphere and evolution to aerobic metabolism.

The earth was formed 4.6 billion years ago by accretion of solid material condensed from the solar nebula ${ }^{[8,9]}$. Two crucial factors have contributed to the origin of an oxidizing atmosphere around the earth: The intermediate gravitational field, resulting both in a retention of heavier gases as oxygen, carbon dioxide and nitrogen and in an escape of lighter gases as hydrogen and helium. Smaller planets as Mercury have a weak gravitational field with no atmosphere at all, whereas large planets as Jupiter and Saturn with a strong gravitational field retain all gases including hydrogen and helium ensuring a reducing atmosphere. The other factor is the temperature that enables water to be in the liquid form.

A primitive atmosphere was formed by the decomposition of inner earth material and brought into the atmosphere by active volcanos. The water vapor in the primitive atmosphere rained out to form the oceans, when the surface of the earth had cooled sufficiently. It has been shown, that under the influence of electric discharges and ultraviolet radiation in the then existing environment a number of organic molecules could originate. Encapsulation by lipid membranes of these organic compounds has been achieved in the laboratory situation.

Although the next step in the evolution could not be reproduced, it seems likely that generated polymers of nucleotides (RNA) eventually were able to catalyze their own replication and to synthesize polypeptides ${ }^{[10]}$. These processes led 3.5 billion years ago to the formation of living cells. Early cells produced adenosine tri-phosphate (ATP) by the conversion of reduced compounds into organic acids as lactic, formic and succinic acid. (ATP has the unique property to store energy in high "energy bonds", which can be used everywhere in the cell.) To protect the cells from the acidic environment cells tended to develop membrane-bound $\mathrm{H}^{+}$pumps driven by electron transfer or / and ATP hydrolysis [11]. Reversal of the ATP driven $\mathrm{H}^{+}$pump made them function as an ATP-synthase. By combining parts of the electron transfer chains photosynthetic bacteria could employ the radiant energy of the sun to use $\mathrm{H}_{2} \mathrm{O}$ as an electron donor to convert $\mathrm{N}_{2}$ and $\mathrm{CO}_{2}$ to amino acids and carbohydrates and oxygen was released to the atmosphere as a waste product. The increase of oxygen in the atmosphere was very slowly, and has been dated 2 billion years ago. By geological evidence it is assumed that the current level of atmospheric oxygen was attained between 1.5 to 0.5 billion years ago. Because of the availability of oxygen some bacteria developed the ability to use oxygen as the final electron acceptor and lost the capability to photosynthesis. Mitochondria first arose when such aerobic bacteria were endocytosed by primitive eucaryotic cells. The more favourable energy conversion supported eucaryotic cells with mitochondria to express their genetic information in different ways and to evolve to multi-cellular organisms. 


\section{The Oxygen Cascade ${ }^{[12]}$}

Oxygen is vital for the effective generation of ATP. Generally it is assumed that the critical oxygen level in the mitochondrion is $0.1-0.3 \mathrm{kPa}^{[12,13]}$. Consequently, an oxygen gradient exists between the air and the mitochondrion: the oxygen cascade. The different steps of this cascade will be discussed, subsequently.

\subsection{Inspired $\mathrm{pO}_{2}\left(\mathrm{p}_{i} \mathrm{O}_{2}\right)$}

The normal value of the concentration of atmospheric oxygen is $20.94 \%$ or 0.2094 fractional concentration. When gas is humidified with the inhalation through the respiratory tract, the oxygen will be diluted and the $\mathrm{pO}_{2}$ will be reduced. Therefore, the inspiratory $\mathrm{pO}_{2}\left(\mathrm{P}_{i} \mathrm{O}_{2}\right)$ at a body temperature of $37^{\circ} \mathrm{C}$ and a barometric pressure of 760 $\mathrm{mmHg}$ is:

$$
\begin{aligned}
& \mathrm{p}_{1} \mathrm{O}_{2}=0.2094 \cdot(760-47)-149 \mathrm{~mm} \mathrm{Hg} \\
& \mathrm{p}_{1} \mathrm{O}_{2}=0.2094 \cdot(101.3-6.3)=19.9 \mathrm{kPa}
\end{aligned}
$$

\subsection{Alveolar $\mathrm{pO}_{2}\left(\mathrm{p}_{\mathrm{Alv}} \mathrm{O}_{2}\right)^{[12,14]}$}

Alveolar oxygen tension is the result of the oxygen delivered by the alveolar ventilation and the oxygen uptake by pulmonary blood and oxygen consumption. The relation between $\mathrm{P}_{\mathrm{Al}} \mathrm{O}_{2}$ and alveolar ventilation is described by a hyperbola with the horizontal asymptote equivalent to the $\mathrm{p}_{\mathrm{i}} \mathrm{O}_{2}$. By increasing the inspiratory oxygen concentration $\left(\mathrm{FiO}_{2}\right)$ the relation is changed in so far that the horizontal asymptote is increased. An increase in $\mathrm{VO}_{2}$ will also modify the relation between $\mathrm{P}_{\mathrm{Alv}} \mathrm{O}_{2}$ and alveolar ventilation: as $\mathrm{VO}_{2}$ increases, $\mathrm{P}_{\mathrm{Alv}} \mathrm{O}_{2}$ is reduced even when alveolar ventilation increases.

The simplified form of the alveolar oxygen tension equation is:

$$
\mathrm{p}_{\mathrm{Alv}} \mathrm{O}_{2}=\mathrm{p}_{\mathrm{i}} \mathrm{O}_{2}-\mathrm{P}_{\mathrm{Alv}} \mathrm{CO}_{2} / \mathrm{RQ}+\mathrm{F}
$$

RQ is the respiratory exchange ratio, that corrects for the fact that usually less carbondioxide is produced than oxygen is consumed. $\mathrm{F}$ is a correction factor for the differences in volume between inspired and expired volume of gas. The $\mathrm{P}_{\mathrm{Alv}} \mathrm{O}_{2}$ in a patient, whose RQ is 0.8 , is $108 \mathrm{mmHg}$.

An inverse relationship exists between $\mathrm{p}_{\mathrm{Alv}} \mathrm{CO}_{2}$ and alveolar ventilation. When alveolar ventilation decreases, $\mathrm{P}_{\mathrm{Alv}} \mathrm{CO}_{2}$ increases proportionally. It is generally accepted that $\mathrm{P}_{\mathrm{Alv}} \mathrm{CO}_{2}$ differs very little from the partial pressure of $\mathrm{CO}_{2}$ in the arterial blood $\left(\mathrm{p}_{2} \mathrm{CO}_{2}\right)$. This is why $\mathrm{P}_{2} \mathrm{CO}_{2}$ is accepted as an indicator for hypo- or hyperventilation ${ }^{[14]}$.

\subsection{The alveolar/arterial $\mathrm{pO}_{2}$ difference}

The next step in the oxygen cascade is of great importance and plays a major role in the pathophysiology of many respiratory disorders. Normally in a healthy adult the alveolar/arterial $\mathrm{pO}_{2}$ difference will not exceed $2 \mathrm{kPa}(15 \mathrm{mmHg})^{[12]}$. Two main causes of an increased alveolar/arterial $\mathrm{pO}_{2}$ difference will be discussed.

\subsubsection{Venous admixture or shunt ${ }^{[15]}$}

Venous admixture is defined as the degree of admixture of mixed venous blood with pulmonary end-capillary blood, which would be required to produce the observed difference between the arterial and the pulmonary end-capillary $\mathrm{pO}_{2}$. (usually taken to 
equal ideal alveolar $\mathrm{p}_{\mathrm{Al}} \mathrm{O}_{2}$ ). Venous admixture is a calculated amount of blood to produce the observed arterial $\mathrm{pO}_{2}$ and not the actual amount of venous blood, which mingles with arterial blood. Venous admixture is thus a convenient index, but defines neither the precise volume nor the anatomical pathway of the shunt. There are different pathways of the shunt venous admixture:

a) Venae cordis minimae (thebesian veins) are small veins of the left heart which drain directly into the left chamber. The venous blood has a low oxygen content and produces a substantial decrease of the arterial $\mathrm{pO}_{2}$.

b) bronchial veins: venous drainage of the lung pass directly to the pulmonary veins; The flow is $1 \%$ or less from the cardiac output. However, it can increase in bronchiectasis, emphysema and coarctation of the aortae to values of $10 \%$.

c) congenital heart disease

d) pulmonary infection

e) pulmonary oedema

In neonatal medicine venous admixture did not get as much attention as in adult intensive care medicine, but recently the values of venous admixture were studied in a group of preterm mechanically ventilated newborn infants ${ }^{[16]}$. A range between $10 \%$ and $40 \%$ was defined in this group of patients.

\subsubsection{Ventilation / perfusion (V/Q) scatter}

There are two important reasons why a scatter of V/Q values results in an increased alveolar / arterial $\mathrm{pO}_{2}$ difference.

a) Increased flow of blood through lung regions with a low V/Q ratio and with a low $\mathrm{p}_{\mathrm{a}} \mathrm{O}_{2}$ cannot be balanced by the decreased amount of blood with a high $\mathrm{p}_{2} \mathrm{O}_{2}$ perfusing lung regions with a high $\mathrm{V} / \mathrm{Q}$ ratio.

b) The $\mathrm{p}_{2} \mathrm{O}_{2}$ of the blood that has passed through the low V/Q regions is disproportional low by the position of the oxygen dissociation curve in comparison to the increase of the $\mathrm{p}_{\mathrm{a}} \mathrm{O}_{2}$ of the blood passed through the regions of the lung with a high V/Q ratio.

In neonatal medicine the scatter of V/Q ratios has been discussed by Krauss [17] and was determined to play a role in the first hours after birth and in respiratory disorders as meconium aspiration and transient tachypnoea of the newborn.

\section{4}

Oxygen transport by hemoglobin

Oxygen transport to and from the tissues is dependent on the oxygen affinity of the hemoglobin molecule. Hemoglobin is made up of four polypeptide globin chains each holding one heme. Heme consists of a porphyrin ring with an atom of a two valency ferrous iron at its centre, that is capable to form a reversible bond with oxygen without being irreversibly oxidized to the three valency ferric iron ${ }^{[18]}$.

\subsubsection{Adult Hemoglobin (HbA)}

\subsubsection{Structure and stereochemistry}

Hemoglobin is a tetramer containing four polypeptide globin chains, two $\alpha$ and two $\beta$ chains, joined by variable contacts. The contacts between $\alpha_{1}$ and $\beta_{1}$ and between $\alpha_{2}$ and $\beta_{2}$ are the most extensive and remain the same in oxy- and deoxyhemoglobin. However, the contacts between $\alpha_{1}$ and $\beta_{2}$ and between $\alpha_{2}$ and $\beta_{1}$ are changed during oxygenation. These changes are associated with a shift in the quaternary structure of hemoglobin from the tense $(\mathrm{T})$ state (low-oxygen affinity, "deoxyhemoglobin") to the 
relaxed (R) state (high-oxygen affinity, "oxyhemoglobin"). The T state is stabilized by electrostatic bounds between the subunits of the molecule ${ }^{[19]}$. When oxygen is bound to the ferrous iron of the heme, the iron is pulled into the plane of the porphyrin ring. This movement is transmitted to the globin subunit and weaken these electrostatic bounds that stabilized the $\mathrm{T}$ state. This initiates the quaternary structure change from $\mathrm{T}$ state to $\mathrm{R}$ state.

Due to these conformational changes needed in the $\mathrm{T}$ state and due to the orientation of the heme in the globin the binding of oxygen in the T state is energetically unfavourable in contrast to oxygen binding in the $\mathrm{R}$ state. The $\mathrm{R}$ state has consequently an affinity for oxygen 100 fold higher than that of the $T$ state. The switch from $T$ state to $R$ state normally takes place when the second or the third molecule of oxygen is bound.

As oxygen binds to hemoglobin, the equilibrium between the $T$ and $R$ states of hemoglobin shifts to a higher concentration of the $\mathrm{R}$ state and this accounts for the sigmoid shape of the oxyhemoglobin dissociation curve ${ }^{[8,19]}$.

\subsubsection{Oxygen affinity}

The affinity of oxygen for hemoglobin is illustrated by the position of the oxyhemoglobin dissociation curve: Oxygen saturation plotted against oxygen tension yield the characteristic sigmoid shape of the oxyhemoglobin dissociation curve. The affinity of oxygen for hemoglobin is reflected by the $\mathrm{p}_{50}$, which expresses the oxygen tension at which $50 \%$ of the hemoglobin is bound to oxygen. The $p_{50}$ can be estimated with an acceptable accuracy from $\mathrm{pH}, \mathrm{pO}_{2}$ and oxygen saturation paired values ${ }^{[20.22]}$. A significant error could be induced in the estimation of the $\mathrm{p}_{50}$, particularly if $\mathrm{p}_{50}$ is calculated from an oxygen saturation values at the extremes of the oxyhemoglobin dissociation curve ${ }^{[22]}$. The position of the oxyhemoglobin dissociation curve is affected by several factors. For example, a shift in the oxyhemoglobin dissociation curve to the right (increasing $\mathrm{P}_{50}$ and lowering oxygen affinity) may be caused by a decrease in $\mathrm{pH}$, an increase in $\mathrm{pCO}_{2}$, an increase in 2,3diphosphoglycerate (2,3-DPG) and an increase in temperature ${ }^{[23]}$.

a) $\mathrm{pH}$ (Bobr effect) and $\mathrm{p} \mathrm{CO}_{2}$

Hydrogen ions lower the oxygen affinity of the $\mathrm{T}$ structure and slow down the transition from the $T$ to $R$ structure of the hemoglobin molecule. This effect is achieved by fortifying salt bridges of the $\mathrm{T}$ structure. The Bohr effect once more is affected by other factors as $\mathrm{pCO}_{2}, 2,3-\mathrm{DPG}$ and temperature in a interrelated way. $\mathrm{CO}_{2}$ reacts with uncharged amino-groups of both $\alpha$ and $\beta$ globins to form carbamate. Haldane effect accounts for the increased binding of $\mathrm{CO}_{2}$ to deoxyhemoglobin.

b) 2,3-diphosphoglycerate (2,3 DPG)

2,3-DPG is a metabolic intermediate of the anaerobic glycolysis. 2,3-DPG decreases oxygen affinity and increases $\mathrm{P}_{50}$. This effect of 2,3-DPG is achieved by two different mechanisms: 2,3-DPG forms salt bridges between the two $\beta$ globins of deoxyhemoglobin and consequently stabilizes the T state and 2,3-DPG is a highly charged anion and due to the impermeability of the erythrocyte cell membrane induces a decrease of the intracellular $\mathrm{pH}$ and consequently lower oxygen affinity by the Bohr effect.

\section{c) Temperature}

Perutz ${ }^{[18]}$ described the effect of temperature on the binding of hemoglobin and oxygen. The reaction of the heme-iron complex with oxygen is exothermic (gives off heat). Consequently, a rise in temperature hinders the reaction between heme and oxygen and shifts the oxyhemoglobin dissociation curve to the right. High temperatures decrease the affinity of hemoglobin and oxygen, whereas cold environmental temperatures increase oxygen hemoglobin affinity. This effect can also be demonstrated in hemoglobin monomers and is in fact impaired in the tetrameres of hemoglobin by increased heat absorption by heme-heme interaction. Adaptations of the hemoglobin molecule to different environmental 
temperatures have been described in different animals and species ${ }^{[24]}$.

For example, in arctic ruminants, such as reindeer a normal oxygen supply can be delivered to the peripheral tissues even at very low temperatures due to a low-temperature sensitivity of the hemoglobin molecule ${ }^{[25]}$. It was demonstrated by Condo et al. ${ }^{[26]}$ that the low temperature sensitivity of porcine blood occurred only in the presence of 2,3-DPG probably due to the interaction between 2,3-DPG, $\mathrm{Cl}$ and the hemoglobin molecule.

d) Other factors

Other factors as carboxyhemoglobin level, inorganic phosphate, chloride and bicarbonate ions, metabolic and endogenous states as activity, dormancy and developmental stage affect the function of hemoglobin and have been described in numerous different animals and species ${ }^{[24,27,28]}$.

\subsubsection{Hemoglobin switching}

Hemoglobin production in humans is characterized by two major "switches" during development in the hemoglobin composition of red cells. During the first 3 months of gestation, human red cells contain embryonic hemoglobins, whereas during the last 6 months of gestation red cells contain predominantly fetal hemoglobin. The transition from fetal to adult hemoglobin occurs during the perinatal period and first year of life ${ }^{[29]}$.

The functional genes for $\epsilon, \gamma$ and $\beta$ globins of the embryonic, fetal and adult hemoglobin, respectively, are situated on the human $\beta$ gene cluster on chromosome $11 \mathrm{p}$. The globin genes are arranged according to the order of their expression during ontogeny. It is not clear how their differential expression during development is regulated. The cellular factors involved in the process of gene switching are transcription factors, globin locus control region, cis-acting sequences, trans acting factors and chromosomal gene order $[29,30]$. The role of this last factor -the chromosomal gene order- was studied by Peterson et al [31]. The authors concluded that gene order played only a minor role in the globin gene switching.

It seems that the developmental maturity of the fetus or a developmental clock intrinsic to the cells determines the progression of hemoglobin switching ${ }^{[29]}$. Several observations support this concept. Hybrids of fetal erythroblasts or transplanted fetal stem cells switch according to the age of the fetus from which the erythroblasts were obtained. In addition, the administration to very low birth weight infants of recombinant erythropoietin did not delay nor increase the developmentally programmed decline of hemoglobin F synthesis ${ }^{[32]}$.

However, environmental factors can modulate the developmental clock of switching. Fetal hypoxemia ${ }^{[33]}$ during late gestation increased the $\mathrm{HbF}$ synthesis greater than can be expected for gestational age. In infants with congenital cyanotic heart disease ${ }^{[34]}$, bronchopulmonary dysplasia ${ }^{[35]}$ or severe anemia of prematurity ${ }^{[36]}$ higher levels of hemoglobin, total $\mathrm{HbF}$ and $\mathrm{HbF}$ synthesis were demonstrated. Furthermore, Bard et al. ${ }^{[37]}$ showed that the level of $\mathrm{HbF}$ seemed to be dependent on glucose level. Hyperglycemia accomplishes this effect by increased fetal oxidative metabolism and increased oxygen consumption resulting in fetal hypoxemia. It was demonstrated that the hyperglycemic fetus synthesized more fetal hemoglobin than expected for the period of fetal development. In adult life fetal hemoglobin continues to be produced in several inherited and acquired conditions ${ }^{[29]}$. 


\subsubsection{Fetal hemoglobin $(\mathrm{HbF})$}

\subsubsection{Structure}

The structure of fetal hemoglobin $(\mathrm{HbF})$ is very similar to that of $\mathrm{HbA}$, being a tetrameres with two $\alpha$ and two non $\alpha$ globins. The non $\alpha$ chains do not differ in the number but in the sequence of amino acids from $\beta$ chains and are designated $\gamma$ chains. In the $\gamma$ chain a difference has been found, that either alanine $\left(\gamma^{\text {ala }}\right)$ or glycine $\left(\gamma^{\mathrm{kly}}\right)$ may be present at position 136, without any functional significance. Bard et al. ${ }^{[8]}{ }^{[3]}$ investigated the change in $\gamma^{\text {sly }}$ to $\gamma^{\text {ata }}$ chain ratio in the switch over of $\mathrm{HbF}$ to adult HbA. The authors concluded that during initial decrease of $\mathrm{HbF}$ synthesis in preterm infants the ratio of $\gamma^{\text {ely }}$ and $\gamma^{\text {ata }}$ ratio did not change. But after a postconceptual age of $44 \mathrm{wk}$ when the $\mathrm{HbF}$ synthesis decreased below $42 \pm 15 \%$ the ratio became more variable and decreased. The relative amount of $\gamma^{\text {ely }}$ globins in fetal life is $70 \%$, whereas in adult life the small amount $\mathrm{HbF}$ synthesized contains around $40 \% \gamma^{\text {ely }}$ globins.

A separate component of $\mathrm{HbF}$, which is designated $\mathrm{HbF}_{\mathrm{b}}$, was found in $20 \%$ of the total $\mathrm{HbF}$. In $\mathrm{HbF}_{1}$ the glycine residues in either half or all of the $\gamma$ chains are bound with an acetyl group. 2,3 DPG does not interact at all with $\mathrm{HbF}_{1}$ and therefore, $\mathrm{HbF}_{1}$ has a very high affinity for oxygen.

\subsubsection{Oxygen affinity}

Fetal blood has a higher oxygen affinity than adult blood. However, this difference is disappeared, when $\mathrm{HbF}$ and $\mathrm{HbA}$ are isolated and stripped of phosphate. Therefore, the different interaction with 2,3-DPG is considered to be responsible for the difference in oxygen affinity between fetal and adult blood. The replacement in $\mathrm{HbF}$ of histidine by an uncharged serine reduces the binding sites with 2,3-DPG. In addition, a further reduction of 2,3-DPG binding sites in $\mathrm{HbF}_{1}$ explains the lack of any effect of 2,3DPG on oxygen affinity in $\mathrm{HbF}_{\mathrm{l}}$. The position of the oxyhemoglobin dissociation curve of fetal hemoglobin is affected by several factors as well.

a) $\mathrm{pH}$ (Bohr effect) and $\mathrm{p} \mathrm{CO}_{2}$ effect

The Bohr effect in fetal blood is not significantly different from that in adult blood. No separate $\mathrm{PCO}_{2}$ effect can be discerned in fetal blood with normal 2,3-DPG levels. This means that acidosis immediately effectuates a reduction of oxygen affinity by the Bohr effect. But since acidosis induces a reduction of 2,3-DPG, changes in oxygen affinity will be reversed. The distinct effects of $\mathrm{pH}$ on the level of 2,3-DPG and of 2,3DPG on oxygen affinity, together with the Bohr effect will balance one another both in fetal blood as in adult blood ${ }^{[23]}$.

\section{b) 2,3-diphosphoglycerate (2,3 DPG)}

In the study of Wimberley ${ }^{[23]}$ and confirmed by others the effect of 2,3-DPG on oxygen affinity $\left(\mathrm{p}_{50}\right)$ of $\mathrm{HbF}$ was $43 \%$ compared with the effect of 2,3-DPG on the $\mathrm{p}_{50}$ of $\mathrm{HbA}$. Half of this effect is due to the intracellular $\mathrm{pH}$ change within the erythrocyte, whereas the other half is due to a direct molecular interaction between hemoglobin and 2,3DPG. 2,3-DPG levels at birth in preterm and full term infants are within the normal adult range. In a study on fresh cord blood of non-stressed, non-asphyxiated normal newborns from uncomplicated pregnancies from 24-42 weeks of gestation, it was concluded that the level of 2,3-DPG is rather constant, and that the decrease in fetal oxygen affinity as gestation progresses is related mainly to the reduction in amount of $\mathrm{HbF}^{[39,40]}$. In healthy preterm and full term infants 2,3-DPG increases postnatally in contrast with preterm infants with respiratory problems ${ }^{[2,39]}$.

The level of 2,3-DPG is directly related to plasma $\mathrm{pH}$. This means that acidosis is associated with low levels of 2,3-DPG and alkalosis with high levels of 2,3-DPG. 2,3-DPG 
levels do not correlate with $\mathrm{paO}_{2}$ or $\mathrm{ctO}_{2}$. Furthermore, the level of 2,3-DPG in newborn lambs seemed to be dependent on glucose levels ${ }^{[00]}$. It was shown that during glucose infusion $p_{50}$ and 2,3-DPG / hemoglobin ratio were significantly decreased in comparison with physiological saline infusion. One of the mechanisms to explain this effect is the inhibition or deactivation of the glucose-6- phosphatase with a concomitant suppression of 2,3-DPG synthesis. Delivoria-Papadopoulos et al. ${ }^{[1]]}$ described the postnatal changes in oxygen affinity in piglets. Since piglets only have one type of hemoglobin, the increasing values of $\mathrm{p}_{s_{0}}$ postnatally have been attributed to increased levels 2,3-DPG.

\section{c) Temperature}

The role of temperature in human fetal hemoglobin and of other modulators of oxygen affinity was investigated by Giardina et al. ${ }^{[2]}$ The overall heat production of oxygen binding was not different between $\mathrm{HbA}$ and $\mathrm{HbF}$ in the absence of 2,3-DPG. However, in the presence of 2,3-DPG and under physiological circumstances the heat production of oxygen binding of $\mathrm{HbF}$ was $60 \%$ of $\mathrm{HbA}$. This means that by virtue of the interplay between 2,3-DPG and temperature $\mathrm{HbF}$ has an increased oxygen affinity in comparison with $\mathrm{HbA}$. In bovine fetal hemoglobin Clementi et al. ${ }^{[43]}$ could demonstrate the lower overall heat of oxygenation in the presence 2,3-DPG. The authors speculated over the function of the decreased heat production on oxygen binding of $\mathrm{HbF}$ in the presence of 2,3-DPG. This difference between $\mathrm{HbA}$ and $\mathrm{HbF}$ could favour the heat exchange between the fetus and mother. After birth the decreased temperature sensitivity of $\mathrm{HbF}$ could facilitate a normal oxygen supply to the peripheral tissues.

\subsubsection{Modulation of oxygen affinity}

Modulating oxygen affinity to enable oxygen supply to the tissues have raised much interest especially in neonatal and intensive care medicine. The effects of modulating oxygen affinity on oxygenation have been studied in animal experiments during normoxic, anemic, circulatory hypoxic and hypoxic hypoxic conditions:

\section{a) Normoxemic conditions}

During normoxemic conditions the effects of low oxygen affinity $\left(\mathrm{p}_{50}: 29 \mathrm{mmHg}\right)$ and high oxygen affinity $\left(\mathrm{p}_{50}: 18 \mathrm{mmHg}\right)$ were examined in newborn lambs ${ }^{[4]}$. Oxygen consumption, oxygen extraction, arterial and venous oxygen saturation and cardiac output were not different between the low and high oxygen affinity group. Venous $\mathrm{pO}_{2}$ was significantly higher in the low oxygen affinity group. The authors speculate that, since venous $\mathrm{pO}_{2}$ is a good approximation of the mean tissue oxygen tension, lowering oxygen affinity could increase the mean tissue oxygen tension.

b) Anemic bypoxic conditions

The effect of low ( $p_{50}: 32 \mathrm{mmHg}$ ) and high $\left(\mathrm{p}_{\mathrm{s}_{0}}: 19 \mathrm{mmHg}\right)$ oxygen affinity at different degrees of anemia was compared in newborn lambs ${ }^{[45]}$. Venous $\mathrm{pO}_{2}$ differed between the high and low oxygen affinity group, whereas arterial and venous oxygen content were not different between the high and low affinity group. Cardiac output was more increased in the low affinity group during severe anemia. In the low affinity group oxygen consumption remained stable whereas in the high affinity group oxygen consumption decreased during severe anemia. The data indicate that during severe anemia blood with a high $\mathrm{p}_{\mathrm{s}}$ (low oxygen affinity) is more capable of adequately oxygenating tissues than that with a low $\mathrm{p}_{50}$ (high oxygen affinity), especially by increasing cardiac output. Again, mixed venous $\mathrm{PO}_{2}$ was lower in the high affinity group during severe anemia ${ }^{[45}$.

\section{c) Circulatory bypoxic conditions}

Schumaker et al. ${ }^{[46]}$ reported a study in mongrel dogs in which oxygen delivery was reduced by removing blood volume in a group with a normal $\mathrm{p}_{\mathrm{s} 0}(28.4$ torr) and a 
reduced $\mathrm{p}_{\mathrm{so}}$ (20.3 torr). The hypothesis was that a higher critical oxygen delivery was found in the group with a reduced $\mathrm{p}_{50}$ because of an increased oxygen affinity. However, critical $\mathrm{DO}_{2}$ and critical oxygen extraction ratio were similar in both groups. As oxygen delivery was reduced below the critical level the extraction ratio continued to increase, which was significantly higher among normal $p_{50}$ than among low $p_{50}$. Several mechanisms were mentioned to explain this finding: Redistribution of blood flow in the group with low $\mathrm{p}_{50}$ or the convergence of the different oxyhemoglobin dissociation curves at critically low capillary $\mathrm{pO}_{2}$ could explain the similar critical oxygen delivery in both groups to some extent. Furthermore, the authors question whether the increased oxygen affinity in the group with a low $\mathrm{p}_{5_{0}}$ is an important determinant of oxygen unloading and whether other mechanisms as rheological properties of blood at very low cardiac output and vasoconstrictor tone may begin to limit oxygen consumption before blood-tissue oxygen diffusion becomes significant. Since the extraction ratio continued to increase in the group with a normal $\mathrm{p}_{50}$, diffusion limitation seemed to play a role however, only at deliveries at which $\mathrm{VO}_{2}$ is already depressed.

\section{d) bypoxic bypoxic conditions}

Lister ${ }^{\left[{ }^{[7]}\right.}$ examined the effects of high $\left(\mathrm{p}_{\mathrm{s}_{0}}: 27 \mathrm{mmHg}\right)$ and low $\left(\mathrm{p}_{\mathrm{s}_{0}}: 35 \mathrm{mmHg}\right)$ oxygen affinity in newborn lambs during hypoxic hypoxia. During hypoxic hypoxia $\left(\mathrm{FiO}_{2}\right.$ - 0.1 ) oxygen delivery and consumption decreased. After exchange transfusion during hypoxia oxygen delivery and oxygen consumption increased to near normoxic levels. These changes were concomitant with an increase of cardiac output and stroke volume.

\subsubsection{Clinical studies on modulation oxygen affinity}

In an observational study in 20 critically ill patients Myburg et al. ${ }^{[48]}$ found a reduced $\mathrm{p}_{50}$. The value of $\mathrm{p}_{50}$ was strongly correlated with $\mathrm{pH}$ and base excess. In the discussion the authors speculate that a decreased level of 2,3-diphosphoglycerate due to a chronic acidosis or hypophosphatemia played an important role in the reduction of $\mathrm{p}_{50}$ in critically ill patients.

Besides this observational study two clinical trials have been performed in premature infants to determine whether an exchange transfusion with fresh adult blood could provide clinical benefits. Oski ${ }^{[49]}$ reported and reviewed these clinical trials employing exchange transfusions as an adjunct of conventional therapy. A decreased mortality was reported in those infants in whom an exchange transfusion was employed. The combined results of these trials reported an increased survival rate in the exchange group $(58.2 \%)$ vs. $(25.3 \%)$. The exchange transfusion resulted in an increase in 2,3-DPG, a decrease of fetal hemoglobin and an increase in $\mathrm{p}_{50}$. However, these changes could not be correlated with the eventual outcome of the infants who received an exchange transfusion. Additionally, within 7 hours after exchange transfusion an unanticipated rise of arterial oxygen tension was found. This response could not be attributed to an increased $\mathrm{p}_{50}$, but more to an improved pulmonary ventilation or pulmonary circulation. In both trials it was reported that central venous $\mathrm{PO}_{2}$ was increased after exchange transfusion concomitant with the findings in animal trials. It seemed that an increased venous $\mathrm{pO}_{2}$ as a consequence of a high $\mathrm{p}_{50}$ induced by an exchange transfusion could be one of the factors that enhance pulmonary perfusion and possibly ameliorate cardiac output.

Theoretically, the advantage of shifting the oxyhemoglobin curve is dependent on arterial $\mathrm{pO}_{2}$ and venous $\mathrm{pO}_{2}{ }^{[50]}$. For example, a right shifted curve improves the maximal possible tissue oxygen uptake at any arterial $\mathrm{pO}_{2}$, when venous $\mathrm{pO}_{2}$ is $40 \mathrm{mmHg}$. However, when venous $\mathrm{pO}_{2}$ is $10 \mathrm{mmHg}$ the maximal tissue oxygen uptake is improved in the presence of hypoxemia by a left ward shifted curve, since oxygen loading in the lung and systemic oxygen transport is enhanced. Because uptake and $\mathrm{p}_{\mathrm{v}} \mathrm{O}_{2}$ differ considerably from 
organ to organ and within organs the benefits or drawbacks of a shift in the oxyhemoglobin curve cannot be predicted a priori.

With the theoretical possibility that shifting the oxyhemoglobin curve of the newborn to the right oxygen extraction may decrease in certain conditions, together with the risks of the exchange procedure itself and with the data from clinical trials where many other factors may have caused the increased survival, it is concluded that exchange transfusion at present cannot be recommended in the regular care of newborn infants.

\subsection{Oxygen uptake by the tissues}

Whereas the oxygen transport from the lungs to the tissues is accomplished by convective or bulk flow, oxygen uptake by the tissues is accomplished by diffusion of oxygen to the tissues. The process of diffusion can be described as the movement of oxygen across the cytosol and membrane of the erythrocyte, through the plasma into the tissues according to a concentration gradient ${ }^{[51]}$. Several models have been proposed to characterize this process of oxygen uptake by the tissues.

The Krogh model is the eldest and most simplified model of oxygen diffusion to the tissues ${ }^{[52,53]}$. This model describes oxygen transport from the centrally located capillary to the periphery of the tissues surrounding this capillary as a cylinder. Kety extended the model accounting for the $\mathrm{pO}_{2}$ changes along the longitudinal axis of the capillary. In the skeletal muscle with the well-ordered longitudinally located capillaries the Krogh-Kety model seemed to be a good approximation. However, in this simplified model more complex microvasculature was ignored and some additional assumptions were made:

1) simplified tissue geometry

2) the instantaneous release of oxygen by the erythrocytes

3) neglected changes in oxygen transport within the capillary

4) neglected effect of myoglobin

5) a constant and uniform oxygen consumption

\subsubsection{Tissue vascular geometry}

In tissues with a more complex vascular geometry the Krogh-Kety model is not sufficient to predict tissue oxygen values. Consequently, other more complex models (multi-capillary) were developed to reproduce a more reliable tissue oxygen profile. In studies on the in the cheek retractor muscle in the hamster the influence of the microvascular geometry on oxygen exchange was studied ${ }^{[54,55]}$. It was demonstrated that the release of oxygen from a capillary seems to be strongly influenced by its proximity to arterioles and venules, that either supply oxygen to the capillaries or augment its release. These diffusive interactions might change under different hemodynamic conditions.

\subsubsection{Kinetics of the oxyhemoglobin dissociation}

Gutierrez addressed the question of the time required by the erythrocytes to release oxygen to the tissues ${ }^{[51]}$. He developed a model that took into account the time component or the kinetics of the dissociation of oxyhemoglobin into oxygen and deoxyhemoglobin. The model formulated equations for different compartments along the capillary. The model predicts that plasma oxygen is not replenished completely due to the limit of the rate of the oxyhemoglobin dissociation. The plasma $\mathrm{pO}_{2}$ lags behind the equilibrium $\mathrm{PO}_{2}$; when the blood reaches the venous pool $\mathrm{pO}_{2}$ will equilibrate again resulting in an increase of the venous $\mathrm{PO}_{2}$, compared with the capillary $\mathrm{pO}_{2}$. According to Gutierrez this discrepancy between plasma $\mathrm{pO}_{2}$ and venous $\mathrm{pO}_{2}$ will increase in the case of anemic and hypoxic hypoxia due to the slower rate of dissociation, when $\mathrm{cO}_{2}(\mathrm{Hb})$ is 
reduced.

\subsubsection{Intracapillary resistance to oxygen}

During oxygen transport from the erythrocyte to the cell membrane several theoretical resistive forces to oxygen diffusion are encountered. The cytosol and the cell membrane of the erythrocyte have been mathematically and experimentally determined to be of a negligible resistance for oxygen diffusion ${ }^{[32,56}$. However, the plasma phase, with its very low oxygen solubility, limits the ability to transfer oxygen from the red cells to the tissues and affects the uniformity of oxygen flux at the capillary wall and is an important resistive component in the oxygen uptake $[52,5,58]$. The effect of the low plasma oxygen solubility was demonstrated in hemodilution studies inducing an expansion of the plasma phase and an increased red cell spacing, consequently, affecting the oxygen flux to the

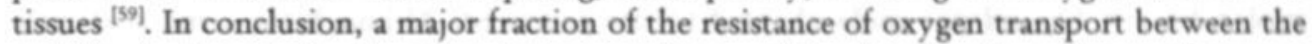
red blood cell and mitochondrion is intra capillary and is related to the pathway of oxygen diffusion through the plasma gaps ${ }^{[60]}$.

\subsubsection{Myoglobin}

The Krogh-Kety model neglects the effect of the presence of myoglobin in skeletal muscles. The myoglobin molecule is a monomer variety of the hemoglobin molecule present in the vertebrate red muscle and heart. Myoglobin has a role in the storage of oxygen and has a buffer capacity, when oxygen delivery is reduced. Another role of myoglobin, namely the facilitated diffusion of oxygen, has now been established ${ }^{[52]}$. To illustrate the magnitude of the facilitated diffusion by myoglobin, the ratio of the facilitated oxygen diffusion to the free oxygen diffusion is reported to be $3: 1$ in red muscle at the $\mathrm{p}_{50}$ of myoglobin ${ }^{[61]}$. Additionally, it was demonstrated that myoglobin rich skeletal muscle can sustain a high $\mathrm{VO}_{2}$ with a relatively low $\mathrm{pO}_{2}$ due to the facilitated diffusion of oxygen.

\subsubsection{Constant and uniform oxygen consumption}

Inside the cell oxygen consumption is almost exclusively situated in the mitochondrion. It was demonstrated that $\mathrm{pO}_{2}$ distribution was homogeneous in the cytosol, provided that mitochondria are uniformly distributed within the cell. However, mitochondria can be distributed heterogeneously in the tissues ${ }^{[52]}$. Mainwood et al. showed that mitochondria were more prominently positioned around capillaries and that mitochondrial density decreased with increasing distance from the capillary ${ }^{[56]}$. However, Hoppeler et al. concluded that these findings are largely species and muscle dependent and that it is too early to draw definitive conclusion upon the relationship between mitochondria and microvascular architecture ${ }^{[62]}$.

\subsection{Oxygen consumption within the cells}

Oxygen enables the energy contained in food to be converted into a form of controlled energy released by the formation of Adenosine Tri-Phosphate (ATP). ATP has the unique property to store energy in high "energy bonds" which on hydrolysis release 11 $-13 \mathrm{kcal} /$ mole ATP. Three chemical processes can be discerned within the cell related to the conversion of energy ${ }^{[12,63]}$.

\subsubsection{Glycolysis}

Glucose enters the cell by a process of facilitated or carrier mediated diffusion, which is enhanced by insulin. Then a conversion to glucose-6-phosphate (enzyme: glucosekinase, ATP consuming process) takes place. This molecule can be used for anabolic 
metabolism (glycogenesis) or for the release of energy. (glycolysis). Glycolysis involves a process of ten reactions in the cytosol of the cell with the net gain of two molecules of ATP and ends with the formation of two molecules of pyruvic acid. There is also a release of protons and electrons, which combine with nicotamide adenine dinucleotide $\left(\mathrm{NAD}^{+}\right)$to form NADH and free hydrogen ions. The whole process of glycolysis comprises the anaerobic metabolism of glucose. Thus, ATP can be produced even in the absence of oxygen by the process of glycolysis.

\subsubsection{Citric acid cycle}

The next step in the generation of energy is the transport of pyruvate into the mitochondrion. There acetyl-CoA is formed from pyruvate by the pyruvate dehydrogenase complex. Then, in successive steps in the citric acid cycle acetyl-CoA is transformed and 2 molecules of $\mathrm{CO}_{2}$ and one molecule of ATP are produced. Although the citric acid cycle constitutes part of aerobic metabolism, none of the reactions makes direct use of molecular oxygen. The most important contribution of the citric acid cycle is the production of high energy electrons in the electron carriers $\mathrm{NADH}$ and $\mathrm{FADH}_{2}$.

\subsubsection{Oxidative phosphorylation}

The complicated transfer of these electrons along the inner membrane of the mitochondrion to oxygen is called the oxidative phosphorylation, since this process yields 34 molecules of ATP, and is dependent on oxygen.

\subsubsection{Fat and protein}

Other substrates as fat and protein are oxidized by transformation and deamination, respectively in order to enter the citric acid cycle. Fat is first oxidized into glycerol and fatty acids. Glycerol is transformed into glyceraldehyde-3-phosphate, which is an intermediate in the glycolytic pathway. Fatty acids are transported into the mitochondria and degraded to acetyl-CoA with the generation of $\mathrm{NADH}$ and $\mathrm{FADH}_{2}$. Amino acids are deaminated in the liver and the carbon skeleton is converted to the various intermediates of the glycolytic pathway and citric acid cycle.

\subsection{The mitochondrion: the end-organelle for oxygen consumption and the final step of the oxygen cascade.}

\subsubsection{Anatomy and function ${ }^{[11]}$}

Mitochondria are present in all eucaryotic cells, and are subcellular organelles, that convert energy to forms that can be used for numerous cell functions. Mitochondria are mobile and constantly changing their shape. They are bounded by two different membranes, creating two compartments: the innermembrane space or matrix and the much smaller intermembrane space between the outer and inner membrane. Because the outer membrane is permeable for all molecules of 5000 daltons or less, the inter membrane space is similar to the cytosol. The innermembrane space or matrix contains a different set of proteins because of the impermeability of the inner membrane. The phospholipid cardiolipin contributes to this impermeability, especially for ions. The inner membrane is highly convoluted, forming the cristae in the matrix and increase the surface of the inner membrane. Specific translocase proteins are needed to transfer pyruvate, fatty acids (carnithine), amino acids and intermediates for oxidative metabolism from the cytosol into the matrix space. The citric acid cycle with the generation of the electron carriers $\mathrm{NADH}^{+}$and $\mathrm{FADH} 2$ is located in the matrix of the mitochondrion. 
The inner mitochondrial membrane has a crucial role in the oxidative phosphorylation. The process of electron transfer starts when the electrons are removed from $\mathrm{NADH}^{+}$and accepted by the NADH dehydrogenase complex. Then the electrons pass through 40 proteins which are grouped in three large enzyme complexes and two electron carriers. These enzyme complexes exist as independent entities in the plane of the inner membrane of the mitochondrion. Each complex has a greater electron affinity as his predecessor and electrons pass sequentially from one complex to another until they are finally transferred to oxygen, which has the greatest electron affinity. It is the last of the enzyme complexes, the cytochrome oxidase complex or cytochrome aa3, that finally catalyzes an efficient reduction of oxygen, by anchoring the oxygen molecule between a heme linked iron atom and a copper atom until it has picked up a total of four electrons ${ }^{[64]}$. The cytochrome oxidase reaction accounts for $90 \%$ of the total oxygen uptake in the cells. Cyanide is toxic to cells because it binds tightly to this complex and thereby blocks all electron transport.

This energetically favourable electron transport is coupled to a $\mathrm{H}^{+}$transfer across the inner membrane from the matrix to the intermembrane space. The $\mathrm{H}^{+}$transfer generates a gradient across the inner membrane which is composed of a membrane potential $(140 \mathrm{mV})$ and of a concentration $(\mathrm{pH})$ gradient $(60 \mathrm{mV})$ and is called the electrochemical proton gradient $(200 \mathrm{mV})$. Down the electrochemical gradient a proton flow backwards through the enzyme ATP-synthase is used to drive the synthesis of ATP and to produce large amounts of ATP. The enzyme ATP-synthase is an inner membrane bound protein complex that synthesizes ATP when protons flow through down the electrochemical proton gradient.

\subsubsection{Uncoupling the electron transfer from the ATP synthesis.}

Several substances have been known to uncouple the electron transport from the synthesis of ATP. These agents act as to provide additional channels for protons to flow through the inner membrane and consequently to diminish the electrochemical gradient. Remarkably, when an uncoupling agent has been added to the cells the electron transfer and oxygen consumption is increased in a large extent. It seems that the magnitude of the electrochemical gradient is a feed back for both the electron transfer as the ATP synthesis. In some specialized cells as brown fat cells the electron transfer and ATP synthesis are normally uncoupled; consequently, the energy of the electron transfer is converted into heat.

\subsubsection{The genome of mitochondria ${ }^{[11]}$}

In contrast to other subcellular organelles mitochondria contain a functional DNA. However, most of the proteins in mitochondria are encoded in the nuclear DNA and imported from the cytosol, but some are encoded by the organelle DNA. Mitochondrial DNA does not encode for proteins used outside the mitochondrion. Mitochondrial DNA is circular and distributed in the matrix and in contrast to nuclear DNA all DNA appears to be part of the encoding system leaving little room for regulatory DNA sequences. In addition, there are differences in the genetic code with a reduced fidelity of the DNA replication. Both DNA strands are completely transcribed, but only the transcripts made on one (heavy) strand are extensively processed.

The inheritance of characteristics encoded by mitochondrial DNA is in several ways very different from the inheritance of characteristics encoded by nuclear DNA $[65,66]$ : The inheritance of the mitochondrial DNA in humans is uniparental and more precisely maternal, because the sperm cell does not contain mitochondria. Secondly, mutations accumulate through maternal lineage, since mitochondrial DNA does not recombine. 
Mutations and normal mitochondrial DNA can coexist within the same cell, a phenomenon called heteroplasmy. By divisions and replications the proportion of mutant mitochondrial DNA can augment or diminish according to the principles of non-mendelian inheritance. Mitochondrial DNA is 10 times more prone to mutations due to several reasons: Since mitochondrial DNA has no introns, mutations will always damage an encoding segment; Furthermore, an ineffective repair system together with a continuous exposition to oxygen free radicals generated by the oxidative phosphorylation are other factors that contribute to the increased vulnerability of mitochondrial DNA.

All tissues in the body depend on integral mitochondrial function and an increasing number of diseases has been contributed to mitochondrial disorders. Aging itself was attributed to age related dysfunctions of the mitochondrial DNA mediated by accumulating oxidative damage.

\subsubsection{The mitochondrion during perinatal development}

Data of the fetal and postnatal mitochondrial development still remain substantially limited to animal data. In early fetal period in the rat liver mitochondria have the same dimensions and shape as in adulthood, but the number of mitochondria is much lower than in adulthood ${ }^{[6]}$. Later in fetal life mitochondria increase in size but not in number. Although the dimensions of mitochondria increase, this growth keeps in pace with the increasing cytoplasm and mitochondrial cell fraction remains constant. Biochemical changes during this period as a decreasing cytochrome-c oxidase and cardiolipin activity and increasing glutamate dehydrogenase reflect the increasing matrix volume relative to the inner membrane surface area.

In the postnatal period within one day after birth mitochondria decrease in size and in volume and start to proliferate rapidly. This process results in an increase in fraction and in number of mitochondria per unit of cytoplasm. The proliferation phase is characterized by an increasing mitochondrial membrane area relative to matrix space. The data on postnatal enzyme development show an increase within the first week after birth especially for the inner membrane components as cytochrome-c oxidase. The mitochondrial proliferation seems to be initiated by the synthesis of key proteins and by an accumulation of adenine nucleotide in the matrix ${ }^{[68,69]}$. Mitochondrial development is affected by hypothyroidism by reducing mitochondrial proliferation ${ }^{[70]}$ and by adrenal steroid hormones by up regulating cytochrome-c oxidase expression in a tissue specific manner ${ }^{[71]}$.

The lower activity of oxidative enzymes during the fetal period relative to postnatal and adult period was confirmed in other tissues as rat brain ${ }^{[72]}$, rat heart tissue ${ }^{[73]}$, rat kidney ${ }^{[74]}$ and human skin fibroblasts ${ }^{[75]}$.

Hence, it seems, that the perinatal period is characterized by a switch from low oxidative metabolism to efficient oxidative phosphorylation by a rapid proliferation and maturation of cellular mitochondria.

Venous oxygen saturation ${ }^{[76]}$

Venous oxygen saturation is defined as the oxygen saturation in the venous blood after it has traversed the capillary bed of a certain tissue. The value of venous oxygen saturation in the venous blood in the right heart or in the pulmonary artery $\left(\mathrm{SvO}_{2}\right)$ is the average of the venous blood from all the tissues. Kandel and Aberman ${ }^{[7]}$ have expressed three criteria for the validity of the measurement of $\mathrm{SvO}_{2}$ in the right heart or pulmonary artery:

1) $\mathrm{SvO}_{2}$ should include all the blood that has traversed all the capillary beds 
capable of extracting oxygen. Apart from the blood of the thebesian veins and bronchial arteries, the $\mathrm{SvO}_{2}$ measurement in the right atrium, right ventricle or pulmonary artery meet this criterium. $\mathrm{SvO}_{2}$ measurement in the superior or inferior caval vein does not fulfil this criterium and the $\mathrm{SvO}_{2}$ value is in fact different between these two measurement sites

2) $\mathrm{SvO}_{2}$ should exclude any blood that has not traversed capillary beds. The value of $\mathrm{SvO}_{2}$ is unreliable when a considerable amount of blood is shunting from the left side to the right side of the heart as in the presence of an atrium - or ventricle septum defect.

3) $\mathrm{SvO}_{2}$ should be measured in blood mixed so completely, that a single uniform oxygen saturation value can be encountered. Kandel and Aberman $m$ state that only measurements in the pulmonary artery fulfils this criterium. However, some studies show evidence that the right atrium is an as proper measurement location as the pulmonary artery $[8, r y] . \mathrm{SvO}_{2}$ is determined by the oxygen transport to the tissues, or the oxygen delivery $\left(\mathrm{DO}_{2}\right)$ and by the oxygen extraction in the capillary bed of the tissues. $\mathrm{DO}_{2}$ is determined by cardiac output $(\mathrm{Q} t)$ and the total oxygen content of the arterial blood $\left(\mathrm{caO}_{2}\right)$ $[63,80,81]$.

$$
\mathrm{DO}_{2} \mathrm{ml} \cdot \mathrm{kg}^{-1} \cdot \mathrm{min}^{-4}=\mathrm{caO}_{2} \mathrm{ml} \cdot \mathrm{dl}^{-4} \cdot 10 \cdot \mathrm{Qt} \mathrm{ml}^{-\mathrm{kg}^{-1} \cdot \mathrm{min}^{-4}}
$$

$\mathrm{caO}_{2}$ is determined by hemoglobin concentration $(\mathrm{Hb})$ and oxygen saturation $\left(\mathrm{SaO}_{2}\right)$ and the oxygen in solution expressed by the partial pressure of oxygen $\left(\mathrm{paO}_{2}\right)$.

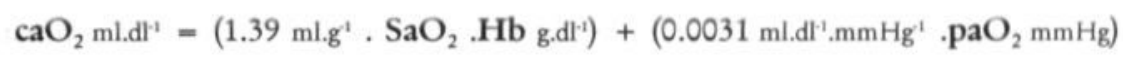

Oxygen extraction or oxygen consumption $\left(\mathrm{VO}_{2}\right)$ is according to the Fick equation determined by the difference between arterial $\left(\mathrm{caO}_{2}\right)$ and venous oxygen content $\left(\mathrm{cvO}_{2}\right)$ and cardiac output $(\mathrm{Qt})$.

$$
\mathrm{VO}_{2} \mathrm{ml} \cdot \mathrm{kg}^{-1} \cdot \mathrm{min}^{-1}=\left(\mathrm{caO}_{2}-\mathrm{cvO}_{2}\right) \mathrm{ml}^{-1 l^{-1}} \cdot 10 \cdot \mathrm{Qt} \mathrm{l} \mathrm{kg}^{-1} \cdot \mathrm{min}^{-1}
$$

When we combine and rearrange equation (2) and (3) and neglect the small volume of oxygen dissolved in the blood,

$$
\begin{aligned}
& \mathrm{VO}_{2} \mathrm{ml} \cdot \mathrm{kg}^{-1} \cdot \mathrm{min}^{-1}=\left(1.39 \mathrm{ml} \cdot \mathrm{g}^{-1} \cdot \mathrm{Hb}_{\mathrm{g} \cdot \mathrm{dl}^{-1}}\right) \cdot\left(\mathrm{SaO}_{2}-\mathrm{SvO}_{2}\right) \cdot 10 \cdot \mathrm{Qt} 1 . \mathrm{kg}^{1} \cdot \mathrm{min}^{-1} \\
& \mathrm{SvO}_{2}=\mathrm{SaO}_{2}-\mathrm{VO}_{2} \mathrm{ml} \cdot \mathrm{kg}^{-1} \cdot \mathrm{min}^{-1} \cdot\left(1.39 \mathrm{ml} \cdot \mathrm{g}^{-1} \cdot \mathrm{Hb}_{\mathrm{g}} \cdot \mathrm{dl}^{-1} \cdot 10 \cdot \mathrm{Qt} \mathrm{l} \cdot \mathrm{kg}^{-1} \cdot \mathrm{min}^{-1}\right)^{-1}
\end{aligned}
$$

we can see that changes of the venous oxygen saturation $\left(\mathrm{SvO}_{2}\right)$ can be due to changes in $\mathrm{VO}_{2}$, and in the factors that constitute $\mathrm{DO}_{2}$, such as arterial oxygen saturation $\left(\mathrm{SaO}_{2}\right)$, hemoglobin $(\mathrm{Hb})$ and cardiac output $(\mathrm{Qt}) . \mathrm{SvO}_{2}$ reflects the combined sufficiency of all these variables.

The effect of changes of the individual variables for the value of $\mathrm{SvO}_{2}$ have been described by different authors ${ }^{[77,82,83]} . \mathrm{SvO}_{2}$ is affected considerably by changes in oxygen consumption $\left(\mathrm{VO}_{2}\right)$, such as reductions in $\mathrm{VO}_{2}$ during anesthesia and hypothermia, and elevations of $\mathrm{VO}_{2}$ during convulsions or postoperative shivering ${ }^{\left[{ }^{[8]}\right.}$. Changes in the variables, that constitute the oxygen delivery $\left(\mathrm{DO}_{2}\right)$ as $\mathrm{SaO}_{2}, \mathrm{Hb}$ and cardiac output $(\mathrm{Qt})$ have their effect on $\mathrm{SvO}_{2}$, as well ${ }^{[81]}$. One must be very cautious to use $\mathrm{SvO}_{2}$ measurement to monitor exclusively one of these variables, particularly when other variables are unstable. There is a poor correlation between $\mathrm{SvO}_{2}$ and individual determinants of the oxygen transport ${ }^{[76]}$.

$\mathrm{SvO}_{2}$ is a monitor of the balance between $\mathrm{DO}_{2}$ and $\mathrm{VO}_{2}{ }^{[76,77]}$. When $\mathrm{DO}_{2}$ is 
decreased, several compensatory mechanisms may be called into play: increased cardiac output or increased oxygen extraction (ie, decreasing $\mathrm{SvO}_{2}$ ) are the most common compensatory mechanisms [7]. For example, in the case of a severe anemia cardiac output can increase triple fold above the normal value and $\mathrm{SvO}_{2}$ can decrease from $75 \%$ to values below $40 \%{ }^{855}$. Consequently a seven to nine-fold increase in $\mathrm{DO}_{2}$ can be accomplished, provided that cardiac performance and tissue oxygen uptake are not compromised. In the case of cardiac failure, only one of the compensatory mechanisms - increased oxygen extraction - can be called into play. Therefore, patients seem to be less tolerant to a reduction of cardiac output they are to a reduction of $\mathrm{SaO}_{2}$ or hemoglobin concentration.

Another compensatory mechanism in the case of hypoxia or reduced cardiac output is a redistribution of blood flow. The quantity of blood flow from the different organs determines the value of $\mathrm{SvO}_{2}$ in addition to $\mathrm{DO}_{2}$ and $\mathrm{VO}_{2}$. For example, venous blood from a high flow / low oxygen extraction organ as the kidney determines the value of $\mathrm{SvO}_{2}$ in a greater extent than venous blood from a low flow / high extraction organ as the heart. During shock or cardiac failure, a reduction of renal blood flow together with an increase of the blood flow to coronary vascular bed of the heart will decrease the $\mathrm{SvO}_{2}$ value substantially. $\mathrm{SvO}_{2}$ is consequently a flow-weighted average of venous oxygen saturation values from all the tissues. In fact, redistribution of blood flow and an increased oxygen extraction or a decreased $\mathrm{SvO}_{2}$ are partly analogous mechanisms, since by a redistribution of blood to low flow / high extraction organs oxygen extraction will increase and $\mathrm{SvO}_{2}$ will decrease.

Monitoring $\mathrm{SvO}_{2}$ enables the estimation of the shunt index, an estimate of the venous admixture and fractional oxygen extraction.

\section{Shunt Index $=\left(100-\mathrm{SaO}_{2}\right) /\left(100-\mathrm{SvO}_{2}\right)$}

The shunt index is an estimate of the venous admixture and is a calculated percentage of blood, that refers to the degree of admixture of mixed venous blood with pulmonary endcapillary blood, which would be required to produce the observed difference between the arterial and the pulmonary end-capillary $\mathrm{pO}_{2}{ }^{[15]}$. The shunt index as an estimate of the venous admixture obtained by continuous pulse and venous oximetry (dual oximetry) has been suggested and studied in adult intensive care medicine ${ }^{[86,87]}$. Bongard et al. ${ }^{[88]}$ described a computer modelling of the shunt index and found limitations in the accuracy of the estimate of venous admixture, when errors in the $\mathrm{SaO}_{2}$ value were present.

Fractional oxygen extraction is an assessment of the peripheral tissue oxygen utilization and an instantaneous feedback on circulatory and respiratory therapy ${ }^{[89]}$.

Fractional oxygen extraction $=\left(\mathrm{SaO}_{2}-\mathrm{SvO}_{2}\right) / \mathrm{SaO}_{2}$

Mathematically it can be expected that a good correlation exists between fractional oxygen extraction and $\mathrm{SvO}_{2}$. However, fractional oxygen extraction based on $\mathrm{SvO}_{2}$ reflects global oxygen extraction and therefore tissue hypoxia in individual organs cannot be excluded ${ }^{[0]}$.

4.1

Summary

$\mathrm{SvO}_{2}$ is flow-weighted average of venous oxygen saturation values from all the tissues. $\mathrm{SvO}_{2}$ is the combined sufficiency of all the variables that constitute $\mathrm{DO}_{2}$ and $\mathrm{VO}_{2}$. Consequently, $\mathrm{SvO}_{2}$ is a monitor of the balance between $\mathrm{DO}_{2}$ and $\mathrm{VO}_{2}$. When the relation of $\mathrm{DO}_{2}$ and $\mathrm{VO}_{2}$ is out of balance, several compensatory mechanisms could come into play to restore the balance. Increased oxygen extraction or a decreased $\mathrm{SvO}_{2}$ are one of the most common compensatory mechanism. A decreased $\mathrm{SvO}_{2}$ is a sign, that one of the variables, that constitute $\mathrm{DO}_{2}$ and $\mathrm{VO}_{2}$ is impaired. $\mathrm{SvO}_{2}$ enables the estimation of the shunt index and fractional oxygen extraction. 
II

\section{Hypoxia}

\section{Definitions}

\section{Cellular hypoxia}

Definition of cellular bypoxia

Alteration in substrate utilization during bypoxia

Anaerobic sources of energy (1): Glycolysis

Control of glycolysis

Lactate

Lactate production

Lactate utilization

Lactate as a monitor of tissue hypoxia in adult intensive care medicine Lactate in neonatal medicine Anaerobic sources of energy (2): Phosphocreatine reaction Mechanisms of cell damage during bypoxia

\section{Systemic hypoxia}

Hypoxic bypoxia

Acute hypoxic hypoxia and oxygen transport

Cardiovascular responses during development

Chronic hypoxic hypoxia

Anemic hypoxia

Oxygen transport and compensatory mechanisms

Comparing hypoxic and anemic hypoxia

Chronic anemic hypoxia

Circulatory bypoxia

Critical cardiac output

Chronic circulatory hypoxia 
In the past hypoxia was defined as a condition with a low $\mathrm{paO}_{2}$ or low $\mathrm{SaO}_{2}$. In more recent years the definition of hypoxia has been focused to the target of oxygen transport: the peripheral tissues. In the report of a consensus conference ${ }^{[9]}$ hypoxia was defined as a condition in which the cells of a tissue have abnormal oxygen utilization, such that the tissue is experiencing anaerobic metabolism.

Terms as hypoxic, anemic, circulatory and histotoxic hypoxia are more related to the disorders that can lead to hypoxia ${ }^{[2]}$. Connet et al. ${ }^{[93]}$ defined hypoxia as " oxygenlimited cellular energy failure". The central point is the balance between ATP demand and ATP generated by aerobic metabolism. This balance depends on the interaction between several subsystems as oxidative phosphorylation, Krebs cycle, glycolysis, substrate supply, membrane transport and cell energetics. In this review the consequences of hypoxia will be discussed both at cellular level and at systemic, multiorgan level.

\section{Cellular hypoxia}

\subsection{Definition of cellular hypoxia}

A common definition for cellular hypoxia is a "pathologic condition in which cellular energy requirements are greater than aerobic energy production" ${ }^{[97,98]}$. Oxygen is the ultimate electron acceptor in the respiratory chain. The last enzyme complex of the respiratory chain, cytochrome oxidase, catalyses the reduction of oxygen and this reaction accounts for $90 \%$ of the $\mathrm{VO}_{2}$. The critical intracellular $\mathrm{pO}_{2}$ has been defined as the $\mathrm{pO}_{2}$ below which electron transport and oxidative phosphorylation are minimized. In isolated mitochondria the critical $\mathrm{pO}_{2}$ has been estimated as low as $0.1-1 \mathrm{mmHg}$. However, when critical $\mathrm{pO}_{2}$ was defined as $\mathrm{pO}_{2}$ associated with a certain redox state of the cytochrome oxidase complex, an as 10 times higher critical $\mathrm{pO}_{2}$ value was demonstrated in intact hepatocytes [99]. It was hypothesized, that clustering and uneven distribution of mitochondria are the major reasons for this difference.

The redox state of the mitochondria is reflected by the ratio of NADH / NAD . An increased level of NADH and consequently an increased redox state is induced by a decreased oxygen availability, although other factors as substrate availability and citric acid cycle activity may also affect the $\mathrm{NADH}$ level. The ratio of $\mathrm{NADH} / \mathrm{NAD}^{+}$in the cytosol is reflected by the ratio of lactate / pyruvate $[100,101]$.

It is known that some cells have a greater tolerance for bypoxia than other cells, dependent on cell activity and tissue origin. For example, skeletal muscle recover after 30 minutes complete ischaemia, whereas brain cells are irreversibly damaged after 5 minutes of hypoxia.

\subsection{Alteration in substrate utilization during hypoxia or intensive exercise ${ }^{[99]}$}

The oxygen requirements for ATP formation varies between different substrates. The oxidation of free fatty acids requires $10 \%$ more oxygen than the oxidation of carbohydrates. During aerobic metabolism the normal substrate for cellular energy production are in the myocytes, for example, lipids, lactate and glucose, in that order. However, during hypoxic conditions the oxidation of glycogen is the preferred pathway. This switch from fat to glucose oxidation during hypoxia was demonstrated in several different cell lines ${ }^{[9]]}$. 


\subsection{Anaerobic sources of energy (1): Glycolysis}

Glycolysis is a number of ten subsequent chemical reactions decomposing glucose to two molecules of pyruvate. Glycolysis occurs in the cytoplasm entirely without oxygen and with the net gain of two molecules of ATP. Although glycolysis is a very inefficient energetic process, since only 3 per cent of the total energy of the glucose molecule is used, it is a very important process to produce energy, when oxygen is not available ${ }^{[102]}$.

\subsubsection{Control of glycolysis}

Glycogen is the main source for the glycolysis. The availability of glycogen and the breakdown of glycogen, (glycogenolysis), are regulating steps for the substrate availability for the glycolysis. The initial step in glycogenolysis is catalyzed by phosphorylase. The phosphorylase can be activated by hormones as epinephrine and glucagon. Factors as $\mathrm{Ca}^{2+}$, AMP and inorganic phosphate also activate glycogenolysis. However, $\mathrm{H}^{+}$ions and acidosis inhibit glycogenolysis and muscle contraction ${ }^{[9]}$.

Glycolysis itself is controlled by the cellular need of ATP. ATP controls one of the reactions in the glycolysis by the inhibition of the enzyme phosphofructokinase. $\mathrm{H}^{+}$ions and citrate potentiate this inhibition. On the other hand ADP and inorganic Phosphate increase the activity of phosphofructokinase, thereby stimulating glycolysis.

In summary, it seems that both glycogenolysis and glycolysis are increased by $\mathrm{Ca}^{2+}, \mathrm{ADP}, \mathrm{AMP}$ and inorganic phosphate and inhibited by ATP and $\mathrm{H}^{+}$ions.

\subsubsection{Lactate}

The end products of glycolysis -pyruvate, $\mathrm{NADH}$ and $\mathrm{H}^{+}$- may react with each other and lactate may be formed [102]. The conversion from pyruvate to lactate is catalyzed by the enzyme lactic dehydrogenase (LDH). Since lactate diffuses out of the cells to the interstitial fluid, glycolysis can be continued for around 30 to 40 seconds.

\subsubsection{Lactate production}

Lactate is produced by all tissues, but brain cells, erythrocytes and renal cells are considered as the most prominent lactate synthesizing cells ${ }^{[103]}$. One of the main factors determining lactate production is the balance between pyruvate production and pyruvate utilization. As pyruvate production is determined by glycolysis, pyruvate utilization is determined by the metabolism of pyruvate in the citric acid cycle or by gluconeogenesis. These two different pathways are catalyzed by pyruvate dehydrogenase and pyruvate carboxylase, respectively. These enzymes can be inhibited by insufficient quantities of cofactors, as NADH or ATP and by conditions as starvation and diabetes. All these interacting factors and conditions may affect the balance between pyruvate production and utilization and may lead to lactate acidosis ${ }^{[103]}$.

Another factor, that has a great impact on the lactate production is the redox state of the cytosol [104]. As was mentioned above, the redox state of the cytosol is dependent upon the oxygen availability in the mitochondria. An increased redox state reflecting an increased ratio between the reduced and oxidized molecules in the cytosol is associated with lactate production. Decreased oxygen is the most common condition increasing the redox state, but toxins and certain drugs can also affect the redox state and stimulate lactate production ${ }^{[105]}$.

\subsubsection{Lactate utilization}

The utilization of lactate is characterized by a reconversion to pyruvate after which pyruvate is either oxidized in the citric acid cycle or reconverted in the gluconeogenesis back to glucose ${ }^{[104]}$. The gluconeogenesis occurs prominently in the liver 
and kidney. On the other hand in the brain, heart and skeletal muscle, lactate can directly be used for energy.

\subsubsection{Lactate as a monitor of tissue hypoxia in adult intensive care medicine ${ }^{[05]}$.}

Lactate was proposed as a metabolic monitor of shock and tissue hypoxia. Wasserman et al. ${ }^{[106]}$ confirmed in a human study the concept that lactate did not increase gradually and continuously, but only when a threshold oxygen consumption is exceeded. The course of the lactate values during progressive graded hypoxia is best described by the biphasic dual-line in contrast to a single-line or polynomial line technique ${ }^{[10 \%]}$.

The amount of lactate produced is correlated with the oxygen debt and the severity of the shock. In agreement with this lactate appeared to have a prognostic value. Several authors have demonstrated an increased mortality in shock, when lactate levels were higher than $2-4 \mathrm{mmol} / \mathrm{L}$. Serial lactate determinations in critically ill patients can even improve the prognostic value. On the other hand, other factors as hepatic reserve and nutrition status may affect the plasma lactate concentration ${ }^{[105]}$.

\subsubsection{Lactate in neonatal medicine}

In neonatal medicine lactate was used as a monitor of tissue hypoperfusion and tissue hypoxia. In a newborn animal experiment induced group B streptococcal sepsis induced an increased arterial lactate concentration. Lactate production was most prominent in those tissues, in which oxygen uptake was reduced, as skeletal muscle and cerebral tissue ${ }^{[108]}$. In preterm infants the effect of sepsis on carbohydrate metabolism was observed. No significant changes were seen in the glucose and insulin concentration. However, plasma lactate concentration was increased. The authors concluded that plasma lactate may be an early clinical marker of neonatal sepsis ${ }^{[109]}$. A common problem in neonatology is when to give an erythrocyte transfusion in healthy preterm infants with anemia of prematurity. In an observational study it was concluded, that lactate could be a predictor for erythrocyte transfusion need in this group of patients ${ }^{[110]}$. Plasma lactate concentration as a predictor of outcome was investigated in a retrospective study in neonates requiring extracorporeal membrane oxygenation (ECMO). In non-survivors lactate levels before and after ECMO were significantly higher than in survivors ${ }^{[111]}$. Several metabolic parameters among which lactate have been studied in perinatal asphyxia to determine severity and to predict outcome. Increased plasma lactate concentration seemed to have a low sensitivity and a low positive predictive value for adverse outcome ${ }^{[112]}$.

In summary, plasma lactate concentration has been used in neonatal medicine to monitor tissue hypoxia and to estimate tissue damage after asphyxia. It seemed that elevated levels of lactate were associated with tissue hypoxia in sepsis, anemia of prematurity and in infants who need ECMO. The association between lactate and outcome after asphyxia is less obvious.

\section{4}

Anaerobic sources of energy (2): Phosphocreatine reaction ${ }^{[9,102]}$

Phosphocreatine is a protein that consists of creatine and an inorganic high energy phosphate bond. By breaking down this bond enough energy is released to regenerate ATP from ADP. The break down of phosphocreatine is catalyzed by the enzyme creatine kinase and is promoted by the end products of the hydrolysis of ATP: ADP and inorganic phosphate. Therefore, the break down of phosphocreatine is connected with the hydrolysis of aerobic ATP and reflects more an increased energy demand than an anaerobic condition. Both the ATP hydrolysis and phosphocreatine breakdown result in an increased intracellular inorganic phosphate. The increased intracellular inorganic phosphate stimulate glycogenolysis, glycolysis and oxidative phosphorylation. 
In summary the phosphocreatine system has an important function in the first 5 to 10 seconds of intense exercise. In addition glycolysis can be continued for a period of 30 to 40 seconds. Longer periods of exercise need to be answered by the oxidative metabolism. Phosphocreatine reaction and glycolysis produces ATP 4 and 2.5 times as rapidly as normal oxidative metabolism in the mitochondria, respectively ${ }^{[113]}$.

\subsection{Mechanisms of cell damage during hypoxia ${ }^{[97,98]}$}

Cellular acidosis The major source of $\mathrm{H}^{+}$ions during hypoxia is the immediate hydrolysis of ATP formed during glycolysis. The simultaneously formed lactate will consume $\mathrm{H}^{+}$ions in the process of gluconeogenesis and oxidation in the Krebs cycle. When lactate utilization in these pathways is impaired (tissue hypoxia, toxicity) lactic acidosis will ensue ${ }^{[104]}$. Intracellular acidosis may damage the cell by the following mechanisms: loss of adenine nucleotides, as AMP precursors, $\mathrm{ADP}, \mathrm{ATP}$ and $\mathrm{NADH}$, from the mitochondrion and inhibition of the $\mathrm{Na}^{+} / \mathrm{Ca}^{2+}$ exchanger resulting in an increased intracellular calcium. Increase in intracellular calcium concentration: The intracellular $\mathrm{Ca}^{2+}$ concentration is closely regulated by membrane bound ATP controlled $\mathrm{Ca}^{2+}$ pumps, $\mathrm{Na}^{+} / \mathrm{Ca}^{2+}$ exchangers and voltage dependent $\mathrm{Ca}^{2+}$ pumps. In the case of hypoxia intracellular $\mathrm{Ca}^{2+}$ will increase by inhibition of the before mentioned $\mathrm{Ca}^{2+}$ pumps. Increased intracellular $\mathrm{Ca}^{2+}$ induces phospholipase, which damage the cell membrane, induces ATPases in the plasmamembrane, induces breaks in DNA and finally induces the expression of genes important in initiating cell death and apoptosis ${ }^{[98]}$. Formation of oxygen free radicals: Free oxygen radicals are responsible for the reperfusion damage after the hypoxic incident. One of the main mechanisms generating free oxygen radicals include the action of the $\mathrm{O}$ form of xanthine oxidase upon reoxygenation.

\section{Systemic hypoxia}

Hypoxia in terms of oxygen delivery $\left(\mathrm{DO}_{2}\right)$ and consumption $\left(\mathrm{VO}_{2}\right)$ at systemic level was investigated by Cain ${ }^{[14,115]}$. He found a biphasic relationship between $\mathrm{DO}_{2}$ and $\mathrm{VO}_{2} . \mathrm{VO}_{2}$ was found to be independent of the systemic $\mathrm{DO}_{2}$, when $\mathrm{DO}_{2}$ decreased over a wide range due to different compensatory mechanisms. Hypoxia or anaerobic metabolism will only ensue, when $\mathrm{DO}_{2}$ is reduced below a critical level and $\mathrm{VO}_{2}$ will decline. In anesthetized human patients the biphasic relationship between $\mathrm{DO}_{2}$ and $\mathrm{VO}_{2}$ was established by Shibutani et al [116]. The idea of the biphasic relationship between $\mathrm{DO}_{2}$ and $\mathrm{VO}_{2}$ was questioned by Schligtig and Pinsky ${ }^{[11]}$. They argued that in most physiological situations $\mathrm{VO}_{2}$ varies several fold during the course of a normal day and that the increased $\mathrm{VO}_{2}$ is not supported by increased oxygen extraction but by an increased $\mathrm{DO}_{2}$ (oxygen demand dependency). It seems that one can speak only of a biphasical relationship between $\mathrm{DO}_{2}$ and $\mathrm{VO}_{2}$, when oxygen demand is kept constant.

In this review on systemic hypoxia the different disorders that can lead to tissue hypoxia as hypoxic, anemic and circulatory hypoxia will be discussed, since different compensatory mechanisms have been described.

\subsection{Hypoxic hypoxia}

3.1.1 Acute hypoxic hypoxia and oxygen transport in the neonatal animal.

The biphasic relationship between $\mathrm{DO}_{2}$ and $\mathrm{VO}_{2}$ was confirmed in different neonatal animals during acute hypoxic hypoxia [118-120]. Torrance et al. attempted to define the arterial $\mathrm{pO}_{2}$ threshold for oxygen-restricted metabolism, as confirmed by metabolic 
acidosis ${ }^{[118]}$ and increased lactate concentration ${ }^{[19]}$, during graded hypoxia in neonatal piglets. Normal acid-base balance was maintained with a wide range of $\mathrm{paO}_{2}$, values to 5.3 $\mathrm{kPa}(40 \mathrm{mmHg})$. Below this $\mathrm{paO}_{2}$ value a progressive metabolic acidosis ensued. This threshold value was confirmed in the fact that also lactate increased below a $\mathrm{paO}_{2}$ level of $40 \mathrm{mmHg}$.

Moss et al. ${ }^{[120]}$ studied metabolic responses during graded alveolar hypoxia in conscious lambs to test whether there is a difference between the metabolic response at different age. The biphasic response, i.e. $\mathrm{VO}_{2}$ and lactate concentration were unchanged except at the lowest inspired oxygen concentration, was confirmed in all three age groups. Since baseline $\mathrm{DO}_{2}$ and $\mathrm{VO}_{2}$ were higher in the youngest group of animals ( $<1$ week), the critical $\mathrm{DO}_{2}$ level was higher in the youngest animals compared with the two other groups. Lactate increased when $\mathrm{VO}_{2}$ decreased more than 15 percent below baseline. It seems that there is a bufferzone in the reduction of $\mathrm{VO}_{2}$, before lactate increased. For this, mechanisms of an increased lactate clearance or of an initial reduction of non-essential metabolism (for example: growth) was suggested.

\subsubsection{Acute hypoxic hypoxia and cardiovascular compensatory mechanisms during development}

The cardiovascular response to acute hypoxia in the late fetus consists of a decrease in heart rate, a variable change (often increase) of the mean arterial pressure and an increase in peripheral vascular resistance ${ }^{[21,122]}$. The cardiac output is redistributed in favour of the cerebral and myocardial circulation at expense of the gastro-intestinal, pulmonary and renal circulation. These responses are mediated by chemoreceptors and local tissue factors. In the study of Bartelds et al. ${ }^{[23]}$ it was shown, that carotid and not aortic chemoreceptors mediate the cardiovascular response in the fetus. Sidi et al. ${ }^{[124]}$ studied the cardiovascular responses to acute hypoxemia in lambs after birth. The authors evaluated the responses and blood flow distribution together with the influence of age during moderate $\left(\mathrm{FiO}_{2}=0.16\right)$ and severe $\left(\mathrm{FiO}_{2}=0.09\right)$ hypoxia. Cardiopulmonary response included an early rise in heart rate, cardiac output, and arterial blood pressure during moderate hypoxemia. With severe hypoxemia cardiac output was unchanged and arterial blood pressure decreased along with a metabolic acidosis. The regional redistribution of blood flow during hypoxia changed similarly in all age groups: heart and brain flow increased; no change in flow to muscle and bone; renal, skin and GI tract flow decreased. This redistribution resulted in a increasing $\mathrm{DO}_{2}$ to the heart, an unchanged $\mathrm{DO}_{2}$ to the brain and a decreased $\mathrm{DO}_{2}$ to all other organs. Another finding of this study was, that in younger lambs with a given change of oxygen consumption, metabolic acidosis and lactate was less pronounced. Younger lambs seemed to tolerate a decreased $\mathrm{VO}_{2}$ better than older lambs. After birth, the response to acute hypoxic hypoxemia is markedly different from the response in utero: Heart rate and ventilation increase. Several mechanisms have been mentioned to explain this different response: pulmonary stretch receptors stimulated by an increased ventilation overruling chemical receptors, different responses between aortic and carotid bodies or developmental differences in chemoreceptor sensitivity ${ }^{[124]}$. In the study of Koehler et al. ${ }^{[125]}$ regional blood flow changes during acute isocapnic hypoxia $\left(40-50 \% \mathrm{caO}_{2}(\mathrm{Hb})\right.$ reduction) induced by a reduced inspiratory oxygen administration were compared in newborn and adult sheep. The responses were qualitatively similar in cerebral, myocardial and skeletal muscle, where flow increased. In lambs renal and skin flow decreased, whereas in adult sheep it increased. In lambs small intestine flow was unchanged, but was increased in adults. It seemed, that a trend could be observed towards lesser vasoconstriction in the renal and gastro-intestinal vascular beds in the adult sheep compared with the neonatal counterpart. The authors speculate that mechanisms, as a direct effect of hypoxia on the central nervous system or an 
increased sensitivity of the aortic chemoreflex possibly may play a role in the cardiovascular response in neonatal lambs ${ }^{[125]}$.

\subsubsection{Chronic hypoxic hypoxia and cardiovascular compensatory mechanisms during development}

In a chronic lamb model Teitel et al. ${ }^{[126]}$ evaluated the effects of hypoxemia produced by a right to left shunt (atrium septostomy and pulmonary artery stenosis by an inflatable balloon) with a normal alveolar $\mathrm{pO}_{2}$. Arterial oxygen saturations were reduced to 60 to $75 \%$. Systemic cardiac output decreased initially but quickly returned to normal values. $\mathrm{DO}_{2}$ decreased concomitantly, but increased during the study period, because of the increase in hemoglobin concentration and cardiac output. Oxygen consumption indexed to weight remained within the normal range during the study period. However growth rate decreased dramatically. Again, it was speculated that oxygen consumption is redistributed from facultative or non-essential metabolism to increased cardiorespiratory work.

In a subsequent study in this chronic hypoxic lamb model Bernstein et al. ${ }^{[12]}$ evaluated the question whether a redistribution of blood flow could account for the dramatic decrease in growth rate. Chronic hypoxemia did not alter total cardiac output. However, in contrast to the acute hypoxemia ${ }^{[124]}$, chronic hypoxemia is not associated with increases in myocardial and cerebral blood flow. Cardiac output and cerebral blood flow initially increased but returned to control levels. Blood flow to the kidneys, spleen, gastrointestinal tract, carcass and skin remained decreased during the study period. Hemoglobin concentration gradually increased and systemic $\mathrm{DO}_{2}$ returned to control values. However, $\mathrm{DO}_{2}$ to kidneys, spleen, GI-tract, carcass and skin remained reduced. This decreased oxygen and substrate delivery to the gastro-intestinal tract, liver and carcass may account for the effect on growth in chronic hypoxemia.

\subsection{Anemic hypoxia}

\subsubsection{Oxygen transport and compensatory mechanisms}

Anemic hypoxia is characterized by a reduction of the arterial oxygen content $\left(\mathrm{caO}_{2}(\mathrm{Hb})\right)$ with a normal or even increased $\mathrm{paO}_{2}$. Compensatory mechanisms to preserve oxygen consumption include an a) increased cardiac output, b) decreased systemic vascular resistance, c) an increased oxygen extraction, d) a shift of the hemoglobin oxygen dissociation curve and e) a redistribution of regional blood flow ${ }^{[128-130]}$

a) Cardiac output increases significantly in proportion to the decrease of hematocrit. The extent of the rise was reported between 40 to $125 \%$. The mechanisms for the increased cardiac output have been attributed in conscious animals to an increased heart rate, and in anesthetized animals to an increased stroke volume. An increased stroke volume was suggested to be generated by an increased venous return to the heart, a reduction of the left ventricular afterload and an increased myocardial contractility. As a consequence of the increased myocardial contractility it was seen that oxygen consumption may increase at the initially steps of hemodilution. The increased venous return to the heart, and the reduction of the left ventricular afterload are a direct consequence of the

b) reduced blood viscosity and consequently decreased systemic vascular resistance. Although peripheral vasodilation may play a role it seems that principally the decreased blood viscosity is responsible for an increased blood flow in the microcirculation.

c) Since further compensatory increase in flow is limited when hematocrit is reduced below $30 \%$ to $25 \%$, peripheral oxygen extraction starts to play a more important 
role below this hematocrit value. Maximal oxygen extraction values to $79 \%$ have been encountered associated with very low $\mathrm{SvO}_{2}$ values.

d) Chronic anemia induces a rise in the concentration of 2,3-diphosphoglycerate and therefore induces a sbift of the oxygen dissociation curve to the right, facilitating oxygen release to the tissues.

e) A redistribution of regional blood flow was reported during anemic hypoxia. Together with the increased cardiac output a disproportionally increased coronary blood flow was found. An increase proportionate to the increased cardiac output was found in the vertebral and the superior mesenterial arteries and in the lower aorta. In the renal, hepatic and carotid arteries the blood flow increased proportionally less than the increase in cardiac output.

\subsubsection{Comparing hypoxic and anemic hypoxia.}

Cain ${ }^{[114]}$ compared hypoxic and anemic hypoxia in dogs. He found, that oxygen uptake started to decrease and lactate started to increase at similar levels of systemic $\mathrm{DO}_{2}$. However, venous $\mathrm{pO}_{2}$ at this critical level of $\mathrm{DO}_{2}$ was higher at anemic hypoxia than in hypoxic hypoxia. Venous $\mathrm{pO}_{2}$ is, theoretically, the lowest driving pressure of oxygen diffusion to the tissues. It seems curious, that at critical $\mathrm{DO}_{2}$, below which oxygen restricted metabolism will ensue, the lowest driving pressure for oxygen diffusion is different between two types of hypoxia. Explanation for this phenomenon includes the fact that the full range of the oxyhemoglobin dissociation curve is used and even at the lowest $\mathrm{DO}_{2}$ level, high arterial $\mathrm{SaO}_{2}$ and $\mathrm{paO}_{2}$, and consequently also higher values of $\mathrm{PvO}_{2}$ and $\mathrm{SvO}_{2}$, are observed. In addition, differences in the redistribution of blood flow and microcirculation during anemic hypoxia compared with hypoxic hypoxia may play a role [131].

\subsubsection{Chronic anemic hypoxia}

Cardiovascular adaptations to chronic anemia were studied in the newborn lamb [133]. After two weeks of anemia (hemoglobin level $60 \%$ of normal) measurements were performed. The major compensatory responses were an increase of heart rate, cardiac output and oxygen extraction. Blood flow to the heart and brain increased and flow to the viscera and carcass did not change. In chronic hypoxic hypoxia ${ }^{[127]}$ it was found, that hemoglobin increased and systemic $\mathrm{DO}_{2}$ normalized again within two weeks. In contrast to chronic anemic hypoxia heart rate and cardiac output did not change and blood flow to the visceral organs decreased. Normal $\mathrm{paO}_{2}$ during anemic hypoxia may normalize blood flow to the visceral organs via peripheral chemoreceptors, whereas low $\mathrm{paO}_{2}$ in hypoxic hypoxia may decrease bloodflow to the visceral organs.

No difference of the mixed venous oxygen tension or saturations, between anemic and hypoxemic hypoxia were found in this chronic hypoxia model.

\subsection{Circulatory hypoxia}

\subsubsection{Critical cardiac output during development}

Circulatory hypoxia in the neonatal animal model has obtained attention in studies designed to determine the critical value of cardiac output below which oxygen consumption decreased and anaerobic metabolism ensues ${ }^{[134]}$. Cardiac output was lowered progressively in unsedated, conscious 2 weeks, 4 weeks and 8 weeks old lambs. Baseline cardiac output showed the expected decline in the older age groups. In the 2 and 4 weeks old lambs the absolute critical level of the cardiac output was identical but in the oldest 
lambs the critical levels were significantly lower. However, the critical level calculated as a fraction from baseline was significantly higher in the 4 weeks old lambs. Probably , this phenomenon is due to the nadir of the physiological anemia at this age. Subsequently, to determine the effect of hemoglobin on critical cardiac output Heusser et al. ${ }^{[153]}$ reduced cardiac output at different hemoglobin concentrations. Despite different hemoglobin concentrations baseline cardiac output was not different. Since fractional oxygen extraction was increased in the lower Hgb concentration groups baseline oxygen consumption was similar in all the different $\mathrm{Hgb}$ groups. Critical cardiac output calculated as a fraction from baseline was significantly higher in the lower Hgb concentration groups. Critical total systemic $\mathrm{DO}_{2}$ and fractional oxygen extraction were not different between the $\mathrm{Hgb}$ groups. The authors conclude that $\mathrm{VO}_{2}$ decreases when $\mathrm{DO}_{2}$ is reduced below a certain level, but this critical level is not dependent on the manner in which $\mathrm{DO}_{2}$ is reduced.

Fahey et al. ${ }^{[136]}$ addressed the issue of non-essential oxygen consumption and investigated the repayment of the oxygen deficit in 2 week and 8 week old lambs. They found that 2 week old lambs after a critical reduction of cardiac output maintained oxygen consumption during recovery slightly below baseline, whereas in 8-week old lambs oxygen consumption in the recovery period remained above baseline. Moreover, lactate increased compared with the oxygen deficit at a significantly lower rate in the 2-week old lambs. Consequently, 2-week old lambs showed a lower oxygen debt and a lower lactate concentration at severe reduced cardiac output. In other words it seemed, that 2-week old lambs decreased their metabolic needs by suppressing their facultative or non-essential metabolism in contrast to older lambs in comparable conditions.

\subsubsection{Chronic circulatory hypoxia}

Chronic circulatory (reduced cardiac output) and hypoxic hypoxia were compared, while lactate and hypoxanthine levels were determined during both types of hypoxia ${ }^{[137]}$. Lactate was linearly related to the cumulative oxygen debt in both types of hypoxia, but the slope of the regression was greater for circulatory than for hypoxic hypoxia. Hypoxanthine was only linearly related to oxygen debt in circulatory hypoxia. The authors speculated that the more pronounced redistribution of the bloodflow away from the liver and the kidneys during low cardiac output resulted in a decreased elimination of lactate and hypoxanthine, particularly. 


\section{Monitoring Oxygen; Oximetry}

1

1.1

1.1.1

1.2

2

2.1

2.1 .1

2.1 .2

2.1.2.1

2.1.2.2

2.1 .3

2.2

2.2 .1

2.2 .2

2.2 .3

2.2 .4

2.2 .5

2.2.6

\section{General principles of oximetry}

Fiberoptic reflection oximetry

Fiberoptic oximetry by the Oximetrix Opticath

Pulse oximetry

Accuracy and reliability of oximetry

Fiberoptic catbeter oximetry

Accuracy of fiberoptic oximetry in umbilical arterial catheters

Accuracy of fiberoptic oximetry in pulmonary artery catheters for $\mathrm{SvO}_{2}$

Accuracy of fiberoptic oximetry in pulmonary artery catheter during different conditions

Summary

The position of the fiberoptic catheter for the measurement of $\mathrm{SvO}_{2}$

Pulse oximetry

Accuracy studies

Different definitions of oxygen saturation

Dyshemoglobins, anemia and pulse oximetry

Accuracy in neonatal medicine

Usefulness of pulse oximetry

Summary 


\section{General principles of oximetry}

The term oximetry has been used for the measurement of oxygen saturation [1:s] The measurement of oxygen saturation currently includes:

a) non- invasive monitoring of the arterial oxygen saturation of hemoglobin, now primarily by pulse oximetry;

b) invasively monitoring both arterial, mixed venous and jugular bulb venous or intracardiac oxygen saturation by a fiberoptic catheter system; c) deter

c) determining the oxygen saturation of drawn blood using multiple wavelengths

The basic principle underlying all oximetry is the difference in light absorption between oxyhemoglobin $\left(\mathrm{O}_{2} \mathrm{Hb}\right)$ and deoxyhemoglobin $(\mathrm{HHb})$. In the spectral range from $600-700 \mathrm{~nm}$. $\mathrm{O}_{2} \mathrm{Hb}$ has a lower absorbance than $\mathrm{HHb}$, while at higher wavelengths (above $800 \mathrm{~nm}$.) a reciprocal relationship is seen with a higher absorbance for $\mathrm{O}_{2} \mathrm{Hb}$ compared with $\mathrm{HHb}{ }^{[138,160]}$. If both wavelengths of light are used, a ratio $(R)$ of absorbance at 660 nm. to absorbance $>800 \mathrm{~nm}$. can be determined.

The second principle in oximetry, the Lambert-Beer's law, states that the absorbance of incident light in a solution with a solute is proportional to the concentration of that solute ${ }^{[1+1]}$ and that in a solution with several solutes the total absorbance is equal to the sum of the independent solutes. In the case of hemoglobin, the absorbance of light and the ratio $(R)$ of absorbance at $660 \mathrm{~nm}$. to absorbance $>800 \mathrm{~nm}$. are proportional to the concentrations of $\mathrm{O}_{2} \mathrm{Hb}$ and $\mathrm{HHb}$. With this in mind a so-called calibration curve can be generated with oxygen saturation as a function of the ratio $(R)$. Because the optics of the devices and probes do not completely fulfil the requirements of the Lambert-Beer's law and the relation between oxygen saturation and $R$ is non-linear, the calibration curve in the currently available oximeters is derived from the relation between the value of $R$ and invasive arterial oxygen saturation measurements ${ }^{[138,142]}$. Since oximetry is based on the light absorbance from hemoglobin, it is therefore, unlike the oxyhemoglobin dissociation curve, unaffected by $\mathrm{pH}$ and $\mathrm{pCO}_{2}$.

\subsection{Fiberoptic reflection oximetry.}

The measurement of oxygen saturation of non-hemolyzed blood by reflected light was first described in $1949^{[138,139]}$. The principle of reflection oximetry was used for fiberoptic catheters. A fiberoptic reflection oximeter measures oxygen at the tip of the catheter. The catheter contains two bundles of optical fibers, one guides light into the blood; the other one guides the reflected (back-scattered) light to one or more photocells ${ }^{[143]}$. Usually two light emitting diodes (LED's) emit light at two different wavelengths at a rate of $200-300 \mathrm{~Hz}$. The reflected light from the blood is focused on a photocell, amplified and computed to the ratio of the light reflections at the two different wavelengths. The relation ship between the ratio and oxygen saturation is represented by a slightly curved line. The light reflection is affected by hemoglobin concentration, variation in blood flow and erythrocyte shape ${ }^{[143,144]}$, dependent on wavelength and oxygen saturation.

\subsubsection{Fiberoptic oximetry by the Oximetrix Opticath}

Brown et al. ${ }^{[22]}$ described the fiberoptic reflection oximetry catheter, Opticath, used in our studies and manufactured by Oximetrix. (Mountain View, Ca, USA.) The light source of the Oximetrix oximeter consists of, in contrast to other fiberoptic catheter systems, three diodes that emit light (LED) at three different wavelengths $\lambda 1=670$ $\mathrm{nm} ., \lambda 2=700 \mathrm{~nm}$. and $\lambda 3=800 \mathrm{~nm}$. These wavelengths were chosen to minimize the effects 
introduced by changes in hematocrit and bloodflow. They were selected after analysis of data obtained from in vitro experiments and in vivo studies conducted in anesthetized animals and human volunteers. A pulsegenerator sequentially activates each diode for 1 msec followed by an equal interval when no diodes are energized. This four period cycle occurs at a rate of $244 \mathrm{~Hz}$. The light from each diode is transmitted to the blood through one of the two catheter fiberoptics. The light reflected by the $\mathrm{O}_{2} \mathrm{Hb}$ and $\mathrm{HHb}$ is transmitted by the other receiving fiberoptic bundle to a photodiode. The electrical signal from the photodiode represents the reflected light intensity $(I)$ measurement made at the wavelength of each emitting diode. The signals are amplified and sent separately to the oximeter in the same sequence in which the LED's are energized. The oximeter provides two ratios of light intensity $I_{1}^{600} / I_{2}^{700}$ and $I_{3}^{800} / I_{2}^{700}$, that are used to determine oxygen saturation. One ratio was found to be independent of the hematocrit in the upper range of oxygen saturation values and the other ratio was independent of the hematocrit in the lower range of oxygen saturation values. One of the ratio's is selected when appropriate by electronic switching techniques and the use of weighing factors. By using these three wavelengths computing two ratios the computed oxygen saturation was aimed to be independent of changes in hematocrit and of other wavelength-dependent characteristics.

\section{$1.2 \quad$ Pulse oximetry.}

Pulse oximetry was developed based on the ingenious idea to analyze the change in light absorption produced by arterial pulsations ${ }^{[10,141]}$. Pulse oximetry analyzes the transmitted light, that consists of two components. The first component varies with the pulsation of the blood. The second component is a constant light output level that passes through the tissues without being absorbed or scattered. These two components are referred as AC components and DC components, respectively. Dividing the AC level by the DC level gives a corrected AC level reflecting the combined light transmission of $\mathrm{O}_{2} \mathrm{Hb}$ and $\mathrm{HHb}$. The ratio $R$ indicates the corrected AC level at $660 \mathrm{~nm}$ divided by the corrected AC level at $940 \mathrm{~nm}$. $R$ is then converted to a oxygen saturation value using the calibration curve. Since specifically pulsatile, arterial blood is observed, absorbances and reflections from other tissues, pigmentation and venous and capillary blood are ignored ${ }^{[188,142]}$.

\section{Accuracy and reliability of oximetry}

\subsection{Fiberoptic catheter oximetry}

\subsubsection{Accuracy of fiberoptic oximetry used as an umbilical arterial catheter in neonatal medicine.}

The accuracy of the fiberoptic catheter system has been tested in very different and several ways. Initially fiberoptic catheters were used as umbilical arterial catheters to measure continuously arterial oxygen saturation in newborn infants. Wilkinson et al. [145] and Krouskop et al. ${ }^{[1+6]}$ assessed the use and the accuracy of a 4 Fr. fiberoptic catheter (Oximetrix, Mountain View, $\mathrm{Ca}$ ) as an arterial umbilical catheter in sick newborn infants. In 1039 comparisons with bench measured blood samples correlation analysis revealed a correlation coefficient of $\mathrm{r}=0.97$. A mean error of $0.74 \pm 2.17$ percent saturation was found. Accuracy was not affected by bilirubin level up to $18 \mathrm{mg} / \mathrm{dl}$, variations in hematocrit (range from $19 \%-66 \%$ ), exchange transfusion, changes in hemoglobin oxygen affinity and fetal hemoglobin. Haessler et al. ${ }^{[14]}$ reported the use of an intra-arterial fiberoptic catheter (U 425 oximetry catheter (Abbott, Chicago,Ill.) compared with pulse 
oximetry and Co-oximetry during cardiopulmonary bypass. Saturation readings were obtained in $99 \%$ of the fiberoptic catheter readings and in $60 \%$ to $84 \%$ of the readings by pulse oximetry. Pulse oximetry failed during cardiopulmonary bypass with non-pulsatile flow and hypothermia. The mean difference and SD were for pulse oximetry $-0.8 \pm 1.0 \%$ and for catheter oximetry $0.4 \pm 1.0 \%$. The authors concluded that the performance of the fiberoptic catheter was excellent and superior to pulse oximetry without the necessity to perform an in vitro analysis.

\subsubsection{Accuracy of fiberoptic oximetry used in pulmonary artery catheters for the} measurement of mixed venous oxygen saturation $\left(\mathrm{SvO}_{2}\right)$.

With the coupling of the fiberoptic device to the pulmonary artery catheters of 7.5 Fr. fiberoptic reflectance oximetry for the continuous measurement of mixed venous oxygen saturation came into the adult intensive care arena ${ }^{[1+8,169]}$. Since more devices using two and three wavelengths light sources came into the market, studies comparing these devices appeared. Gettinger et al. ${ }^{[150]}$ compared the accuracy and stability of two fiberoptic (Oximetrix and Edwards) catheters with a reference Co-oximeter in an animal study. Regression line and correlation coefficient differed significantly between the two catheters. However, Reinhart et al. ${ }^{[151]}$ found little difference between these same devices in a human clinical study. Deviations of more than 5\% occurred in $13 \%$ (Edwards) and $20 \%$ (Oximetrix) of the measurements.

Leighton et al. ${ }^{[152]}$ examined two oximetry catheters (Oximetrix and EdwardsSAT2) in a swine model over a wide range of physiological states. They concluded that both systems performed equally well over a range of oxygen saturation from $18 \%$ to $90 \%$. In contrast, Rouby et al. ${ }^{[153]}$ showed that the Oximetrix system was more accurate in patients with circulatory shock and respiratory failure than the other catheter systems.

Scuderi et al. ${ }^{[154,155]}$ evaluated three mixed venous oxygen saturation catheters in thirty critically ill patients. Improvements in the catheter design, computer algorithms, and optical modules warranted a new comparison study between the most recent versions of the different fiberoptic catheter systems. The three catheter systems involved were Oximetrix, Edwards SAT 2 and Viggo Spectramed. Readings were compared with a Cooximeter IL 282. using a four wave length spectrophotometric technique. The mean difference and SD between the three fiberoptic catheters and the Co-oximeter were $-1.98 \pm$ $3.07,1.80 \pm 3.49$ and $-2.28 \pm 5.24$, respectively. The authors concluded, that Oximetrix and Edwards SAT-2 demonstrated a closer agreement with Co-oximetry than Viggo Spectramed. As a continuous monitor to detect changes or trends these devices are acceptable. However, none of these catheters provided evidence that they would perform within \pm 2 per cent of Co-oximetry, as was specified by the manufacturer. In a subsequent study Scuderi et al. ${ }^{[156]}$ compared the three same fiberoptic catheters in a controlled laboratory environment using a blood flow loop with whole fresh human blood. The purpose of this study was to examine whether the limitations of these devices were inherent to the oximeter technology or to the confounding effects of a given patients anatomy and physiology. They found that the mean difference \pm SD were $3.20 \pm 2.47,-1.25 \pm 3.36$ and $-9.97 \pm 7.05$ for the Oximetrix, Edwards SAT 2 and Viggo Spectramed, respectively. Since in the controlled laboratory environment results were similar to the results in clinical studies, the authors conclude in the discussion that the lack of agreement between the catheter readings and the Co-oximetry are inherent to the fiberoptic reflection oximetry.

\subsubsection{Accuracy of fiberoptic oximetry used in pulmonary artery catheter during different conditions.}

Mixed venous oxygen, measured by the fiberoptic reflectance oximetry has been 
reported to be affected by various conditions including hypertriglyceridemia, severe anaemia, free hemoglobin solutions, methemoglobinemia, carboxyhemoglobinemia, and hyperbilirubinemia.

Howdieshell et al. ${ }^{[157]}$ described the reliability of in vivo mixed venous oxygen saturation measured by the Oximetrix system during the infusion of progressive concentrations of Intralipid. The authors conclude that in vivo mixed venous oxygen saturation remained constant and reliable during hypertriglyceridemia while in vitro measurement (CO-Oximeter; Instrumentation Laboratories, Lexington, $\mathrm{Ma}$ ) were artifactually reduced by the falsely high values of methemoglobin. This is explained by the light scattering properties of triglycerides and its interference of the absorbance of light at the wavelength of methemoglobin. It is concluded that continuous in vivo oximetry remains reliable during lipid infusion.

Theoretically, severe anemia is expected to affect the accuracy of oximeter monitors. Fiberoptic reflectance oximetry estimate relative concentrations of oxyhemoglobin by measuring the ratios of reflected light intensity. In the absence of hemoglobin or with a small concentration of hemoglobin there should be no change in signal with changes in oxygenation or only a small change relative to the background noise. Woerkens et al. ${ }^{[158]}$ evaluated the accuracy of a mixed venous oxygen saturation catheter (Spectracath) during acutely induced changes in hematocrit in humans. The accuracy of the studied fiberoptic catheter was not affected by changes in hematocrit or cardiac output $\left(r^{2}\right.$ $=0.87)$. However, changes in hematocrit in this study were limited to hematocrit values between $18 \%$ and $40 \%$. Lee et al. ${ }^{[159]}$ described the accuracy of continuous oximetry (Oximetrix) during progressive isovolemic anemia. Data were collected while fractional oxygen inspired concentration $\left(\mathrm{FiO}_{2}\right)$ was varied from 1.00 to 0.05 in seven steps. The dogs underwent isovolemic hemodilution and the $\mathrm{FiO}_{2}$ was again varied. the sequence continued until no data could be obtained. The accuracy of the catheter system (Oximetrix) was indicated by a mean difference and SD of $-0.7 \pm 8.6 \%$. The accuracy as assessed was similar for hematocrits between $15 \%$ to $40 \%$. Below a hematocrit of $10 \%$ the accuracy of fiberoptic oximetry became less acceptable: (mean difference $\pm \mathrm{SD}:-11.5 \pm 11.8$ ).

Kong et al. ${ }^{[160]}$ tested two pulmonary catheters (SAT 2 and Oximetrix, Opticath) on their ability to measure oxyhemoglobin saturations in haemoglobin solutions. The performances of both catheters were excellent in the measurement of oxygen saturation in whole blood and hemodiluted blood, however, when hemoglobin solutions are used, the performance is poor and oxygen saturation catheter readings are inaccurate. Increasing methemoglobin was found in the haemoglobin solutions and could partially explain the inaccurate readings of the fiberoptic oximetry.

The Oximetrix opticath was tested as a pulmonary artery catheter in five anesthetized dogs in which increasing levels of methemoglobin were induced ${ }^{[6]}$. In the presence of increasing levels of methemoglobin $\mathrm{SvO}_{2}$ readings overestimated progressively the value of the oxygen saturation defined as the ratio between oxyhemoglobin and the hemoglobin available for oxygen transport, also called functional oxygen saturation. For example with a methemoglobin concentration $>40 \%$ the mean difference \pm SD between the catheter reading and the functional oxygen saturation determined by Co-oximetry was $24.1 \pm 10.4$ $\%$.

The same group ${ }^{[7]}$ examined the accuracy of the Oximetrix catheter in dogs ventilated with increasing inspired concentrations of carbon monoxide. Carboxyhemoglobin levels ranged from $0 \%$ to $70 \%$. Mixed venous oxygen saturation readings measured in the pulmonary artery overestimated the value of oxygen saturation defined as the ratio between oxyhemoglobin and total hemoglobin also including dyshemoglobins as carboxyhemoglobin. Mixed venous oxygen saturation readings approximately equal 
functional oxygen saturation defined as the ratio between oxyhemoglobin and hemoglobin available for oxygen transport.

In the first reports about accuracy ${ }^{[165,146]}$ it was already described that catheter readings were not dependent on the values of bilirubin up to $18 \mathrm{mg} / \mathrm{dl}$.

Mault et al. ${ }^{[161]}$ described the use of the $4 \mathrm{Fr}$. Oximeter fiberoptic catheter as a monitor of the venous oxygen value of the ECMO circuit. The mean difference between the catheter readings and the Co-Oximetry were: $-0.2 \% \pm 4.5 \%$.

\subsubsection{Summary}

Pulmonary artery oximetry relies on complex optical phenomena involving absorption, reflection and refraction of light within a suspension of erythrocytes in plasma. The accuracy of the measurements also is affected by physiological factors such as hematocrit, erythrocyte velocity and turbulence, pulsatile bloodflow and artifact induced by catheter tip interaction with the blood vessel. The pulmonary catheters are said to yield test results similar to spectro-photometers as Radiometer OSM or Co- oximeter. Most data comparing pulmonary catheter readings and hemoximeters support that PA catheters are capable of providing clinically useful trending data. The most used catheters (Oximetrix and Edwards SAT2) are comparable in accuracy and reliability. However, these catheter devices cannot provide the accuracy of $2 \%$ as specified by the manufacturers. Fiberoptic catheter oximetry can be used to monitor the mixed venous oxygen saturation during various conditions and physiological disturbances. The limitations of the fiberoptic oximetry must be taken into account especially the relative broad dispersion of the values compared with Co-oximetry. Therefore, one must be cautious to interpret absolute values.

\subsubsection{The position of the fiberoptic catheter for a reliable measurement of mixed venous oxygen saturation $\left(\mathrm{SvO}_{2}\right)$.}

In small newborn infants venous oxygen saturation can be monitored easily and with much less patient risk by a catheter inserted through the umbilical vein into the right atrium than by a pulmonary artery catheter. However, catheter motion, chamber wall reflection, filtering technique to calculate oxygen saturation, intra-atrial left-to-right shunting and the possible insufficient mixing of the blood may affect the feasibility of the right atrium as a measurement site for mixed venous oxygen saturation.

In several studies central venous oxygen saturation $\left(\mathrm{ScvO}_{2}\right)$ measured in the right atrium or in one of the venae cavae has been examined as a substitute for $\mathrm{SvO}_{2}$ measured in the pulmonary artery.

Barratt-Boyes and Wood ${ }^{[162]}$ described the values of oxygen saturation of blood in the venae cavae, right heart chambers and pulmonary vessels in 26 healthy subjects. The venous blood withdrawn from the inferior vena cava, the superior vena cava, right atrium, right ventricle and pulmonary artery equalled 83 (76 to 88), 76.8 (66 to 84), 79.5 (72 to 86), 78.5 (64 to 84$)$ and 78.4 (73 to 85$)$ per cent oxygen saturation, respectively. There is a slight but significant reduction of the oxygen saturation of the venous blood during its passage through the ventricle probably caused by the streamline flow of the coronary sinus draining into the right ventricle. However, the mean difference between oxygen saturation in the right atrium and in the pulmonary artery in paired samples was only $0.3 \pm 3.5$ per cent oxygen saturation. In another study Freed et al. ${ }^{[163]}$ examined the oxygen saturation values at different locations in the central venous circulation of the heart. They found as well that right atrial oxygen saturation was only $0.7 \%$ higher than the pulmonary arterial saturation. As in the data from Barratt-Boyes and Wood ${ }^{[162]}$ the data in this study showed less variability in the distal samples, such as in the right ventricular outflow tract, suggesting better mixing in the distal part of the central venous circulation of the heart. 
In animal studies oxygen saturation values obtained in the right atrium ${ }^{[7]]}$ or in the superior vena cava ${ }^{[79]}$ were compared with oxygen saturation in the pulmonary artery. The studies were performed over a broad range of cardiorespiratory conditions including hypoxia, hemorrhage and resuscitation. In 464 paired data ${ }^{[7]}$ obtained by fiberoptic oximetry mean oxygen saturation in the right atrium $(54.1 \pm 10.6 \%)$ was very close to the value in the pulmonary artery $(53.2 \pm 11.1 \%)$. A close tracking of changes across a wide range of hemodynamic conditions between the two measurement sites were found. In 179 samples ${ }^{[79]}$ the mean difference between $\mathrm{SvO}_{2}$ and $\mathrm{ScvO}_{2}$ obtained in the superior vena cava was $3.7 \pm 2.9$ percent saturation. Additionally, more than $20 \%$ of the $\mathrm{ScvO}_{2}$ readings differed more than $5 \%$ from the $\mathrm{SvO}_{2}$ value.

In human clinical studies results are more contradictory. Berridge ${ }^{[164]}$ examined the influence of cardiac output on the correlation between mixed venous and central venous oxygen saturation. In 76 samples obtained in 51 patients he found a close correlation between $\mathrm{ScvO}_{2}$ and $\mathrm{SvO}_{2}$ irrespective of the cardiac output using a standard thermodilution technique. Tahvanainen et al. ${ }^{[165]}$ estimated the value of $\mathrm{ScvO}_{2}$ compared with $\mathrm{SvO}_{2}$ to calculate pulmonary shunt and arteriovenous oxygen difference. Central venous blood was sampled through the proximal port of a pulmonary artery catheter in critically ill patients. A significant positive correlation of the variables and of the subsequent changes were found. However, the broad confidence intervals allowed remarkable errors in the estimation of pulmonary shunts and other derived variables based on central venous oxygen saturations.

Martin et al. ${ }^{[166]}$ described in a clinical study in 7 critically ill patients the reliability of the $\mathrm{ScvO}_{2}$ readings obtained in the lower part of the vena cava superior. The mean difference and $\mathrm{SD}$ was $0.3 \pm 10 \%$ in 580 comparisons between $\mathrm{SvO}_{2}$ and $\mathrm{ScvO}_{2}$. Differences of $>5 \%$ were obtained in $50 \%$ of the compared values. The authors concluded that the measurement of $\mathrm{ScvO}_{2}$ can not substitute $\mathrm{SvO}_{2}$. Faber ${ }^{[16]]}$ examined the relation between central venous and mixed venous oxygen content in 24 critically ill patients. A relatively poor association between central venous and mixed venous oxygen saturation was found: $(\mathrm{r}=0.75)$. A proposed algorithm to estimate the value of mixed venous oxygen content from central venous oxygen content seemed of limited value. Brandt et al. ${ }^{[168]}$ disputed the use of central venous catheters as a substitute for mixed venous oxygen saturation measurement and considered the measurement in the right atrium as unreliable and inaccurate because of catheter motion and incomplete mixing of the venous blood.

We may conclude, that only slight differences exist between the right atrium oxygen saturation compared with the pulmonary artery oxygen saturation as determined during cardiac catheterization. In animal studies and smaller clinical studies these slight differences were confirmed. In clinical studies using the superior vena cava as measurement site differences were larger and it was concluded that $\mathrm{ScvO}_{2}$ could not substitute $\mathrm{SvO}_{2}$ measurement.

The drawbacks of the oxygen measurement in the right atrium are probably also valid in neonatal medicine. However, the measurement of venous oxygen saturation in newborn infants is limited to the right atrium, since the use of a pulmonary artery catheter is difficult and hazardous. Umbilical venous catheters have been used frequently with a relatively low incidence of complications and a fiberoptic catheter could be placed in the right atrium as a estimate of mixed venous oxygen saturation ${ }^{[169]}$.

The drawbacks of right atrial oxygen saturation measurement must be taken into account by careful consideration of the position of the catheter, frequent in vivo calibration and caution in the calculation of oxygen transport variables based on central venous oxygen saturations. 


\subsubsection{Accuracy studies}

Yelderman and $\mathrm{New}^{\left[{ }^{120}\right]}$ were among the first to conclude, that the pulse oximeter in 79 pooled data from five young adults accurately measures $\mathrm{SaO}_{2}$ in the range of $70 \%$ $100 \%$. In pre(term) infants pulse oximetry (Nellcor N200) was assessed as a monitor of oxygenation and $\mathrm{SaO}_{2}$ readings compared with the $\mathrm{SaO}_{2}$ measurement by the hemoximeter showed a significant correlation $(\mathrm{r}-0.90)^{[1] !}$. Hay compared the $\mathrm{SaO}_{2}$ readings obtained by pulse oximetry (Ohmeda) with the arterial samples obtained by the hemoximeter. Regression analysis yielded a good correlation $(r-0.99, p<0.001)^{[1 / 2 !}$.

In these and in other studies accuracy was studied by regression analysis. However, regression analysis was found to be inadequate because a good correlation does not imply an accurate measurement ${ }^{[13\}]}$. The mean difference and standard deviation between the pulse oximeter readings and the laboratory hemoximeter values are currently the preferred indices to assess accuracy ${ }^{[174]}$.

In several reports ${ }^{[1 / 4+17]}$ pulse oximeters of different brands were described and compared. In most studies the mean difference between the pulse oximeter readings and the laboratory hemoximeter values were below $\pm 3 \%$ at $\mathrm{SaO}_{2}$ values above $70 \%$. Accuracy at lower levels of saturation $\left(\mathrm{SaO}_{2}\right.$ values $\left.<80 \%\right)$ have been studied by Schmitt et al. ${ }^{[(\gamma \gamma)}$ in children with congenital cyanotic heart disease. Pulse oximetry overestimated (mean difference and SD: $5.8 \% \pm 4.8$ ) the true value at lower levels of saturation. In a review ${ }^{[174]}$ the overestimation of pulse oximetry values at lower level of saturation was confirmed for pulse oximeters of different brands.

\subsubsection{Different definitions of oxygen saturation}

Another aspect of accuracy was discussed by Thilo et al. ${ }^{[179]}$ in a study in which she compared two different pulse oximeters (Nellcor and Ohmeda). Both oximeters were used simultaneously in the same infant with an arterial umbilical catheter. The Nellcor correlated best with the oxyhemoglobin defined as $\left(\mathrm{O}_{2} \mathrm{Hb}\right) /\left(\mathrm{O}_{2} \mathrm{Hb}+\mathrm{HHb}\right)$, while Ohmeda correlated best with oxyhemoglobin defined as $\left(\mathrm{O}_{2} \mathrm{Hb}\right) /\left(\mathrm{O}_{2} \mathrm{Hb}+\mathrm{HHb}+\mathrm{COHb}+\right.$ metHb). Some manufacturers apparently considered in the data read out the presence of a small percentage of dyshemoglobins, whereas others considered oxygen saturation the percentage of hemoglobin bound to oxygen compared with the hemoglobin capable of binding. These two "different" oxygen saturations were called fractional and functional oxygen saturations, respectively. However, these new terms were called unnecessary and self-contradictory ${ }^{[1,2,4]}$. In the study of Thilo et al. ${ }^{[179]}$ this difference influenced the relation between $\mathrm{paO}_{2}$ and $\mathrm{SaO}_{2}$ value as registered by the pulse oximeter. A paO $\mathrm{O}_{2}$ between 50 and $100 \mathrm{mmHg}$ was correlated with a Nellcor $\mathrm{SaO}_{2}$ between $92 \%$ and $98 \%$ and with an Ohmeda $\mathrm{SaO}_{2}$ between $90 \%$ and $96 \%$. The authors concluded that different brands of pulse oximeters are not interchangeable.

\subsubsection{Dyshemoglobins, anemia and pulse oximetry}

The effect of dyshemoglobins as carboxyhemoglobin $(\mathrm{COHb})$ and methemoglobin $(\mathrm{MetHb})$ on pulse oximetry was studied by Barker and Tremper ${ }^{[6,180]}$. With respect to $\mathrm{COHb}$ the pulse oximeter continued to read an oxygen saturation of $90 \%$, while the actual $\mathrm{O}_{2} \mathrm{Hb}$ fell below $30 \%$. Pulse oximeter readings approximate the sum of $\mathrm{COHb}$ and $\mathrm{O}_{2} \mathrm{Hb}$ and consequently overestimate the $\mathrm{O}_{2} \mathrm{Hb}^{[180]}$. With respect to metHb ${ }^{[6]}$ pulse oximeter readings overestimated progressively the value of the oxygen saturation. In the presence of significant levels of dyshemoglobins, laboratory Co-oximetry should supplement pulse oximetry. 
Severe anemia is, theoretically, expected to affect the accuracy of pulse oximetry. Lee et al. ${ }^{[159]}$ described the accuracy of pulse oximetry during progressive isovolemic anemia in dogs. Data were collected while $\mathrm{FiO}_{2}$ was varied from 1.00 to 0.05 and isovolemic hemodilution was induced. Below a hematocrit of $10 \%$ mean difference and SD worsened from $0.2 \% \pm 7.6$ to $-5.4 \% \pm 18.8$. Decreased accuracy with increasing level of anemia was confirmed by Severinghaus et al ${ }^{[181]}$.

\subsubsection{Accuracy in neonatal medicine}

In contrast to previous suggestions fetal hemoglobin $(\mathrm{HbF})$ does not affect the accuracy of pulse oximetry measurements, since absorption characteristics at the measured wavelengths are the same in fetal as in adult hemoglobin ${ }^{[182,183]}$.

High bilirubin plasma levels did not affect the $\mathrm{SaO}_{2}$ readings of the pulse oximeters as evaluated by Veyckemans ${ }^{[184]}$ and Beall ${ }^{[185]}$. Since pulse oximeters use 660 and $940 \mathrm{~nm}$ wavelength and bilirubin has a broad single peak at $460 \mathrm{~nm}$, interference is from a theoretical point of view not likely. However, during the catabolism of hemoglobin bilirubin and carbon monoxide are formed. In this study ${ }^{[184]}$ icteric patients had a small higher level of carboxyhemoglobin than non-icteric patients $(1.8 \% \pm 0.7$ vs. $1.3 \% \pm 0.8)$. Interference by phototherapy was studied by Zubrow ${ }^{[186]}$, but he could not find any such effect in a neonatal intensive care unit.

Iyer et al. ${ }^{[187]}$ evaluated the influence of hypothermia in neonates and infants undergoing cardiac surgery. The mean difference was within an acceptable range $(< \pm 3$ $\%$ ) at foot probe site temperatures above $29^{\circ} \mathrm{C}$. When foot probe site temperatures decreased below $27^{\circ}$ C. $46 \%$ of the pulse oximetry readings differed more than $3 \%$ from hemoximeter oxygen saturations.

Skin pigmentation seemed to cause an overestimation of the oxygen saturation of the blood ${ }^{[188]}$. However, as the skin of a newborn baby is less pigmented, limitations of pulse oximetry in neonatal care have not been reported.

A reduced accuracy in pulse oximetry has been reported due to motion artifact [189]. In order to reduce motion artifact the ECG-signal was coupled to the oximeter to synchronize plethysmographic signal to heart rate. Barington et al. ${ }^{[190]}$ reported a $50 \%$ reduction of false alarms due to motion artifact when ECG coupling was added in a neonatal intensive care unit. As pulse oximeter readings that are generated by motion artefact tend to be $85 \%$ in accordance with a ratio $(R)$ of 1.0 , the plethysmographic signal amplitude is displayed to facilitate the interpretation of the saturation data of the pulse oximeter.

\subsubsection{Usefulness of pulse oximetry}

The usefulness of pulse oximetry has been established in several studies performed in the operating room, intensive care unit and emergency department. Coté et al. ${ }^{[191]}$ performed a study in pediatric patients divided in two groups, in which the oximeter data were either available or unavailable to the anesthesia team. The "unavailable group" experienced a greater number of major hypoxic events (24 vs. 11) and an increased total time of hypoxia ( $42 \mathrm{~min}$ vs. $27 \mathrm{~min}$ ). The authors concluded, that pulse oximetry is efficient to provide an early warning of desaturation, prior to the development of signs and symptoms of hypoxemia. In another study ${ }^{[192]}$ the same group compared pulse oximetry and capnography. Blinding the oximeter data increased the number of desaturations (31 vs. 12) in contrast to blinding the capnograph data. In addition, Poets et al. ${ }^{[193]}$ determined the value of pulse oximetry in an observational study in the neonatal intensive care unit. Apparently well preterm (range 28 to 36 weeks) infants showed episodes of prolonged hypoxemia unaccompanied by apneic pauses or bradycardia and therefore undetectable for 
cardiorespiratory monitors. Mower et al. ${ }^{[194]}$ gave evidence that the use of pulse oximetry in children presenting to emergency department triage may result in significant changes in medical treatment in a small proportion of children.

\subsubsection{Summary}

In summary, pulse oximetry is a useful and accurate monitor of arterial oxygen saturation. The accuracy is limited in the presence of dyshemoglobins, severe anemia and moderate to severe hypoxemia. In these conditions laboratory oximetry should supplement pulse oximetry. 


\section{Neonatal Oxygen Therapy}

Historical notes

Normal values and limits to define byperoxia and bypoxia.

Arterial oxygen tension: normal values in healthy (pre)term newborn infants Arterial oxygen tension: normal values defined in relation to other variables. Hyperoxic threshold

Arterial oxygen saturation: normal values in healthy (pre)term infants Arterial oxygen saturation: normal values defined in relation to other variables Conclusions

$\mathrm{SvO}_{2}$ and $\mathrm{DO}_{2} / \mathrm{VO}_{2}$ Relationship in Critical Care Medicine

\section{Observational reports on $\mathrm{SvO}_{2}$ measurement}

$\mathrm{SvO}$, as a monitor of cardiac output

Oxygen delivery $\left(D O_{y}\right) /$ Oxygen consumption $\left(V O_{\nu}\right)$ relationship

Biphasic relationship

Pathologic oxygen supply dependency

Etiologic mechanisms studied in the animal model

Criticism on the concept of pathologic oxygen supply dependency.

New studies examining the $\mathrm{DO}_{2} / \mathrm{VO}_{2}$ relationship

The $\mathrm{DO}_{2} / \mathrm{VO}_{2}$ relationship in pediatric and neonatal patients

$\mathrm{SvO} \mathrm{O}_{2}$ measurement and the $\mathrm{DO}_{2} / \mathrm{VO}_{2}$ relationship

Supranormal $\mathrm{DO}_{2}$ and $\mathrm{SvO}_{2}$ as goal-oriented therapy in critically ill patients

Studies to validate maximal $\mathrm{DO}_{2}$ as goal-oriented therapy

$\mathrm{SvO}_{2}$ as goal-oriented therapy

Criticism on supranormal $\mathrm{DO}_{2}$ as a goal-oriented therapy

Summary 
62

Chapter 2: Review Oxygen Transport 
In this chapter among the many options of improving oxygen transport two important management strategies are discussed. Neonatal oxygen therapy, so directly associated with the history of neonatal medicine, will be addressed. In particular, the estimation of the normal $\mathrm{paO}_{2}$ and $\mathrm{SaO}_{2}$ range. Secondly, the debate about the $\mathrm{DO}_{2}$ and $\mathrm{VO}_{2}$ relationship and the strategy of optimizing $\mathrm{DO}_{2}$ and $\mathrm{SvO}_{2}$ in adult intensive care medicine will be reviewed.

\section{Neonatal oxygen therapy}

\subsection{Historical notes}

Oxygen therapy is one of the earliest applied therapies in neonatal medicine, but also one associated with numerous dilemmas ${ }^{[14]}$ and misadventures ${ }^{[195]}$. The observation, that periodic breathing in preterm infants could be converted to regular breathing led in the decade 1942 to 1952 to the general policy to place all small infants in high oxygen environment. When the suspicion was raised, that this routine high oxygen treatment was related to retrolental fibroplasia with the blinding of numerous children, it was recommended that oxygen in concentrations greater than $40 \%$ only should be used in exceptional circumstances. However, during the subsequent era of restricted oxygen use mortality and morbidity increased and it was suggested that each sighted baby gained may have cost 16 deaths ${ }^{[1 \%, 997]}$.

Oxygen administration increased again in the 60's. New reported side- effects as bronchopulmonary dysplasia and pulmonary hemorrhage stressed the need for monitoring oxygenation. Intermittent measurement of arterial oxygen tension $\left(\mathrm{paO}_{2}\right)$ in samples drawn from an umbilical arterial catheter became clinical practice in the 60's and 70's. The continuous measurement of arterial oxygen saturation $\left(\mathrm{SaO}_{2}\right)$ in newborn infants by a fiberoptic catheter used as an umbilical arterial catheter was reported by Wilkinson ${ }^{(145)}$ and Krouskop ${ }^{[146]}$. Non-invasively and continuously transcutaneously measured $\mathrm{paO}_{2}$ revealed the variability of $\mathrm{paO}_{2}$, particularly during the respiratory distress syndrome. In addition, the performance of this monitoring device seemed to be dependent upon perfusion of the skin, temperature of the electrode, patient's age and probe placement ${ }^{[198]}$. Pulse oximetry, introduced in the 80's has now became common clinical practice in neonatal intensive care and has converted the clinician's attention from oxygen tension to oxygen saturation and oxygen content again.

1.2 Normal values and limits of the normal range as to define hyperoxia and hypoxia of arterial oxygen tension and arterial oxygen saturation.

When a new monitoring device is introduced in direct patient care it is necessary to describe normal values and to define the limits of the normal range. In general, studies trying to do this use two approaches:

1) Studies describe and examine the 'normal range' of data in a comparable but healthy population. However, it must be stressed, that from data in normal healthy infants it cannot be inferred that values below the normal range are pathologic and subsequently, require treatment.

2) Studies compare the values with a related variable, of which already normal values and limits have been described, or relate the value with the occurrence of unwanted effects. 


\subsubsection{Arterial oxygen tension $\left(\mathrm{paO}_{2}\right)$ : normal values in healthy (pre)term newborn} infants

With the advent of the continuous monitoring of transcutaneous $\mathrm{paO}_{2}$ studies were performed to describe the $\mathrm{paO}_{2}$ in term and preterm infants, the longitudinal development of $\mathrm{paO}_{2}$ and the modulating effect of sleep and awake states. Mok ${ }^{[199]}$ examined transcutaneously measured $\mathrm{paO}_{2}$ in 55 term infants from birth to 6 months to obtain normal data related to age and behavioral state. The mean values in the first week for the different states (awake, feeding, quiet sleep, active sleep) were: 83.5, 73.4, 78.5 and $73.4 \mathrm{~mm}$ $\mathrm{Hg}$, respectively. The $\mathrm{paO}_{2}$ increased until the age of 6 weeks. In preterm infants both Mok ${ }^{[200]}$ and Hoppebrouwers ${ }^{[201]}$ found that the mean $\mathrm{paO}_{2}$ was lower in the preterm stage. The results from preterm infants at corrected postconceptional age could not be differentiated from those of control term infants.

\subsubsection{Arterial oxygen tension $\left(\mathrm{paO}_{2}\right)$ : normal values defined in relation to other variables.}

\subsubsection{Hyperoxic threshold}

With regard to defining a hyperoxic threshold all attention has been focused to retrolental fibroplasia or retinopathy of prematurity (ROP). Retrolental fibroplasia was first described by Terry in $1942{ }^{[202]}$. The etiological role of oxygen in the pathogenesis of retrolental fibroplasia was recognized in the early 50's. The threshold of $\mathrm{paO}_{2}$ at which ROP occurred was studied by Aranda et al ${ }^{[203]}$. They correlated retinal vessel changes with the maximal value of $\mathrm{paO}_{2}$. The data in this study suggested that a $\mathrm{paO}_{2}$ value above 100 $\mathrm{mm} \mathrm{Hg}$ may result in retinal vascular changes. It was suggested, that the introduction of continuous non-invasive transcutaneous measurement of $\mathrm{paO}_{2}$ might reduce ROP or might identify a threshold $\mathrm{paO}_{2}$ value above which ROP might occur. However, Bancalari et al. ${ }^{[204]}$ were not able to show a clear evidence that continuous monitoring of $\mathrm{paO}_{2}$ and adjusting the $\mathrm{FiO}_{2}$, aiming at a $\mathrm{paO}_{2}$ range between 50 and $70 \mathrm{~mm} \mathrm{Hg}$, had an impact on the incidence of ROP in infants $<1000$ grams. Flynn et al. ${ }^{[205]}$ could present evidence supporting an association between prolonged exposure to transcutaneously monitored $\mathrm{paO}_{2}$ of $80 \mathrm{~mm} \mathrm{Hg}$ or higher and the incidence and severity of ROP. Cunningham et al. [206] found that an increased variability of transcutaneous $\mathrm{paO}_{2}$ was a significant predictor of severe ROP.

In conclusion, since a transcutaneous measured $\mathrm{paO}_{2}$ value of $80 \mathrm{~mm} \mathrm{Hg}$ could be identified as one of the factors in the pathogenesis of ROP and since hemoglobin is maximally bound with oxygen at a $\mathrm{paO}_{2}$ above 70 and $80 \mathrm{~mm} \mathrm{Hg}{ }^{[14]}$, there is no clinical or physiological basis to increase the $\mathrm{paO}_{2}$ above this level.

\subsubsection{Hypoxic threshold}

With regard to defining a hypoxic threshold only few studies have been performed to assess the lower limit of arterial oxygen tension. It was noted that during the era of restricted oxygen in response to the first reports about retrolental fibroplasia mortality and neurological morbidity increased $[196,197]$. However, these reports were non-randomized observations without the assessment of a critical $\mathrm{paO}_{2}$ value. In a study of Tuchschmidt et al. ${ }^{[207]}$ high altitude hypoxia was induced in young adults and $\mathrm{paO}_{2}$ was compared with lactate, hypoxanthine and ST-T changes of the ECG. In contrast to hypoxanthine, which remained unchanged, lactate started to increase significantly in the $\mathrm{paO}_{2}$ range of 40 to 50 $\mathrm{mm} \mathrm{Hg}$. The ST-T segment of the ECG was depressed during severe hypoxia $\left(\mathrm{paO}_{2}=30\right.$ $\mathrm{mm} \mathrm{Hg}$ ). Hrbek et al. ${ }^{[208]}$ recorded visual evoked responses in premature infants with idiopathic respiratory distress syndrome. He found, that the responses were more affected, 
when $\mathrm{paO}_{2}$ decreased below $55 \mathrm{~mm} \mathrm{Hg}$. Other reports have documented other adverse effects of low $\mathrm{paO}_{2}$ in newborn infants such as the effect of a low $\mathrm{paO}_{2}$ on pulmonary vasculature and ductus arteriosus. Moss et al. ${ }^{[209]}$ performed one of the few human studies in the postnatal period in newborn infants breathing $13 \%$ oxygen resulting in oxygen saturations, that varied between $46 \%$ and $82 \%$ corresponding to a $\mathrm{paO}_{2}$ of 17 to 30 $\mathrm{mmHg}{ }^{[210]}$. It was shown that these levels of $\mathrm{paO}_{2}$ caused a rise in pulmonary arterial pressure and resistance.

Bard et al. ${ }^{[210]}$ attempted to determine whether decreasing arterial blood saturation from $95 \%$ to $90 \%$ could cause pulmonary vasoconstriction and dilation of the ductus arteriosus in preterm newborn infants assessed by Doppler echocardiography. Saturations of $95 \%$ and $90 \%$ corresponded to a mean $\mathrm{paO}_{2}$ of $87 \pm 5 \mathrm{~mm} \mathrm{Hg}$ and $55 \pm 3 \mathrm{~mm} \mathrm{Hg}$, respectively. The decrease did not have any effect on pulmonary hemodynamics and ductus arteriosus. In addition, no differences were found between the two extremes in these groups of patients with either a $\mathrm{paO}_{2}$ greater that $100 \mathrm{~mm} \mathrm{Hg}$ or less than $50 \mathrm{~mm} \mathrm{Hg}$.

Émond et al. ${ }^{[211]}$ examined in vitro the relation between $\mathrm{SaO}_{2}$ and $\mathrm{paO}_{2}$ in cord blood of ten newborn infants of less than 30 weeks and less than 1000 grams by gas mixing tonometry. The mean $p_{50}$ and $p_{x o}$ were $18.3 \pm 1.9 \mathrm{~mm} \mathrm{Hg}$ and $40.8 \pm 3.6 \mathrm{~mm} \mathrm{Hg}$. This study demonstrated the fetal nature of the oxygen dissociation curve of the very low birth weight infant and what $\mathrm{paO}_{2}$ is needed for a $90 \%$ oxygen saturation. The authors concluded that, since at this saturation the end of the steep rise of the hemoglobindissociation curve is reached and the hemoglobin is almost completely saturated the guidelines of the AAP ( 50 to $80 \mathrm{~mm} \mathrm{Hg})^{[212]}$ should probably be lowered to 45 to $60 \mathrm{~mm} \mathrm{Hg}$. The transfusion of adult packed cells could increase the $p_{90}$ in preterm infants. However, since term infants with a fetal hemoglobin of approximately $70 \%$ had a $p_{90}$ of $47.6 \pm 2.5 \mathrm{~mm}$ $\mathrm{Hg}$, the limits of values of $\mathrm{paO}_{2}$ inferred in this study are also valid for infants who have received several transfusions.

At last, also Schultze et al. ${ }^{[16]}$ performed a non-randomized cross-over study by targeting the higher $(97 \pm 1.7 \%)$ versus the lower $(92 \pm 3.8 \%)$ end of the recommended range of pulse oximetry. These ranges of oxygen saturations corresponded to a mean $\mathrm{paO}_{2}$ of $78 \pm 14 \mathrm{~mm} \mathrm{Hg}$ and $52 \pm 6 \mathrm{~mm} \mathrm{Hg}$, respectively. $\mathrm{VO}_{2}$ and cardiac output remained unchanged during the lower oxygen condition, whereas $\mathrm{SvO}_{2}$ decreased and oxygen extraction increased. Targeting the lower range of $\mathrm{SaO}_{2}$ resulted in an increased oxygen extraction whereas other potential compensatory mechanisms may not need to be called into play.

In conclusion, the lower limit of $\mathrm{paO}_{2}$ during oxygen therapy in neonatal care could probably be defined at $45 \mathrm{~mm} \mathrm{Hg}(6 \mathrm{kPa})$ since at this level approximately $90 \%$ of the hemoglobin is bound to oxygen and since no adverse effects have been found such as pulmonary vasoconstriction or decreased $\mathrm{VO}_{2}$.

\subsubsection{Arterial oxygen saturation $\left(\mathrm{SaO}_{2}\right)$ : normal values in healthy (pre)term new- born infants.}

Poets et al. ${ }^{[213]}$ examined baseline $\mathrm{SaO}_{2}$ monitored by pulse oximetry in combination with the analysis of breathing pattern in healthy full term infants in the second month of life. The pulse oximeter used was the Nellcorr N 100 (beat to beat mode). The baseline $\mathrm{SaO}_{2}$ during regular breathing was $99.8 \%(97-100)$ (median and range) with a low variability. The desaturation episodes $\left(\mathrm{SaO}_{2}<80 \%\right.$ during $>4$ seconds) occurred particularly during non-regular breathing or apnoeic pause. The different reference range 92 to $93 \%$ (CI 88 - 97) described by Thilo ${ }^{[214]}$ in healthy term infants measured in the first 48 hrs could be explained by the use of a pulse oximeter of a different brand (Ohmeda) and the fact that the measurements were performed at an altitude of $1610 \mathrm{~m}$. 
In 66 preterm infants baseline $\mathrm{SaO}_{2}$ values were examined at term age (37 weeks) by Poets et al. ${ }^{[215]}$. The median baseline $\mathrm{SaO}_{2}$ was $99.4 \%(88.9-100)$ with a higher variability than in full term infants. $12 \%$ Of the preterm infants had a median $\mathrm{SaO}_{2}$ value below $97 \%$. The desaturation episodes were more frequent in infants with a shorter gestation. The authors concluded, that during stable regular breathing preterm infants had baseline $\mathrm{SaO}_{2}$ in the same range as the full term infants.

This last study was extended by a population of preterm infants and follow up recordings six weeks after discharge ${ }^{[216]}$. Baseline $\mathrm{SaO}_{2}$ at a gestational age of 37 weeks in 160 infants was $99.6 \%(88.7-100)$. In the follow up recordings $\mathrm{SaO}_{2}$ increased to values of $100 \%(95.3-100)$ with a lower variability. When the follow up recordings were compared with the recordings made in full term infants at the same postconceptional age ${ }^{[213]}$ a higher baseline $\mathrm{SaO}_{2}$ in the preterm infants was found without a difference in the number of desaturation episodes. Maturation of respiratory control and improvement in the matching of ventilation and perfusion are thought to explain the increase of baseline $\mathrm{SaO}_{2}$ and the decrease in desaturations.

All these studies were performed in infants at the time of discharge. Richard ${ }^{[217]}$ obtained baseline $\mathrm{SaO}_{2}$ measured by pulse oximetry in 55 preterm infants at 24 hours of age, breathing room air. The median gestational age was 35 weeks. Median baseline $\mathrm{SaO}_{2}$, measured only during regular breathing was $99.4 \%(90.7-100)$. These results are similar to the results in older preterm infants. Less desaturation episodes were found compared with the study of preterm infants at discharge ${ }^{[216]}$. This can be explained by the fact that apnoeas with episodes of desaturation rarely are found before the third day of live.

The authors question in the discussion whether recommendations to keep $\mathrm{SaO}_{2}$ at for example 87 to $92 \%{ }^{[218,219]}$ can be considered appropriate, if $95 \%$ of healthy preterm infants maintain a baseline $\mathrm{SaO}_{2}$ at a level greater than $95 \%$. They concluded that the results suggest that baseline $\mathrm{SaO}_{2}$ in preterm infants is maintained at lower values than normal. On the other hand, the authors recognized that for infants receiving ventilatory support other recommendations have to be made than based upon the examination of healthy preterm infants. For example, in order to avoid hyperoxemia with oxygen tensions above $80 \mathrm{~mm} \mathrm{Hg}$ the authors cannot recommend $\mathrm{SaO}_{2}$ values above $95 \%$, although obviously these values are normal for healthy preterm infants during the first days of life.

To estimate normal $\mathrm{SaO}_{2}$ values one has to take into account environmental factors as residency at high altitude and genetic adaptations of the population to a reduced oxygen availability. In a study ${ }^{[220]}$ in Tibet ( $3658 \mathrm{~m}$ above sea level) $\mathrm{SaO}_{2}$ was compared in 15 native Tibetan infants, whose ancestors inhabited the Himalayan plateau for 25.000 years and in $15 \mathrm{Han}$ infants whose ancestors moved to Tibet after $1951 . \mathrm{SaO}_{2}$ values were lower in Han infants than in Tibetan infants at all times, in all conditions and during all activities. At four month of age $\mathrm{SaO}_{2}$ values of $\mathrm{Han}$ infants were $85 \% \pm 4$ while awake and $76 \% \pm 5$ during quiet sleep. In the Tibetan infants $\mathrm{SaO}_{2}$ values were $88 \% \pm 4$ while awake and $86 \% \pm 5$ during quiet sleep.

\subsubsection{Arterial oxygen saturation $\left(\mathrm{SaO}_{2}\right)$ : normal values and alarm limits defined in relation to $\mathrm{paO} 2$.}

Hay et al. ${ }^{[172,221]}$ reviewed oxygen therapy in relation with the arrival of pulse oximetry in the neonatal intensive care unit. In this report $\mathrm{SaO}_{2}$ values of $92 \pm 3 \%$ obtained by pulse oximetry (Ohmeda) excluded all $\mathrm{paO}_{2}$ values below $45 \mathrm{~mm} \mathrm{Hg}$ and above $100 \mathrm{~mm} \mathrm{Hg}$. Southall ${ }^{[222]}$ compared pulse oximeter $\mathrm{SaO}_{2}$ values, measured by the Nellcor N100, with direct arterial line oxygen saturation and with direct in line $\mathrm{PO}_{2}$. The patient population included 24 neonatal and 53 pediatric intensive care patients. Hypoxia defined as $\mathrm{paO}_{2}$ values $<50 \mathrm{~mm}$ was detected by $\mathrm{SaO}_{2}$ value below $90 \%$ with a sensitivity 
of $88 \%$, and hyperoxia defined as $\mathrm{paO}_{2}$ values $>100 \mathrm{~mm} \mathrm{Hg}$ was detected by $\mathrm{SaO}_{2}$ above $98 \%$ with a sensitivity of $90 \%$.

The problem how to detect the hyperoxic threshold by pulse oximetry in relation to arterial oxygen tension was considered in several reports ${ }^{[223-226]}$. Walsh et al. ${ }^{[223]}$ evaluated the accuracy of pulse oximetry in acute and chronic preterm newborn infants by assessing the relation between $\mathrm{SaO}_{2}$ and $\mathrm{paO}_{2}$. The authors concluded that in chronic infants pulse oximetry saturations and their derived $\mathrm{paO}_{2}$ values were well correlated with measured $\mathrm{paO}_{2}$, whereas in acute infants pulse oximetry reflects $\mathrm{paO}_{2}$, unreliably. These infants had higher $\mathrm{SaO}_{2}$ values, positioned at the flat upper part of the oxygen dissociation curve, where small changes in $\mathrm{SaO}_{2}$ reflect large changes in the $\mathrm{paO}_{2}$. Bucher ${ }^{[224]}$ stated that the reliability of pulse oximetry to detect hyperoxemia is controversial, because small changes in oxygen saturation above $90 \%$ are associated with relatively large changes in $\mathrm{paO}_{2}$. He examined the sensitivity and specificity of two different types of pulse oximeters (Nellcor and Ohmeda) in detecting hyperoxemia defined as $\mathrm{paO}_{2}>90 \mathrm{~mm} \mathrm{Hg}$. Sensitivity was defined as the proportion of hyperoxemia correctly classified by pulse oximetry and specificity the proportion of nonhyperoxemia correctly classified by pulse oximetry. In his study setting the alarm limit at $95 \%$ the Nellcor N100 had $100 \%$ sensitivity and $38 \%$ specificity, whereas Ohmeda had a lower sensitivity $(37 \%)$ with a specificity of $83 \%$. To detect hyperoxemia the optimal alarm limit defined as a sensitivity of $95 \%$ and a maximal specificity was for Nellcor $96 \%$ and for Ohmeda $90 \%$.

Poets ${ }^{[225]}$ evaluated the detection of hyperoxia defined as a $\mathrm{paO}_{2}>80 \mathrm{~mm} \mathrm{Hg}$ in 50 patients of the pediatric intensive care. From 202 similar measurements it was concluded that the upper alarm limit set at $95 \%, 95 \%$ of hyperoxemia, defined as a $\mathrm{PO}_{2}>80 \mathrm{~mm}$ $\mathrm{Hg}$ could be identified. These conclusions were drawn for the Nellcor N200 and in a population with a relatively right warded shift of the oxygen dissociation curve in comparison with a preterm newborn population. Therefore, one must be cautious to extrapolate these results to pulse oximeters of other manufacturers and to a neonatal intensive care setting.

Wasunna et al. ${ }^{[218]}$ evaluated pulse oximetry in preterm infants (range 26 - 32 weeks) at a postnatal age of 8 to $48 \mathrm{hrs}$. The pulse oximeter evaluated was the Ohmeda 3700. $\mathrm{SaO}_{2}$ of 86 to $92 \%$ corresponded to a $\mathrm{paO}_{2}$ of $5-13 \mathrm{kPa} . \mathrm{paO}_{2}$ was measured by an umbilical $\mathrm{PO}_{2}$ electrode. $\mathrm{SaO}_{2}$ values above $92 \%$ were sometimes associated with $\mathrm{paO}_{2}$ values to $14 \mathrm{kPa}$.

Paky and Koeck ${ }^{[226]}$ reached the same conclusions in a study performed to detect hyperoxemia and hypoxemia and to define alarm limits. A total of $792 \mathrm{SaO}_{2}$ readings and corresponding $\mathrm{paO}_{2}$ from 146 infants were compared. Predictive value analysis of pulse oximetry readings related to arterial oxygen tension confirmed the ability to identify both hyperoxemia $\left(\mathrm{paO}_{2}>90 \mathrm{~mm} \mathrm{Hg}\right)$ and hypoxemia $\left(\mathrm{paO}_{2}<40 \mathrm{~mm} \mathrm{Hg}\right)$. However, alarm limits could not be established at a sensitivity level of 0.90 . At a sensitivity level of 0.85 an alarm range was 92.5 - $95 \%$ could identified. The authors concluded, that pulse oximetry alarm limits should be used with caution and one must be aware of the limitation to detect with a high level of sensitivity both hyperoxemia and hypoxemia.

\subsubsection{Conclusions}

At present pulse oximetry is the most used continuous oxygen monitor in neonatal intensive care medicine. In the observational studies, according to the studies on transcutaneously measured $\mathrm{pO}_{2}, \mathrm{SaO}_{2}$ values were observed to increase with age. In these studies in healthy (pre)term infants rather high $\mathrm{SaO}_{2}$ values are encountered. The current guidelines as published by manuals ${ }^{[219]}$, working groups ${ }^{[227]}$ and national pediatric associations ${ }^{[212,228]}$ provide limits for $\mathrm{paO}_{2}$ values ranging between $40(5.5 \mathrm{kPa})$ and $80(11$ 
$\mathrm{kPa}$ ). From the studies mentioned it must be concluded that alarm limits with a sufficient sensitivity and specificity could hardly be deduced. In neonatal clinical medicine $\mathrm{SaO}_{2}$ limits between $85-90 \%$ and $92-96 \%$ have been used. The discrepancy between the high $\mathrm{SaO}_{2}$ values in healthy infants and the lower values in therapeutical guidelines led to some debate ${ }^{[229,230]}$. In addition one must remember that different brands have used different calibration curves resulting in a different correlation between $\mathrm{SaO}_{2}$ and $\mathrm{paO}_{2}$. Also blood transfusions and changes in $\mathrm{pH}$ can change this relationship. With these thoughts in mind the mentioned limits of $\mathrm{SaO}_{2}$ can only be used supplemented by regular monitoring of blood gases with the measurement of $\mathrm{paO}_{2}$.

\section{$\mathrm{SvO}_{2}$ and $\mathrm{DO}_{2} / \mathrm{VO}_{2}$ relationship in critical care medicine}

\subsection{Observational reports on $\mathrm{SvO}_{2}$ measurement}

Continuous $\mathrm{SvO}_{2}$ measurement by a fiberoptic catheter was initially reported as a valuable warning system for deterioration in cardiopulmonary function and as an indicator of the effects of various therapeutic maneuvers ${ }^{[148,7]}$. Divertie et al. ${ }^{[149]}$ reported that the ability to measure $\mathrm{SvO}_{2}$ continuously has reduced the need for repeated measurements of cardiac output and blood gases.

\section{2}

\section{$\mathrm{SvO}_{2}$ as a monitor of cardiac output}

In three small studies in patients with respiratory failure ${ }^{[231]}$ and with chronic congestive failure ${ }^{[232,233]}$ the relation between $\mathrm{SvO}_{2}$ and cardiac output was evaluated and individual analysis yielded a good correlation in the majority of the patients.However, a number of other studies concluded that continuous monitoring of $\mathrm{SvO}_{2}$ was not a sensitive measure of cardiac output. Kyff et al. ${ }^{[234]}$ described that decreases in $\mathrm{SvO}_{2}$ by $5 \%$ and $10 \%$ corresponded with an decrease in cardiac index in only 45.5 and $61 \%$ of measurements, respectively. Changes in cardiac index corresponded only in $30 \%$ with changes in similar direction in patients with myocardial infarction. In another study during aortic surgery no significant correlation between $\mathrm{SvO}_{2}$ and cardiac index could be found during the most critical periods of surgery ${ }^{[235]}$. In two other studies ${ }^{[236,237]}$ in critically ill patients it was concluded that $\mathrm{SvO}_{2}$ measurement could not substitute intermittent cardiac output and $\mathrm{VO}_{2}$ determinations. It was recognized that changes in $\mathrm{SvO}_{2}$ values may be assumed to be due to changes in cardiac output but also to changes in arterial oxygen saturation, $\mathrm{O}_{2}$ uptake, hemoglobin, shift of the oxyhemoglobin dissociation curve or a combination of these variables. As mentioned by Nelson ${ }^{[82]}, \mathrm{SvO}_{2}$ monitoring does not yield specific information regarding any individual oxygen transport variable. In addition, Jain et al. ${ }^{[238]}$ considered that the relation between $\mathrm{SvO}_{2}$ and cardiac output is nonlinear according to the Fick equation. In his study on critically ill patients with cardiac failure a curvi-linear relationship was observed. Using linear regression the mean slope and correlation coefficient were dependent on whether the baseline $\mathrm{SvO}_{2}$ and cardiac output were located on the steep or flat portion of the curvi-linear $\mathrm{SvO}_{2}$-cardiac output curve.

The curvi-linear relation between $\mathrm{SvO}_{2}$ and cardiac index was established by Buheitel et al. ${ }^{[240]}$ in his study performed on a pediatric ICU. This group showed a uniform $\mathrm{VO}_{2}$ and $\mathrm{caO}_{2}(\mathrm{Hb})$, which could explain the good correlation coefficient $(\mathrm{r}=0.90)$. In a less uniform population Mahutte et al. ${ }^{[241]}$ compared the linear and curvi-linear regression analysis upon the relation between $\mathrm{SvO}_{2}$ and cardiac output. Using the curvi-linear regression analysis the correlation coefficient improved, but remained rather poor $(\mathrm{r}=0.45)$, due to the individual variability in $\mathrm{SaO}_{2}$, hemoglobin and $\mathrm{VO}_{2}$.

In summary, $\mathrm{SvO}_{2}$ reflects the combined sufficiency of all the variables, that 
constitute the oxygen delivery and uptake and cannot be used to monitor exclusively one of these variables, particularly when other variables are unstable. Due to the curvi-linear relationship between $\mathrm{SvO}_{2}$ and cardiac output it is difficult to predict the change of one based on the other.

\subsection{Oxygen delivery $\left(\mathrm{DO}_{2}\right) /$ Oxygen consumption $\left(\mathrm{VO}_{2}\right)$ relationship}

\subsubsection{Biphasic relationship}

Animal experimental data in which the $\mathrm{DO}_{2}$ has been progressively reduced either by hypoxia or by anemia, show a biphasic relationship between the $\mathrm{DO}_{2}$ and $\mathrm{VO}_{2}$ [114,115); When $\mathrm{DO}_{2}$ is reduced, the $\mathrm{VO}_{2}$ remains constant over a wide range of $\mathrm{DO}_{2}$. Below a critical value of $\mathrm{DO}_{2}, \mathrm{VO}_{2}$ starts to decrease and becomes dependent upon $\mathrm{DO}_{2}$. Shibutani et al. ${ }^{[16]}$ established the biphasic relationship between $\mathrm{DO}_{2}$ and $\mathrm{VO}_{2}$ in anesthetized patients. The critical $\mathrm{DO}_{2}$ could be identified at a $\mathrm{DO}_{2}$ value of $300 \mathrm{ml} / \mathrm{min} / \mathrm{m}^{2}$. The phenomenon, that below the critical $\mathrm{DO}_{2}$ a reduction of $\mathrm{DO}_{2}$ leads to a decrease of $\mathrm{VO}_{2}$, is called "physiologic oxygen supply dependency".

\subsubsection{Pathologic oxygen supply dependency}

Komatsu et al. ${ }^{262]}$ compared the relationship between $\mathrm{DO}_{2}$ and $\mathrm{VO}_{2}$ in patients directly after cardiopulmonary bypass with and without increased lactate levels. In patients with low lactate levels $\mathrm{VO}_{2}$ decreased proportionally, when $\mathrm{DO}_{2}$ decreased below the critical $\mathrm{DO}_{2}$ level of $300 \mathrm{ml} / \mathrm{min} / \mathrm{m}^{2}$. However, in patients with an increased lactate level no apparent critical $\mathrm{DO}_{2}$ level could be identified. For the entire range of $\mathrm{DO}_{2}$ values $\mathrm{VO}_{2}$ decreased proportionally and a plateau phase could not be discerned. This phenomenon, that $\mathrm{VO}_{2}$ is dependent upon $\mathrm{DO}_{2}$ above the normal critical $\mathrm{DO}_{2}$ is called "pathologic oxygen supply dependency" (see figure).

Pathologic oxygen supply dependency was observed in patients with ARDS ${ }^{[243,244]}$, respiratory failure not due to ARDS ${ }^{[245,246]}$, sepsis ${ }^{[24,248]}$ and with advanced malignancy ${ }^{[249]}$, after burn injury ${ }^{[250]}$ cardiopulmonary resuscitation ${ }^{[242]}$ and after acute liver failure and liver transplantation ${ }^{[251]}$, and during congestive heart failure ${ }^{[252]}$.

\subsubsection{Etiologic mechanisms studied in the animal model}

Several etiologic mechanisms that might account for this phenomenon of pathologic oxygen supply dependency have been suggested ${ }^{[253]}$. One of the main features is the inability to increase oxygen extraction in response to a reduction of $\mathrm{DO}_{2}$. In the experimental dog model induced bacteremia and endotoxemia produced an increased critical DO2 and a decreased oxygen extraction at the whole body level and at the level of individual organs such as the gut ${ }^{[254]}$ and in a lesser degree the hind limb muscle ${ }^{[107]}$. A peripheral oxygen extraction defect was explained by Bredle and Cain ${ }^{[25]}$, who emphasized the importance of vasoconstrictor tone for oxygen extraction. They found an association between a lower oxygen extraction ratio and a flattening of the pressure / flow slope in the limb vasculature of endotoxin injected dogs indicating a loss of vasoconstrictor tone and vascular reactivity. Other mechanisms, such as a disorder of the redistribution of blood flow during a reduction of $\mathrm{DO}_{2}$ and arteriovenous shunting of blood past nutritional capillaries ${ }^{[256]}$ have been mentioned. Microembolization was demonstrated in experimental animals to limit the capillary surface reducing the oxygen extraction and to stimulate the release of the thromboxane $\mathrm{A} 2{ }^{[257]}$, enhancing the effect of microembolization. 


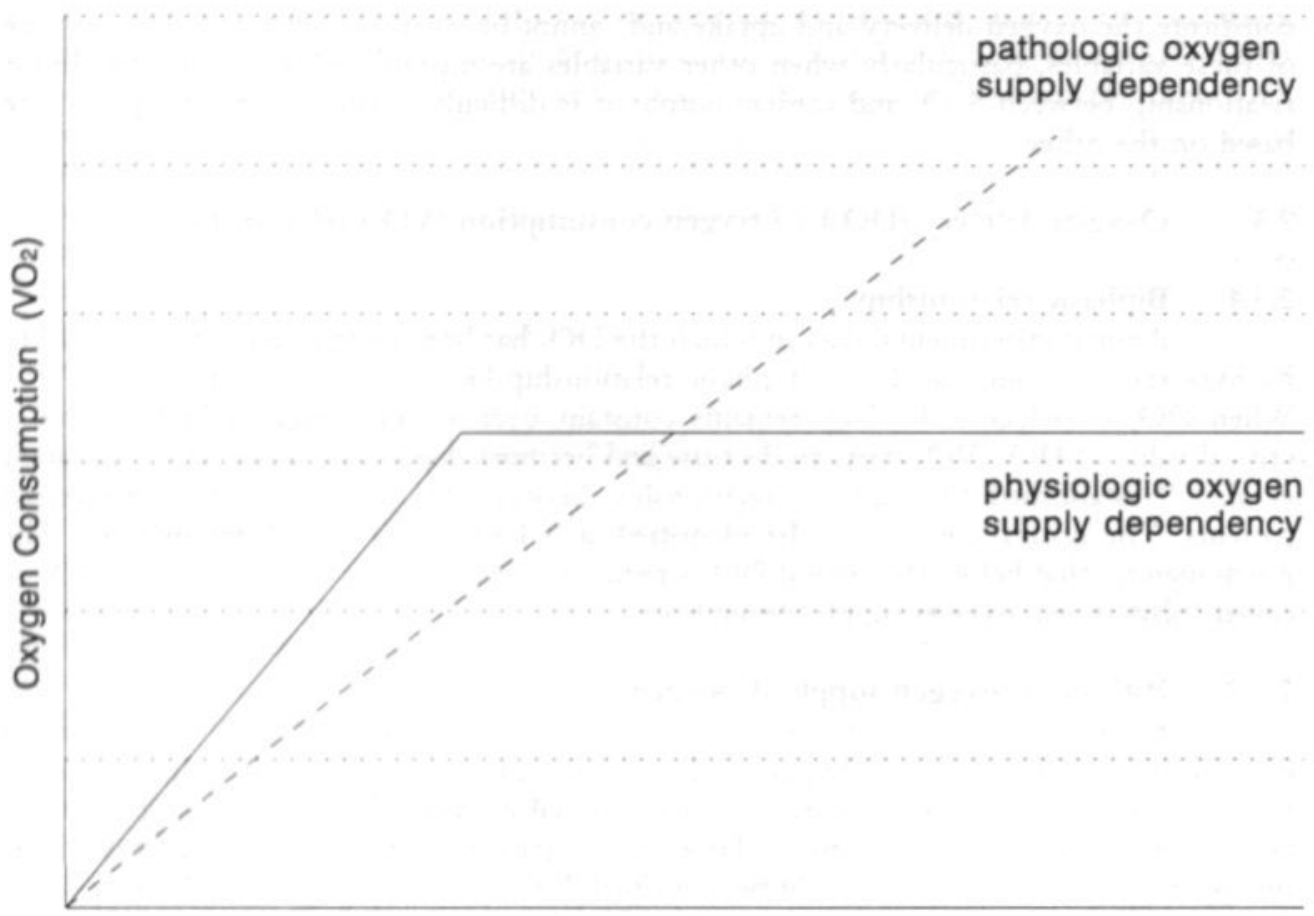

Oxygen Delivery $\left(\mathrm{DO}_{2}\right)$

figure In "pathologic oxygen supply dependency" $\mathrm{VO}_{2}$ is dependent upon $\mathrm{DO}_{2}$ above the normal critical $\mathrm{DO}_{2}$ in contrast to "physiologic oxygen supply dependency".

\subsubsection{Criticism on the concept of pathologic oxygen supply dependency.}

The question has been raised whether the disorders in the biphasic relationship between $\mathrm{DO}_{2}$ and $\mathrm{VO}_{2}$ as obtained in the endotoxic animal model by reducing $\mathrm{DO}_{2}$, are similar to the phenomenon of pathologic oxygen supply dependency in critically ill patients [258]. In animals the oxygen extraction failed to increase during a reduction in $\mathrm{DO}_{2}$, whereas in critically ill patients it was observed, that oxygen extraction failed to decrease when $\mathrm{DO}_{2}$ was increased ${ }^{[253]}$.

Another criticism was expressed by Russell and Phang [259] reviewing the methodology of the measurement of $\mathrm{DO}_{2}$ and $\mathrm{VO}_{2}$ in the clinical studies and the documented pathologic dependence of $\mathrm{VO}_{2}$ upon $\mathrm{DO}_{2}$. Their criticism consisted of 1) the use of the indirect determination of $\mathrm{VO}_{2}$ calculated as the product of cardiac output and arteriovenous oxygen content difference, 2) of the mathematical coupling of the shared variables (cardiac output, hemoglobin and arterial saturation) in the Fick equation of $\mathrm{VO}_{2}$ and $\mathrm{DO}_{2}$ and 3) of the use of pooled data of different patients.

\subsubsection{New studies examining the $\mathrm{DO}_{2} / \mathrm{VO}_{2}$ relationship}

Therefore, clinical studies have been performed in patients with severe sepsis and/or acute respiratory failure ${ }^{[260.264]}$ measuring $\mathrm{VO}_{2}$ independently by calorimetry. In these studies the phenomenon of pathologic oxygen supply dependency could not be established. Vermeij ${ }^{[260]}$ and Mira ${ }^{[261]}$ comparing the indirect $\mathrm{VO}_{2}$ with the direct $\mathrm{VO}_{2}$ measured by calorimetry concluded that the use of indirect $\mathrm{VO}_{2}$ led to an erroneous 
conclusion concerning the relationship between $\mathrm{DO}_{2}$ and $\mathrm{VO}_{2}$. Hanique et al. ${ }^{[263]}$ reported that in 32 critically ill patients after volume loading the mean indirect $\mathrm{VO}_{2}$ increased, whereas the mean direct $\mathrm{VO}_{2}$ remained unaltered. Analysis of their indirect and direct determined $\mathrm{VO}_{2}$ data ${ }^{[26]}$ revealed that the two determinations did not provide similar results. Moreover, indirect calculations of the $\mathrm{VO}_{2}$ were not as reproducible as the direct measurements. This was explained by the higher variability of the calculated $\mathrm{VO}_{2}$ as a consequence of the cumulative effects of the errors of measurements of the different variables of the Fick equation.

In two more recent studies ${ }^{[265,266]}$ carefully designed in relation with the direct measurement of $\mathrm{VO}_{2}$, pathologic oxygen supply dependency could be demonstrated in some patients. In these patients a critical $\mathrm{DO}_{2}$ and plateau of $\mathrm{VO}_{2}$ could not be observed. $\mathrm{DO}_{2}$ was augmented by a dobutamine infusion ${ }^{[25]}$ or by crystalloid and colloid infusions [266]. It was discussed that by increasing blood flow, organ metabolism and myocardial work may increase and consequently $\mathrm{VO}_{2}$.

\subsubsection{The $\mathrm{DO}_{2} / \mathrm{VO}_{2}$ relationship in pediatric and neonatal patients}

In pediatric and neonatal intensive care studies on the relationship between $\mathrm{DO}_{2}$ and $\mathrm{VO}_{2}$ are limited. Lucking et al. ${ }^{[26]}$ found in septic pediatric patients a linear relationship between $\mathrm{DO}_{2}$ and $\mathrm{VO}_{2}$ determined indirectly by calculation. Mink ${ }^{[2 \omega]}$ and Dietrich ${ }^{[269]}$ examined the metabolic response to increasing $\mathrm{DO}_{2}$ by erythrocyte transfusion. $\mathrm{VO}_{2}$ did not change, whereas oxygen extraction decreased. Seear et al. ${ }^{[20]}$ studied the relationship in post-cardiac surgery infants receiving blood transfusions or adrenaline infusions. In post cardiac surgery infants $\mathrm{VO}_{2}$ was not increased when $\mathrm{DO}_{2}$ was increased by erythrocyte transfusion, whereas when $\mathrm{DO}_{2}$ was increased by adrenaline infusion $\mathrm{VO}_{2}$ increased significantly. This rise was thought to be due to increased cell metabolism analogous to exercise physiology. The authors concluded that the results did not support the concept of pathological oxygen supply dependency.

\section{4 $\mathrm{SvO}_{2}$ measurement and the $\mathrm{DO}_{2} / \mathrm{VO}_{2}$ relationship}

These considerations have implications for the measurement of $\mathrm{SvO}_{2}$, since $\mathrm{SvO}_{2}$ reflects the residual oxygen content after tissue $\mathrm{VO}_{2}$. When, in the plateau phase of the biphasic relationship, $\mathrm{DO}_{2}$ is reduced, $\mathrm{VO}_{2}$ can maintain at the same level by an increase of the oxygen extraction and consequently by a decrease of $\mathrm{SvO}_{2}$. Shibutani et al. ${ }^{[116]}$ reported, that at $\mathrm{DO}_{2}$ levels greater than $300 \mathrm{ml} / \mathrm{min} / \mathrm{m}^{2}$ a reduction of $\mathrm{SvO}_{2}$ was proportional to a decrease of $\mathrm{DO}_{2}$. Below the critical $\mathrm{DO}_{2}$ value $\mathrm{VO}_{2}$ decreased and $\mathrm{SvO}_{2}$ was not related to $\mathrm{DO}_{2}$. In several studies describing the phenomenon of pathologic oxygen supply dependency the poor correlation between $\mathrm{DO}_{2}$ and $\mathrm{SvO}_{2}$ was reported ${ }^{[242-250]}$. The measurement of $\mathrm{SvO}_{2}$, initially seen as an index for over-all tissue oxygenation was considered not accurately to reflect tissue oxygenation or changes in $\mathrm{DO}_{2}$ or cardiac output ${ }^{[243]}$. In studies, in which $\mathrm{VO}_{2}$ independently was measured, $\mathrm{SvO}_{2}$ either increased proportionally ${ }^{[261,269]}$ to $\mathrm{DO}_{2}$ or was not related to $\mathrm{DO}_{2}{ }^{[265,266]} . \mathrm{SvO}_{2}$ related to so different variables seemed to be of limited value.

In summary, the biphasic relationship between $\mathrm{DO}_{2}$ and $\mathrm{VO}_{2}$ has been confirmed in human clinical studies. The question remains whether the phenomenon of a pathologic oxygen supply dependency really exists. With the use of the direct independent measurement of the $\mathrm{VO}_{2}$ pathologic oxygen supply dependency seemed to be of less frequent occurrence than initially was assumed. However, in individual critical ill patients $\mathrm{VO}_{2}$ was shown to be dependent upon $\mathrm{DO}_{2}$ with an impairment of the oxygen transport from the capillaries to the tissues and, consequently, a decreased oxygen extraction ratio. The measurement of $\mathrm{SvO}_{2}$ will be of limited value, when the phenomenon of pathologic 
oxygen supply dependency is present. According to the pulmonary artery catheter consensus statement ${ }^{[271]} \mathrm{SvO}_{2}$ measurement may be considered in intensive care patients, when a pulmonary artery catheter is used and when therapy will be based upon oxygen transport end points, although randomized clinical outcome studies did not support the value of continuous venous oximetry.

\subsection{Supranormal $\mathrm{DO}_{2}$ and $\mathrm{SvO}_{2}$ as goal-oriented therapy in critically ill patients}

One of the therapeutic consequences of the concept of oxygen supply dependency was the idea to augment $\mathrm{DO}_{2}$ to supranormal values, thereby increasing $\mathrm{VO}_{2}$ and reversing tissue hypoxia and oxygen debt. This so-called goal-oriented supranormal $\mathrm{DO}_{2}$ therapy was examined in several clinical trials $[272283]$.

Bland and co-workers ${ }^{[272253]}$ identified the different values of oxygen transport parameters between survivors and non-survivors in adult critical ill patients. In survivors cardiac index, $\mathrm{DO}_{2}$ and $\mathrm{VO}_{2}$ were greater than in non-survivors. It is noteworthy, that the mean value of cardiac index, $\mathrm{DO}_{2}$ and $\mathrm{VO}_{2}$ in non-survivors were within the normal range, whereas in survivors supranormal values were encountered. Therefore, it was concluded, that the goals of therapy should not be the normal values of unstressed, healthy subjects, but the supranormal values of survivors of life-threatening illness. Volume therapy and inotropic agents were used to increase cardiac index and $\mathrm{DO}_{2}$.

\subsubsection{Studies to validate maximal $\mathrm{DO}_{2}$ as a goal-oriented therapy}

Shoemaker et al. ${ }^{[276]}$ tested the hypothesis, that the supranormal values of oxygen transport parameters may be valuable therapeutic goals for high-risk critically ill patients. He compared three groups of patients: a) with a central venous catheter and a group b) with a pulmonary artery catheter and c) with a pulmonary artery catheter and a treatment protocol to achieve supranormal oxygen transport values. Mortality and rate of complications were not different between the first two groups, but mortality was decreased in the pulmonary artery supranormal treatment group. The authors concluded, that for high-risk post-operative patients treatment aiming at supranormal oxygen transport values is more appropriate. Boyd et al. ${ }^{[27]]}$ confirmed in a prospective trial in high-risk surgical patients the reduced mortality ( $22 \%$ vs. $6 \%$ ) of the supranormal $\mathrm{DO}_{2}$ treatment strategy. The group of Schoemaker et al. ${ }^{[278,279]}$ stressed the importance of the time frame in which the supranormal values are reached. In a prospective study ${ }^{[27]}$ the protocol patients (supranormal $\mathrm{DO}_{2}$ values within $24 \mathrm{hrs}$ after admission) had a significant lower mortality $(18 \%$ vs. $37 \%)$ than control patients.

Tuchsmidt et al. ${ }^{[280]}$ and $\mathrm{Yu}$ et al. ${ }^{[281]}$ did not find a significant reduction between the control and the supranormal $\mathrm{DO}_{2}$ treatment group in a septic and a mixed group of patients, respectively. However, in a subset analysis between patients who actually achieved supranormal $\mathrm{DO}_{2}$ values, whether self generated or as result from therapy, and patients with normal $\mathrm{DO}_{2}$, a significant difference in mortality was found.

However, Hayes et al. ${ }^{[222]}$ found in a prospective randomized trial even an increased mortality in the supranormal $\mathrm{DO}_{2}$ treatment group (54 \% vs. $34 \%$ ). The authors gave several reasons for these results: 1) $\mathrm{VO}_{2}$ associated with the reversal of tissue hypoxia and oxygen debt was not increased in the treatment group; 2) in this study a patient population with a higher APACHE II score was encountered than in other studies; 3 ) in contrast to other studies patients in whom the therapeutic goals were only achieved by fluid administration were not assigned to the study. When all the patients, including those patients who were not assigned to the study, were considered in whom the target $\mathrm{DO}_{2}$ levels were achieved, $90 \%$ of the patients survived and left hospital. This supports the idea that the ability to achieve a high level of $\mathrm{DO}_{2}$ and $\mathrm{VO}_{2}$ indicates a larger physiological 
reserve, less severe illness and a better prognosis [282]. In a retrospective study ${ }^{[283]}$ of a subgroup of patients with sepsis this idea was confirmed. Survivors were characterized by the ability to increase both $\mathrm{DO}_{2}$ and $\mathrm{VO}_{2}$, whereas non-survivors failed to increase $\mathrm{VO}_{2}$.

\subsubsection{Normal $\mathrm{SvO}_{2}$ values as goal-oriented therapy}

Since $\mathrm{SvO}_{2}$ reflects the balance between $\mathrm{DO}_{2}$ and $\mathrm{VO}_{2}$ consumption, studies evaluating treatment targeting supranormal levels of $\mathrm{DO}_{2}$ and $\mathrm{VO}_{2}$ included the measurement of $\mathrm{SvO}_{2}$. Normal $\mathrm{SvO}_{2}$ values were defined as one of the treatment goals in critically ill patients. Gattinoni et al. ${ }^{[24]}$ performed a randomized trial to determine whether targeting a normal value for $\mathrm{SvO}_{2}(>70 \%)$ or supranormal value for cardiac index would improve morbidity and mortality in critically ill patients. 762 Patients were randomly assigned to the control group, to the cardiac index group or to the $\mathrm{SvO}_{2}$ group. No differences in mortality and morbidity were found at the time of discharge or six month later. Subgroup analysis of the patients in whom hemodynamic targets were achieved, did not show any difference in mortality.

Kremzar et al. ${ }^{[285]}$ determined in a retrospective non-randomized study in 40 patients with multiple injuries whether maintaining normal values for $\mathrm{SvO}_{2}(70-75 \%)$ is more relevant to survival than maintaining supranormal oxygen transport parameters per se. In the $\mathrm{SvO}_{2}$ group normal $\mathrm{SvO}_{2}$ values were maintained by correcting hypovolemia, anaemia and hypoxemia and by the administration of dobutamine, which resulted in an average $\mathrm{DO}_{2}$ value of $605-688 \mathrm{ml} / \mathrm{min} / \mathrm{m}^{2}$. In the supranormal $\mathrm{DO}_{2}$ group an average $\mathrm{DO}_{2}$ value of $835 \mathrm{ml} / \mathrm{min} / \mathrm{m}^{2}$ was achieved by continuous administration of fluids and increasing doses of dobutamine. An increased survival and decreased proportion of organ failure was found in the $\mathrm{SvO}_{2}$ group ( $96 \%$ vs. $65 \%$ ) and $(4 \%$ vs. $35 \%$ ), respectively. The authors concluded, that maintaining a normal $\mathrm{SvO}_{2}$ and increasing $\mathrm{DO}_{2}$ only when required is better than aiming at supranormal $\mathrm{DO}_{2}$ levels.

\subsubsection{Criticism on supranormal $\mathrm{DO}_{2}$ as a goal-oriented therapy}

Besides the conflicting results of the randomized trials more criticism on supranormal $\mathrm{DO}_{2}$ treatment have been reported:

1) The use of catecholamines may be associated with an enhancement of $\mathrm{VO}_{2}$ by direct stimulation of the tissue metabolism independent of its effect on $\mathrm{DO}_{2}$.

2) Arrhythmias and EKG changes have been reported in patients in whom high doses of catecholamines were used ${ }^{[282]}$.

3) The frequency of myocardial infarction, a potential harm of the use catecholamines to maximize $\mathrm{DO}_{2}$, may increase in patients who receive catecholamines.

4) Aggressive fluid administration can induce fluid accumulation with impairment of the microcirculation and with lactate acidosis.

5) Some authors have argued that increasing $\mathrm{DO}_{2}$ seems useless, since the uptake of oxygen at the tissue level is disturbed.

\subsubsection{Summary}

Debate about the efficacy of increasing $\mathrm{DO}_{2}$ in critically ill patients still continues. The difficulty in several prospective trials to reach the supranormal target level of the oxygen transport parameters was mentioned. This difficulty seemed to reflect the different characteristics of the patients and consequently the different ability to achieve the aimed hemodynamic goal. However, adult intensive care centers have adopted this controversial treatment strategy. Several consensus statements ${ }^{[271,287]}$ and a meta analysis the clinical trials ${ }^{\text {[288] }}$ did not support aggressive attempts to increase $\mathrm{DO}_{2}$, although immediate resuscitation and achievement of normal oxygen transport variables are called essential. The $\mathrm{SvO}_{2}$ as an 
ingredient of the goal-oriented therapy has not introduced a new element in this debate. In the $\mathrm{SvO}_{2}$ collaborative trial the oxygen transport parameters were indistinguishable in the control group and the $\mathrm{SvO}_{2}$ group. The care in the control group resulted already in a normal $\mathrm{SvO}_{2}$ value and was not better or worse than the care aimed at supranormal $\mathrm{DO}_{2}$ levels. In the retrospective non-randomized trial the monitoring and targeting of normal $\mathrm{SvO}_{2}$ values in combination with the dobutamine test seemed to be more promising. The conflicting results warrant further studies to validate normal $\mathrm{SvO}_{2}$ values as a goal oriented therapy. 


\section{References}

Zijlstra WG, Maas AHJ, Moran RF. Definition, significance and measurement of quantities pertaining to the oxygen carrying capacity of human blood. Scand J Clin Lab Invest 1996;56, Suppl 224:27-45

Moran RF. The case for standardized terminology: Oxygen saturation values can trick the unwary and lead to clinical misjudgment. Crit Care Med 1993;21:805-807

Wimberley PD, Siggaard-Andersen O, Fogh-Andersen N, Zijlstra WG. Severinghaus JW. Haemoglobin oxygen saturation and related quantities: definitions, symbols and clinical use. Scand J Clin Lab Invest 1990;50, Suppl 203:455-459

Zijlstra WG. Quantities and units in medical science: a plea for standardization. Scand J Clin Lab Invest 1993;53, Suppl 214:131-136

Zander R, Mertzluft F. Oxygen parameters of blood: definitions and symbols. Scand J Clin Lab Invest 1990;50, Suppl 203:177-185

Barker SJ, Tremper KK, Hyatt J. Effects of methemoglobin on pulse oximetry and mixed venous oximetry. Anaesthesiology 1989;70:112-117

Haney M, Tait AR, Tremper KK. Effect of carboxyhemoglobin on the accuracy of mixed venous oximetry monitors in dogs. Crit Care Med 1994;22:1181-1185

Nunn JF. The atmosphere. In: Nunn's applied respiratory physiology. Oxford, Butterworth, Heinemann. 1993, pp 3-12

Kasting JF. Earth's early atmosphere. Science Wash. DC. 1993;259:920-926

Alberts B, Bray D, Lewis J, Raff M, Roberts Watson JD. The evolution of the cell. In: Molecular biology of The Cell, New York \& London, Garland Pub Inc, 1993;pp 3-40

Alberts B, Bray D, Lewis J, Raff M, Roberts Watson JD. Energy conversion: Mitochondria and chloroplast. In: Molecular biology of The Cell, New York \& London, Garland Pub Inc, 1993; pp 653-720

Nunn JF. Oxygen. In: Nunn's applied respiratory physiology. Oxford, Butterworth, Heinemann. 1993, pp 247-305

Ledingham IMcA, Naguib M. Overview: Evolution of the concept of Fick to the present day. In: Edwards JD, Shoemaker WC, Vincent JL. (eds.) Oxygen transport. Principles and practice. London, W.B. Saunders Co Ltd. 1993; pp 3-21

Duc G. Oxygen therapy. In: Vert P, Stern L. eds. Neonatal Medicine. Paris: Masson 1987: 505 537

Nunn JF. Distribution of pulmonary ventilation and perfusion. In: Nunn's applied respiratory physiology. Oxford, Butterworth, Heinemann. 1993, pp 178-197

Schultze A, Whyte RK, Clifton Way R, Sinclair JC. Effect of the arterial oxygenation level on cardiac output, oxygen extraction and oxygen consumption in low birth weight infants receiving mechanical ventilation. J Pediatr 1995;126:777-784

Krauss AH. Ventilation - perfusion relationships in neonates. In: Thibeault DW, Gregory GA. (eds.) Neonatal pulmonary care. Norwalk, Cn, Appleton. 1986: pp 123-148

Perutz MF. Molecular anatomy, physiology, and pathology of hemoglobin. In: Stamatoyannopoulos G, Nienhuis AW, Majerus PW, Varmus H. (eds): The molecular basis of blood diseases, Philadelphia, PA, Saunders, 1987, p.127-177

Wardrop CAJ, Holland BM, Jones JG. Red-cell physiology. In: Gluckman PJ, Heymann MA. (Eds.): Perinatal physiology. Philadelphia, PA, Saunders, 1997, p.868-876.

Severinghaus JW. Simple, accurate equations for human blood $\mathrm{O}_{2}$ dissociation computations. J Appl Physiol 1979;43:599-602

Siggaard-Andersen O, Wimberley PD, Gothgen IH, Siggaard-Andersen M. A mathematical model of the hemoglobin-oxygen dissociation curve of human blood and of the oxygen partial pressure as a function of temperature. Clin Chem 1984;30:1646-1651 
Brown EG, Krouskop RW, McDonnel FE, Monge CC, Winslow RM. A technique to continuously measure arteriovenous oxygen content difference and $\mathrm{p}_{\mathrm{s}_{0}}$ in vivo. J Appl Physiol 1985;58:13831389

Wimberley PD. Fetal hemoglobin, 2,3-diphosphoglycerate and oxygen transport in the newborn premature infant. Scand J Clin Lab Invest 1982;42:Supp 160:13-149

Weber RE, Jensen FB. Functional adaptations in hemoglobin from ectothermic vertebrates. J Exp Biol

Giardina B, Condo SG, Petruzzelli R, Bardgard A Brix O. Thermodynamics of oxygen binding to arctic hemoglobins: the case of reindeer. Biophys Chem 1990;37:281-286

Condo SG, Corda M, Sanna MT, Pellegrini MG, Ruiz MP, Castagnola M, Giardina B. Molecular basis of low-temperature instability in pig hemoglobins. Eur J Biochem 1992;209:773-776

Gustin P. Detry B, Cao ML, Chenut F, Robert A, Ansay M, Frans A, Clerbeaux T. Chloride and inorganic phosphate modulate binding of oxygen to bovine red blood cells. J Appl Physiol 1994;77:202-208

Zwart A, Kwant B, Oeseburg B, Zijlstra WG. Human whole-blood oxygen affinity: effect of carbon monoxide. J Appl Physiol 1984;57:14-20

Stamatoyannopoulos G, Nienhuis AW. Hemoglobin switching. In: Stamatoyannopoulos G, Nienhuis AW, Majerus PW, Varmus H. (eds): The molecular basis of blood diseases, Philadelphia, PA, Saunders, 1994, pp. 107-155

Cunningham JM, Jane SM. Hemoglobin switching and fetal hemoglobin reactivation. Semin Hematol 1996;33:9-23

Peterson KR, Stamatoyannopoulos G. Role of gene order in development control of human gamma- and beta-globin gene expression. J Mol Cell Biol 1993;13:4836-4843

Bard $\mathrm{H}$, Widness JA. Effect of recombinant human erythropoietin on the switch over from fetal to adult hemoglobin synthesis in preterm infants. J Pediatr 1995;127:478-480

Bard H, Fouron JC, Prosmanne J, Gagnon J. Effect of hypoxemia on fetal hemoglobin synthesis during late gestation. Pediatr Res 1992;31:483-485

Bard H, Fouron JC, Gagnon C, Gagnon J. Hypoxemia and increased fetal hemoglobin synthesis. J Pediatr 1994;124:941-943

Bard H, Prosmanne J. Elevated levels of fetal hemoglobin synthesis in infants with bronchopulmonary dysplasia. Pediatrics 1990;86:193-196

Bard H, Lachance C, Widness JA, Gagnon C. The reactivation of fetal hemoglobin synthesis during anemia of prematurity. Pediatr Res 1994;36:253-256

Bard $\mathrm{H}$, Fouron JC. The increase in fetal hemoglobin synthesis in the fetal lamb during hyperglycemic hypoxemia. Am J Obstet Gynecol 1988;159:1269-1272

Bard H, Widness JA, Ziegel EE, Gagnon C, Peri KG. The proportions of G-gamma and A-gamma globins in the fetal hemoglobin synthesized in preterm and term infants. Pediatr Res 1995;37:361364

Bard H, Faesdale F. Red cell oxygen affinity, hemoglobin type, 2,3-diphosphoglycerate, and $\mathrm{pH}$ as a function of fetal development. Pediatrics 1979;64:483-487

Bard H, Fouron JC, Prosmanne J. The inhibition of the postnatal rise of 2,3-diphosphoglycerate in newborn lambs as a result of glucose perfusion. Pediatr Res 1988;24:470-472

Delivoria-Papadopoulos M, Martens RJ, Forster II RE, Oski FA. Postnatal changes in oxygenhemoglobin affinity and erythrocyte 2,3-diphosphoglycerate in piglets. Pediatr Res 1974;8:64-66

Giardina B, Scatena R, Clementi M, Cerroni L, Nuutinen M, Brix O, Sletten SN, Castagnola M, Condo SG. Physiological relevance of the overall delta $\mathrm{H}$ of oxygen binding to fetal human hemoglobin. J Mol Biol 1993;229:512-516 by fetal bovine hemoglobin. J Mol Biol 1996;255:229-234 
Fouron JC, Bard H, Guennec Le JC, Van Ameringen MR. Effect of fetal or adult red cells on tissue oxygenation and myocardial function in normoxemic newborn lambs. Pediatr Res 1981;15:967-970

Van Ameringen MR, Fouron JC, Bard H, Le Guennec JC, Prosmanne J. Oxygenation in anemic newborn lambs with high or low oxygen affinity red cells. Pediatr Res 1981;15:1500-1503

Schumaker PT, Long R, Wood LDH. Tissue oxygen extraction during hypovolemia: role of hemoglobin $\mathrm{P}_{\mathrm{s}}$. J Appl Physiol 1987;62:1801-1807

Lister G. Oxygen transport in the intact hypoxic newborn lamb: Acute effects of increasing ps. Pediatr Res 1984;16:172-177

Myburgh JA, Webb RK, Worthley LIG. The $\mathrm{p}_{\mathrm{x}}$ is reduced in critically ill patients. Intensive Care Med 1991;17:355-358

Oski FA. Clinical implications of the oxyhemoglobin dissociation curve in the neonatal period. Crit Care Med 1979;7:412-418

Woodson RD. Physiological significance of oxygen dissociation curve shifts. Crit Care Med 1979;7:368-373

Gutierrez G. The rate of oxygen release and the effect on capillary oxygen tension: a mathematical study. Resp Physiol 1986;63:79-96

Popel AS: Theory of oxygen transport to tissues. Crit Rev Biomed Engin 1989;17:257-321

Bos K. Mathematical modeling of oxygen transport from capillaries to tissue. Thesis. Catholic University Nijmegen, The Netherlands. 1997

Ellsworth ML, Pittman RN: Arterioles supply oxygen to capillaries by diffusion as well by convection. Am J Physiol 1990;258:H1240-H1243

Pittman RN: Influence of microvascular architecture on oxygen exchange in skeletal muscle. Microcirculation 1995;2:1-18

Hoofd L, Kreuzer F. Oxygen transfer from blood to mitochondria. In: Crystal RG, West JB, Weibel ER, Barnes PJ. (Eds.) The lung. Scientific foundations. vol 2. Lippingcott-Raven, New York, pp 1913-1923

Fan FC, Chen RYZ, Schuessler GB. Effects of hematocrit variations on regional hemodynamics and oxygen transport in the dog. Am J Physiol 1980;238:H545-H552

Biro GP, Anderson PJ, Curtis SE. Stroma free hemoglobin: its presence does not improve oxygen supply to the resting hindlimb vascular bed of hemodiluted dogs. Can J Physiol Pharmacol 1991;69:1656-1662

Federspiel WJ, Salerius RH: An examination of the contribution of red cell spacing to the uniformity of oxygen flux at the capillary wall. Microvasc Res 1984;27:273-285

Popel AS. Invited editorial on " A finite model of oxygen diffusion in the pulmonary capillaries". J Appl Physiol 1997;82:1717-1718

Honig CR, Gayeski TEJ, Groebe K. Myoglobin and oxygen gradients. In: Crystal RG, West JB, Weibel ER, Barnes PJ. (Eds.) The lung. Scientific foundations. vol 2. Lippingcott-Raven, New York, pp 1925-1933

Hoppeler H, Mathieu-Costello O, Kayar SR. Mitochondria and microvascular design. In: Crystal RG, West JB, Weibel ER, Barnes PJ. (Eds.) The lung. Scientific foundations. vol 2. LippingcottRaven, New York, pp 1913-1923

Little RA, Edwards JD. Applied Physiology. In: Edwards JD, Shoemaker WC, Vincent JL. (Eds) Oxygen Transport; principles and practice. London, Saunders, 1993, pp 21-40

Babcock GT, Wilkström M. Oxygen activation and the conservation of energy in cell respiration. Nature 1992;356:301-308

Sokol Rj. Expanding spectrum of mitochondrial disorders. J Pediatr 1996;128:597-599

Johns DR. Mitochondrial DNA and disease. N Engl J Med 1995;333:638-644

Aprille JR. Perinatal development of mitochondria in rat liver. In Physiology and pathology of mitochondria. ed: Fiskum G. Van Vostrand Reinhold, New York 1986: 66-94 
Valcarce C, Navarette RM, Encabo P, Loeches E, Satrustegui J, Cuezva JM. Postnatal development of rat liver mitochondrial functions. The roles of protein synthesis and of adenine nucleotides. J Biol Chem 1988;263:7767-7775

69 Joyal JL, Hagen T, Aprille JR. Intramitochondrial protein synthesis is regulated by matrix adenine content and requires calcium. Arch Biochem Biophys 1995;319:322-330

$70 \quad$ Izquierdo JM, Jimenez E, Cuezva JM. Hypothyroidism affects the expression of the $\beta-\mathrm{F}_{1}-\mathrm{ATP}$ ase gene and limits mitochondrial proliferation in rat liver at all stages of development. Eur J Biochem $1995 ; 232: 344-350$

Prieur B, Bismuth J, Delaval E. Effects of adrenal steroid hormones on mitochondrial maturation during late fetal period. Eur J Biochem 1998;252:194-199

Bates TE, Almeida A, Heales SJ Clark JB. Postnatal development of the complexes of the electron transport chain in isolated rat brain mitochondria. Dev Neurosc 1994;16:321-327

Schagger $\mathrm{H}$, Noack $\mathrm{H}$, Halngk W, Brandt U, von Jagow G. Cytochrome-C oxidase in developing rat heart. Enzymic properties and amino-terminal sequences suggest identity of the fetal heart and the adult liver isoform. Eur J Biochem 1995;230:235-241

Delaval E, Razanoelina M, Bastin J, Bismuth J, Geloso JP. Mitochondrial activity of rat kidney during ontogeny. J Dev Physiol 1990;14:1-5

Allen RG, Keogh BP, Tresini M, Gerhard GS, Volker C, Pignolo RJ, Horton J, Cristofalo VJ. Development and age associated differences in electron transport potential and consequences for oxidant generation. J Biol Chem 1997;272:24805-24812

Cernaianu AC, Nelson LD. The significance of mixed venous oxygen saturation and technical aspects of continuous measurement. In: Edwards JD, Shoemaker WC, Vincent JL. (Eds) Oxygen Transport; principles and practice. London, Saunders, 1993, pp 99-124

Kandel G, Aberman A. Mixed venous oxygen saturation. Its role in the assessment of the critical patient. Arch Int Med 1983;143:1400-1402

Davies GG, MendenHall J, Symreng T. Measurement of right atrial oxygen saturation by fiberoptic oximetry accurately reflects mixed venous oxygen saturation in swine. J Clin Monit 1988;4:99. 102

Reinhart K, Rudolph T, Bredle DL, Hanneman L, Cain SM. Comparison of central venous to mixed venous oxygen saturation during changes in oxygen supply/demand. Chest 1989;95:12161221

Schweiss JF. Mixed venous hemoglobin saturation: Theory and application. Int Anesthesiol Clin 1987;25:113-136

Kupeli IA, Satwicz PR. Mixed venous oximetry. Int Anesthesiol Clin 1989;27:176-183

Nelson LD. Continuous venous oximetry in surgical patients. Ann Surg 1986;329-333

Lehot JJ, Durand PG. Mixed venous oxygen saturation monitoring in surgery. In: Edwards JD, Shoemaker WC, Vincent JL.(Eds). Oxygen Transport; principles and practice. London, Saunders, 1993, pp $125-136$

Zwischenberger JB, Kirsh MM, Dechet RE. Suppression of shivering decreases oxygen consumption and improves hemodynamic stability during postoperative rewarming. Ann Thorac Surg 1987; 43:428-431

Schligtig R, Cowden LW, Chatman BR. Tolerance of unusually low mixed venous oxygen saturation: Adaptations in the chronic low cardiac output syndrome. Am J Med 1986;80:813-818

Räsänen J, Downs JB, Malec DJ, Seidman P. Estimation of oxygen utilization by dual oximetry. Ann Surg 1987: 206: 621-623

Carrol GC. A continuous monitoring technique for management of acute pulmonary failure. Chest $1987 ; 92: 467-469$

Bongard FS, Leighton TA. Continuous dual oximetry in surgical critical care. Indications and limitations. Ann Surg 1992;216:60-68

Räsänen J. Role of dual oximetry in the assessment of pulmonary function. In: Reinhart K, Eyrich K. (Eds) Clinical aspects of $\mathrm{O}_{2}$ transport and tissue oxygenation. Springer Verlag, Berlin, 1989, 230240 
Reinhart $\mathrm{K}$. Monitoring $\mathrm{O}_{2}$ transport and tissue oxygenation in critically ill patients. In: Reinhart $\mathrm{K}$, Eyrich K. Editors. Clinical aspects of $\mathrm{O}_{2}$ transport and tissue oxygenation. Berlin: Springer Verlag, 1989; pp 193-211

Consensus conference. Tissue hypoxia. How to detect, how to correct how to prevent. Am J Respir Crit Care Med 1996; 154:1573-1578

Finch CA, Lenfant C. Oxygen transport in man. New Engl J Med 1970;286:407-415

Connet RJ, Honig CR, Gayeski TEJ, Brooks GA. Defining hypoxia: a systems view of $\mathrm{VO}_{2}$, glycolysis, energetics, and intracellular $\mathrm{pO}_{2}$. J Appl Physiol 1990;68:833-842

Robin ED. Of men and mitochondria: Coping with hypoxic dysoxia. Am Rev Respir Dis 1980;122:517-531

Shapiro BA, Cane RD. Blood gas monitoring: Yesterday, today, and tomorrow. Crit Care Med 1989;17:573-581

Shapiro BA. Assessment of oxygenation: Today and tomorrow. Scan J Clin Invest 1990;50:197-202

Guttierez G. Cellular energy metabolism during hypoxia. Crit Care Med 1991;19:619-626

Guttierez G. Cellular effects of hypoxia and ischemia. In: Crystal RG, West JB, Weibel ER, Barnes PJ. eds. The Lung. Scientific foundations. Philadelphia, Lippingcott-Raven, 1997, pp 1969-1987

Sahlin K. Aerobic and anaerobic processes of energetics. In: Crystal RG, West JB, Weibel ER, Barnes PJ. eds. The Lung. Scientific foundations. Philadelphia, Lippingcott-Raven,1997, pp 1889. 1899

Cain SM, Curtis SE. Systemic and regional oxygen uptake and delivery and lactate flux in endotoxic dogs infused with dopexamine. Crit Care Med 1991;19:1552-1560

Balaban RS. Regulation of oxidative phosphorylation in the mammalian cell. Am J Physiol 1990;258:C377-C385

Guyton AC. Metabolism of carbohydrates and formation of adenosine triphosphate. In Guyton AC. Textbook of medical physiology. 7th edition. Philadelphia, Saunders 1986, pp 808-817

Kreisberg RA. Lactate homeostasis and lactic acidosis. Ann Intern Med 1980;92(1):227-237

Mizock BA. Lactic Acidosis. Disease-a-Month 1989;4:235-300

Mizock BA, Falk JL. Lactic acidosis in critical illness. Crit Care Med 1992;20:80-93

Wasserman K, Koike A. Is the anaerobic threshold truly anaerobic. Chest 1992;101:211S-218S

Samsel RW, Schumaker PT. Determination of the critical $\mathrm{O}_{2}$ delivery from experimental data: sensitivity to error. J Appl Physiol 1988;64:2074-2082.

Barefield ES, OH W, Stonestreet BS. Group B streptococcus-induced acidosis in newborn swine: regional oxygen transport and lactate flux. J Appl Physiol 1992;72:272-277

Fitzgerald MJ, Goto M, Myers TF. Zeller WP. Early metabolic effects of sepsis in the preterm infant: Lactic acidosis and increased glucose requirement. J Pediatr 1992;121:951-955

Izraeli S, Ben-Sira L, Harell D, Naor N, Ballin A, Davidson S. Lactic acid as a predictor for erythrocyte transfusion in healthy preterm infants with anemia of prematurity. J Pediatr 1993;122:629-631.

Cheung PY, Finer NN, Plasma lactate concentration as a predictor of death in neonates with severe hypoxemia requiring extracorporeal membrane oxygenation. J Pediatr 1994;125:753-758

Ruth V, Raivio KO. Perinatal brain damage: predictive value of metabolic acidosis and the apgar score. BMJ 1988;297:24-27

Wilmore JH, Costill DL. Energy for movement. Basic energy systems. In: Wilmore JH, Costill DL. Physiology of sport and exercise. Campaign, Human kinetics. 1994; pp 94-120.

Cain SM. Oxygen delivery and uptake in dogs during anemic and hypoxic hypoxia J Appl Physiol 1977;42:228-234

Cain SM. Effects of time and vasoconstrictor tone on oxygen extraction during hypoxic hypoxia. J Appl Physiol 1978;45:219-223

Shibutani K, Komatsu T, Kubal K, Sanchala V, Kumar V, Bizzari DV. Critical level of oxygen delivery in anesthetized man. Crit Care Med 1983;11:640-643 
117 Schlichtig R, Pinsky MR. Defining the hypoxic threshold. Intensive Care Med 1991;19:147-149

118 Torrance SM, Wittnich C. The effect of varying arterial oxygen tension on neonatal acid-base balance. Pediatr Res 1992;31:112-116

119 Torrance SM, Wittnich C. Blood lactate and acid-base balance in graded neonatal hypoxia: evidence for oxygen-restricted metabolism. J Appl Physiol 1994;77:2318-2324

120 Moss M, Moreau G, Lister G. Oxygen transport and metabolism in the conscious lamb: the effects of hypoxemia. Pediatr Res 1987;22:177-183

121 Walker AM, Cannata JP, Dowling MH, Ritchie BC, Maloney JE. Age-dependent pattern of autonomic heart rate control during hypoxia in fetal and newborn lambs. Biol Neonate 1979;35:198-208

122 Giussani DA, Spencer JAD, Hanson MA. Fetal cardiovascular responses to hypoxemia. Fetal and Maternal Medicine Review 1994;6:17-37.

123 Bartelds B, van Bel F, Teitel DF, Rudolph AM. Carotid not aortic, chemoreceptors mediate the fetal cardiovascular response to acute hypoxemia in lambs. Pediatr Res 1993;34:51-55

124 Sidi D, Kuipers JRG, Teitel D, Heymann MA, Rudolph AM. Developmental changes in oxygenation and circulatory responses to hypoxemia in lambs. Am J Physiol 1983;245:H674-H682

125 Koehler RC, Traystman RJ, Jones Jr MD. Regional bloodflow and $\mathrm{O}_{2}$ transport during hypoxic and CO hypoxia in neonatal and adult sheep. Am J Physiol 1985;245:H118-H124

126 Teitel D, Sidi D, Bernstein D, Heymann MA, Rudolph AM. Chronic hypoxemia in the newborn lamb: Cardiovascular, hematopoietic and growth adaptations. Pediatr Res 1985;19:1004-1010

127 Bernstein D, Teitel D, Sidi D, Heymann MA, Rudolph AM. Redistribution of regional bloodflow and oxygen delivery in experimental cyanotic heart disease in newborn lambs. Pediatr Res 1987;22:389-393

128 Trouwborst A, Tenbrink R, Fennema M, Bucx M, Broek WGM v.d, Trouwborst-Weber BK. Cardiovascular responses, hemodynamics and oxygen transport to tissue during moderate isovolemic hemodilution in pigs. In Piiper J. eds. Oxygen transport to the tissues XII. Plenum Press, New York, 1990:873-878

129 Trouwborst A, Woerkens ECSM van, Tenbrink R. Hemodilution and oxygen transport. In Erdman W, Bruley DF. eds. Oxygen transport to the tissues XIV. Plenum Press, New York, 1992:431-440

130 Robertie PG, Gravlee GP. Safe limits of isovolemic hemodilution and recommendations for erythrocyte transfusion. Int Anesthesiol Clin 1990;28(4):197-204

131 Cain SM. Peripheral oxygen uptake and delivery in health and disease. Clinics in Chest Med 1982;4:139-148

132 Kreuzer F, Cain SM. Regulation of the peripheral vasculature and tissue oxygenation in health and disease. Critical Care Clin 1985;1:453-470

133 Bernstein D, Teitel DF, Rudolph AM. Chronic anemia in the newborn lamb: Cardiovascular adaptations and comparison to chronic hypoxemia. Pediatr Res 1988;23:621-627

134 Fahey JT, Lister G. Postnatal changes in critical cardiac output and oxygen transport in conscious lambs. Am J Physiol 1987;253:H100-H106

135 Heusser F, Fahey JT, Lister G. Effect of hemoglobin concentration on critical cardiac output and oxygen transport. Am J Physiol 1989;253:H527-H532

136 Fahey JT, Lister G. Response to low cardiac output: Developmental differences in metabolism during oxygen deficit and recovery in lambs. Pediatr Res 1989;26:180-187

137 Moss M. Kurzner S, Razlog Y, Lister G. Hypoxanthine and lactate concentrations in lambs during hypoxic and stagnant hypoxia. Am J Physiol 1988;255:H53-H59

138 Zijlstra W. G. Oximetry: A historical introduction. In: Fetal and neonatal physiological measurements. Ed: Lafeber HN. Elsevier Science Publişher. Amserdam 1991:97-103

Severinghaus JW. Astrup P. History of blood gas analysis. Oximetry. Int Anesthesiol Clin $1987 ; 25(3): 167-204$ 
140 Thilo EH, Brockway Curlander J, Hay WW. Pulse oximetry. In: Physiological monitoring and instrumental diagnosis in perinatal and neonatal medicine. Eds: Brans YW, Hay WW. Cambridge University Press, Cambridge.1995:147-161

141 Hay WW, Thilo EH, Brockway Curlander J. Pulse oximetry in neonatal medicine. Clinics in perinatology 1991;18:441-472

142 Pologe JA, Pulse oximetry: Technical aspects machine design. Int Anesthesiol Clin 1987;25(4):137. 175

143 Landsman MLJ, Knop N, Kwant G, Mook GA, Zijlstra WG. A fiberoptic reflection oximeter. Pfluegers Arch 1978; 373:273-282

144 Mook GA, Osypka P, Strum RE, Wood EH. Fiberoptic reflection photometry on blood. Cardiovasc Res 1968;2:199-209

145 Wilkinson AR, Phibbs RH, Gregory GA. Continuous measurement of oxygen saturation in sick newborn infants. J Pediatr 1978;93:1016-1090

146 Krouskop R, Cabatu EE, Chelliah BP, McDonnel FE, Brown EG. Accuracy and clinical utility of an oxygen saturation catheter. Crit Care Med 1983;11:744-749

147 Haessler R, Brandl F, Zeller M, Briegel J, Peter K. Continuous intra-arterial oximetry, pulse oximetry and Co-oximetry during cardiac surgery. J Cardiathorac Vasc Anesth 1992;6:668-673

148 Baele PL, McMichan JC, Marsh HM, Sill JC, Southorn PA. Continuous monitoring of mixed venous oxygen saturation in critically patients. Anesth Analg 1982;61:513-517

149 Divertie MB, McMichan JC. Continuous monitoring of mixed venous oxygen saturation. Chest $1984 ; 85: 423-428$

150 Gettinger A, DeTrailia MC, Glass D. In vivo comparison of two mixed venous saturation catheters. Anesthesiology 1987;66:373-375

151 Reinhart K, Moser N, Rudolph T, Bredle D, Specht M, Gramm HJ, Goeke J, Eyrich K. Accuracy of two mixed venous saturation catheters during long-term use in critically ill patients. Anes. thesiology 1988;69:769-773

152 Leighton T, Liu SY, Lee TS, Klein S, Bongard F. Simultaneous in-vivo comparison of 2-versus 3wavelength mixed venous oximetry catheters. Anesthesiology 1991; 75:A408

153 Rouby JJ, Poete P, Bodin L, Bourgeois JL, Arthaud M, Viars P. Three mixed venous oxygen catheters in patients with circulatory shock and respiratory failure. Chest 1990;98:954-958

154 Scuderi PE, Bowton DL, Meredith JW, Harris LC, Brockschmidt J. Clinical evaluation of three mixed venous oxygen saturation catheters. Anesthesiology 1990;V73:A484

155 Scuderi PE, Bowton DL, Meredith JW, Harris LC, Brockschmidt Evans J, Anderson RL. A comparison of three pulmonary artery oximetry catheters in intensive care unit patients. Chest 1992;102:896-905

156 Scuderi PE, MacGregor DA, Bowton DL, James RL. A laboratory comparison of three pulmonary artery oximetry catheters. Anesthesiology 1994;81:245-253

157 Howdieshell TR, Sussman A, Dipiro J, McCarten M, Mansbergen A. Reliability of in vivo mixed venous oximetry during experimental hypertriglyceridemia. Crit Care Med 1992;20:999-1004

Woerkens ECSM, Trouwborst A, Tenbrink R. Accuracy of a mixed venous oxygen saturation catheter during acutely induced changes in hematocrit in humans. Crit Care Med 1991;19:1025-1029

Lee S. Tremper KK, Barker SJ. Effects of anemia on pulse oximetry and continuous mixed venous hemoglobin saturation monitoring in dogs. Anesthesiology 1991;75:118-122

Kong CS, Ryder IG, Kahn R, Gregory L, Mackenzie CF. In vitro oxyhemoglobin saturation measurements in haemoglobin solutions using fiberoptic catheters. $\mathrm{Br}$ J Anaest 1995;74:201-208

Mault J.R, Santoro-Nease A, Leonard R.A, Ungerleider R.M. Continuous fiberoptic venous oximetry during neonatal ECMO: Analysis of accuracy and longevity. Crit Care Med 1992;20:S11

Barratt-Boyes BG, Wood EH. The oxygen saturation of blood in the venae cavae, right-heart chambers and pulmonary vessels of healthy subjects. J Lab Clin Med 1957;50:93-106

Freed M, Miettenen OS, Nadas A. Oximetric detection of intracardiac left to right shunts. $\mathrm{Br}$ Heart J 1979;42:690-694 
164 Berridge JC. Influence of cardiac output on the correlation between mixed venous and central venous oxygen saturation. Br J Anaesthesia 1992;69:409-410

165 Tahvanainen J, Meretoja O, Nikki P. Can central venous blood replace mixed venous blood samples. Crit Care Med 1982;10:758-761

166 Martin C, Auffray JP, Badetti G, Papazian L, Gouin F. Monitoring of central venous oxygen saturation versus mixed venous oxygen saturation in critically ill patients. Intensive Care Med 1992;18:101-104

Faber T. Central venous versus mixed venous oxygen content. Acta Anaesthesiol Scand 1995;39: S107:33-36

168 Brandt L, Mertzlufft F. Zur aussagekraft "zentral venoser" blutproben. "Zentralvenoser" vs. gemischtvenoser $\mathrm{O}_{2}$ status. Anaesthesist 1991;40:131-144

169 Dudell G, Cornisch JD, Bartlett RH. What constitutes adequate oxygenation? Pediatrics 1990;85:3941

Yelderman M, New W. Evaluation of pulse oximetry. Anesthesiology 1983;349-352

Jennis MS, Peabody JL. Pulseoximetry: an alternative method for the assessment of oxygenation in newborn infants. Pediatrics 1987;79:524-528

Hay WW, Brockway Curlander J. Eyzaqquirre M. Neonatal pulse oximetry: Accuracy and reliability. Pediatrics 1989;83:717-722

173 Bland JM, Altman DG. Statistical methods for assessing agreement between two methods of clinical measurement. Lancet 1986; i:307-317

Severinghaus JW, Kelleher JF. Recent developments in pulse oximetry. Anesthesiology 1992;76:1018-1038.

Choe H, Tashiro C, Fukumitsu K, Masahru Y, Yoshiya I. Comparison of recorded values from six pulse oximeters. Crit Care Med 1989;17:678-681

Nickerson BG, Sarkisan C, Tremper K. Bias and precision of pulseoximeters and arterial oximeters. Chest 1988;93:515-517

Bowes WA, Corke BC, Hulka J. Pulse oximetry: A review of the theory, accuracy, and clinical applications. Obstet Gynec 1989;74:541-546

179 Thilo EH, Anderson D, Wasserstein ML, Schmidt J, Luckey D. Saturation by pulse oximetry: Comparison of the results obtained by instruments of different brands. J Pediatr 1993;122:620-626.

180 Barker SJ. Tremper KK. The effect of carbon monoxide inhalation on pulseoximetry and transcutaneous $\mathrm{pO}_{2}$. Anesthesiology 1987;66:677-679.

181 Severinghaus JW, Koch SO. Effect of anemia on pulse oximeter accuracy at low saturation. J Clin Monit 1990;6:85-88

Pologe J, Raley D. Effects of fetal hemoglobin on pulse oximetry. J Perinatol 1987;7:324-326

Rajadurai VS, Walker AM, Yu VY, Oates A. Effect of fetal hemoglobin on the accuracy of pulse oximetry in preterm infants. J Paediatr Child Health 1992;28:43-46

Veyckemans F., Baele P, Guillaume JE, Willems E, Robert A, Clerbaux T. Hyperbilinbinemia does not interfere with hemoglobin saturation measured by pulse oximetry. Anesthesiology 1989;70:118-122

Beall SN, Moorthy SS. Jaundice, oximetry, and spurious hemoglobin desaturation. Anesth Analg 1989;68:806-807

Zubrow AB, Henderson GW, Imaizumi SO, Pleasure JR. Pulse oximetry in sick premature infants and the effect of phototherapy and radiant warmers in the oxygen saturation read out. Am J Perinatol 1990;7:75-78

lyer P, McDougall P, Loughan P, Mee RB, Al-Tawill K, Carlin J. Accuracy of pulse oximetry in hypothermic neonates and infants cardiac surgery. Crit Care Med 1996;24:507.511

Volgyesi GA, Spahr-Schopfer I. Does skin pigmentation affect the accuracy of pulse oximetry? An in vitro study. Anesthesiology 1991;75:A407 
Barker SJ, Shah NK. Effects of motion on the performance of pulse oximeters in volunteers. Anesthesiology 1996;85:774-781

Barington KJ, Finer NN, Ryan CA. Evaluation of pulse oximetry as a continuous monitor technique in the neonatal intensive care unit. Crit Care Med 1988;16 1147-1153

Coté CJ, Goldstein EA, Coté MA, Hoaglin DC, Ryan JF. A single blind study of pulse oximetry in children. Anesthesiology 1988;68:184-188

\section{Polaner D. A single blind study of combined pulse oximetry and capnography in children. Anesthesiology 1991;74:980-987}

Poets CF, Stebbens VA, Richard D, Southall DP. Prolonged episodes of hypoxemia in preterm infants undetectable by cardiorespiratory monitors. Pediatrics 1995;95:860-863

Mower WR, Sachs C, Nicklin EL, Baraff LJ. Pulse oximetry as a fifth pediatric vital sign. Pediatrics 1997; $99: 681-686$

Silverman WA. Setting a limit in the treatment of neonates: all or none? In: Duc G. Huch A, Huch R. eds. The very low birth weight infant; A challenge to neonatology and obstetrics. New York: Georg Thieme Verlag, 1990:111-128

\section{Cross KW. Costs of preventing retrolental fibroplasia. 1973;15:954-956}

Bolton DPG, Cross KW. Further observations on costs of preventing retrolental fibroplasia. Lancet $1974 ; 445-448$

Poets CF, Southall DP. Non-invasive monitoring of oxygenation in infants and children: practical considerations and areas of concern. Pediatrics 1994;93:737-745

Mok JYQ, McLaughin FJ, Pintar M, Hak H, Amaro-Galvez R, Levison H. Transcutaneous monitoring of oxygenation: what is normal? J Pediatr 1986; 108:365-371

Mok JYQ, Hak H, McLaughin FJ, Pintar M, Canny GJ, Levison H. Effect of age and state of wakefulness on transcutaneous oxygen values in preterm infants; A longitudinal study. J Pediatr 1988; 113:706-709

Hoppenbrouwers T, Hodgeman JE, Arakawa K, Durand M, Cabal LA. Transcutaneous oxygen and carbon dioxide during the first half year of life in premature and normal term infants. Pediatr Res 1992;31:73-79

Terry TL. Extreme prematurity and fibroblastic overgrowth of persistent vascular sheath behind each crystalline lens. I. Preliminary report. Amer J Ophtal 1942;25:203-204

Aranda JV, Saheb N, Stern L, Avery ME. Arterial oxygen tension and retinal vasoconstriction in newborn infants. AJDC 1971;122:189-194

Bancalari E, Flynn J, Goldberg RN, Bawol R, Cassady J, Schiffman J, Feuer W, Roberts J, Gillings D, Sim E. Influence of transcutaneous oxygen monitoring on the incidence of retinopathy of prematurity. Pediatrics 1987;79:663-669

Flynn J, Bancalari E, Sim Snyder E, Goldberg RN, Bawol R, Feuer W, Cassady J, Schiffman J, Feldman HI, Bachinsky B, Buckley E, Roberts J, Gillings D. A cohort study of transcutaneous oxygen tension and the incidence and severity of retinopathy of prematurity. N Engl J Med 1992;326:1050-1054

Cunningham S, Fleck BW, Elton RA, McIntosch N. Transcutaneous oxygen levels in retinopathy of prematurity. Lancet 1995;346:1464-1465

Tuchschmid PE, Boutellier U, Koller EA, Duc GV. Comparison of hypoxanthine, lactate, and ECG signs as indicators of hypoxia. Pediatr Res 1981;15:28-31

Hrbek A, Karlberg P, Kjellmer I, Olsson T, Riha M. Clinical application of evoked EEG responses in newborn infants II: Idiopathic respiratory distress syndrome. Develop Med Child Neurol 1978;20:619-626

Moss AF, Emmannouilliedes GC, Adams FH. Response of ductus arteriosus and pulmonary and systemic arterial pressures to changes in oxygen environment in the newborn infant. Pediatrics 1964;33:937-944 
211 Émond D, Lachance C, Gagnon J, Bard H. Arterial partial pressure of oxygen required to achieve $90 \%$ saturation of hemoglobin in very low birth weight newborns. Pediatr 1993;91:602-604

212 American Academy of Pediatrics and American College of Obstetricians and Gynecologists. Guidelines for perinatal care. 3rd ed. Washington, DC. 1992:197-203

213 Poets CF, Stebbens VA, Alexander JR, Arrowsmith WA, Salfield SAW, Southall DP. Oxygen saturation and breathing patterns in infancy. 1: Full term infants in the second month of life. Arch Dis Child 1991;66:569-573

214 Thilo EH, Park-Moore B, Berman ER, Carson BS. Oxygen saturation by pulse oximetry in healthy infants at an altitude of $1610 \mathrm{~m}$ (5280 ft). AJDC 1991;145:1137-1140

215 Poets CF, Stebbens VA, Alexander JR, Arrowsmith WA, Salfield SAW, Southall DP. Oxygen saturation and breathing patterns in infancy. 2: Preterm infants at discharge from special care. Arch Dis Child 1991;66:574-578

216 Poets CF, Stebbens VA, Alexander JR, Arrowsmith WA, Salfield SAW, Southall DP. Arterial oxygen saturation in preterm neonates at discharge from the hospital and six weeks later. Arch Dis Child 1992;62:882-888

217 Richard D, Poets CF, Neale S, Stebbens VA, Alexander JR, Southall DP. Arterial oxygen saturation in preterm neonates without respiratory failure. J Pediatr 1993;123:963-968

Wasunna A, Whitelaw AG. Pulse oximetry in preterm infants. Arch Dis Child 1987;62:882-888

Stark AR, Richardson D. Blood gas monitoring. In Cloherty JP, Stark AR. Manual of neonatal care. Boston: Little, Brown, 1991:209-214

20 Niemeyer S, Yang P, Shanmina; Drolkar; Zhuang J, Moore LG. Arterial oxygen saturation in Tibetan and Han infants born Lhasa, Tibet. N Engl J Med 1995;333:1248-1252

Hay WW, Thilo E, Brockway Curlander J. Pulseoximetry in neonatal medicine. Clin.in Perinatol. $1991 ; 18: 441-72$

Southall DP, Bignalll S, Stebbens VA, Alexander JR, Rivers RPA, Lissauer T. Pulse oximeter and transcutaneous arteria; oxygen measurements in neonatal and paediatric intensive care. Arch Dis Child 1987;62:882-888

Walsh MC, Noble LM, Carlo WA, Martin RJ. Relationship of pulse oximetry to arterial oxygen tension in infants. Crit Care Med 1987; 15:1102-1105

Bucher HU, Fanconi S, Baekert P, Duc G. Hyperoxemia in newborn infants: Detection by pulseoximetry. Pediatrics 1989;84:226-230

5 Poets CF, Wilken M, Seidenberg J, Southall DP, Hardt H von der. Reliability of a pulseoximeter in the detection of hyperoxemia. J Pediatr 1993;122:87-90

26 Paky F, Koeck CM. Pulse oximetry in ventilated preterm newborns: reliability of detection of hyperoxaemia and hypoxaemia, and feasibility of alarm settings. Acta Paediatr 1995;84:613-616

27 Joint working group of the British Association of Perinatal Medicine and the Research Unit of the Royal College of Physicians. Development of audit measures and guidelines for good practice in the management of neonatal respiratory distress syndrome. Arch Dis Child 1992;67: 1221-1227

28 Swyer PR, Boston RW, Murdock A, Pare C, Rees EP, Segal S, Sinclair JC. Oxygen therapy in the newborn infant. Statement by the fetus and newborn committee of the canadian pediatric society. Can Med Assoc J 1975;113:750-763

231 Fahey PJ, Harris K, Vanderwarf C. Clinical experience with continuous monitoring of mixed venous oxygen saturation in respiratory failure. Chest 1984;85:748-752

232 Richard C, Thuilez C, Pezzano M, Bottineau G, Giudicelli JF, Auzepy P. Relationship between mixed venous oxygen saturation and cardiac index in patients with chronic congestive heart failure. Chest 1989;95:1289-1294 
233 Hassan E, Green JA, Nara AR, Jarvis RC, Kasmer RJ, Pospisil R. Continuous monitoring of mixed venous oxygen saturation as an indicator of pharmacological intervention. Chest 1989;95:406-409

234 Kyff JV, Vaughn S, Yang SC, Raheja R, Puri VK. Continuous monitoring of mixed venous oxygen saturation in patients with acute myocardial infarction. Chest 1989;95:607-611

Shenaq SA, Casar G, Chelly JE, Ott H, Crawford ES. Continuous monitoring of mixed venous oxygen saturation during aortic surgery. Chest 1987;92:796-799

Vaughn S, Puri VK. Cardiac output changes and continuous mixed venous oxygen saturation in the critically ill. Crit Care Med 1988;16:495-498

Schmidt CR, Frank LR, Forsyte SB, Estafanous FG. Continuous $\mathrm{SvO}_{2}$ measurement and oxygen transport patterns in cardiac surgery patients. Crit Care Med 1984;12:523-527

Jain A, Shroff SG, Janicki JS, Reddy HK, Weber KT. Relation between mixed venous oxygen saturation and cardiac index. Nonlinearity and normalization for oxygen uptake and hemoglobin. Chest 1991;99:1403-1409

Silance PG, Simon C, Vincent JL. The relation between cardiac index and oxygen extraction in acutely ill patients. Chest 1994;105:1190-1197

Buheitel G, Scharf J, Hofbeck M, Singer H. Estimation of cardiac index by means of the arterial and the mixed venous oxygen content and pulmonary oxygen uptake determination in the early post-operative period following surgery of congenital heart disease. Intensive Care Med 1994;20:500503

Mahutte CK, Jaffe MB, Sasse SA, Chen PA, Berry RB, Sassoon CSH. Relationship of thermodilution cardiac output to metabolic measurements and mixed venous oxygen saturation. Chest 1993;104:1236-1242

242 Komatsu T, Shibutani K, Okamoto K, Kumar V, Kubal K, Sanchala V, Lees DE. Critical level of oxygen delivery after cardiopulmonary bypass. Crit Car Med 1987;15:194-197

Danek SJ, Lynch JP, Weg JG, Danzker DR. The dependence of oxygen uptake on oxygen delivery in the adult respiratory distress syndrome. Am Rev Resp Dis 1980;122:387-395

Clarke C, Edwards JD, Nightingale P, Mortimer AJ, Morris J. Persistence of supply dependency of oxygen uptake at high levels of delivery in adult respiratory distress syndrome. Crit Care Med 1991;19:497-502.

5 Dorinsky PM, Costello JL, Gadek JE. Relationships of oxygen uptake and oxygen delivery in respiratory failure not due to the adult respiratory distress syndrome. Chest 1988;93:1013-1019

Ronco JJ, Montaner JSG, Fenwick JC, Ruedy J, Russel JA. Pathologic dependence of oxygen consumption on oxygen delivery in acute respiratory failure secondary to AIDS-related pneumocystis carinii pneumonia. Chest 1990;98:1463-1466

47 Astiz ME, Rackow EC, Falk JL, Kaufman BS, Weil MH. Oxygen delivery and consumption in patients with hyperdynamic septic shock. Crit Care Med 1987;15:26-28

4 Guttierez G, Pohil RJ. Oxygen consumption is linearly related to $\mathrm{O}_{2}$ supply in critically ill patients. J Crit Care 1986;1:45-53

49 Silverman $\mathrm{HJ}$, Abrams J, Rubin LJ. Effects of interleukin-2 on oxygen delivery and consumption in patients with advanced malignancy. Chest 1988;94:816-821

50 Demling RH, Lalonde C, Fogt F, Zhu D, Liu Y. Effect of increasing oxygen delivery postburn on oxygen consumption and oxidant-induced lipid peroxidation in the adult sheep. Crit Care Med 1989;17:1025-1030

Steib A, Freys G, Gohard R, Curzola U, Ravanello J, Lutun P, Boudjema K, Ottenni JC. Tissue oxygenation during liver transplantation. Crit Care Med 1992;20:977-983

Mohsenifar Z, Amin D, Jasper AC. Dependence of oxygen consumption on oxygen delivery in patients with chronic congestive hart failure. Chest 1987;92:447-452

Cain SM, Curtis SE. Experimental models of pathologic oxygen supply dependency. Crit Care Med 1991;19:603-643

Nelson DP, Samsel RW, Wood LDH, Schumacker PT. Pathological supply dependence of systemic and intestinal oxygen uptake during endotoxemia. J Appl Physiol 1988;64:2410-2419 
255 Bredle DL, Cain SM. Systemic and muscle oxygen uptake/delivery after dopexamine infusion in endotoxic dogs. Crit Care Med 1991;19:198-204

256 Schumacker PT, Cain SM. The concept of a critical oxygen delivery. Intensive Care Med 1987; 13:223-229

257 Ellsworth ML, Goldfarb RD, Alexander RS. Microembolization induced oxygen utilization impairment in the canine gracilis muscle. Adv Shock Res 1981;193:296

258 Dantzker DR, Foresman B, Gutierez G. Oxygen supply and utilization relationships. A reevaluation. Am Rev Respir Dis 1991;143:675-679

259 Russell JA, Phang PT. The oxygen delivery / consumption controversy. Approaches to management of the critically ill. Am J Respir Crit Care Med 1994;149:533-537

Vermeij CG, Feenstra BWA, Bruining HA. Oxygen delivery and oxygen uptake in postoperative and septic patients. Chest 1990;98:415-420

Mira JP, Fabre JE, Baigorri F, Coste J, Annat G, Artigas A, Nitenberg G, Dhainaut JFA. Lack of oxygen supply dependency in patients with severe sepsis. Chest 1994;106:1524-1531

Ronco JJ, Fenwick JC, Tweedale MG, Wiggs BR, Phang T, Cooper DJ, Cunningham KF, Russell JA, Walley KR. Identification of the critical oxygen delivery for anaerobic metabolism in critically ill septic and non-septic humans. JAMA 1993;270:1724-1730

63 Hanique G, Dugernier T, Laterre PF, Dougnac A, Roeseler J, Reynaert MS. Significance of pathologic oxygen supply dependency in critically ill patients: Comparison between measured and calculated methods. Intensive Care Med 1994;20:12-18

64 Hanique G, Dugernier T, Laterre PF, Roeseler J, Dougnac A, Reynaert MS. Evaluation of oxygen uptake and delivery in critically ill patients: a statistical reappraisal. Intensive Care Med 1994;20:19. 26

265 Backer De D, Moraine JJ, Berre J, Kahn RJ, Vincent JL. Effects of dobutamine on oxygen consumption in septic patients. direct versus indirect determinations. Am J Respir Crit Care Med 1994;150:95-100

266 Yu M, Burchell S, Takiguchi SA, McNamara JJ. The relationship of oxygen consumption measured by indirect calorimetry to oxygen delivery in critically ill patients. J Trauma 1996;41:41-47

267 Lucking SE, Williams TM, Chaten FC, Metz RI, Mickell JJ. Dependence of oxygen consumption in pediatric septic shock and low oxygen extraction. Crit Care Med 1990;18:1316-1319

268 Mink RB, Pollack MM. Effect of blood transfusion on oxygen consumption in pediatric septic shock. Crit Care Med 1990;18:1087-1091

269 Dietrich KA, Conrad SA, Herbert CA, levy GF, Romero MD. Cardiovascular and metabolic response to red blood cell transfusion in critically ill volume resuscitated non-surgical patients. Crit Care Med 1990;18:940-944

270 Seear M, Wensley D, MacNab A. Oxygen consumption-oxygen delivery relationship in children. J Pediatr 1993;123:208-214

271 Pulmonary artery catheter consensus conference participants. Pulmonary artery catheter consensus conference: consensus statement. Crit Care Med 1997;6:910-925

272 Bland RD, Shoemaker WC. Probability of survival as a prognostic and severity of illness score in critically ill patients. Crit Care Med 1985;13:91-96

273 Bland RD, Shoemaker WC, Abraham E, Cobo JC. Hemodynamic and oxygen transport patterns in surviving and non-surviving patients. Crit Care Med 1985;13:85-92

274 Shoemaker WC. Hemodynamic and oxygen transport patterns in shock: Pathophysiology, monitoring,outcome prediction and therapy. In: Edwards JD, Shoemaker WC, Vincent JL. (Eds) Oxygen Transport; principles and practice. London, Saunders, 1993, pp 70-98

275 Prielipp RC, MacGregor DA, Butterworth JF, Meredith JW, Levy JH, Wood KE, Coursin DB. Pharmacodynamics and pharmacokinetics of Milrinone administration to increase oxygen delivery in critically ill patients. Chest 1996;109:1291-1301

Shoemaker WC. Appel PL, Kram HB, Waxman K, Lee TS. Prospective trial of supranormal values of survivors as therapeutic goals in high-risk surgical patients. Chest 1988;94:1176-1186 
Boyd O, Grounds M, Bennet D. A randomized clinical trial of the effect of deliberate perioperative increase of oxygen delivery on mortality in high-risk surgical patients. JAMA 1993;270:2699-2707

Bishop MH, Schoemaker WC, Appel PL, Meade P, Ordog GJ, Wasserberger J, Wo CJ, Rile DA, Kram HB, Umali R, Kennedy F, Shuleshko J, Stephen CM, Shori SK, Thadepalli HD. Prospective, randomized trial of survivor values of cardiac index, oxygen delivery, and oxygen consumption as resuscitation endpoints in severe trauma. J Trauma 1995; 38:780-787

279 Schoemaker WC, Belzberg H. Maximizing oxygen delivery in high-risk surgical patients. Crit Care Med 1997;25:714-715

280 Tuchschmidt J, Fried J, Astiz M, Rackow E. Elevation of cardiac output and oxygen delivery improves outcome in septic shock. Chest 1992;102:216-220

281 Yu M, Levy MM, Smith P, Tagikuchi SA, Miyasaki A, Hasaniya N, Myers SA. Effect of maximizing oxygen delivery on morbidity and mortality rates in critically ill patients: A prospective randomized trial. Crit Care Med 1993;21:830-838

Hayes MA, Timmins AC, Yau EHS, Palazzo M, Hinds CJ, Watson D. Elevation of systemic oxygen delivery in the treatment of critically ill patients. N Engl J Med 1994;330:1717-1722

Hayes MA, Timmins AC, Yau EHS, Palazzo M, Watson D, Hinds CJ. Oxygen transport patterns in patients with sepsis syndrome or septic shock: influence of treatment and relationship to outcome. Crit Care Med 1997;25:926-936

Gattinoni L, Brazzi L, Pelosi P, Latini R, Tognoni G, Pesenti A, Fumagalli R, for the SvO, collaborative group. A trial of goal-oriented hemodynamic therapy in critically ill patients. N Engl J Med 1995;335:1025-1032

285 Kremzar B, Spec-Marn A, Kompan L, Cerovic O. Normal values of $\mathrm{SvO}_{2}$ as therapeutic goal in patients with multiple injuries. Intensive Care Med 1997;23:65-70

Yu M, Takanishi D, Myers SA, Tagikuchi SA, Severino R, Hasaniya N, Levy MM, McNamara J. Frequency of mortality and myocardial infarction during maximizing oxygen delivery: A prospective randomized trial. Crit Care Med 1995;23:1025-1032

Third european consensus conference in intensive care medicine. Tissue hypoxia: How to detect, how to correct, how to prevent. Am J Respir Crit Care Med 1996; 154:1573-1578

Heyland DK, Cook DJ, King D. Maximizing oxygen delivery in critically ill patients: A methodologic appraisal of excellence. Crit Care Med 1996;24:317-324 


\section{Chapter 3}

\section{Mixed Venous Oxygen Saturation $\left(\mathrm{SvO}_{2}\right)$ and biochemical parameters of hypoxia during progressive hypoxemia in 10-14 day old piglets.}

Mark A.H.B.M. van der Hoeven, Wiel J. Maertzdorf, Carlos E. Blanco.

Pediatric Research 1997;42:878-884 


\section{Abstract}

In this study we wanted to assess the relationship between mixed venous oxygen saturation $\left(\mathrm{SvO}_{2}\right)$ and tissue oxygenation. For that, we compared the values of $\mathrm{SvO}_{2}$ with oxygen delivery $\left(\mathrm{DO}_{2}\right)$, oxygen consumption $\left(\mathrm{VO}_{2}\right)$ and markers of tissue hypoxia as lactate and pyruvate during progressive hypoxemia. Eight $10-14$ days old piglets were anesthetized, tracheotomized, intubated and ventilated. A fiberoptic catheter was placed in the carotid artery to monitor arterial oxygen saturation $\left(\mathrm{SaO}_{2}\right)$. A thoracotomy was performed and a fiberoptic catheter was placed in the pulmonary artery to monitor $\mathrm{SvO}_{2}$. A transit time ultrasound flow probe was positioned around the ascending aorta to measure aorta flow. Progressive graded hypoxemia was induced by decreasing fractional inspiratory oxygen concentration $\left(\mathrm{FiO}_{2}\right)$ from 1.0 to $0.30,0.21,0.15$ and 0.10 . After each $\mathrm{FiO}_{2}$ interval blood samples were taken for blood gases, lactate and pyruvate. $\mathrm{DO}_{2}$ and $\mathrm{VO}_{2}$ were calculated. $\mathrm{SvO}_{2}$ decreased similarly to $\mathrm{SaO}_{2}$. A value of $\mathrm{SvO}_{2}$ of more than $40 \%$ excluded oxygen restricted metabolism. When $\mathrm{DO}_{2}$ decreased below a critical range $(8,4-12,8 \mathrm{ml} / \mathrm{kg} \cdot \mathrm{min})$, $\mathrm{SvO}_{2}$ decreased below $15 \%$, and lactate and lactate/pyruvate ratio increased. We conclude, a) that baseline $\mathrm{SvO}_{2}$ values excluded oxygen restricted metabolism, b) that $\mathrm{SvO}_{2}$ values between $15 \%$ and $40 \%$ were not a marker for oxygen restricted metabolism and c) that $\mathrm{SvO}_{2}$ values below $15 \%$ were associated with oxygen restricted metabolism. Reduced $\mathrm{SvO}_{2}$ values must be interpreted as a change of the factors, that determine the balance between $\mathrm{DO}_{2}$ and $\mathrm{VO}_{2}$ and as a warning that, with further reduction of $\mathrm{SvO}_{2}$, oxygen restricted metabolism can develop. 


\section{Introduction}

Mixed venous oxygen saturation $\left(\mathrm{SvO}_{2}\right)$ reflects the residual oxygen after tissue oxygen extraction and represents the combined sufficiency of arterial oxygen content $\left(\mathrm{caO}_{2}\right)$, cardiac output $(\mathrm{Qt})$ and tissue oxygen consumption $\left(\mathrm{VO}_{2}\right)^{[1]}$. In adult intensive care $\mathrm{SvO}_{2}$ has been used to monitor cardiac output. In neonatal medicine $\mathrm{SvO}_{2}$ monitoring is used during extracorporeal support to monitor the sufficiency of oxygen delivery $\left(\mathrm{DO}_{2}\right)^{(2)}$. Continuous $\mathrm{SvO}_{2}$ measurement was proposed in neonatal intensive care to monitor the oxygen sufficiency at the tissue level, but it is only used occasionally ${ }^{[1,3]}$.

We have determined the feasibility and the accuracy of a fiberoptic catheter system in the newborn, providing a continuous central $\mathrm{SvO}_{2}$ measurement in the right atrium ${ }^{[4]}$. We have also described $\mathrm{SvO}_{2}$, values in 1-7 days old preterm infants breathing room air ${ }^{[5]}$. However, critical values of $\mathrm{SvO}_{2}$ below which oxygen sufficiency at the tissue level is threatened, have not been properly evaluated in the newborn period.

It is known, that, when $\mathrm{DO}_{2}$ at the tissue level is insufficient, oxygen restricted metabolism will develop and the concentration of biochemical markers of tissue hypoxia such as lactate and pyruvate will appear in increased concentrations in the blood $[6,7]$,

In this study we attempted to assess the relation between $\mathrm{SvO}_{2}$ and tissue oxygen sufficiency. Hence, we examined the values of $\mathrm{SvO}_{2}$ in comparison with $\mathrm{DO}_{2}, \mathrm{VO}_{2}$ and biochemical markers of tissue hypoxia in order to determine a normal and safe range of $\mathrm{SvO}_{2}$ and to determine a critical value of $\mathrm{SvO}_{2}$ below which oxygen restricted metabolism will develop.

\section{Materials and methods:}

This study was approved by the animal care committee of the University of Maastricht.

\section{Animal preparation}

Eight piglets between 10 and 14 days of age were anesthetized using halothane for induction, tracheotomized, intubated and ventilated with room air. Anesthesia was maintained by continuous intravenous infusion of pentobarbital sodium and pancuronium in glucose $10 \%$ as required. A 4 Fr. fiberoptic catheter (Abbott Lab, Chicago Ill. USA) was placed in the right carotid artery for continuous monitoring of arterial oxygen saturation $\left(\mathrm{SaO}_{2}\right)$, for blood sampling and for monitoring arterial blood pressure. A $5 \mathrm{Fr}$. catheter was placed in the jugular or femoral vein for fluid administration. A thoracotomy was performed and the ductus arteriosus was ligated. A transit time ultrasound blood volume flow probe (Transonic System Inc, Ithaca, NY, USA) was positioned around the ascending aorta to monitor continuously aorta blood flow. The pulmonary artery was catheterized with a 4 Fr. fiberoptic catheter (Abbott Lab, Chicago Ill. USA) for monitoring $\mathrm{SvO}_{2}$ continuously and for blood sampling. A rectal probe was placed to monitor core body temperature.

\section{Protocol}

The piglets were ventilated to maintain $\mathrm{P}_{2} \mathrm{CO}_{2}$ at $5.0 \pm 1.0 \mathrm{kPa}$. with a pressure limited, time cycled ventilator (Bourns BP-200, Medical Systems, Inc. Ca. USA). Inspiratory gas was warmed and humidified. We induced progressive graded hypoxemia by changing the proportion of oxygen/nitrogen in the inspiratory gas resulting in a fractional inspiratory oxygen concentration $\left(\mathrm{FiO}_{2}\right)$ of $1.0,0.30,0.21,0.15$, and 0.10 . Every fixed $\mathrm{FiO}_{2}$ was kept for an interval of 15 minutes. When blood pressure dropped or bradycardia occurred at the lowest $\mathrm{FiO}_{2}$, the interval was shortened or discontinued. At the end of each interval blood samples were taken simultaneously from the carotid artery for blood gases, 
hemoglobin, lactate, pyruvate and from the pulmonary artery for blood gases and hemoglobin. The study included two series of the different $\mathrm{FiO}_{2}$ intervals with a one hour period in between for recovery. We have repeated the series of graded hypoxia, because all animals except one regained a stable condition after the first series of the $\mathrm{FiO}_{2}$ intervals and because more data could be obtained per animal. A blood transfusion was given for accidental blood loss during the operative procedure or when hemoglobin level decreased due to blood sampling during the experiment to maintain a baseline hemoglobin level of $5.0 \pm 1.0 \mathrm{mmol} / \mathrm{L}$.

\section{Measurements}

The fiberoptic catheter system (Oximetrix System, Abbott Laboratories, North Chicago Ill. U.S.A.) includes a fiberoptic catheter and a microprocessor based oximeter. The light back scattered from the oxygenated and deoxygenated blood is transmitted by the receiving fiberoptic bundle to a photodetector. The oximeter computes percentage of oxygen saturation values based on the electrical signals from the photodetector.

$\mathrm{SaO}_{2}, \mathrm{SvO}_{2}$, arterial blood pressure, blood flow in the aorta, heart rate and core body temperature were sampled every 10 seconds, displayed and stored by a software system (Hemodynamic Data Acquiring System (HDAS) developed at the Service Center, University of Maastricht). Blood samples for blood gases were analyzed on an ABL 3 acid base analyzer (Radiometer, Copenhagen, Denmark) corrected to the animal core body temperature. $\mathrm{SaO}_{2}$, arterial hemoglobin $(\mathrm{Hb})(\mathrm{mmol} / \mathrm{l})$ and $\mathrm{SvO}_{2}$ were analyzed on the OSM2 (Radiometer, Copenhagen, Denmark). Lactate and pyruvate were analyzed in arterial blood samples taken simultaneously with the samples $\mathrm{f}$ or acid base analysis. $1 \mathrm{ml}$ Arterial blood was pipetted into a tube containing $1 \mathrm{ml} 1.2 \mathrm{M}$ perchloric acid to obtain proteinfree solution. The enzyme lactate dehydrogenase (LDH) added to this solution, catalyses the conversion of pyruvic acid in the presence of NADH to lactic acid and catalyses the conversion from lactic acid to pyruvic acid in the presence of NAD. The reduced or increased absorbance at $340 \mathrm{~nm}$ becomes a measure of the amount of pyruvic acid and of lactic acid, respectively ${ }^{[8]}$.

\section{Calculations}

- Arterial oxygen content $\left(\mathrm{caO}_{2}\right)$ and venous oxygen content $\left(\mathrm{crO}_{2}\right)$ were calculated using the equations:

$\mathrm{caO}_{2}(\mathrm{ml} / \mathrm{dl})=\left(1.36 \times \mathrm{SaO}_{2} \times \mathrm{Hb}(\mathrm{mmol} / \mathrm{l}) \times 1.611\right)+\left(0.0031 \times \mathrm{paO}_{2}(\mathrm{kPa}) \times 7.5\right)$ and $\mathrm{cvO}_{2}(\mathrm{ml} / \mathrm{dl})-\left(1.36 \times \mathrm{SvO}_{2} \times \mathrm{Hb}(\mathrm{mmol} / \mathrm{l}) \times 1.611+\left(0.0031 \times \mathrm{pvO}_{2}(\mathrm{kPa}) \times 7.5\right)\right.$, respectively.

- Cardiac output $(\mathrm{Qt})$ was determined by the mean value of the bloodflow in the aorta during the last five minutes of each $\mathrm{FiO}_{2}$ interval measured by the flowsensor.

$-\mathrm{DO}_{2}$ was calculated from its definition: $\mathrm{DO}_{2}(\mathrm{ml} / \mathrm{kg} \cdot \mathrm{min})=\mathrm{caO}_{2}(\mathrm{ml} / \mathrm{dl}) \times \mathrm{Qt}(\mathrm{ml} / \mathrm{kg} \cdot \mathrm{min}) / 100$.

$-\mathrm{VO}_{2}$ was calculated using the Fick equation:

$\mathrm{VO}_{2}(\mathrm{ml} / \mathrm{kg} \cdot \mathrm{min})-\mathrm{Qt} / 100 \times \mathrm{caO}_{2}-\mathrm{cvO}_{2}$.

- Fractional oxygen extraction (F.O.E.) was calculated as the $\mathrm{VO}_{2}$ divided by $\mathrm{DO}_{2}$.

- $\mathrm{P}_{50}$ was calculated from venous blood gas samples using $\mathrm{SvO}_{2}$ and $\mathrm{pvO}_{2}$ as has been described in the literature ${ }^{[9]}, \mathrm{O}_{2}$ debt was calculated by multiplying the difference between the mean baseline $\mathrm{VO}_{2}$ at $\mathrm{FiO}_{2}-1.0$ and the estimated $\mathrm{VO}_{2}$ in the $\mathrm{FiO}_{2}$ interval by the duration of that same $\mathrm{FiO}_{2}$ interval.

- Cumulative $\mathrm{O}_{2}$ debt was calculated by summing up the $\mathrm{O}_{2}$ debt of each interval.

- The change of $\mathrm{pHa}, \mathrm{P}_{2} \mathrm{CO}_{2} \mathrm{paO}_{2}, \mathrm{pvO}_{2}, \mathrm{p}_{\mathrm{so}}$, Hemoglobin $(\mathrm{Hb})$, temperature, heart rate, Qt, lactate, pyruvate, lactate/pyruvate ratio, $\mathrm{VO}_{2} \mathrm{c}(\mathrm{a}-\mathrm{v}) \mathrm{O}_{2}$, and F.O.E. was calculated in comparison with the mean baseline value of these items at $\mathrm{FiO}_{2}=1.0$ in each series of $\mathrm{FiO}_{2}$ intervals in each individual animal. Absolute values were used for $\mathrm{SaO}_{2}, \mathrm{SvO}_{2}$ 
and $\mathrm{DO}_{2}$.

\section{Data analysis}

Mean, standard deviation, median value and percentile were calculated by descriptive statistical methods. Data are presented as mean $\pm \mathrm{SD}$. Data at the different $\mathrm{FiO}_{2}$ intervals are presented as absolute values and as a mean change in comparison with the mean baseline values at $\mathrm{FiO}_{2}-1.0$ in each individual animal. To test whether a difference existed between the two series of induced hypoxemia, a Mann-Whitney $U$ test was performed for each $\mathrm{FiO}_{2}$ interval. Baseline data were compared with the data at the different low $\mathrm{FiO}_{2}$ intervals using oneway analysis of variance and contrasted according to Tukey $\mathrm{B}$ method.

To determine the critical value of $\mathrm{DO}_{2}$, that is the $\mathrm{DO}_{2}$ below which the change in lactate concentration increased rapidly, we adapted a technique from Mellits ${ }^{[10,11]}$ to find the section point of two lines of regression. This included constructing the best pair of regression lines that included all points only once. The best pair of regression lines was defined as to minimize the total of the residual sum of squares of each line in the pair. Their intersection point was determined by solving the equations of the pair of regression lines. The $x$-coordinate of the intersection point is the critical $\mathrm{DO}_{2}{ }^{[11]}$. This technique was also applied to change in lactate/pyruvate ratio and change in $\mathrm{VO}_{2}$ versus $\mathrm{DO}_{2}$.

To test whether a value of $\mathrm{SvO}_{2}$ was predictive for a change in lactate, a change in lactate/pyruvate ratio and a change in $\mathrm{VO}_{2}$, a 2 × 2 contingency table was derived for each item and sensitivity, specificity and positive predictive accuracy were calculated. Tests were considered to be significant when $\mathrm{p} \leq 0.05$.

\section{Results:}

Eight piglets were studied with a mean weight of $4.08 \pm 0.8 \mathrm{~kg}$ and at a mean age of $11 \pm 2$ days. In seven piglets a complete protocol of 2 series of experiments could be performed. No significant differences were found between the results of corresponding $\mathrm{FiO}_{2}$ intervals in the two consecutive series of induced hypoxemia. Measured and calculated data during the five $\mathrm{FiO}_{2}$ intervals are shown in table 1. Baseline values regarding cardiac output $(\mathrm{Qt})$, calculated $\mathrm{VO}_{2}$, hemoglobin, $\mathrm{caO}_{2}$, and $\mathrm{p}_{50}$ were consistent with values in 10-14 day old piglets, described by others ${ }^{[12,13]}$.

Hemodynamic responses during the different intervals consisted of an increased heart rate in the last two $\mathrm{FiO}_{2}$ intervals and a decreased bloodpressure at the last interval, whereas cardiac output remained unaltered (table 1).

Progressive graded hypoxemia induced a decrease in $\mathrm{SaO}_{2}$ and $\mathrm{paO}_{2}$ from $98.0 \%$ to $24.7 \%$ and from and $51,4 \mathrm{kPa}$ to $2.7 \mathrm{kPa}$, respectively. $\mathrm{SvO}_{2}$ decreased similarly to the decreasing $\mathrm{SaO}_{2}$ (figure 1). Therefore in all but the lowest $\mathrm{FiO}_{2}$ interval the difference between arterial and venous oxygen content $\left(\mathrm{c}(\mathrm{a}-\mathrm{v}) \mathrm{O}_{2}\right)$ remained unaltered and a constant $\mathrm{VO}_{2}$ was preserved (table 1). In the lowest $\mathrm{FiO}_{2}$ interval $\mathrm{DO}_{2}$ decreased further, and $\mathrm{VO}_{2}$ decreased significantly (table 1, figure 1).

Lactate and pyruvate during baseline showed a broad dispersion of values reflecting different postoperative status: (accidental blood loss, intubation difficulties etc.). The change in lactate and lactate/pyruvate ratio was significantly in the last $\mathrm{FiO}_{2}$ interval. Pyruvate changed not significant from baseline value (table 1).

The relationships between $\mathrm{DO}_{2}$ and change lactate, change lactate/pyruvate ratio and change $\mathrm{VO}_{2}$ were analyzed in figure 2 according to the technique from Mellits ${ }^{[10]}$. The critical $\mathrm{DO}_{2}$ value was $12.86 \mathrm{ml} / \mathrm{kg} \cdot \mathrm{min}$ for lactate, $8,43 \mathrm{ml} / \mathrm{kg} \cdot \mathrm{min}$ for lactate/pyruvate ratio and $11.82 \mathrm{ml} / \mathrm{kg} \cdot \min$ for $\mathrm{VO}_{2}$. 
table 1. Measured and calculated data during baseline and change from baseline during the different $\mathrm{FiO}_{2}$ intervals.

\begin{tabular}{|c|c|c|c|c|c|c|c|c|c|c|c|c|c|c|c|}
\hline & \multicolumn{3}{|c|}{$\begin{array}{l}\mathrm{FiO}_{2}=1,0 \\
\text { baseline }\end{array}$} & \multicolumn{3}{|c|}{$\begin{array}{l}\mathrm{FiO}_{2}=0,3 \\
\text { change }\end{array}$} & \multicolumn{3}{|c|}{$\begin{array}{l}\mathrm{FiO}_{2}=0,21 \\
\text { change }\end{array}$} & \multicolumn{3}{|c|}{$\begin{array}{l}\mathrm{FiO}_{2}=0,15 \\
\text { change }\end{array}$} & \multicolumn{3}{|c|}{$\begin{array}{l}\mathrm{FiO}_{2}=0,10 \\
\text { change }\end{array}$} \\
\hline $\mathrm{pHa}_{\mathrm{a}}$ & 7,43 & \pm & 0,12 & 0.03 & \pm & 0.06 & 0.05 & \pm & 0.07 & 0.01 & \pm & 0.09 & -0.03 & \pm & 0.11 \\
\hline $\mathrm{paCO}_{2}(\mathrm{kPa})$ & 4,5 & \pm & 1,71 & $-0,45$ & \pm & 0,87 & $-0,49$ & \pm & 0.92 & $-0,49$ & \pm & 0,58 & $-0,56$ & \pm & 1,24 \\
\hline $\mathrm{paO}_{2}(\mathrm{kPa})$ & 51,5 & \pm & 17,34 & $-35,3$ & \pm & $12,3 *$ & $-43,8$ & \pm & $10,9 *$ & $-48,7$ & \pm & $10,1 *$ & $-47,6$ & \pm & $10,6^{*}$ \\
\hline $\mathrm{SaO}_{2}(\%)$ & 98,0 & \pm & 2,1 & $-3,6$ & \pm & 5,3 & $-15,6$ & \pm & $12,8 *$ & $-42,2$ & \pm & $12,7^{*}$ & $-73,3$ & \pm & $10,5 *$ \\
\hline $\mathrm{pvO}_{2}(\mathrm{kPa})$ & 5,58 & \pm & 0,97 & $-1,13$ & \pm & $0,65 *$ & $-2,16$ & \pm & $0,85 *$ & $-3,23$ & \pm & $0,83 *$ & $-4,59$ & \pm & $0,93 *$ \\
\hline $\mathrm{SvO}_{2}(\%)$ & 59,5 & \pm & 9,6 & $-10,5$ & \pm & $7,9 *$ & $-22,9$ & \pm & $13,5^{*}$ & $-40,9$ & \pm & 12,6 * & $-59,4$ & \pm & $8,2 *$ \\
\hline$P_{50}\left(k P_{a}\right)$ & 4,68 & \pm & 0,67 & $-0,24$ & \pm & 0,65 & $-0,49$ & \pm & 0,83 & $-0,37$ & \pm & 1,05 & 0,29 & \pm & 2,68 \\
\hline $\mathrm{Hb} .(\mathrm{mmol} / \mathrm{L})$ & 5,6 & \pm & 1,1 & 0,19 & \pm & 0,38 & 0,15 & \pm & 0,45 & 0,54 & \pm & $0,49 *$ & 1,10 & \pm & $0,73 *$ \\
\hline $\mathrm{Qt}(\mathrm{ml} / \mathrm{kg} \cdot \mathrm{min})$ & 165 & \pm & 49 & -4 & \pm & 17 & -2 & \pm & 21 & $-0,7$ & \pm & 32 & -18 & \pm & 36 \\
\hline Mean $P_{m}\left(m m H_{g}\right)$ & 94,2 & \pm & 14,4 & $-0,7$ & \pm & 8,8 & $-4,4$ & \pm & 9,5 & $-6,5$ & \pm & 10,3 & $-21,4$ & \pm & $15,2 *$ \\
\hline Lactate $(\mathrm{mmol} / \mathrm{l})$ & 2,75 & \pm & 1,97 & 0,27 & \pm & 0,48 & 0,58 & \pm & 1,11 & 1,17 & \pm & 1,78 & 4,18 & \pm & $2,61 *$ \\
\hline Pyruvate $(\mu \mathrm{mol} / \mathrm{l})$ & 189,6 & \pm & 99,2 & 19,0 & \pm & 65,3 & 45,8 & \pm & 95,3 & 29,7 & \pm & 76,6 & 66,6 & \pm & 104,5 \\
\hline lact/pyr. ratio & 13,5 & \pm & 3,4 & 1,1 & \pm & 2,4 & 1,2 & \pm & 3,0 & 4,9 & \pm & 6,3 & 19,2 & \pm & 11,9 * \\
\hline $\mathrm{DO} 2(\mathrm{ml} / \mathrm{kg} \cdot \mathrm{min})$ & 22,3 & \pm & 6,4 & $-2,2$ & \pm & 2,1 & $-5,8$ & \pm & $3,1 *$ & $-9,8$ & \pm & $3,5 *$ & $-18,1$ & \pm & $5,2 *$ \\
\hline $\mathrm{VO} 2$ (ml/kg.min) & 9,3 & \pm & 2,0 & 0,3 & \pm & 1,0 & 0,08 & \pm & 1,9 & $-0,91$ & \pm & 1,4 & $-3,9$ & \pm & $2,6 *$ \\
\hline$c(\mathrm{a}-\mathrm{v}) \mathrm{O}_{2}(\mathrm{ml} / \mathrm{dl})$ & 6,14 & \pm & 2,02 & 0,29 & \pm & 0,85 & $-0,17$ & \pm & 1,66 & $-0,70$ & \pm & 1,46 & $-2,34$ & \pm & $1,67^{*}$ \\
\hline F.O.E. & 0,44 & \pm & 0,09 & 0.05 & \pm & 0,07 & 0,10 & \pm & $0,14 *$ & 0,26 & \pm & $0,13^{*}$ & 0,47 & \pm & $0,11 *$ \\
\hline
\end{tabular}

"*' - significant different from baseline. Note that biochemical markers, $\mathrm{VO}_{2}$ and $\mathrm{c}(\mathrm{a}-\mathrm{v}) \mathrm{O}_{2}(\mathrm{Hb})$ only during the last $\mathrm{FiO}_{2}$ interval increase significantly from baseline. 

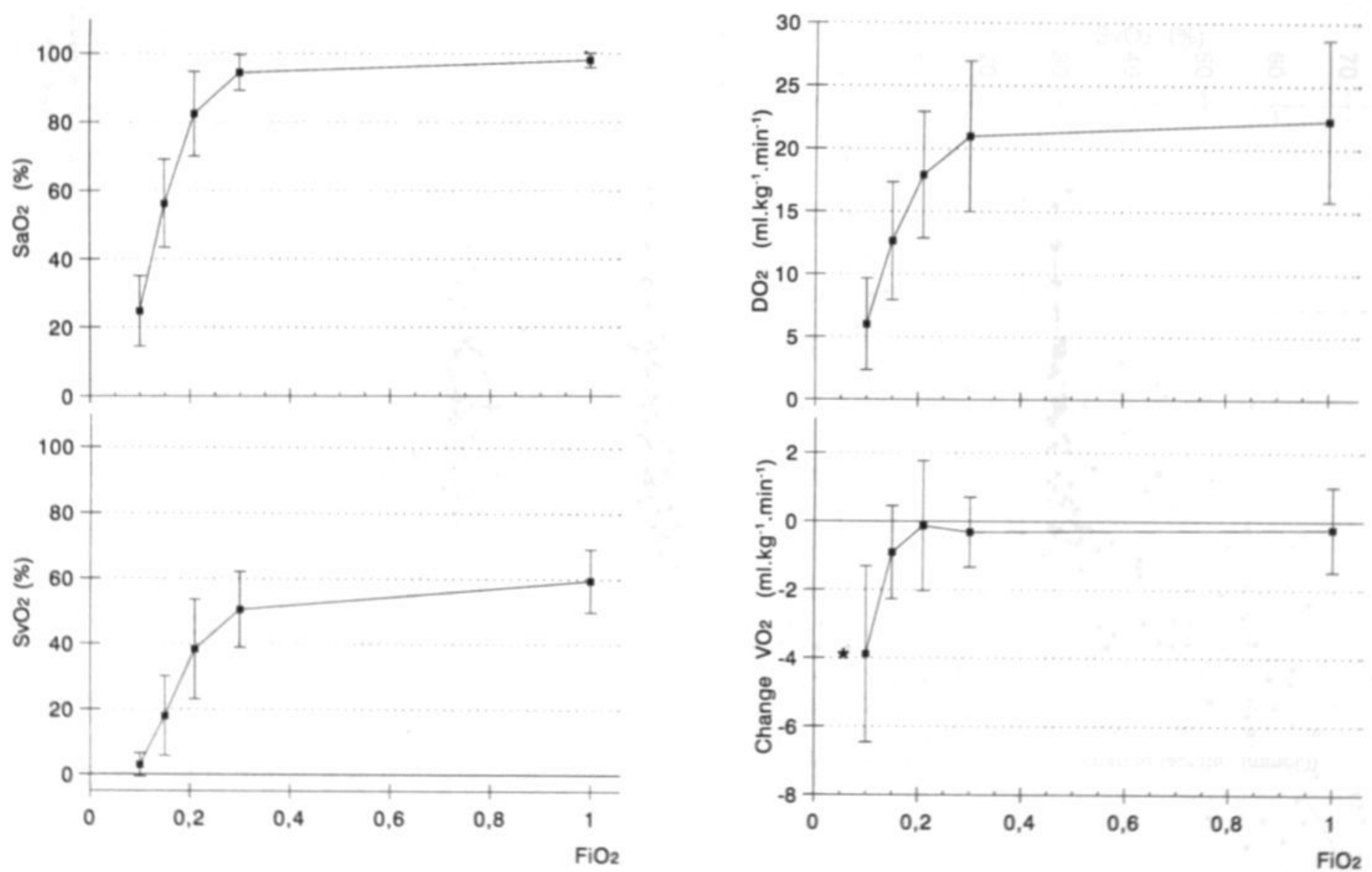

figure 1. $\mathrm{SaO}_{2}, \mathrm{SvO}_{2}, \mathrm{DO}_{2}$ and change $\mathrm{VO}_{2}$ in relation to the different $\mathrm{FiO}_{2}$ intervals. Note that, $\mathrm{SvO}_{2}$ decreased similarly to $\mathrm{SaO}_{2} ; \mathrm{Change}^{\mathrm{VO}}$, was constant in all but the last interval. In the lowest $\mathrm{FiO}_{2}$ interval $\mathrm{DO}_{2}$ further decreased, and change $\mathrm{VO}_{2}$ was significantly reduced ("). Data are presented as mean $\pm \mathrm{SD}$. 

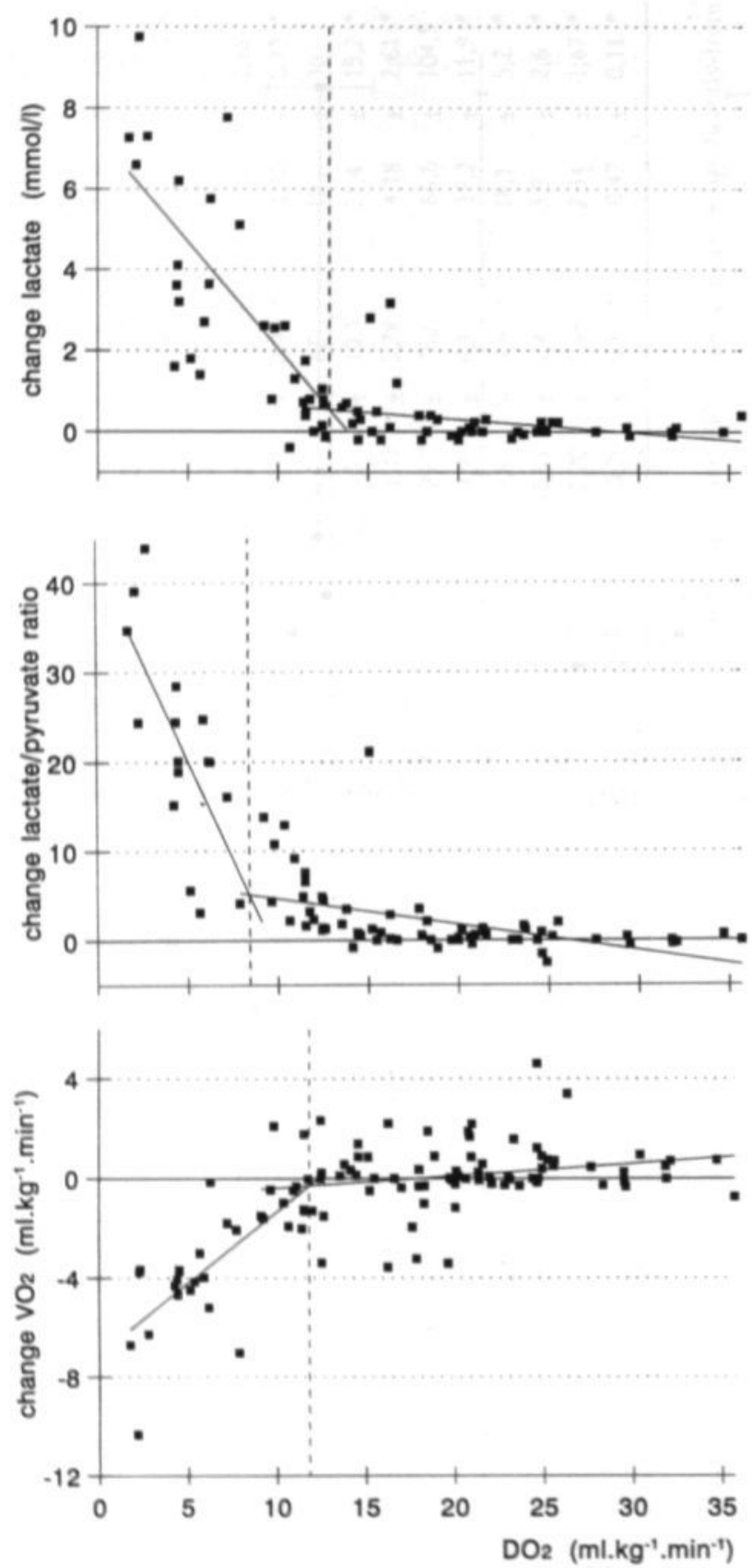

figure 2. Change lactate, change lactate/pyruvate ratio and change $\mathrm{VO}_{2}$ in relation with $\mathrm{DO}_{2}$. A critical $\mathrm{DO}_{2}$ (vertical broken line) could be observed at $12.86,8.46$ and $11.81 \mathrm{ml} . \mathrm{kg}^{-1} \cdot \mathrm{min}^{-1}$, respectively. 


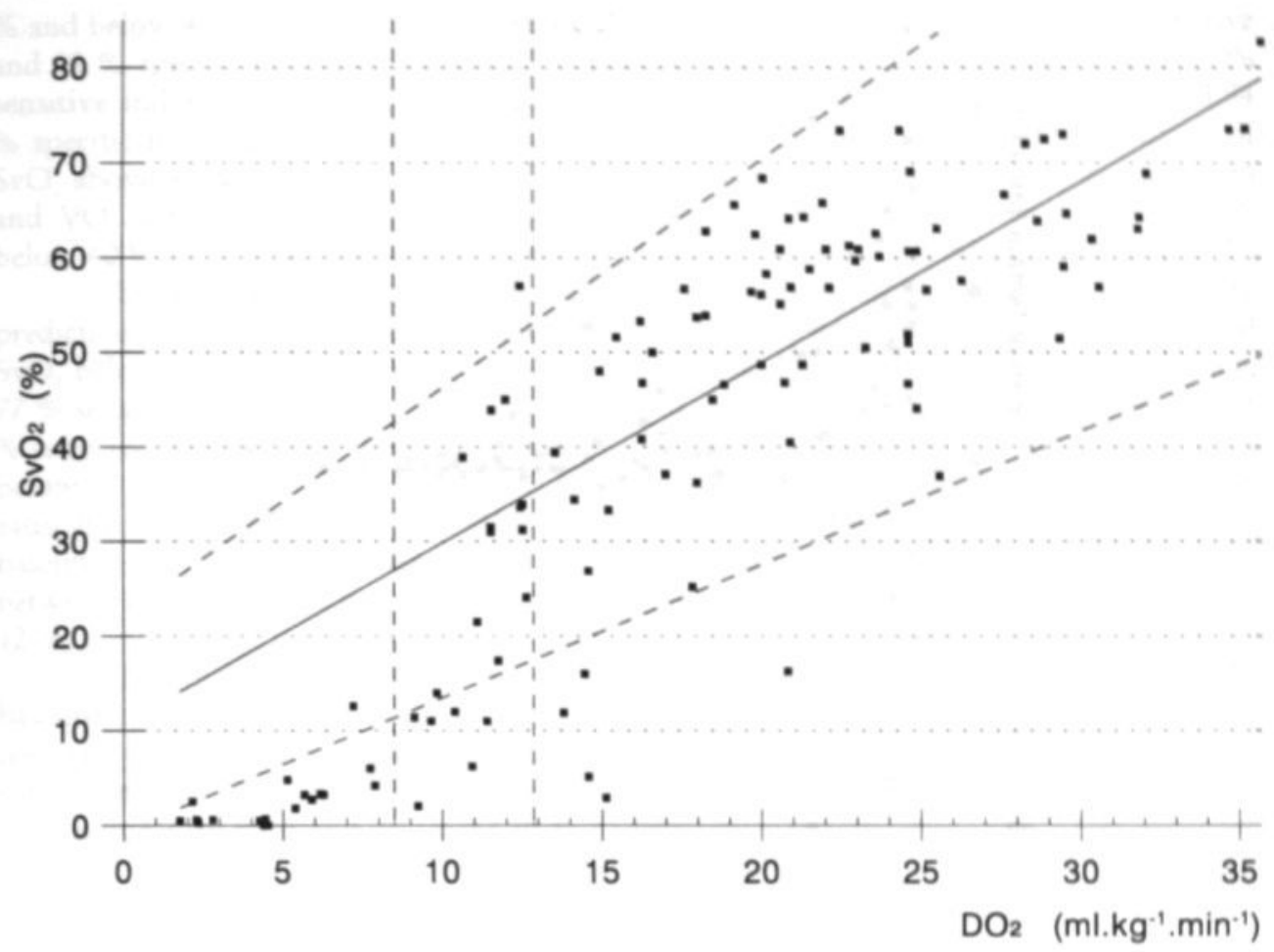

figure 3. $\mathrm{SvO}_{2}$ in relation with $\mathrm{DO}_{2}$. Regression line with confidence intervals is: $2.51 \times \mathrm{DO}_{2}-4.01(\mathrm{r}=$ $0.87 ; p<0.0001$ ). Vertical lines represent critical $\mathrm{DO}_{2}$ calculated for change lactate/pyruvate ratio and change lactate, respectively. Below this critical range of $\mathrm{DO}_{2}(8.43-12.86 \mathrm{ml} / \mathrm{kg} \cdot \mathrm{min}) \mathrm{SvO}_{2}$ values of less than $15 \%$ were observed.

Above the critical $\mathrm{DO}_{2}$, the change of lactate, lactate/pyruvate ratio and $\mathrm{VO}_{2}$ were only slight dependent of $\mathrm{DO}_{2}$. Below the critical $\mathrm{DO}_{2}$ a significant regression coefficient (slope) was obtained.

Linear regression analysis showed a good correlation between $\mathrm{SvO}_{2}$ in relation with $\mathrm{DO}_{2}(\mathrm{r}=0.87 ; p<0.0001)$. When $\mathrm{DO}_{2}$ decreased below the critical range (8.43 and $12.86 \mathrm{ml} / \mathrm{kg} \cdot \mathrm{min}$ ), $\mathrm{SvO}_{2}$ values less than $15 \%$ were observed. (figure 3 ).

In figure 4 the relationship between $\mathrm{SvO}_{2}$ and the change in lactate, the change in lactate/pyruvate ratio and the change in $\mathrm{VO}_{2}$ was examined. We considered a change in lactate of more than $1,03 \mathrm{mmol} / 1$, a change in lactate/pyruvate ratio of more than 2,45 and a change in $\mathrm{VO}_{2}$ of less than $-2,25 \mathrm{ml} / \mathrm{kg} \cdot \min$ as significant, because these values represented the mean change $\pm 2 \mathrm{SD}$ at $\mathrm{FiO}_{2}=1.00$. SvO values of more than $40 \%$ were considered as baseline, as it represented the mean value minus $2 \mathrm{SD}$ in the highest $\mathrm{FiO}_{2}$ interval. $\mathrm{SvO}_{2}$ values of less than $15 \%$ were considered as critical value, as it represented the values encountered below the critical range of $\mathrm{DO}_{2}$. Lactate, lactate/pyruvate ratio and $\mathrm{VO}_{2}$ remained mainly unaltered until $\mathrm{SvO}_{2}$ was less than $15 \%$.

To test whether values of $\mathrm{SvO}_{2}$ above or below $40 \%$ were predictive of a significant change in lactate, in lactate/pyruvate ratio and in $\mathrm{VO}_{2}$, a $2 \mathrm{X} 2$ contingency table was derived for each item; a change in lactate of $\geq 1.03 \mathrm{mmol} / 1$ and of $<1,03 \mathrm{mmol} / 1$, and a change in lactate/pyruvate ratio of $\geq 2,45$ and of $<2,45$ and a change in $\mathrm{VO}_{2}$ of $>$ $-2,25 \mathrm{ml} / \mathrm{kg} \cdot \min$ and $\leq-2,25 \mathrm{ml} / \mathrm{kg}$ min constituted the columns and $\mathrm{SvO}_{2}$ values above 40 

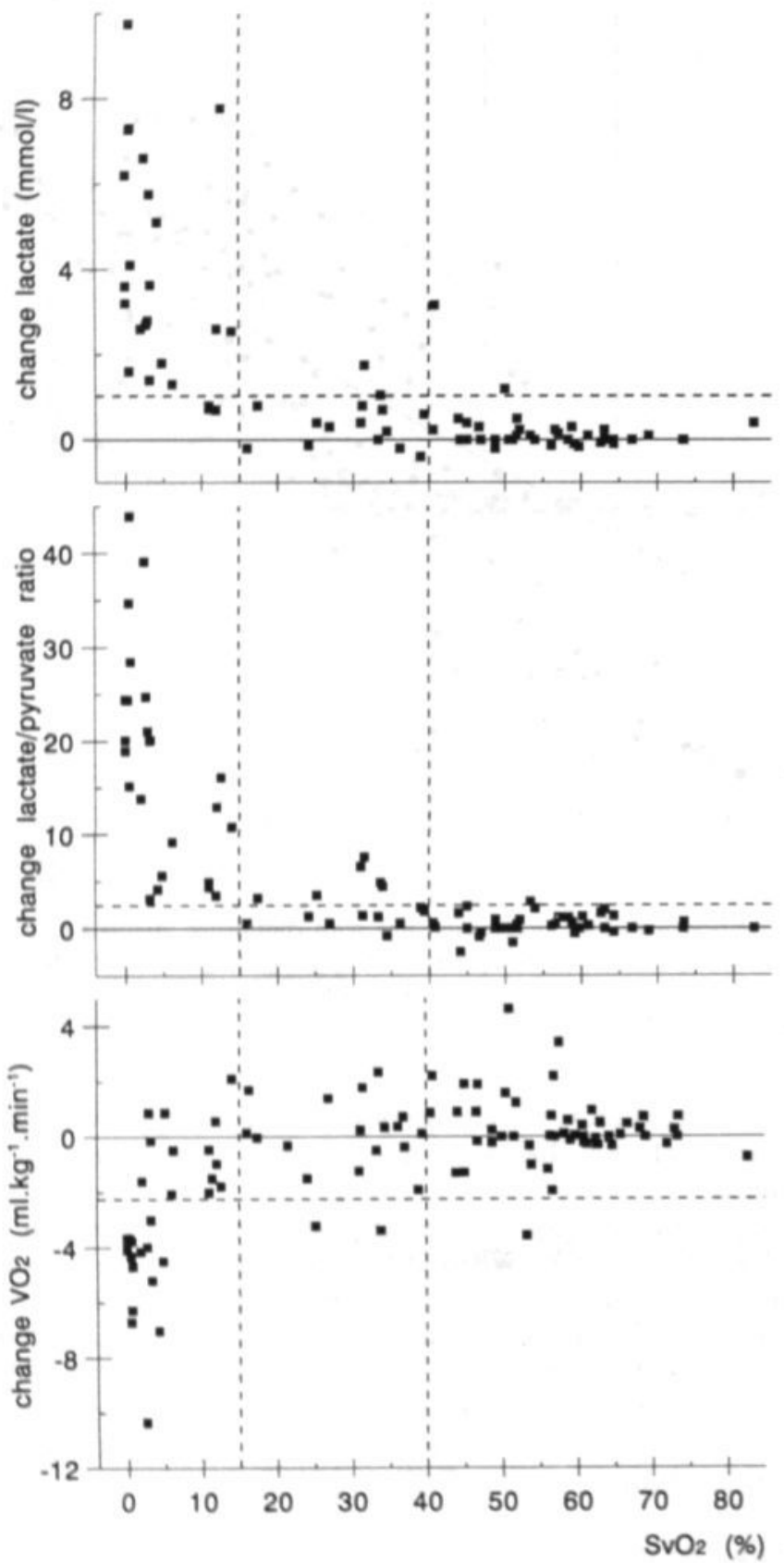

figure 4. Change lactate, change lactate/pyruvate ratio, and change $\mathrm{VO}_{2}$ in relation with $\mathrm{SvO}_{2}$. Vertical broken lines indicate a $\mathrm{SvO}_{2}$ value of $15 \%$ (mean - 2SD at $\mathrm{FiO}_{2}=0.10$ ) and a $\mathrm{SvO}_{2}$ value of $40 \%$ (mean $-2 \mathrm{SD}$ at $\mathrm{FiO}_{2}=1.00$ ). Horizontal broken line indicates change lactate of $1.03 \mathrm{mmol} / \mathrm{l}$ (mean change $+2 \mathrm{SD}$ at $\mathrm{FiO}_{2}=1.0$ ), change lactate/pyruvate ratio of 2.45 (mean change $+2 \mathrm{SD}$ at $\mathrm{FiO}_{2}=1.0$ ) and change $\mathrm{VO}_{2}$ of $-2.25 \mathrm{ml} / \mathrm{kg}$.min (mean change $-2 \mathrm{SD}$ at $\mathrm{FiO}_{2}=1.0$ ). Note, that lactate, lactate/pyruvate ratio and $\mathrm{VO}_{2}$ significantly change, when $\mathrm{SvO}_{2}$ values below $15 \%$ are encountered. 
$\%$ and below $40 \%$ were used for the rows. A value of $\mathrm{SvO}_{2}$ above $40 \%$ was $68 \%$ sensitive and $92 \%$ specific for a change within baseline $\pm 2 \mathrm{SD}$ in lactate concentration and $79 \%$ sensitive and $96 \%$ specific for a change in lactate/pyruvate ratio and $63 \%$ sensitive and 94 $\%$ specific for a change $\mathrm{VO}_{2}$ within baseline $\pm 2 \mathrm{SD}$. The positive predictive accuracy of $\mathrm{SvO}_{2}$ above $40 \%$ was $94 \%, 97 \%$ and $98 \%$ for a change in lactate, lactate/pyruvate ratio and $\mathrm{VO}_{2}$ within baseline $\pm 2 \mathrm{SD}$. However, the positive predictive accuracy of a $\mathrm{SvO}_{2}$ below $40 \%$ for a significant change above baseline \pm 2 SD was only $57 \%, 76 \%$ and $37 \%$.

In the same way we tested whether $\mathrm{SvO}_{2}$ values below or above $15 \%$ were predictive of a significant change in lactate, lactate/pyruvate ratio and $\mathrm{VO}_{2}$. A value of $\mathrm{SvO}_{2}$ below $15 \%$ was $84 \%$ sensitive and $49 \%$ specific for a significant increase in lactate, $77 \%$ sensitive and $100 \%$ specific for a significant increase in lactate/pyruvate ratio and 84 $\%$ sensitive and $96 \%$ specific for a change in $\mathrm{VO}_{2}$. The positive predictive accuracy of $\mathrm{SvO}_{2}$ below $15 \%$ was $87 \%, 100 \%$ and $84 \%$ for a significant change in lactate, lactate/pyruvate ratio and $\mathrm{VO}_{2}$. The positive predictive accuracy of a $\mathrm{SvO}_{2}$ above $15 \%$ for a change within baseline $\pm 2 \mathrm{SD}$ was $92 \%, 86 \%$ and $96 \%$. The positive predictive accuracy of a $\mathrm{SvO}_{2}$ between $15 \%$ and $40 \%$ for a significant change from baseline \pm 2 SD was $13 \%, 60 \%$ and $12 \%$.

In other words $\mathrm{SvO}_{2}$ values above $40 \%$ were very frequently associated with baseline lactate, lactate/pyruvate ratio and baseline $\mathrm{VO}_{2} . \mathrm{SvO}_{2}$ values below $15 \%$ were very frequently associated with increased lactate, lactate/pyruvate ratio and decreased $\mathrm{VO}_{2} . \mathrm{SvO}_{2}$ values between $15 \%$ and $40 \%$ were very occasionally associated with an increased lactate, lactate/pyruvate ratio and decreased $\mathrm{VO}_{2}$.

\section{Discussion}

We assessed the relationship between $\mathrm{SvO}_{2}$ and tissue oxygenation in piglets by inducing graded progressive hypoxemia. The main results of this study were: a) $\mathrm{SvO}_{2}$ values of more than $40 \%$ excluded oxygen restricted metabolism, b) $\mathrm{SvO}_{2}$ values of less than $15 \%$ were associated with oxygen restricted metabolism and c) $\mathrm{SvO}_{2}$ value between $15 \%$ and 40 $\%$ were very frequently associated with normal tissue oxygen metabolism. The aim of this study was neither to determine the value of $\mathrm{SvO}_{2}$ measurement in neonatal intensive care medicine, nor to describe the limits of the range of $\mathrm{SvO}_{2}$ values for direct use in neonatal intensive care. The critical values of $15 \%$ and $40 \%$, found in this study can not be extrapolated to patient care in a neonatal intensive care unit.

This hypoxia model consists of progressive graded hypoxemia by reducing $\mathrm{FiO}_{2}$ in order to reduce $\mathrm{DO}_{2}$. In our study the circulatory adjustments as increased cardiac output to compensate for a decreased $\mathrm{caO}_{2}$ were variable, as it is known from the literature ${ }^{[14]}$. Microcirculatory adjustments were not measured in this study, but may affect the actual oxygen flow from the capillary bed to the cells and may consequently affect the $\mathrm{SvO}_{2}$ value. As other types of hypoxia (anemic hypoxia, circulatory failure hypoxia), could have other patterns of circulatory adjustments and compensations, one must be cautious to extrapolate the findings from this hypoxia model to other types of hypoxia.

The series of graded hypoxemia were started with hyperoxia in the $\mathrm{FiO}_{2}-1.0$ interval with a wide variation in baseline conditions, probably due to animal preparation. This is also illustrated by the fact, that in the third $\mathrm{FiO}_{2}=0.21$ interval a mean $\mathrm{SaO}_{2}$ value of $82 \%$ was present. However, these variations in baseline conditions did not affect the changes induced by the different $\mathrm{FiO}_{2}$ intervals: $\mathrm{SaO}_{2}$, the main factor of $\mathrm{caO}_{2}$, decreased significantly in the $\mathrm{FiO}_{2}$ intervals, resulting in a significant reduction of $\mathrm{DO}_{2}$. $\mathrm{SvO}_{2}$ decreased similarly with $\mathrm{SaO}_{2}$, which maintained a stable difference between arterial and 
venous oxygen content $\left(\mathrm{c}(\mathrm{a}-\mathrm{v}) \mathrm{O}_{2}\right)$ and preserved a constant $\mathrm{VO}_{2}$ in all but the last $\mathrm{FiO}_{2}$ interval (Figure 1). When $\mathrm{FiO}_{2}$ further decreased, $\mathrm{c}(\mathrm{a}-\mathrm{v}) \mathrm{O}_{2}$ decreased and $\mathrm{VO}_{2}$ was reduced with the development of oxygen restricted metabolism and lactic acidosis. The initial reduction of $\mathrm{SvO}_{2}$ was not accompanied by a reduction of $\mathrm{VO}_{2}$ or an increased concentration of lactate. Only with a severe reduction of $\mathrm{SvO}_{2}$ below $15 \%$, regardless of the basal condition of the animal, lactate increased and $\mathrm{VO}_{2}$ decreased.

In our study $\mathrm{SvO}_{2}$ values above $15 \%$ were found with only slight changes in lactate concentration, in lactate/pyruvate ratio and in $\mathrm{VO}_{2}$. In adult intensive care medicine tolerance of unusually low $\mathrm{SvO}_{2}$ values have been described ${ }^{[15]}$. Therefore, the reduction of $\mathrm{SvO}_{2}$ perse is not an indication of oxygen restricted metabolism and lactic acidosis. However, in some instances in our study $\mathrm{SvO}_{2}$ values above $15 \%$ were associated with oxygen restricted metabolism and lactic acidosis. Since $\mathrm{SvO}_{2}$ reflects only the global tissue oxygen extraction, moderately reduced $\mathrm{SvO}_{2}$ values with a normal c(a-v) $\mathrm{O}_{2}$ cannot exclude a reduced $\mathrm{VO}_{2}$ in individual organs, primarily in organs with a high oxygen extraction, like the myocardium and the brain ${ }^{[16,17]}$. In accordance with this we found that the critical $\mathrm{DO}_{2}$ calculated for change in lactate concentration was higher than the critical $\mathrm{DO}_{2}$ calculated for change in $\mathrm{VO}_{2}$. This supports the hypothesis, that oxygen restricted metabolism in individual organs could initiate before a low $\mathrm{SvO}_{2}$ value is observed and global $\mathrm{VO}_{2}$ is reduced.

In adult intensive care medicine the relation between $\mathrm{SvO}_{2}$ and lactic acidosis was studied in relation to prognosis and mortality. Astiz et al. failed to identify a threshold value for $\mathrm{SvO}_{2}$ below which lactate increased. Lactic acidosis developed over a wide range of both $\mathrm{DO}_{2}$ and $\mathrm{SvO}_{2}{ }^{[18]}$. In a retrospective analysis of critical ill patients Rashkin et al. showed that mixed venous oxygen tension was not a reliable indicator of blood lactate ${ }^{[19]}$. Thus, a low $\mathrm{SvO}_{2}$ value can be associated with both a normal tissue oxygen metabolism and an oxygen restricted tissue metabolism. In our study only $\mathrm{SvO}_{2}$ values below $15 \%$ were very frequently associated with oxygen restricted metabolism. However, these findings do not imply, that $\mathrm{SvO}_{2}$ is not useful in the estimation of tissue oxygenation. We found that $\mathrm{SvO}_{2}$ values of more than $40 \%$ (mean - 2SD at $\mathrm{FiO}_{2}-1.0$ ) were not associated with oxygen restricted metabolism. Therefore, this range of $\mathrm{SvO}_{2}$ values can be interpreted as an indication of normal tissue oxygenation i.e. a normal balance between tissue $\mathrm{DO}_{2}$ and $\mathrm{VO}_{2}$. However, even normal and high $\mathrm{SvO}_{2}$ values have been associated with lactic acidosis in diseases with disturbances of the microcirculation with precapillary shunting and inability of the tissues to extract enough oxygen, like sepsis and ARDS ${ }^{[15,20]}$. This was not the case in our study.

Not only the reduction of $\mathrm{DO}_{2}$ and $\mathrm{VO}_{2}$, but also the duration and cumulation of the effects of the different $\mathrm{FiO}_{2}$ intervals must be considered. The cumulation of the oxygen debt in the last three $\mathrm{FiO}_{2}$ intervals can be a reason for the increased lactate concentration in the last $\mathrm{FiO}_{2}$ interval. Cumulative $\mathrm{O}_{2}$ debt was calculated and the correlation between cumulative $\mathrm{O}_{2}$ debt and lactate and lactate / pyruvate ratio analyzed to control for the cumulative effect of different $\mathrm{FiO}_{2}$ intervals. Cumulative $\mathrm{O}_{2}$ debt was linearly related to the change in lactate and in lactate/pyruvate ratio, but the correlation coefficient $(r-0.53 ; r-0.70)$ was not different from the correlation coefficient between the change in $\mathrm{VO}_{2}$ and the change in lactate and in lactate/pyruvate ratio $(\mathrm{r}=0.53 ; \mathrm{r}=$ 0.53 ). The linear correlation analysis between the change in $\mathrm{VO}_{2}$ and cumulative $\mathrm{O}_{2}$ debt yielded a good correlation $(r-0.69, p<0.001)$. Cumulative $\mathrm{O}_{2}$ debt was in this hypoxic piglet model not a better parameter of oxygen restricted metabolism than change in $\mathrm{VO}_{2}$. Additionally no differences were found in changes in lactate concentration and in lactate/pyruvate ratio between the two series of $\mathrm{FiO}_{2}$ intervals. 
In this study $\mathrm{VO}_{2}$ was calculated according to Fick's principle and it was dependent on the precision of $\mathrm{caO}_{2}, \mathrm{cvO}_{2}$ and of cardiac output measurements. The $\mathrm{SvO}_{2}$ values are reliable, because after closure of the ductus arteriosus during the procedure, bloodsamples and fiberoptic catheter readings reflect truly oxygen saturation values of the mixed venous blood. Whereas oxygen saturation measurements and oxygen content are reliable, the different methods of measurement of cardiac output have many error sources ${ }^{[21]}$. The value of calculated $\mathrm{VO}_{2}$ has been questioned ${ }^{[2]}$. In particular when calculated $\mathrm{DO}_{2}$ and calculated $\mathrm{VO}_{2}$ are compared as independent and dependent variables and a pathologic dependence of $\mathrm{VO}_{2}$ on $\mathrm{DO}_{2}$ was demonstrated, erroneous mathematical coupling of shared variables was suggested ${ }^{[23]}$. In our study cardiac output was measured directly by a $7-\mathrm{mm}$ transit-time ultrasonic flow transducer positioned around the aorta. The transducer was precalibrated in vitro. This transit-time ultrasonic technique is described as more precise and as easier to apply than formerly used techniques [24]. The transit-time flow measurements were used as a "gold standard" and confirmed to be accurate compared with a radionuclide-labeled microsphere technique ${ }^{[25]}$. Therefore, we considered the calculated $\mathrm{DO}_{2}$ and $\mathrm{VO}_{2}$, derived from the mentioned data, both reliable and accurate.

The biochemical markers as lactate and pyruvate were used as the indicator for oxygen restricted metabolism. The use of lactate as an index for tissue oxygen sufficiency has several limitations. Lactic acidosis originates only, when lactate production exceeds hepatic, renal and muscle lactate uptake $[7]$. Thus, lactate value is among others dependent on the capacity of liver and kidney to extract and utilize lactate ${ }^{[6]}$. Lactate / pyruvate ratio was measured to estimate the ratio between the reduced and oxidized molecules in the cytosol: this intracellular redox state is dependent upon oxidative function in the mitochondrion ${ }^{[26]}$ and consequently upon an adequate $\mathrm{O}_{2}$ supply to the mitochondrion ${ }^{[2]}$. In contrast, an increase of lactate and pyruvate without a change in lactate / pyruvate ratio could be a result of inactivation or downregulation of the pyruvate dehydrogenase complex, which controls the entry of two carbon fragments from pyruvate into the citric acid cycle ${ }^{[28]}$. It was suggested that the measurement of lactate / pyruvate ratio would discriminate between hypoxic and non-hypoxic induced changes of lactate ${ }^{[2 \pi]}$.

We conclude that in this hypoxia model, a) $\mathrm{SvO}_{2}$ values above $40 \%$ excluded oxygen restricted metabolism, b) that $\mathrm{SvO}_{2}$ values between $15 \%$ and $40 \%$ in general were not associated with oxygen restricted metabolism or lactic acidosis and c) that values of $\mathrm{SvO}_{2}$ below $15 \%$ were associated with oxygen restricted metabolism. When $\mathrm{SvO}_{2}$ is used in patient care, reduction of $\mathrm{SvO}_{2}$ must be interpreted as a reduction of the residual oxygen after tissue oxygen extraction without necessarily affecting $\mathrm{VO}_{2}$ and without a definite indication of lactic acidosis. Reduced $\mathrm{SvO}_{2}$ values must be interpreted as a change of the factors, that determine the balance between $\mathrm{DO}_{2}$ and $\mathrm{VO}_{2}$ and as a warning that, with further reduction of $\mathrm{SvO}_{2}$, oxygen restricted metabolism can develop.

\section{References}

1 O'Connor TA, Hall RT. Mixed venous oxygenation in critically ill neonates. Crit Care Med 1994; 22:343-346

2 Bartlett RH, Cilley RE. Physiology of extracorporeal life support. In: Arensman RM, Cornish JD (eds). Extracorporeal life support. Blackwell, Boston, 1993 pp 89-104

3 Dudell G, Cornisch JD, Bartlett RH. What constitutes adequate oxygenation? Pediatrics 1990,86:39. 41 
van der Hoeven MAHBM, Maertzdorf WJ, Blanco CE. Feasibility and accuracy of a fiberoptic catheter for the measurement of venous oxygen saturation in newborn infants. Acta Paediatr $1995 ; 84: 122-127$

van der Hoeven MAHBM, Maertzdorf WJ, Blanco CE. Continuous central venous oxygen saturation $\left(\mathrm{ScvO}_{2}\right)$ measurement using a fibreoptic catheter in newborn infants. Arch Dis Child 1996;74:F177-F181

Kreisberg RA. Lactate homeostasis and lactic acidosis. Ann Intern Med 1980;92(1):227-237

Mizock BA, Falk JL. Lactic acidosis in critical illness. Crit Care Med 1992;20:80-93

Sigma chemical Company. The quantitative determination of pyruvic acid and lactic acid in whole blood at $340 \mathrm{~nm}$. Sigma technical bulletin. No. 726-UV, No. 826-UV, St Louis, 1976 pp 1-21

Brown EG, Krouskop RW, McDonnel FE, Monge CC, Winslow RE. A technique to continuously measure arteriovenous oxygen content difference and $\mathrm{p}_{s_{0}}$ in vivo. J Appl Physiol 1985;58(4):13831389

Mellits ED. Statistical methods. In: Cheek DB (ed) Human Growth. Lea \& Febiger, Philadelphia, 1968 pp 19.38

Fahey JT, Lister G. Postnatal changes in critical cardiac output and oxygen transport in conscious lambs. Am J Physiol 1987;253:H100-H106

Delivoria-Papadopoulos M, Martens RJ, Forster II RE, Oski FA. Postnatal changes in oxygenhemoglobin affinity and erythrocyte 2,3-diphosphoglycerate in piglets. Pediatr Res 1974;8:64-66. Mount LE, Ingram DL. The pig as a laboratory animal. Academic Press, London, 1971 pp $65-78$

Moss M, Moreau G, Lister G. Oxygen transport and metabolism in the conscious lamb: the effects of hypoxemia. Pediatr Res 1987;22:177-183

Schlichtig R, Cowden WL, Chaitman BR. Tolerance of unusually low mixed venous oxygen saturation. Adaptations in the chronic low cardiac output syndrome. Am J Med 1986;80:813-818

Reinhart K. Monitoring $\mathrm{O}_{2}$ transport and tissue oxygenation in critically ill patients. In: Reinhart $\mathrm{K}$, Eyrich K. (Eds) Clinical aspects of $\mathrm{O}_{2}$ transport and tissue oxygenation. Springer Verlag, Berlin, 1989 pp 193-211

Ceraianu AC, Nelson LD. The significance of mixed venous oxygen saturation and technical aspects of continuous measurement. In: Edwards JD, Shoemaker WC, Vincent JL (Eds) Oxygen transport; Principles and practice. Saunders, London, 1993 pp 99-124

Astiz ME, Rackow EC, Kaufman B, Fay JL, Weil MH. Relationship of oxygen delivery and mixed venous oxygen saturation in patients with sepsis and acute myocardial infarction. Crit Care Med 1988; $16: 655-658$

Rashkin MC, Bosken C, Baughman RF. Oxygen delivery in critically ill patients. Relationship to blood lactate and survival. Chest 1985;87:580-584

Danek SJ, Lynch JP, Weg JG, Dantzker DR. The dependence of oxygen uptake on oxygen delivery in the adult respiratory distress syndrome. Am Rev Respir Dis 1980;122:387-395

Welch E, Duara S, Suguihara C, Bandstra E, Bancalari E. Validation of cardiac output measurement with non-invasive Doppler echocardiography by thermodilution and Fick methods in newborn piglets. Biol Neonate 1994;66:137-145

Bizouarn P, Soulard D, Blanloeil Y, Guillet A, Goarin Y. Oxygen consumption after cardiac surgery - a comparison between calculation by Fick's principle and measurement by indirect calorimetry. Intens Care Med 1992;18:206-209

Russell JA, Phang PT. The oxygen delivery / consumption controversy. Approaches to management of the critically ill. Am J Respir Crit Care Med 1994;149:533-537

Rubertson S, Grenvick $\AA$, Wicklund L. Blood flow and perfusion pressure during open-chest versus closed-chest cardiopulmonary resuscitation in pigs. Crit Care Med 1995;23:715-725

Shiraishi H, Silverman NH, Rudolph AM. Accuracy of right ventricular output estimated by Doppler echocardiograpy in the sheep fetus. Am J Obstet Gynecol 1993;168:947-953

Mizock B. Lactic Acidosis. Disease-a-Month 1989;4:235-300

Wasserman K, Beaver WL, Whipp BJ. Gas exchange theory and the acidosis (anaerobic) threshold. 
27 Wasserman K, Beaver WL, Whipp BJ. Gas exchange theory and the acidosis (anaerobic) threshold. Circulation 1990;81(suppl II):14-30

28 Cain SM, Curtis SE. Systemic and regional oxygen uptake and delivery and lactate flux in endotoxic dogs infused with dopexamine. Crit Care Med 1991;19:1552-1560

\section{Acknowledgement}

This study was supported by Abbott Inc. The Netherlands. 


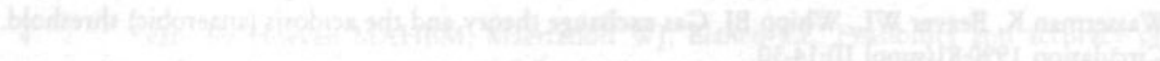

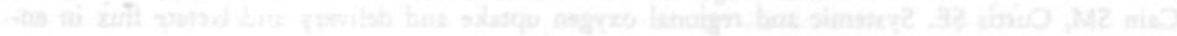




\section{Chapter 4}

Relationship between mixed venous oxygen saturation $\left(\mathrm{SvO}_{2}\right)$ and markers of tissue oxygenation in progressive hypoxic hypoxia and in isovolemic anemic hypoxia in 8-12 days old piglets.

Mark A.H.B.M. van der Hoeven, Wiel J. Maertzdorf, Carlos E. Blanco

Critical Care Medicine: in press 


\section{Abstract}

Objective: To examine the hypothesis that $\mathrm{SvO}_{2}$ values, which reflect the residual oxygen after tissue oxygen extraction, would be similar during hypoxic and anemic hypoxia.

Design: $\mathrm{SvO}_{2}$ values, oxygen delivery $\left(\mathrm{DO}_{2}\right)$, arterial oxygen content $\left(\mathrm{CaO}_{2}\right)$, fractional oxygen extraction (FOE) were compared and critical values were determined based on lactate, lactate/pyruvate ratio and oxygen consumption $\left(\mathrm{VO}_{2}\right)$ during hypoxic and anemic hypoxia.

Setting: Laboratory of Physiology at a University Hospital.

Subjects: Two groups of eight piglets, $8-12$ days old.

Interventions: Piglets were anesthetized, tracheotomized, intubated and ventilated. A thoracotomy was performed and a fiberoptic catheter was placed in the pulmonary artery to monitor $\mathrm{SvO}_{2}$. A transit time ultrasound flow probe was positioned around the ascending aorta to measure aorta flow. Progressive hypoxic hypoxia was induced by decreasing fractional inspiratory oxygen concentration $\left(\mathrm{FiO}_{2}\right)$ from baseline $(0.30-0.75)$ to $0.21,0.15$ and 0.10 . Progressive anemic hypoxia was induced by a repeated isovolemic exchange transfusion with $50 \mathrm{ml}$ pasteurized plasma.

Measurements and Main Results: Fifteen or $\mathbf{3 0}$ minutes after each intervention, samples were taken from the carotid artery for blood gases, hemoglobin, lactate and pyruvate, and from the pulmonary artery for blood gases and hemoglobin. Hemodynamic, $\mathrm{SaO}_{2}$ and $\mathrm{SvO}_{2}$ measurements were made. The calculated $\mathrm{DO}_{2}$ and $\mathrm{VO}_{2}$ decreased in both hypoxic and anemic hypoxia. At the lowest $\mathrm{DO}_{2}$ level of anemic hypoxia, the decrease in $\mathrm{SvO}_{2}$ was less than that in hypoxic hypoxia $(-26 \%$ vs. $-55 \%)$. The range of critical values for $\mathrm{SvO}_{2}$ calculated for each individual piglet below which lactate, lactate/pyruvate ratio and $\mathrm{VO}_{2}$ rapidly changed from baseline value, was significantly lower in hypoxic hypoxia (11 to 24 $\%$ ) than in anemic hypoxia (26 to $48 \%$ ). F.O.E. increased significantly, but not with a change as high as in hypoxic hypoxia $0.31(0.20,0.41) v s .0 .49(0.41$ to 0.54$)$.

Conclusions: In comparison with hypoxic hypoxia, critical values of $\mathrm{SvO}_{2}$ are higher in anemic hypoxia, indicating that oxygen unloading from blood to tissues is impaired in anemic hypoxia. These characteristics in oxygen transport and capillary hemodynamics should be taken into consideration when $\mathrm{SvO}_{2}$ is used in clinical critical care. 


\section{Introduction}

Mixed venous oxygen saturation $\left(\mathrm{SvO}_{2}\right)$ reflects the residual oxygen after tissue oxygen extraction and represents the combined sufficiency of arterial oxygen content $\left(\mathrm{CaO}_{2}\right)$, cardiac output $(\mathrm{Q} t)$ and tissue oxygen consumption $\left(\mathrm{VO}_{2}\right)^{[1]}$. In the adult intensive care, $\mathrm{SvO}_{2}$ has been used to monitor cardiac output. In neonatal medicine, $\mathrm{SvO}_{2}$ monitoring is used during extracorporeal support to monitor the sufficiency of oxygen delivery (DO, [2]. Central $\mathrm{SvO}_{2}$ measurement in the right atrium has been proposed in neonatal intensive care to monitor the oxygen sufficiency at the tissue level [3]. We have determined the feasibility and the accuracy of a fiberoptic catheter system in the newborn, providing a continuous central $\mathrm{SvO}_{2}$ measurement ${ }^{[4]}$ and described the "normal" range of $\mathrm{SvO}_{2}$, values in 1 to 7 days old preterm infants breathing room air ${ }^{[3]}$. The critical range of $\mathrm{SvO}_{2}$, below which oxygen restricted metabolism will develop and the concentration of biochemical markers of tissue hypoxia such as lactate and pyruvate will increase ${ }^{[6,7]}$ was described during hypoxic hypoxia in newborn piglets ${ }^{(8)}$.

As different types of hypoxia (hypoxic hypoxia, anemic hypoxia or circulatory failure hypoxia) could have other patterns of circulatory adjustments and compensations, the actual oxygen flow from the capillary bed to the cells may be affected. Consequently, different $\mathrm{SvO}_{2}$ values may be observed during different types of hypoxia. However, $\mathrm{SvO}_{2}$ and $\mathrm{PvO}_{2}$ reflect the residual oxygen after tissue oxygen extraction and form the lowest driving pressure for oxygen diffusion to the tissues. Therefore, we hypothesized that critical $\mathrm{SvO}_{2}$ values, below which oxygen diffusion to the tissues starts to decrease, would not be different during different types of hypoxia. The aim of this study was to compare the critical range of $\mathrm{SvO}_{2}$ values in progressive hypoxic hypoxia with those in anemic hypoxia. $\mathrm{SvO}_{2}$ values were examined in comparison with $\mathrm{DO}_{2}, \mathrm{VO}_{2}$ and biochemical markers of tissue hypoxia during hypoxic hypoxia and anemic hypoxia. Critical values of $\mathrm{DO}_{2}, \mathrm{FOE}$ and $\mathrm{SvO}_{2}$ were determined and compared in both types of hypoxia.

\section{Materials and methods} Maastricht.

This study was approved by the animal care committee of the University of Animal preparation

Two groups of eight piglets between 8 and 12 days of age were anesthetized using halothane for induction, tracheotomized, intubated and ventilated with room air. Anesthesia was maintained by continuous intravenous infusion of pentobarbital sodium and pancuronium in glucose $10 \%$ as required. A $4 \mathrm{Fr}$. fiberoptic catheter (Abbott Laboratories, North Chicago IL) was placed in the right carotid artery for continuous monitoring of arterial oxygen saturation $\left(\mathrm{SaO}_{2}\right)$, blood sampling and monitoring arterial blood pressure. A $5 \mathrm{Fr}$. catheter was placed in the jugular or femoral vein for fluid administration. A thoracotomy was performed and the ductus arteriosus was ligated. A transit time ultrasound blood volume flow probe (Transonic Systems, Ithaca, NY) was positioned around the ascending aorta to monitor continuously aorta blood flow. The pulmonary artery was catheterized with a $4 \mathrm{Fr}$. fiberoptic catheter so as to continuously monitor $\mathrm{SvO}_{2}$ for blood sampling and pulmonary arterial blood pressure. A rectal probe was placed to monitor core body temperature. 


\section{Protocol}

The piglets were ventilated with a pressure limited, time cycled ventilator (Bourns BP-200, Medical Systems, Riverside, CA). Inspiratory gas was warmed and humidified. $\mathrm{PaCO}_{2}$ was maintained in a range between 27 and 45 torr.

In the hypoxic hypoxia group, progressive graded hypoxia was induced in eight piglets by changing the proportion of oxygen/nitrogen in the inspiratory gas. A variable fractional inspiratory oxygen concentration $\left(\mathrm{FiO}_{2}\right)$ of 0.30 to 0.75 was used during baseline. Progressive graded hypoxia was induced by a $\mathrm{FiO}_{2}$ of $0.21,0.15$, and 0.10 , respectively. Every fixed $\mathrm{FiO}_{2}$ was kept for an interval of 15 minutes. At the end of each interval, blood samples were simultaneously taken from the carotid artery for blood gases, hemoglobin, lactate and pyruvate and from the pulmonary artery for blood gases and hemoglobin. The study included two series of different $\mathrm{FiO}_{2}$ intervals with a one hour period in between for recovery. The series of graded hypoxia, could be repeated because all animals except one regained a stable condition after the first series of the $\mathrm{FiO}_{2}$ intervals and consequently more data could be obtained per animal. A blood transfusion was given for accidental blood loss during the operative procedure or when the hemoglobin level decreased because of blood sampling during the experiment to maintain a baseline hemoglobin level between 7.0 and $12 \mathrm{gr} / \mathrm{dl}$.

In the anemic hypoxia group, progressive anemia was induced in eight piglets by a repeated isovolemic exchange transfusion with $50 \mathrm{ml}$ pasteurized plasma. Thirty minutes after each exchange transfusion, blood samples were taken for the same determinations as in the hypoxic hypoxia group. During this procedure, piglets were ventilated with a $\mathrm{FiO}_{2}$ of 1.0 .

\section{Measurements}

The fiberoptic catheter system (Oximetrix System, Abbott Laboratories) includes a fiberoptic catheter and a microprocessor-based oximeter. The back scattered light from the oxygenated and deoxygenated blood is transmitted by the receiving fiberoptic bundle to a photodetector. The oximeter computes percentage of oxygen saturation values based on the electrical signals from the photodetector.

$\mathrm{SaO}_{2}, \mathrm{SvO}_{2}$, arterial and pulmonary artery blood pressures, blood flow in the aorta, heart rate and core body temperature were sampled every 10 secs, displayed and stored by a software system (Hemodynamic Data Acquiring System (HDAS), University of Maastricht, the Netherlands). Blood samples for blood gases were analyzed on an ABL 3 acid-base analyzer (Radiometer, Copenhagen, Denmark) corrected for the animal core body temperature. $\mathrm{SaO}_{2}, \mathrm{SvO}_{2}$ and hemoglobin $(\mathrm{gr} / \mathrm{dl})$ were analyzed on the OSM2 oximeter (Radiometer, Copenhagen, Denmark). Lactate and pyruvate were analyzed in arterial blood samples by an enzymatic spectrophotometric method (Sigma Chemical St Louis,MO).

\section{Calculations}

- Arterial oxygen content $\left(\mathrm{CaO}_{2}\right)$ and venous oxygen content $\left(\mathrm{CvO}_{2}\right)$ were calculated as the product of hemoglobin concentration, hemoglobin oxygen saturation and a hemoglobin oxygen binding capacity of $1.36 \mathrm{ml} / \mathrm{dl}$.

- Cardiac output $(\mathrm{Qt})$ was determined by the mean value of the blood flow in the aorta during the last five minutes of each $\mathrm{FiO}_{2}$ interval or hemoglobin interval measured by the flowsensor.

- $\mathrm{DO}_{2}$ and $\mathrm{VO}_{2}$ were calculated as the product of the cardiac output and arterial oxygen content and the difference between arterial and venous oxygen content, respectively.

- Fractional oxygen extraction (F.O.E.) was calculated as the $\mathrm{VO}_{2}$ divided by $\mathrm{DO}_{2}$. - $\mathrm{P}_{50}$ was calculated from venous blood gas samples using $\mathrm{SvO}_{2}$ and $\mathrm{PvO}_{2}$ as has been described in the literature. ${ }^{[\vartheta]}$ 
- The change of the parameters was calculated in comparison with the baseline value of these items in each individual animal.

- Oxygen debt was calculated by multiplying the change in $\mathrm{VO}_{2}$ in a certain interval by the duration of that interval.

Data analysis

Data were retrospectively standardized to four $\mathrm{DO}_{2}$ levels: $\mathrm{DO}_{2}$ values above 18 $\mathrm{ml} \cdot \mathrm{min}^{-1} \cdot \mathrm{kg}^{-1}, \mathrm{DO}_{2}$ values between 12 and $18 \mathrm{ml} \cdot \mathrm{min}^{-1} \cdot \mathrm{kg}^{-1}, \mathrm{DO}_{2}$ values between 6 and 12 $\mathrm{ml} \cdot \mathrm{min}^{-1} \cdot \mathrm{kg}^{-1}$, and $\mathrm{DO}_{2}$ values below $6 \mathrm{ml} \cdot \mathrm{min}^{-1} \cdot \mathrm{kg}^{-1}$.

Data at baseline are presented as the median (25th -75 th percentile) of the absolute values. Data standardized to the four $\mathrm{DO}_{2}$ levels are presented as the median value (25th 75 th percentile) of the changes in comparison with the baseline value in each individual animal.

To test whether a difference existed in the hypoxic hypoxia between the two consecutive series of induced hypoxemia the results in the corresponding $\mathrm{FiO}_{2}$ intervals were compared using a Mann-Whitney U test.

Data of the different $\mathrm{DO}_{2}$ levels within each type of hypoxia group were compared using the Kruskall-Wallis one way of variance. When the null hypothesis that a parameter had an equal distribution in all $\mathrm{DO}_{2}$ levels, could be rejected, a Mann-Whitney $\mathrm{U}$ test between the different $\mathrm{DO}_{2}$ levels and the highest $\mathrm{DO}_{2}$ was performed adjusting the significance level for the number of comparisons by performing the Bonferroni test.

Between the types of hypoxia data of the same $\mathrm{DO}_{2}$ level were compared using a Mann-Whitney U test.

The critical value of $\mathrm{DO}_{2}$ was calculated for each piglet, that is the $\mathrm{DO}_{2}$ below which the change in lactate concentration increased rapidly. To do this, we adapted a technique from Mellits ${ }^{[1-12]}$ to find the section point of two lines of regression. This included constructing the best pair of regression lines that included all points only once. The best pair of regression lines was defined as to minimize the total of the residual sum of squares of each line in the pair. Their intersection point was determined by solving the equations of the pair of regression lines. The $x$-coordinate of the intersection point is the critical $\mathrm{DO}_{2}{ }^{[11]}$. The critical $\mathrm{DO}_{2}$ for each piglet was also determined for change in lactate/pyruvate ratio and change in $\mathrm{VO}_{2}$ applying this same technique. Likewise, critical values for each piglet of $\mathrm{CaO}_{2}, \mathrm{SvO}_{2}$ and of $\mathrm{FOE}$ were determined. To compare these critical values between hypoxic hypoxia and anemic hypoxia a Mann-Whitney U test was performed.

Linear regression analysis was performed to relate $\mathrm{DO}_{2}$ and $\mathrm{SvO}_{2}$ (least squares method) in the hypoxic hypoxia and the anemic hypoxia group. To test whether linear regression was appropriate, an analysis of the residuals was performed. The linear regression equations in hypoxic hypoxia and anemic hypoxia were contrasted using covariant analysis.

\section{Results}

Two groups of eight piglets were studied; they had a median weight of $3.2(2.8$, $4.1) \mathrm{Kg}$ and a median age of $9(8,12)$ days.

No significant differences were found between the results of corresponding $\mathrm{FiO}_{2}$ intervals in the two consecutive series of induced hypoxemia.

Table 1 shows the measured and calculated data during hypoxic hypoxia standardized for $\mathrm{DO}_{2} \cdot \mathrm{SaO}_{2}$ and $\mathrm{SvO}_{2}$ decreased in the lowest $\mathrm{DO}_{2}$ level $77 \%$ and $55 \%$ from baseline, respectively. 
table 1: Measured and calculated data during baseline and the change from baseline sta median (25th, 75th percentile)

\begin{tabular}{|c|c|c|c|c|c|}
\hline \multicolumn{2}{|c|}{$\mathrm{DO}_{2}$ levels $\left(\mathrm{ml} \cdot \mathrm{min}^{-1} \cdot \mathrm{kg}\right.$ ) } & $\begin{array}{r}>18 \\
\text { change }\end{array}$ & $\begin{array}{l}12-18 \\
\text { change }\end{array}$ & $\begin{array}{r}6-12 \\
\text { change }\end{array}$ & $\begin{array}{r}<6 \\
\text { change } \\
\end{array}$ \\
\hline $\mathrm{pHa}$ & $7.45(7.40,7.47)$ & $0.01(-0.05,0.05)$ & $0.07\left(0_{33}, 0.10\right)$ & $0.03(-0.14,0.08)$ & $-0.02(-0.09,0.00)$ \\
\hline $\mathrm{PaCO}_{2}$ (torr) & $33(28,41)$ & $O(-4,4)$ & $3(-7,-1)$ & $-6(-12,3)$ & $-3(-12,2)$ \\
\hline $\mathrm{PaO}_{2}$ (torr) & $315(97,465)$ & $-13(-127,12)$ & $-201\left(\begin{array}{l}(-7,-1) \\
375,-15)\end{array}\right.$ & $-275(-360,-43)$ & $.292(-435,-82)$ \\
\hline $\mathrm{SaO}_{2}(\%)$ & $97(89,98)$ & $O(-2,2)$ & $j(-17,0)$. & $-48(-53,-11)$ & $-77(-78,-69)$ \\
\hline $\mathrm{CaO}_{2}(\mathrm{ml} / \mathrm{dl})$ & $12.4(11.0,14.5)$ & $0(-0.5,0.9)$ & $-1.6(3.6,-0.8)$. & $-5.6(-7.6,-1.7)$ * & $-10.4(-11.0,-8.6)$ \\
\hline $\mathrm{PvO}_{2}$ (torr) & $37(35,43)$ & $-3(-7,3)$ & $-12.0,-0.8)$ & $-19(-26,-13)$ * & $-30(-39,-25)$ \\
\hline $\mathrm{SvO}_{2}(\%)$ & $54(47,61)$ & $-2(-6,3)$ & 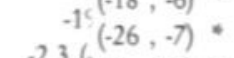 & $-40(-52,-25)$ * & $-55(-63,-50)$ \\
\hline $\mathrm{CvO}_{2}(\mathrm{ml} / \mathrm{dl})$ & $7.2(6.1,8.2)$ & $-0.2(-0.6,0.6)$ & $-2.3(-9,-1.0)$ & $-4.3(-5.8,-2.3) \cdot$ & $-7.2(-8.3,5.8)$ \\
\hline $\mathrm{Ca}-\mathrm{vO}_{2}(\mathrm{~mL} / \mathrm{dl})$ & $5.4(4.5,7.7)$ & $O(-0.3,0.3)$ & $0.0(0.5,0.5)$ & $-0.7(-1.7,0.7)$ & $-2.9(-4.2,-2.3)$ \\
\hline$P_{50}$ (torr) & $34(32,37)$ & $0(0,0)$ & $2(-7,0)$ & $-1(-5,6)$ & $-1(-10,6)$ \\
\hline $\mathrm{Hb}(\mathrm{g} / \mathrm{dl})$ & $9.3(8.1,9.7)$ & $0(-1.2,0.12)$ & $-0.0(0.3,0.6)$ & $0.8(0.1,1.6)$ & $2.2(0.6,3.0)$ \\
\hline $\mathrm{Qt}\left(\mathrm{ml} \cdot \mathrm{min}^{-1} \cdot \mathrm{kg}^{-1}\right)$ & $165(118,218)$ & $O(-10,7)$ & $2(-9,8)$ & $2(-9,18)$ & $-22(-54,-2)$ \\
\hline mean $\mathrm{P}_{\infty}\left(\mathrm{mmH}_{\mathrm{g}}\right)$ & $90(80,105)$ & $0(-3,5)$ & $2(-7,1)$ & $.7(-15,1)$ * & $-25(-37,-16)$ \\
\hline mean $\mathrm{P}_{\text {rim }}\left(\mathrm{mmH}_{\mathrm{k}}\right)$ & $17(14,26)$ & $0(-1,4)$ & $0.4010^{2}(-1,4)$ & $5(0,11)$ & $5(2,10)$ \\
\hline Lactate $(\mathrm{mmol} / \mathrm{l})$ & $2.05(1.2,3.1)$ & $0(0,0)$ & $0.40\left(0_{20}^{2}, 0.68\right)$. & $1.50(0.53,3.31)$ * & $3.85(2.02,7.12)$ \\
\hline Pyruvate $(\mu \mathrm{mol} / \mathrm{l})$ & $169(105,205)$ & $O(-1,1)$ & $13(-14,63)$ & $36(5,66)$ & $33(-15,132)$ \\
\hline lact/pyr.ratio & $11.0(9.5,13.5)$ & $0(0,0.8)$ & $1.10 .5,3.3)$ * & $7.1(3.4,13.9)$ * & $24.4(16.1,32.9)$ \\
\hline $\mathrm{DO}_{2}\left(\mathrm{ml} \cdot \mathrm{min}^{-1} \cdot \mathrm{kg}^{\prime}\right)$ & $19.6(16.4,21.3)$ & $0(-0.9,1.0)$ & $-2.9(5.9,-1.2)$ & $-6.2(-11.7,-3.8)$ * & $-16.4(-18,-11)$ \\
\hline $\mathrm{VO}_{2}\left(\mathrm{ml} \cdot \mathrm{min}^{-1} \cdot \mathrm{kg}^{7}\right)$ & $8.7(7.5,10.0)$ & $0.0(-0.2,0.6)$ & $-0.46 .7,0.1)$ & $-1.3(-1.8,-0.4)$ & $-4.4(-5.1,-3.7)$ \\
\hline FOE & $0.47(0.39,0.52)$ & $0(-0.04,0.04)$ & $0.11(0,0.19)$ & $0.26(0.15,0.35)$ & $0.49(0.41,0.54)$ \\
\hline $\mathrm{O}_{2}$ debt $\left(\mathrm{ml} \cdot \mathrm{kg}^{\prime}\right)$ & & $-1.5(-16,3.6)$ & $-1.0(-9,10.1)$ & $22.6(4.9,40.1)$ * & $51.3(35.2,89.4)$ \\
\hline
\end{tabular}


table 2: Measured and calculated data during baseline and the change from baseline standardized to four levels of $\mathrm{DO}_{2}$ during anemic hypoxia. Values are median (25th , 75th percentile)

\begin{tabular}{|c|c|c|c|c|c|c|c|}
\hline \multicolumn{2}{|c|}{$\mathrm{DO}_{2}$ levels $\left(\mathrm{ml} \cdot \mathrm{min}^{-1} \cdot \mathrm{kg}^{\prime}\right)$} & $\begin{array}{r}>18 \\
\text { change }\end{array}$ & $\begin{array}{l}12-18 \\
\text { change }\end{array}$ & \multicolumn{2}{|l|}{$\begin{array}{r}6-12 \\
\text { change }\end{array}$} & \multicolumn{2}{|l|}{$\begin{array}{r}<6 \\
\text { change }\end{array}$} \\
\hline $\mathrm{pHa}$ & $7.44(7.42,7.49)$ & $0.00(-0.01,0.00)$ & $-0.02(-0.06,0.0) \mathbf{S}$ & $-0.09(-0.18,-0.05)+5$ & +5 & $0.22(-0.45,0.06)$ & *s \\
\hline $\mathrm{PaCO}_{2}$ (torr) & $32(28,36)$ & $0(0,1)$ & $0(0,3) \mathrm{s}$ & $1(0,5) \mathrm{S}$ & & $-3(-6,2)$ & \\
\hline $\mathrm{PaO} 2$ (torr) & $490(450,510) \mathbf{S}$ & $0(-9,16) \mathbf{S}$ & $1(-3,3) \mathbf{S}$ & $9(-32,27)$ & & $13(-32,57)$ & \\
\hline $\mathrm{SaO}_{2}(\%)$ & $99(98,99) \mathbf{S}$ & $0(0,0)$ & $-1(-2,0) \mathrm{S}$ & $-2(-3,0) S$ & & $-6(-10,0) \mathbf{S}$ & S \\
\hline $\mathrm{CaO}_{2}(\mathrm{ml} / \mathrm{dl})$ & $10.3(9.8,11.7)$ & $0(-1.6,0.1)$ & $-3.2(-4.5,0.1)$ & $-6.3(-7.1,-5.6)$ & & $-8.4(-9.8,-7.1)$ & 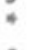 \\
\hline $\mathrm{PvO}_{2}$ (torr) & $43(37,54)$ & $0(-1,2)$ & $-4(-6,1) \mathbf{S}$ & $-7(-13,-2)$ & & $=3(-12,7) \mathrm{s}$ & S \\
\hline $\mathrm{SvO}_{2}(\%)$ & $54(45,71)$ & $0(-1,2)$ & $-6(-10,-1)$ \%s & $-23(-30,-16)$ & & $-26(-36,-6) 4$ & "s \\
\hline $\mathrm{CvO}_{2}(\mathrm{ml} / \mathrm{dl})$ & $5.1(4.8,6.4) \mathrm{S}$ & $0(-1.1,0.1)$ & $-2.6(-3.5,-0.5) *$ & $-4.7(-5.7,3.7) *$ & & $-5.2(-7.3,-4.1)$ 의 & +s \\
\hline $\mathrm{Ca}_{\mathrm{a}-\mathrm{vO}} \mathrm{O}_{2}(\mathrm{ml} / \mathrm{dl})$ & $5.5(3.7,6.4)$ & $0(-0.3,0.3)$ & $-0.4(-0.9,0.0)$ & $-1.3(-2.4,0.9)$ & & $-3.2(4.1,-1.4)$ & 4 \\
\hline$P_{s o}$ (torr) & $39(36,42) \mathbf{S}$ & $0(-1,1)$ & $2(0,6) \mathrm{s}$ & $7(3,13)$ & 5 & $19(7,40) \div$ & 45 \\
\hline $\mathrm{Hb}(\mathrm{gr} / \mathrm{dl})$ & $6.6(6.3,7.6) \mathbf{S}$ & $0(-1.2,0.1)$ & $-2.3(-3.4,-0.1)$ \% & $-4.6(-5.3,3.9)+9$ & 5 & $-6.2(-7.2,-5.2)+$ & *s \\
\hline $\mathrm{Qt}\left(\mathrm{ml} \cdot \mathrm{min}^{-1} \cdot \mathrm{kg}^{\prime}\right)$ & $180(127,215)$ & $3(-4,17)$ & $19(0,40) \mathrm{S}$ & $45(1,64) \mathrm{s}$ & & $.39(-78,24)$ & \\
\hline meanP $\left(\mathrm{mm} \mathrm{H}_{\mathrm{g}}\right)$ & $81(77,89)$ & $0(-3,2)$ & $-5(-15,1)$ & $-28(-35,-17)$ & s & $-35(-60,-13)$ & $*$ \\
\hline mean $\mathrm{P}_{\text {pam }}(\mathrm{mm} \mathrm{Hg})$ & $20(18,24)$ & $0(-3,6)$ & $O(-3,1)$ & $O(-1,1)$ & & $1(-5,22)$ & \\
\hline Lactate $(\mathrm{mmol} / \mathrm{l})$ & $1.03(0.65,1.25)$ & $-0.03(-0.1,0.05)$ & $-0.12(-0.22,0.01) \mathrm{S}$ & $0.47(-0.03,2.40)$ & & $8.52(5.07,11.2) *$ & *s \\
\hline Pyruvate $(\mu \mathrm{mol} / \mathrm{T})$ & $107(86,120)$ & $-2(-11,1)$ & $-9.5(-26,1)$ & $10(-18,49)$ & & $106(-6.5,197)$ & os \\
\hline Lact/pyr.ratio & $9.1(7.7,10.2) \mathrm{S}$ & $0.0(-0.6,-1)$ & $0.0(-0.6,0.6) \mathrm{s}$ & $3.5(1.4,12.3)$ * & & $24.0(20.1,29.1)$ & $*$ \\
\hline $\mathrm{DO}_{2}\left(\mathrm{ml} \cdot \mathrm{min}^{-4} \cdot \mathrm{kg}^{\prime}\right)$ & $18.5(14.5,22.1)$ & $O(-1,0.5)$ & $-4.7(-6.6,-0.6)=$ & $-9.5(-12.8,-5.5) *$ & & $-14.4(-17.6,-12.5)^{\circ}$ & • \\
\hline VO2 (ml.min $\left.{ }^{-1} \cdot \mathrm{kg}^{-1}\right)$ & $8.3(7.1,10.4)$ & $0(-0.3,0.2)$ & $-0.4(-0.7,0.0)$ & $-1.0(-2.0,-0.5)$ & & $-5.4(-6.8,-3.5)$ & * \\
\hline FOE & $0.52(0.37,0.59)$ & $0(0,0.02)$ & $0.09(0.03,0.15)$ & $0.29(0.20,0.32) *$ & 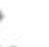 & $0.31(0.20,0.41)$ & 4s \\
\hline $\mathrm{O}_{2}$ debt (ml.kg-) & & $0(-0.7,7)$ & $5.3(-0.8,15.1)$ & $31.4(14.3,62.1)$ & ts & $135.9(100.4,214)$ & +s \\
\hline
\end{tabular}

To convert torr to $\mathrm{kPa}$ multiply the value by 0.1333

$\mathrm{DO}_{2}$, oxygen delivery; $\mathrm{PaCO}_{2}$, arterial partial pressure of carbon dioxide, $\mathrm{PaO}_{2}$, arterial partial pressure of oxygen; $\mathrm{SaO}_{2}$, arterial oxygen saturation; $\mathrm{CaO}$, arterial oxygen content; $\mathrm{PvO}_{2}$, venous partial pressure of oxygen; $\mathrm{SvO}_{2}$, mixed venous oxygen saturation; $\mathrm{CvO}_{2}$, venous oxygen content; $\mathrm{C}(\mathrm{a}-\mathrm{v}) \mathrm{O}_{2}$,

difference between arterial and venous oxygen content; $\mathrm{P}_{\mathrm{s} s}$, partial pressure of oxygen at $50 \%$ oxygen saturation; $\mathrm{H}_{\mathrm{g} b}$, hemoglobin; $\mathrm{Qt}$, cardiac output; mean $\mathrm{P}_{\text {se }}$, mean blood pressure in the aorta; mean $\mathrm{P}_{\mathrm{pum}}$, mean bloodpressure in the pulmonary artery; lact/pyr.ratio, ratio between lactate and pyruvate, $\mathrm{VO}_{3}$, oxygen consumption; F.O.E, fractional oxygen extraction;

'*' - significant different from the highest $\mathrm{DO}_{2}$ level. ' $\mathrm{S}$ ' = significant different between alveolar and anemic hypoxia in the similar $\mathrm{DO}, 2$ level. 


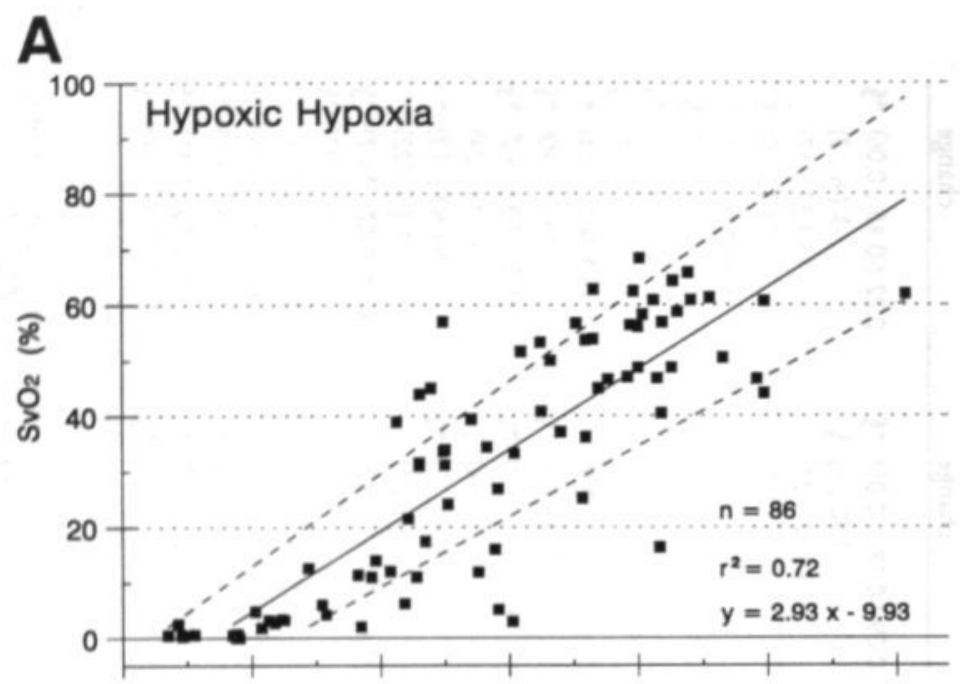

B

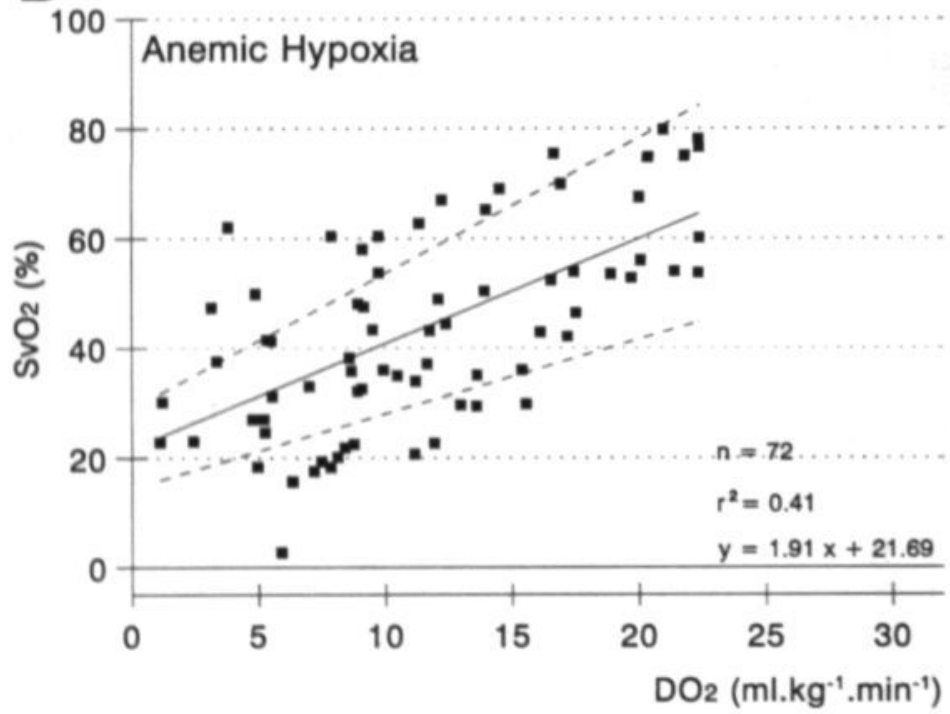

figure 1. Relationship of oxygen delivery $\left(\mathrm{DO}_{2}\right)$ and mixed venous oxygen saturation $\left(\mathrm{SvO}_{2}\right)$ during hypoxic (A) and anemic hypoxia (B). The linear regression equation for hypoxic hypoxia (2.93, DO,-9.93$)$ was significantly different from the regression line during anemic hypoxia $\left(1.91\right.$. $\left.\mathrm{DO}_{2}+21.70\right) \cdot(p$ $<0.001$, covariant analysis).

$\mathrm{VO}_{2}$ decreased significantly $1,3(0.4,1.8) \mathrm{ml} . \mathrm{kg}^{-1} \cdot \mathrm{min}^{-1}$ and $4.4(3.7,5.1) \mathrm{ml} . \mathrm{kg}$ ${ }^{1} \cdot \mathrm{min}^{-1}$, respectively in the two lowest levels of $\mathrm{DO}_{2}$. Consequently, in these $\mathrm{DO}_{2}$ levels, lactate and the lactate/pyruvate ratio increased significantly, whereas pyruvate did not change from baseline. Hemodynamic responses during the different $\mathrm{DO}_{2}$ levels consisted of an unaltered cardiac output and systemic mean blood pressure except at the lowest $\mathrm{DO}_{2}$ level, at which systemic blood pressure decreased. In contrast to systemic blood pressure, pulmonary mean blood pressure increased with increasing hypoxic hypoxia. 


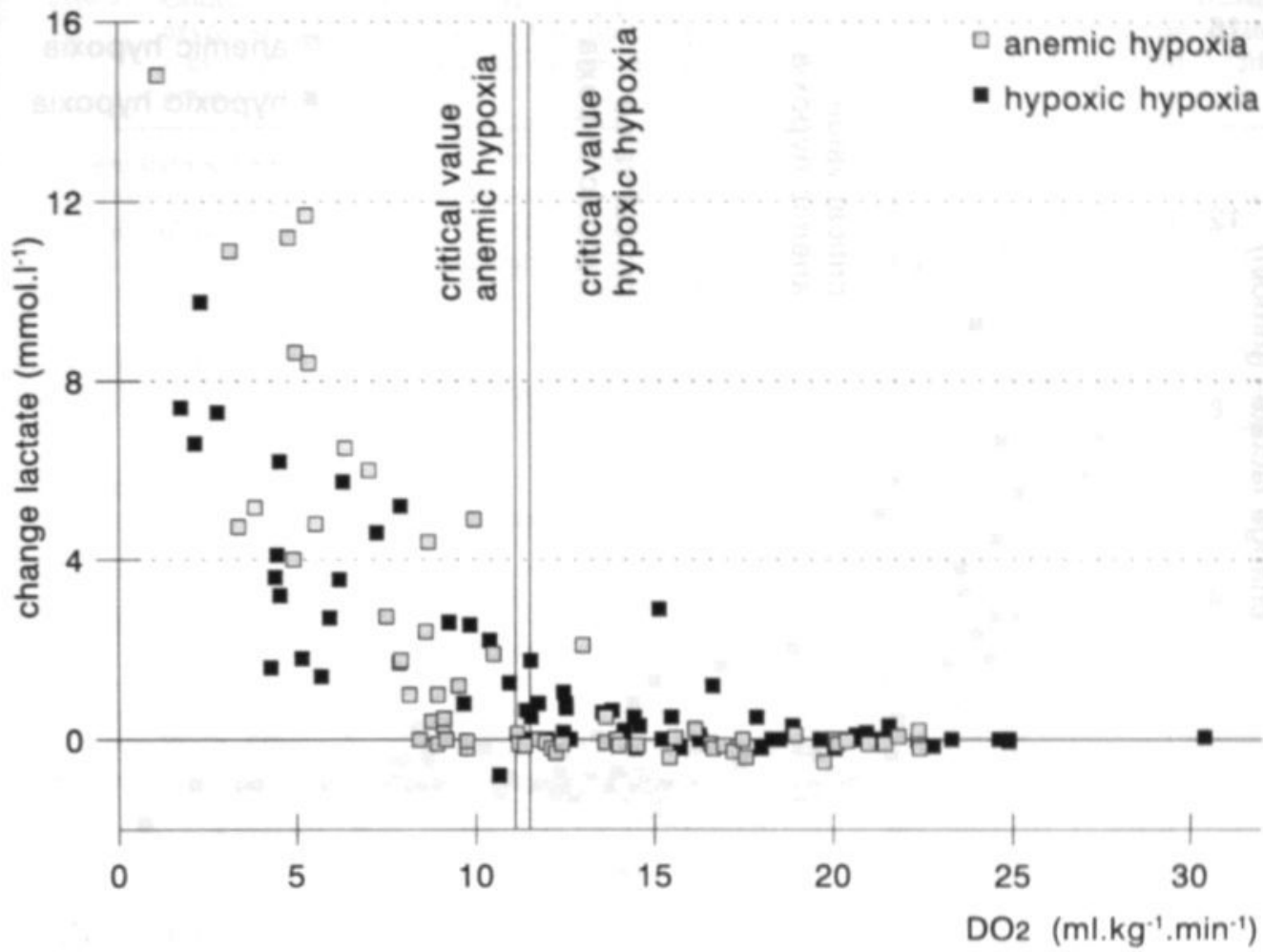

figure 2: Oxygen delivery $\left(\mathrm{DO}_{2}\right)$ and change lactate during hypoxic and anemic hypoxia. The median of the critical values of $\mathrm{DO}_{2}$ determined in each individual piglet with regard to change lactate were not different between hypoxic and anemic hypoxia: $: 1.5 \mathrm{ml} . \mathrm{kg}^{1} \cdot \mathrm{min}^{-1}(10.4,12.8) v 8.11 .1 \mathrm{ml} . \mathrm{kg}^{1} \cdot \mathrm{min}^{-1}$ $(10.2,12.8)$, respectively.

Table 2 shows measured and calculated data for the anemic hypoxia group standardized for $\mathrm{DO}_{2}$. Baseline values for $\mathrm{PaO}_{2}(490$ torr $(450,510)$ were significantly higher in comparison with baseline values in the hypoxic hypoxia group ( 315 torr $(97$, 465). Baseline hemoglobin and $\mathrm{CvO}_{2}$ were significantly higher in the hypoxic hypoxia group in comparison with the anemic hypoxia group. The baseline value of $\mathrm{p}_{50}$ was higher in the anemic hypoxia group. $\mathrm{SvO}_{2}$ and $\mathrm{PvO}_{2}$ decreased during the progressive decrease in $\mathrm{DO}_{2}$, whereas $\mathrm{SaO}_{2}$ and $\mathrm{PaO}_{2}$ remained largely unaltered. At the lowest $\mathrm{DO}_{2}$ level of anemic hypoxia, the change in $\mathrm{SvO}_{2}$ was less than that in hypoxic hypoxia $(-26 \%(-36,-6)$ vs. $-55 \%(-63,-50)$. In fact, in anemic hypoxia, the median change of $\mathrm{PvO}_{2}$ at the lowest $\mathrm{DO}_{2}$ level showed an increase $\left(3\right.$ torr $(-12,7)$ compared with the baseline value. $\mathrm{O}_{2}$ debt increased and was significantly different from baseline in the two lowest $\mathrm{DO}_{2}$ levels during both types of hypoxia. The increase of $\mathrm{O}_{2}$ debt was more pronounced during anemic hypoxia than during hypoxic hypoxia.

In figure 1 , we plotted the relationship between $\mathrm{DO}_{2}$ and $\mathrm{SvO}_{2}$ and a linear regression analysis was performed. Residual analysis showed an equal variance and a normal distribution. When the residuals were plotted against the values predicted by the regression line, a random distribution was observed. This analysis showed that necessary assumptions for linear regression were not violated. 


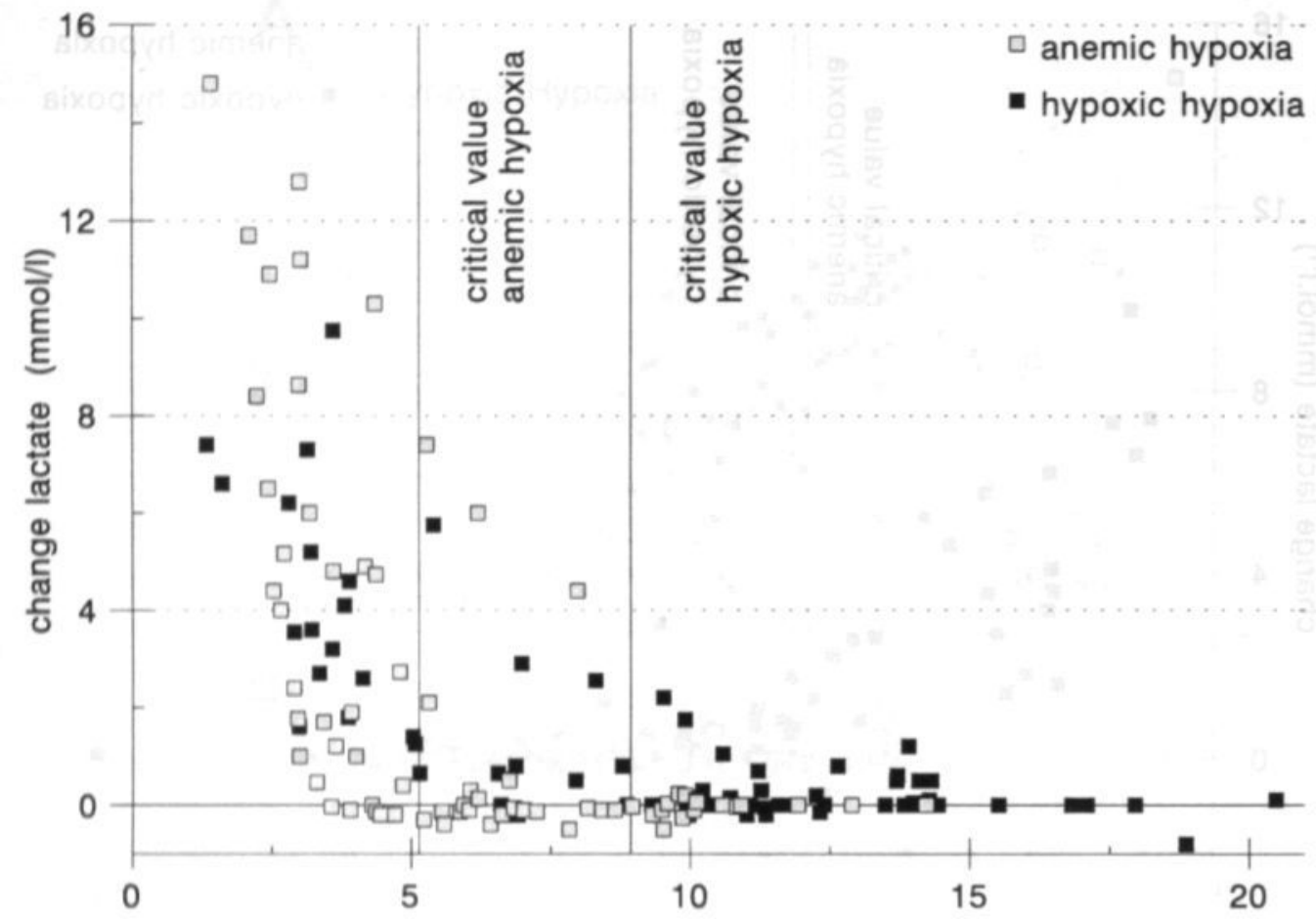

$\mathrm{CaO} 2(\mathrm{ml} / \mathrm{dl})$

figure 3. Arterial oxygen content $\left(\mathrm{caO}_{2}\right)$ and change lactate during hypoxic and anemic hypoxia. The median of the critical values of $\mathrm{caO}_{2}$ determined in each individual piglet below which lactate rapidly increased was significantly different between hypoxic and anemic hypoxia: $8.6 \mathrm{ml} / \mathrm{dl}(6.4,10.9) v$ s. $4.1 \mathrm{ml} / \mathrm{dl}(4.0,6.3)$, respectively; $p=0.002$

The regression equation for hypoxic hypoxia $\left(2.93 . \mathrm{DO}_{2} \cdot 9.93 ; \mathrm{r}^{2}: 0.72\right)$ was signit:antly different from the regression equation for anemic hypoxia $\left(1.91 \cdot \mathrm{DO}_{2}+\right.$ $\left.21.70 ; \mathrm{r}^{2}: 0.41\right) \cdot(p<0.001)$. This means that the decrease in $\mathrm{SvO}_{2}$ for an identical decrease in $\mathrm{DO}_{2}$ is significantly less during anemic hypoxia than during hypoxic hypoxia.

$\mathrm{VO}_{2}$ was decreased in both types of hypoxia. Consequently, lactate and the lactate/pyruvate ratio were significantly increased at the two lowest $\mathrm{DO}_{2}$-levels. However, in anemic hypoxia, lactate and pyruvate increased more at the lowest $\mathrm{DO}_{2}$ level. In the anemic hypoxia group, F.O.E. did not change in equal amount as in hypoxic hypoxia: 0.31 $(0.20,0.41)$ vs. $0.49(0.41,0.54)$. Hemodynamic responses on decreasing $\mathrm{CaO}_{2}$ consisted of an increase in cardiac output and a decrease in systemic blood pressure. At the lowest $\mathrm{DO}_{2}$ level, cardiac output and systemic blood pressure decreased below baseline values. Pulmonary artery pressure remained stable at all $\mathrm{DO}_{2}$ levels in the anemic hypoxia group in contrast to the increased pulmonary pressure in the hypoxic hypoxia group.

Figure 2 and 3 show the relationships between $\mathrm{DO}_{2}$ and $\mathrm{CaO}_{2}$ and lactate, respectively. The critical values of $\mathrm{DO}_{2}$ and $\mathrm{CaO}_{2}$ for each individual piglet concerning the change in lactate, in the lactate/pyruvate ratio and in $\mathrm{VO}_{2}$ were calculated according to the technique of Mellits ${ }^{[10]}$. There were no differences in the critical range of $\mathrm{DO}_{2}$ in hypoxic hypoxia and anemic hypoxia, whereas the critical range of $\mathrm{CaO}_{2}$ was lower in the anemic 
table 3. Critical values of arterial oxygen content $\left(\mathrm{caO}_{2}\right)$, of oxygen delivery $\left(\mathrm{DO}_{2}\right)$, of mixed venous oxygen saturation $\left(\mathrm{SvO}_{2}\right)$ and of fractional oxygen extraction (F.O.E.), below which lactate, lactate / pyruvate ratio increased and oxygen consumption decreased. Values are median (25th, 75th percentile).

\begin{tabular}{|c|c|c|c|c|c|c|c|}
\hline \multicolumn{2}{|c|}{ Oxygen transport variables } & \multicolumn{3}{|c|}{ Hypoxic hypoxia } & \multicolumn{3}{|c|}{ Anemic hypoxia } \\
\hline \multirow[t]{3}{*}{$\mathrm{caO}_{2} \mathrm{crit}(\mathrm{ml} / \mathrm{dl}) *$} & lactate & 8.6 & $(6.4$ & 10.9) & 4.1 & $(4.0$ & 6.3) \\
\hline & lactate / pyruvate ratio & 7.5 & $(6.3$ & , 11.8) & 4.5 & $(3.5$ & $6.9)$ \\
\hline & $\mathrm{VO}_{2}$ & 7.2 & $(6.6$ & 9.6) & 5.4 & $(4.0$ & $6.0)$ \\
\hline \multirow[t]{3}{*}{$\mathrm{DO}_{2}$ crit $\left(\mathrm{ml} \cdot \mathrm{min}^{-1} \cdot \mathrm{kg}^{-1}\right)$} & lactate & 11.5 & $(10.4$ & 12.8) & 11.1 & $(10.2$ & 12.8) \\
\hline & lactate / pyruvate ratio & 12.4 & $(12.0$ & 13.0) & 12.0 & $(10.6$ & 13.9) \\
\hline & $\mathrm{VO}_{2}$ & 13.1 & $(11.4$ & , 13.8) & 12.9 & $(10.0$ & 13.8) \\
\hline \multirow[t]{3}{*}{$\mathrm{SvO}_{2}$ crit $(\%) *$} & lactate & 14 & $(11$ & 24) & 38 & $(30$ & 48) \\
\hline & lactate / pyruvate ratio & 16 & $(14$ & , 21) & 41 & $(26$ & 48) \\
\hline & $\mathrm{VO}_{2}$ & 15 & $(14$ & , 21) & 37 & $(27$ & 47) \\
\hline \multirow[t]{3}{*}{ F.O.E.crit } & lactate & 0.73 & $(0.66$ & $0.75)$ & 0.69 & $(0.67$ & $0.78)$ \\
\hline & lactate /pyruvate ratio & 0.72 & $(0.67$ & $0.73)$ & 0.68 & $(0.68$ & 0.77 ) \\
\hline & $\mathrm{VO}_{2}$ & 0.72 & $(0.71$ & $, \quad 0.74)$ & 0.71 & $(0.64$ & $0.76)$ \\
\hline
\end{tabular}

"*' - significant different between alveolar and anemic hypoxia. $\mathrm{DO}_{2}$ crit, critical value of oxygen delivery; $\mathrm{SvO}_{2}$ crit, critical value of mixed venous oxygen saturation; $\mathrm{CaO}_{2}$ crit, critical value of arterial oxygen content; F.O.E.crit, critical value of fractional oxygen extraction; $\mathrm{VO}_{2}$, oxygen consumption.

hypoxia group ( 3.5 to $6.9 \mathrm{ml} / \mathrm{dl}$ ) than in the hypoxic hypoxia group (6.3 to $11.8 \mathrm{ml} / \mathrm{dl}$ ) (table 3). The critical range for $\mathrm{SvO}_{2}$ below which lactate, the lactate/pyruvate ratio and $\mathrm{VO}_{2}$ rapidly changed from baseline value was significantly lower in hypoxic hypoxia than in anemic hypoxia (11 to $24 \%$ ) vs (26 to $48 \%$ ), respectively (table 3 ). Lactate and the lactate/pyruvate ratio increased and $\mathrm{VO}_{2}$ decreased at a low and small range of $\mathrm{SvO}_{2}$ values during hypoxic hypoxia, whereas during anemic hypoxia lactate and the lactate/pyruvate ratio increased and $\mathrm{VO}_{2}$ decreased at a higher and larger range of $\mathrm{SvO}_{2}$ values. (figure 4). No differences were found in the critical value of F.O.E.

\section{Discussion}

This study showed that in the case of anemic hypoxia, measuring $\mathrm{SvO}_{2}$ reflects better a reduced $\mathrm{DO}_{2}$ than does measuring $\mathrm{SaO}_{2}$. It also demonstrated that the critical range of $\mathrm{SvO}_{2}$ - the main parameter of residual oxygen in venous blood after tissue oxygen extraction - was $26 \%$ to $48 \%$ in anemic hypoxia, whereas the critical range in hypoxic hypoxia was $11 \%$ to $24 \%$. However, the critical values of $\mathrm{DO}_{2}$ and $\mathrm{FOE}$ showed no difference in hypoxic and anemic hypoxia. The decrease in $\mathrm{SvO}_{2}$ for an identical reduction of $\mathrm{DO}_{2}$ was significantly less in anemic hypoxia than in hypoxic hypoxia. These findings suggest that in anemic hypoxia, oxygen unloading from the blood to tissue is impaired. In agreement with this, our study found that fractional oxygen extraction (FOE) above the critical value at the lowest $\mathrm{DO}_{2}$ level was decreased in anemic hypoxia in comparison with hypoxic hypoxia. 

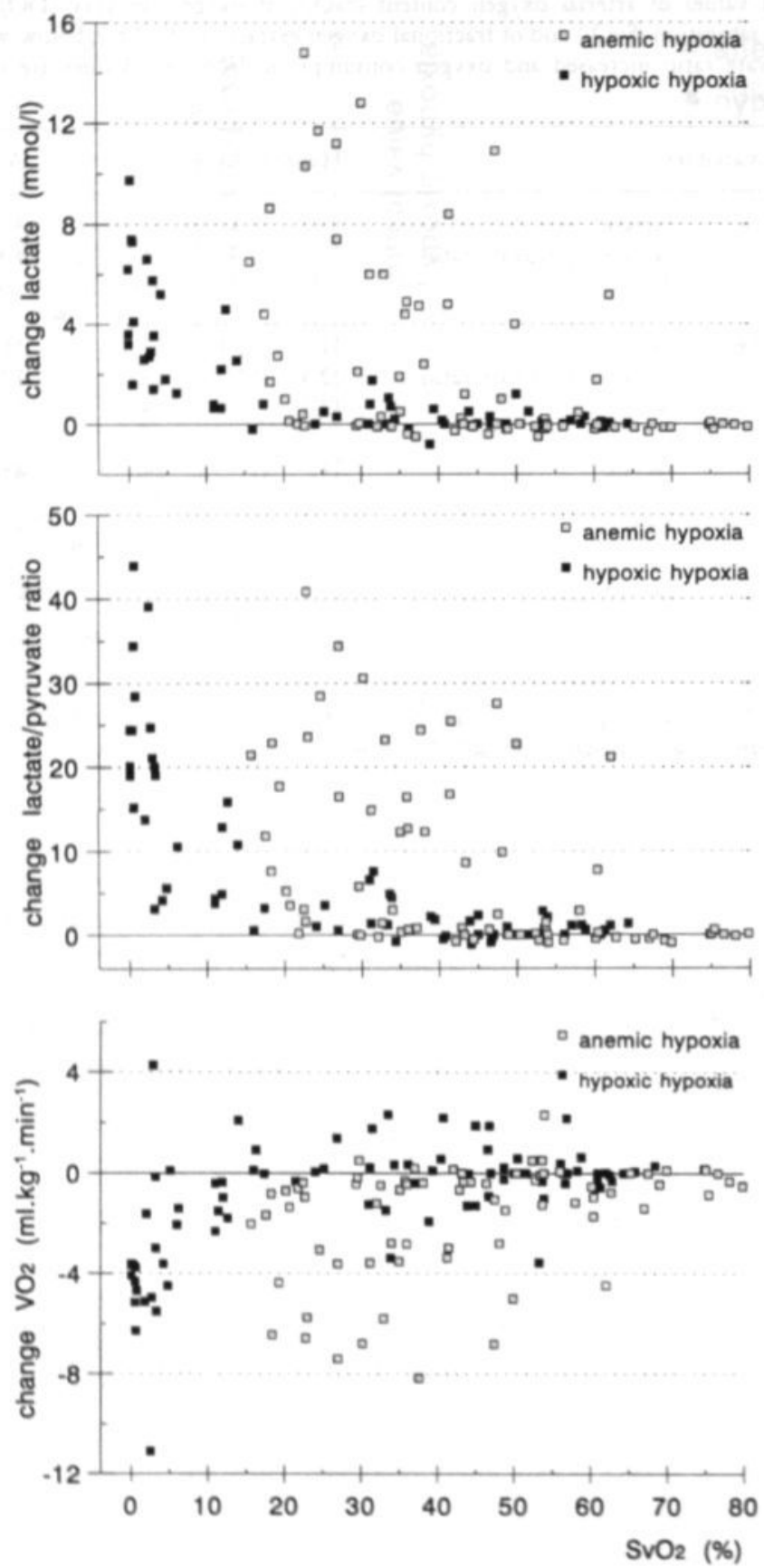

figure 4. Change lactate, lactate/pyruvate ratio and change oxygen consumption $\left(\mathrm{VO}_{2}\right)$ as a function of mixed venous oxygen saturation $\left(\mathrm{SvO}_{2}\right)$ during hypoxic and anemic hypoxia. Note, that during anemic hypoxia higher $\mathrm{SvO}_{2}$ values are associated with increased lactate, lactate/pyruvate ratio and decreased $\mathrm{VO}_{2}$. 
Before addressing the possible reasons for these findings, the model we used will be discussed. To compare the critical values of $\mathrm{SvO}_{2}$ in hypoxic and anemic hypoxia, a progressive graded hypoxia was induced either by administering different nitrogen/oxygen mixtures or performing repeated exchange transfusions. To compare these two different types of hypoxia, a $\mathrm{FiO}_{2}$ of 1.0 was maintained during anemic hypoxia to eliminate any element of hypoxemia.

Differences between the two groups with respect to hemoglobin level and $\mathrm{P}_{50}$ during baseline condition, could affect the response on graded progressive hypoxia. However, these differences did not have any influence on the baseline values of lactate, pyruvate, $\mathrm{VO}_{2}$, F.O.E. or of $\mathrm{SvO}_{2}$. The low hemoglobin level was compensated by an increased cardiac output. The shift of the oxygen dissociation curve affected possibly the value of $\mathrm{PvO}_{2}$ but not of $\mathrm{SvO}_{2}$.

Because of the prolonged procedure of exchange transfusion, the duration of the intervals was longer in the anemic hypoxia group ( 30 minutes) than in the hypoxic hypoxia group (15 minutes). The concept of $\mathrm{O}_{2}$ debt was introduced to account for this time aspect of the protocol. We analyzed the relation between $\mathrm{O}_{2}$ debt and lactate to control for the different durations of the intervals during the two types of hypoxia. $\mathrm{O}_{2}$ debt was linearly related to the change in lactate, but the coefficient of determination during hypoxic hypoxia and anemic hypoxia $\left(r^{2}-0.31 ; r^{2}-0.73\right.$, respectively), was not different from the coefficient of determination between the change in $\mathrm{VO}_{2}$ and the change in lactate $\left(r^{2}-\right.$ $\left.0.37 ; r^{2}-0.67\right) \cdot \mathrm{O}_{2}$ debt introduced to consider the different intervals in the model was not a better parameter of oxygen restricted metabolism than change in $\mathrm{VO}_{2}$. In both types of hypoxia, lactate increased significantly in the two lowest $\mathrm{DO}_{2}$ levels from baseline (table $1,2)$. The values of lactate and the lactate/pyruvate ratio were only used to determine the critical values of different parameters such as $\mathrm{DO}_{2}, \mathrm{CaO}_{2}$ and $\mathrm{SvO}_{2}$, below which lactate and the lactate/pyruvate increased. The increase itself was less important than the moment when the lactate and lactate pyruvate ratio started to increase. In agreement with this, critical values of the different parameters were not different when calculated either for a significant change in lactate or for a change in $\mathrm{VO}_{2}$. (table 3). Hence, we think that the findings in this study are a consequence of the differences in oxygen transport and not of the model we used.

There are several possible reasons to explain the higher values of $\mathrm{SvO}_{2}$ and $\mathrm{PvO}_{2}$ in anemic hypoxia in comparison with hypoxic hypoxia:

a) The reliability and accuracy of the fiberoptic catheter readings can be questioned at these low hemoglobin values. However, in several reports ${ }^{[1,14]}$ different fiberoptic catheter systems, including the one we used, reflected $\mathrm{SvO}_{2}$ values accurately during abrupt changes in cardiac output and hematocrit.

b) In anemic hypoxia, the full range of the oxyhemoglobin dissociation curve is used because even at the lowest $\mathrm{DO}_{2}$ level, high arterial $\mathrm{SaO}_{2}$ and $\mathrm{PaO}_{2}$, and consequently also higher values of $\mathrm{PvO}_{2}$ and $\mathrm{SvO}_{2}$, are found ${ }^{[15,16]}$.

c) Another possible explanation is the rightward shift in the oxyhemoglobin dissociation curve in anemic hypoxia. In the present study, $\mathrm{P}_{50}$ was increased during anemic hypoxia in comparison with hypoxic hypoxia, especially in the lower $\mathrm{DO}_{2}$ levels. However, one must be cautious to interpret the calculated $P_{5}$ values at oxygen saturation values below $20 \%$, because the changing value of $n$ in the Hill equation (because then only one heme group is involved in the oxygen binding) could cause a significant error in the calculated value of $\mathrm{P}_{50}[9,17]$.

The position of the oxyhemoglobin dissociation curve can be modulated by $\mathrm{Cl}$ and inorganic phosphate ions, by the level of 2,3-diphosphoglycerate, by the value of $\mathrm{pH}$ and by the hemoglobin level. In a bovine animal model it was demonstrated that the 
oxygen dissociation curve can be shifted to the right by the infusion of $\mathrm{Cl}$ and inorganic phosphate ions containing fluids ${ }^{[18]}$. In our study exchange transfusions were performed with pasteurized plasma containing normal electrolyte concentrations, but changes in $\mathrm{Cl}$ and inorganic phosphate ions after the exchange transfusions cannot be excluded. In adult patients anemia was associated with an increased level of 2,3-diphosphoglycerate, although in neonatal blood 2,3-diphospho-glycerate was not correlated with the hemoglobin concentration ${ }^{[17,19,20]}$. In the present study $\mathrm{pH}$ decreased significantly in the last two $\mathrm{DO}_{2}$ levels during anemic hypoxia in comparison with hypoxic hypoxia. This could be another reason for a rightward shift of the oxyhemoglobin curve during anemic hypoxia. However, studies examining the effect of a rightward shift in the oxyhemoglobin dissociation curve during normoxic and anemic hypoxic conditions demonstrated that differences in oxygen affinity have consequences for $\mathrm{PvO}_{2}$, but not or in a much lesser degree for $\mathrm{SvO}_{2}$ values or $\mathrm{CvO}$, $[21,22,23]$

d) Higher $\mathrm{SvO}_{2}$ values in anemic hypoxia can be explained through a redistribution of blood flow to different organs. $\mathrm{SvO}_{2}$ does not reflect the oxygen transport balance of any one individual organ, but is an average of saturation data from all perfused tissues, strongly affected by the blood flow through these tissues ${ }^{[24]}$. When the perfusion through high-blood flow and low-oxygen extraction organs increases, the $\mathrm{SvO}_{2}$ value also increases.

During hypoxic hypoxia, a variable and transient response of cardiac output was reported consisting of a redistribution of the regional blood flow in favor of heart and brain and a decrease to the skin, gastrointestinal tract, kidneys and spleen, whereas blood flow to the carcass remained unchanged ${ }^{[2,27]}$. The response in lambs and adult sheep was qualitatively similar for heart and brain with an increase in blood flow, whereas the response differed for the skin, kidney and gastrointestinal tract, in which flow decreased in neonatal sheep and was unchanged or increased in adult sheep ${ }^{[28]}$.

During anemic hypoxia on anesthetized dogs ${ }^{[29]}$, a marked increase in cardiac output was found, with a redistribution in favor of the myocardium and brain. Kidney, liver and gastro-intestinal tract blood flow remained unchanged, which resulted in a linear decrease in oxygen transport to these organs. In anesthetized pigs ${ }^{(30)}$, isovolemic anemic hypoxia resulted in a two-fold increase in cardiac output, with a redistribution in favor of the heart and brain. However, flow increased in all organs including the liver, gastrointestinal tract and kidney.

Interpreting these different studies performed in different species at different ages is difficult. It is clear that in all species, in both hypoxic hypoxia and anemic hypoxia, a regional redistribution of blood flow occurs in favor of the heart and brain. During hypoxic hypoxia, the response in other organs seems to be dependent on age of the animal, with a trend toward more vasoconstriction in younger animals ${ }^{[28]}$. During anemic hypoxia, regional redistribution of the blood flow to other organs than the heart and brain was studied in adult animals and is reported to be unchanged or increased ${ }^{[29,50]}$. The difference in regional redistribution and the unchanged or increased flow to low-oxygen extraction organs in anemic hypoxia can explain to a certain extent the higher $\mathrm{SvO}_{2}$ value observed in anemic hypoxia.

e) Another reason for higher values of $\mathrm{PvO}_{2}$ and $\mathrm{SvO}_{2}$ during anemic hypoxia is an impairment of oxygen uptake at the tissue level. At the lowest $\mathrm{DO}_{2}$ level, we found a lower FOE during anemic hypoxia in comparison with the lowest $\mathrm{DO}_{2}$ level during hypoxic hypoxia (table 2). Tissue oxygen uptake in anemic hypoxia has been related to increased red cell spacing and capillary architecture ${ }^{[31]}$. Hemodilution induces an increased red cell spacing in the capillary bed. The induced expansion of the plasma phase, with its very low oxygen solubility, limits the ability to transfer oxygen from the red cells to the tissues and affects the uniformity of oxygen flux at the capillary wall ${ }^{[0.33]}$. 
The influence of microvascular architecture of the tissues on oxygen exchange was studied in the cheek retractor muscle of the hamster ${ }^{[4,35]}$. In these studies, a more complex tissue oxygenation was demonstrated than Krogh's oxygen transport model, which postulated that oxygen is transferred to the capillaries by convection and released from these capillaries by diffusion. The release of oxygen from a capillary seems to be strongly influenced by its proximity to arterioles and venules, which either supply oxygen to the capillaries or augment its release. These diffusive interactions might change under different hemodynamic conditions. The effect of limited isovolemic hemodilution on microcirculatory hemodynamics and the rate of oxygen transport was studied ${ }^{[56]}$. Because the red blood cell velocity is increased and the red blood cell residence time is reduced during isovolemic hemodilution, a decrease in precapillary oxygen release and in diffusional oxygen transfer to other microvessels was found.

These proposed mechanisms could explain to some extent the higher $\mathrm{PvO}_{2}$ and $\mathrm{SvO}_{2}$ values found in our study during anemic hypoxia in comparison with hypoxic hypoxia. Therefore, our hypothesis that similar critical $\mathrm{SvO}_{2}$ values would be observed in both hypoxic hypoxia and anemic hypoxia was not confirmed.

Previous studies described and compared oxygen transport parameters during different types of hypoxia. The effect of hemoglobin concentration on critical oxygen transport was examined during progressive reductions of cardiac output in one-month old lambs ${ }^{[15]}$. The authors reported a range of critical $\mathrm{PvO}_{2}$ values $(31-36 \mathrm{mmHg})$, irrespective of the variation of hemoglobin concentrations. The difference between these results and ours may be explained in several ways. In this study hemoglobin was only moderately reduced, two factors of oxygen delivery -hemoglobin and cardiac output- were simultaneously modulated and $\mathrm{SaO}_{2}$ was equivalent under all hypoxic conditions. Our results were consistent with the findings of Cain ${ }^{[16,37]}$, who compared hypoxic hypoxia and anemic hypoxia in adult anesthetized dogs and reported different critical values of $\mathrm{PvO}_{2}$ of 17 $\mathrm{mmHg}$ and $45 \mathrm{mmHg}$, respectively. A critical value of $\mathrm{SvO}_{2}$ of $44 \%$, similar with our findings, was reported by Trouwborst et al. ${ }^{[38]}$ during anemic hypoxia in adult pigs, but was not compared with critical values during hypoxic hypoxia. Developmental aspects could account for the different critical F.O.E. value of 0.57 in this adult pig model.

We conclude that the critical value of $\mathrm{SvO}_{2}$ is dependent on the type of hypoxia and is higher in anemic hypoxia. Although developmental and interspecies aspects should be not be disregarded, these characteristics in oxygen transport and capillary hemodynamics should be taken into consideration, when $\mathrm{SvO}_{2}$ is used in clinical critical care.

\section{References}

1 O'Connor TA, Hall RT: Mixed venous oxygenation in critically ill neonates. Crit Care Med 1994:22:343-346

2 Bartlett RH, Cilley RE: Physiology of extracorporeal life support. In: Arensman RM, Cornish JD (eds). Extracorporeal life support. Boston, Blackwell, 1993: pp 89-104

Dudell G, Cornisch JD, Bartlett RH: What constitutes adequate oxygenation? Pediatrics 1990,85:39. 41

Hoeven MAHBM van der, Maertzdorf WJ, Blanco CE: Feasibility and accuracy of a fiberoptic catheter for the measurement of venous oxygen saturation in newborn infants. Acta Paediatr 1995;84:122-127

Hoeven MAHBM van der, Maertzdorf WJ, Blanco CE: Continuous central venous oxygen saturation $\left(\mathrm{ScvO}_{2}\right)$ measurement using a fibreoptic catheter in newborn infants. Arch Dis Child 1996; $74: f 177-f 181$ 
Kreisberg RA: Lactate homeostasis and lactic acidosis. Ann Intern Med 1980;92(1):227-237

Mizock BA, Falk JL: Lactic acidosis in critical illness. Crit Care Med 1992;20:80-93

Hoeven MAHBM van der, Maertzdorf WJ, Blanco CE: Mixed venous oxygen saturation $\left(\mathrm{SvO}_{2}\right)$ and biochemical parameters of hypoxia during progressive hypoxemia in 10-14 day old piglets. Pediatr Res 1997; 42:878-884

Brown EG, Krouskop RW, McDonnel FE et al: A technique to continuously measure arteriovenous oxygen content difference and $\mathrm{p}_{\mathrm{s}}$ in vivo. J Appl Physiol 1985;58:1383-1389.

Mellits ED: Statistical methods. In: Cheek DB (ed) Human Growth. Philadelphia, Lea \& Febiger, 1968: 19-38

Fahey JT, Lister G: Postnatal changes in critical cardiac output and oxygen transport in conscious lambs. Am J Physiol 1987;253:H100-H106

Samsel RW, Schumaker PT: Determination of the critical $\mathrm{O}_{2}$ delivery from experimental data: sensitivity to error. J Appl Physiol 1988;64:2074-2082

Woerkens ESM van, Trouwborst A, Tenbrinck R: Accuracy of a mixed venous saturation catheter during acutely induced changes in hematocrit in humans. Crit Care Med 1991;19:1025-1029

Woerkens ECSM van, Trouwborst A, Tenbrinck R: Comparative study of the accuracy of two fiberoptic mixed venous saturation catheters (Spectracath vs Opticath) during acute in hematocrit and cardiac output in humans. In: Erdmann W, Bruley DF. eds. Oxygen transport to tissue XIV. New York, Plenum Press, 1992: 509-514

Heusser F, Fahey JT, Lister G: Effect of hemoglobin concentration on critical cardiac output and oxygen transport. Am J Physiol 1989;253:H527-H532

Cain SM: Peripheral oxygen uptake and delivery in health and disease. Clinics in Chest Med 1982;4:139-148

Wimberley PD: Fetal hemoglobin, 2,3-diphosphoglycerate and oxygen transport in the newborn premature infant. Scand J Clin Lab Invest 1982;42:Supp 160:1-149

Gustin P. Detry B, Cao ML, et al: Chloride and inorganic phosphate modulate binding of oxygen to bovine red blood cells. J Appl Physiol 1994;77:202-208

Nunn JF: The carriage of oxygen in the blood. in Nunn's applied respiratory physiology 4th ed. Oxford, Butterworth-Heinemann, 1993: 269-282

Robertie PG, Gravlee GP: Safe limits of isovolemic hemodilution and recommendations for erythrocyte transfusion. Int Anesth Clin 1990;28:197-204

Van Ameringen MR, Fouron JC, Bard $\mathrm{H}$, et al: Oxygenation in anemic newborn lambs with high or low oxygen affinity red cells. Pediatr Res 1981;15:1500-1503

Fouron JC, Bard H, Guennec Le JC, et al: Effect of fetal or adult red cells on tissue oxygenation and myocardial function in normoxemic newborn lambs. Pediatr Res 1981;15:967-970.

Lister G: Oxygen transport in the intact hypoxic newborn lamb: Acute effects of increasing pe. Pediatr Res 1984:16:172-177

Ceraianu AC, Nelson LD: The significance of mixed venous oxygen saturation and technical aspects of continuous measurement. In: Edwards JD, Shoemaker WC, Vincent JL (Eds) Oxygen transport; Principles and practice. London, Saunders, 1993: 99-124

Moss M, Moreau G, Lister G: Oxygen transport and metabolism in the conscious lamb: the effects of hypoxemia. Pediatr Res 1987;22:177-183

Sidi D, Kuipers JRG, Teitel D et al: Developmental changes in oxygenation and circulatory responses to hypoxemia in lambs. Am J Physiol 1983;245:H674-H682

Kuwahira I, Gonzales NC, Heisler N et al: Changes in regional blood flow distribution and oxygen supply during hypoxia in conscious rats. J Appl Physiol 1993;74:211-214

Koehler RC, Traystman RJ. Jones Jr MD: Regional blood flow and $\mathrm{O}_{2}$ transport during hypoxic and CO hypoxia in neonatal and adult sheep. Am J Physiol 1985;245:H118-H124.

Fan FC, Chen RYZ, Schuessler GB et al: Effects of hematocrit variations on regional hemodynamics and oxygen transport in the dog. Am J Physiol 1980;238:H545-H552 
30 Woerkens ECSM van, Trouwborst A, Duncker DJGM, et al: Catecholamines and regional hemodynamics during isovolemic hemodilution in anesthetized pigs. J Appl Physiol 1992;72:760. 769

31 Biro GP, Anderson PJ, Curtis SE et al: Stroma free hemoglobin: its presence does not improve oxygen supply to the resting hindlimb vascular bed of hemodiluted dogs. Can J Physiol Pharmacol 1991;69:1656-1662

32 Federspiel WJ, Salerius RH: An examination of the contribution of red cell spacing to the uniformity of oxygen flux at the capillary wall. Microvasc Res 1984;27:273-285.

33 Popel AS: Theory of oxygen transport to tissues. Crit Rev Biomed Engin 1989;17:257-321.

34 Ellsworth ML, Pittman RN: Arterioles supply oxygen to capillaries by diffusion as well by convection. Am J Physiol 1990;258:H1240-H1243.

35 Pittman RN: Influence of microvascular architecture on oxygen exchange in skeletal muscle. Microcirculation 1995;2:1-18.

36 Kuo L, Pittman RN: Effect of hemodilution on oxygen transport in arteriolar networks of hamster striated muscle. Am J Physiol 1988;254:H331-H339.

37 Cain SM: Oxygen delivery and uptake in dogs during anemic and hypoxic hypoxia. J Appl Physiol 1977;42:228-234.

38 Trouwborst A, Tenbrinck R, Woerkens ECSM van: Blood gas analysis of mixed venous blood during normoxic acute isovolemic hemodilution in pigs. Anaesth Analg 1990;70:523-529

Acknowledgement: Supported by Abbott Inc, The Netherlands 


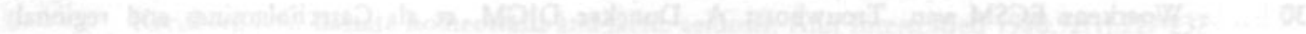
The

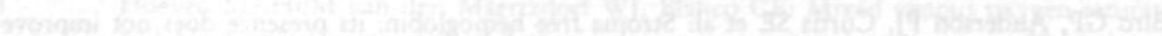

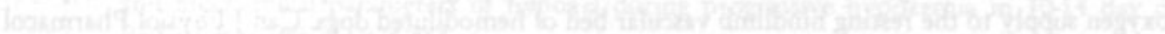

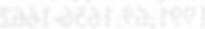




\section{Chapter 5}

Feasibility and accuracy of a fiberoptic catheter for the measurement of venous oxygen saturation in newborn infants.

Mark A.H.B.M. van der Hoeven, Wiel J. Maertzdorf, Carlos E. Blanco

Acta Paediatrica 1995;84:122-127 


\begin{abstract}
The current parameters of oxygenation, arterial oxygen saturation and arterial oxygen pressure represent the availability of oxygen to the tissues. Venous oxygen saturation reflects oxygen extraction and could be a more useful indicator of tissue oxygenation. Therefore, we tested the feasibility and accuracy of a fiberoptic catheter, inserted into the right atrium via the umbilical vein, to measure venous oxygen saturation, continuously. In 24 of $36(67 \%)$ infants the catheter could be placed into the right atrium. Blood samples were withdrawn through the catheter, analyzed with a hemoximeter and compared with simultaneously recorded oximeter values. The fiberoptic catheter readings correlated significantly with hemoximeter values and the mean difference of the 116 paired samples was $-0.37 \%$.

We conclude that the success rate and complications of the fiberoptic catheter were similar to previously published results. The oxygen saturation readings accurately represented oxygen saturation in the right atrium in newborn infants.
\end{abstract}




\section{Introduction}

For more than a decade continuous venous oxygen saturation measurements through a fiberoptic catheter in the pulmonary artery have been used in critically ill adult patients $^{[1,2,3]}$ and postoperative cardiac surgical patients ${ }^{[4,5]}$. In neonatal medicine the current clinical parameters of oxygenation, arterial oxygen pressure $\left(\mathrm{paO}_{2}\right)$ and arterial oxygen saturation $\left(\mathrm{SaO}_{2}\right)$ are poor indicators of tissue oxygenation, because they represent only the availability of oxygen to the tissues. The actual amount of oxygen in the blood, the arterial $\mathrm{O}_{2}$ content $\left(\mathrm{caO}_{2}\right)$, is determined by the $\mathrm{paO}_{2}$, the hemoglobin concentration $(\mathrm{Hb}), \mathrm{O}_{2}$ carrying capacity and the $\mathrm{SaO}_{2}$.

$$
\mathrm{caO}_{2}=\mathrm{paO}_{2} \times 0.0031+1.36 \times \mathrm{Hb} \times \mathrm{SaO} 2
$$

Oxygen delivery $\left(\mathrm{DO}_{2}\right)$ to the tissues is determined by arterial oxygen content $\left(\mathrm{caO}_{2}\right)$ and the cardiac output $(\mathrm{Q} t)$.

$$
\mathrm{DO}_{2}=\mathrm{CaO}_{2} \times \mathrm{Qt}
$$

Overall tissue oxygen extraction $\left(\mathrm{VO}_{2}\right)$ is the product of cardiac output and the difference between arterial and mixed venous oxygen content $\left(\mathrm{cvO}_{2}\right)$.

$$
\mathrm{VO}_{2}=\mathrm{Qt} \times\left(\mathrm{caO}_{2} \cdot \mathrm{cvO}_{2}\right)
$$

As the contribution of $\mathrm{paO}_{2}$ to oxygen content can be neglected, the equation for $\mathrm{VO}_{2}$ can be expressed as:

$$
\begin{aligned}
& \mathrm{vO}_{2}=\mathrm{Qt} \times 1.36 \times \mathrm{Hb} \times 10 \times\left(\mathrm{SaO}_{2}-\mathrm{SvO}_{2}\right) \\
& \mathrm{SvO}_{2}=\mathrm{SaO}_{2}-\mathrm{VO}_{2} / \mathrm{Qt} \times 1.36 \times \mathrm{Hb} \times 10
\end{aligned}
$$

Therefore, venous saturation $\left(\mathrm{SvO}_{2}\right)$ is directly related to arterial oxygen saturation, cardiac output and hemoglobin. However, $\mathrm{SvO}_{2}$ also reflects tissue oxygen extraction and could be a more useful indicator of tissue oxygenation ${ }^{[6]}$.

However, measurement of mixed venous oxygen saturation in small newborn infants through a catheter in the pulmonary artery is hazardous and difficult. On the other hand, catheter placement into the right atrium through the umbilical vein via the ductus venosus is common practice in neonatal care and has a low incidence of complications ${ }^{(7,8)}$. Therefore, we tested the feasibility of a fiberoptic catheter, placed in the right atrium via the umbilical vein, to measure central venous oxygen saturation $\left(\mathrm{ScvO}_{2}\right)$. Furthermore we determined the accuracy of the continuous oxygen saturation readings.

\section{Patients and methods}

This study was approved by the Ethics Committee of the Academic Hospital, Maastricht. The patient population of the feasibility study included 36 infants receiving care on the neonatal intensive care unit. Their clinical condition (Table 1) warranted insertion of an umbilical vein, according to our practice.

The fiberoptic catheter system (Oximetrix System, Abbott Laboratories, North Chicago, IL, USA) includes an optical module, a fiberoptic catheter and a microprocessor- 
based oximeter. The light source in the optical module of the Oximetrix system consists of three diodes emitting light at three different wavelengths $\lambda_{1}=670 \mathrm{~nm}, \lambda_{2}=700 \mathrm{~nm}$ and $\lambda_{3}=800 \mathrm{~nm}$.

A pulse generator sequentially activates each diode for $1 \mathrm{~ms}$ followed by an equal interval when no diodes are energized. This four period cycle occurs at a rate of $244 \mathrm{~Hz}$ [9].

The four french fiberoptic catheter consists of two lumens: one lumen includes the two fiberoptics to transmit the light to and from the blood; the other internal lumen leads from a distal end hole to a standard Luer-Lock hub. This lumen is used for administration of medication and fluids, blood sampling and blood pressure measurement. Performance is similar to that of a 3.5 French single lumen catheter.

Light reflected from the oxygenated and unoxygenated blood is transmitted by the receiving fiberoptic bundle to a photodetector in the optical module. The oximeter computes percentage oxygen saturation values based on the electrical signals from the optical module. The mean value for oxygen saturation over a $5 \mathrm{~s}$ period is displayed digitally, and this value is updated every $1 \mathrm{~s}$.

The Oximetrix computer monitors continuously the optical intensity of the reflected light to warn for abnormal signal conditions. A change of $\pm 30 \%$ in the mean received intensity signal gives a light intensity alarm message as it may indicate a significant change in light reflectance conditions at the catheter tip.

Before insertion the system was calibrated according to the manufacturer's instructions and methodology. This calibration procedure was performed to a disposable standard optical reference, packaged with each catheter. The proper location of the catheter was facilitated by the continuous display of the oxygen saturation value at the tip of the catheter during the insertion procedure. The catheter position was defined as correct when the catheter was positioned in the mid-atrial level or at the transition of the inferior vena cava and the right atrium; the position was evaluated by X-ray and ultrasound techniques. An in vivo calibration was performed after stabilization and establishment of the proper position of the catheter. This calibration procedure was performed at least every 12 hour to check for incorrect oxygen saturation readings. A correction was only performed only when the hemoximeter values of the oxygen saturation in correlated samples showed a discrepancy of $\geq 5 \%$. A constant low rate $(0.1 \mathrm{cc} / \mathrm{h})$, heparinized saline $(0.5 \mathrm{U} / \mathrm{cc})$ infusion was administered continuously through the catheter to avoid fibrin formation in the fiberoptic catheter. After removal of the catheter the tip was inspected for fibrin clot formation.

The objective variables to assess the feasibility of the fiberoptic catheter system included: (a) catheter placement in the proper position; (b) total time the catheters were in place; (c) fibrin clot formation; and (d) incidence of complications.

To determine the accuracy of the oxygen saturation values given by the fiberoptic catheter system, blood samples $(0.4 \mathrm{ml})$ were withdrawn through the catheter and immediately analyzed with a hemoximeter (Radiometer OSM3), which was calibrated routinely every hour.

Data are presented as mean \pm SD. The unpaired Student's $t$-test or Yates' corrected chi-square test was used, where appropriate, to evaluate statistical difference between the groups of patients in which the catheter was properly placed. The in-vivo fiberoptic catheter values and the in-vitro hemoximeter values were analyzed by the least squares method, which yielded a regression line and correlation coefficient. Furthermore, data were analyzed comparing the difference against the mean of the two values ${ }^{[10]}$. The mean difference and SD were calculated and the change in the mean difference with time was estimated. The effect of recalibration was calculated and analyzed using the Student' s $t$-test. Tests were considered to be significant for $p \leq 0.05$. 


\section{Results}

In 24 patients $(67 \%)$ the fiberoptic catheter was placed in the correct position, i.e. at the mid-atrial level or at the transition of the vena cava inferior and the right atrium. The characteristics and diagnostic categories of the 36 patients are summarized in table 1. There were no significant differences between the groups in which the catheter was placed successfully and those in which it was not placed.

Table 1: Birth weight (BW), gestational age (GA), gender, diagnosis and outcome in patients with successful compared with unsuccessful placement of the fiberoptic catheter system. Data are presented as mean $\pm \mathrm{SD}$ or number. There were no significant differences between the two groups.

\begin{tabular}{lll}
\hline & Success $(\mathrm{n}-24)$ & Failure $(\mathrm{n}-12)$ \\
\hline BW $(\mathrm{g})$ & $1484 \pm 883$ & $1747 \pm 883$ \\
GA (weeks) & $30.3 \pm 4$ & $31.6 \pm 5$ \\
Sex (M/F) & $14 / 10$ & $6 / 6$ \\
Mortality & 7 & 3 \\
IRDS & 16 & 7 \\
Asphyxia & 5 & 2 \\
Lung hypoplasia & 2 & 1 \\
Streptococcus group B & 1 & 2 \\
\hline
\end{tabular}

The catheters were left in place for an average of $107 \mathrm{~h}$ (range $1 \mathrm{~h} 20 \mathrm{~min}$ to 172 h). In six infants, at the end of the indwelling period, the light intensity alarm of the fiberoptic catheter system indicated that the signal was affected by unusually small light reflectance at the cathetertip; at that time saturation readings were not considered to be reliable. On two occasions fibrin clot formation was seen by ultrasound in the right atrium around the tip of the catheter. The clots disappeared gradually without therapeutic intervention after removal of the catheter. Small fibrin clots at the tip of the catheter were seen in five infants $(18 \%)$ at inspection after removal.

Complications such as pericardial effusions, cardiac tamponade, cardiac arrhythmias or perforations were not seen.

In order to establish the accuracy of the fiberoptic catheter system, 116 samples were withdrawn through the catheter. These measurements were performed 1-161 h after birth. The median time interval between the samples was $6 \mathrm{~h}$ (10th and a 90th percentiles of 2 and $19 \mathrm{~h}$, respectively).

Correlation analysis of the 116 paired measurements showed a significant correlation $(r-0.93, p<0.001)$, while regression analysis gave the following equation: $y=$ $0.96 x+2.96$ (Fig. 1). The statistical method for assessing agreement between two methods of measurement (10) showed a mean difference of -0.36 percentage points with $95 \%$ confidence intervals of +0.01 to -0.71 . The limits of agreement (mean $\pm 2 \mathrm{SD}$ ) were +7.28 and -8.00 (Fig 2).

The first blood sample after pre-insertion calibration showed a comparable mean difference of $0.57 \%$, with limits of agreement of +7.09 and -5.95 between the hemoximeter and fiberoptic catheter recorded readings.

Figure 3 shows the mean difference and SD between the fiberoptic catheter and the hemoximeter measurements with time. There was no significant effect with time during the study. 


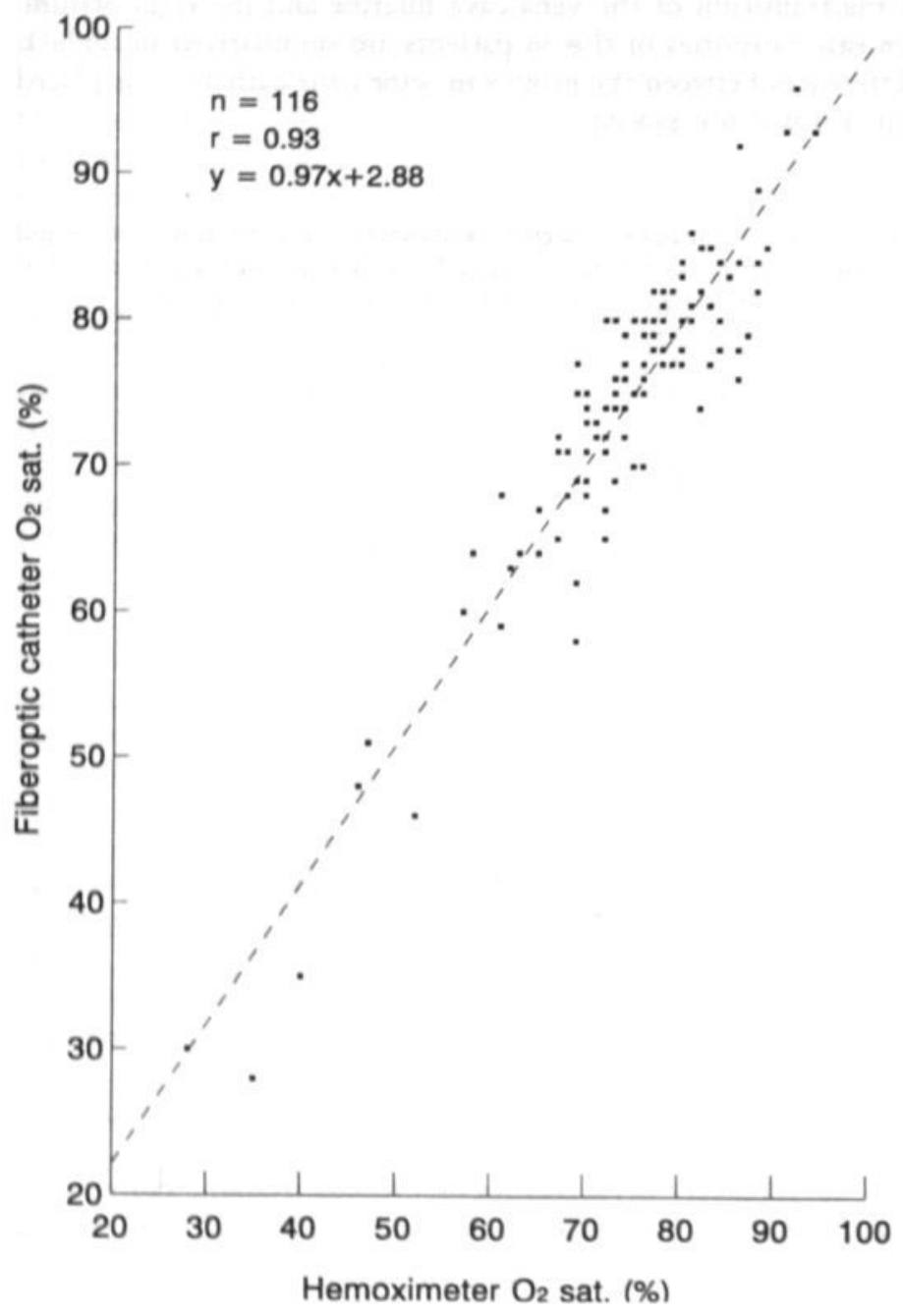

figure 1: Comparison of oxygen saturation values for the fiberoptic catheter with those obtained with the hemoximeter. (linear regression)

In 30 of the 116 samples a discrepancy of $\geq 5 \%$ of more was noted and only then was a correction performed. The actual degree to which the catheter values varied from the hemoximeter readings before they were recalibrated was mean 6.3\% (SD 1.2\%). The effect of recalibration was tested by ignoring the sample values taken after recalibration. The mean difference and SD $(-0.54 \pm 3.70)$ of the uncorrected remaining samples were compared with the mean difference of the values taken after recalibration $(0.45 \pm 4.42)$ and with the previously described mean difference and SD $(-0.36 \pm 3.82)$ of all 116 sample values. Using the unpaired Student's t-test a significant difference could not be demonstrated $(p=0.29$ and 0.74 , respectively). 


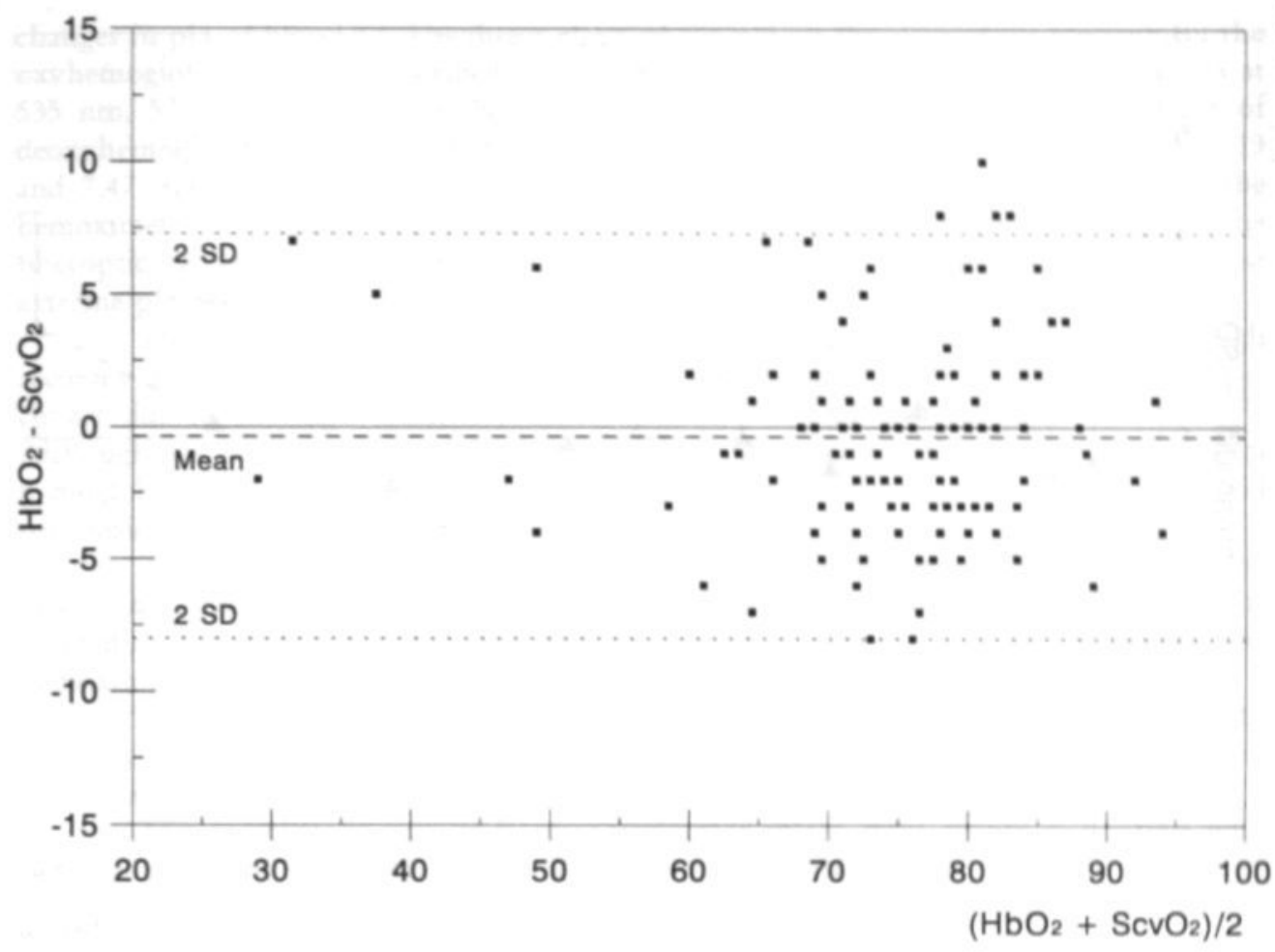

Figure 2: Difference between the fiberoptic catheter $\left(\mathrm{SvO}_{2}\right)$ and the hemoximeter $\left(\mathrm{HbO}_{2}\right)$ values against their means. The mean difference $( \pm 2 \mathrm{SD})$ was $-0.36 \pm 7.64$.

\section{Discussion}

This study reports the feasibility and accuracy of a fiberoptic catheter inserted via the umbilical vein into the right atrium for the measurement of venous oxygen saturation in newborn infants. This study, however, was not designed to describe critical values of $\mathrm{ScvO}_{2}$ in newborn infants or its clinical applications in neonatal intensive care. Although umbilical venous catheterization is a long established and widely used technique in critically ill infants, two drawbacks of this procedure have been reported. Ideally, the tip of the umbilical venous catheter should be placed in the inferior vena cava near the right atrium. The success rate of passing the catheter through the ductus venosus is about $60 \%[7,11,12]$. In this study the fiberoptic catheter was placed successfully into the right atrium in $67 \%$ of infants. This of course could be improved by placing the catheter through another vein by a more invasive technique; however, since its clinical application has not been proved, we decided to place the catheter using the well established umbilical venous catheterization. The other problem is the incidence of fibrin clot formation, varying from small thrombi in the catheter to severe portal vein thrombosis ${ }^{[1]}$. The reported incidence varies from 3 to $44 \%{ }^{[14]}$. In our study we found fibrin clot formation in seven $(29 \%)$ infants.

Despite these drawbacks, umbilical venous catheterization is a common procedure because it is a rapid and simple technique ${ }^{[15]}$. 


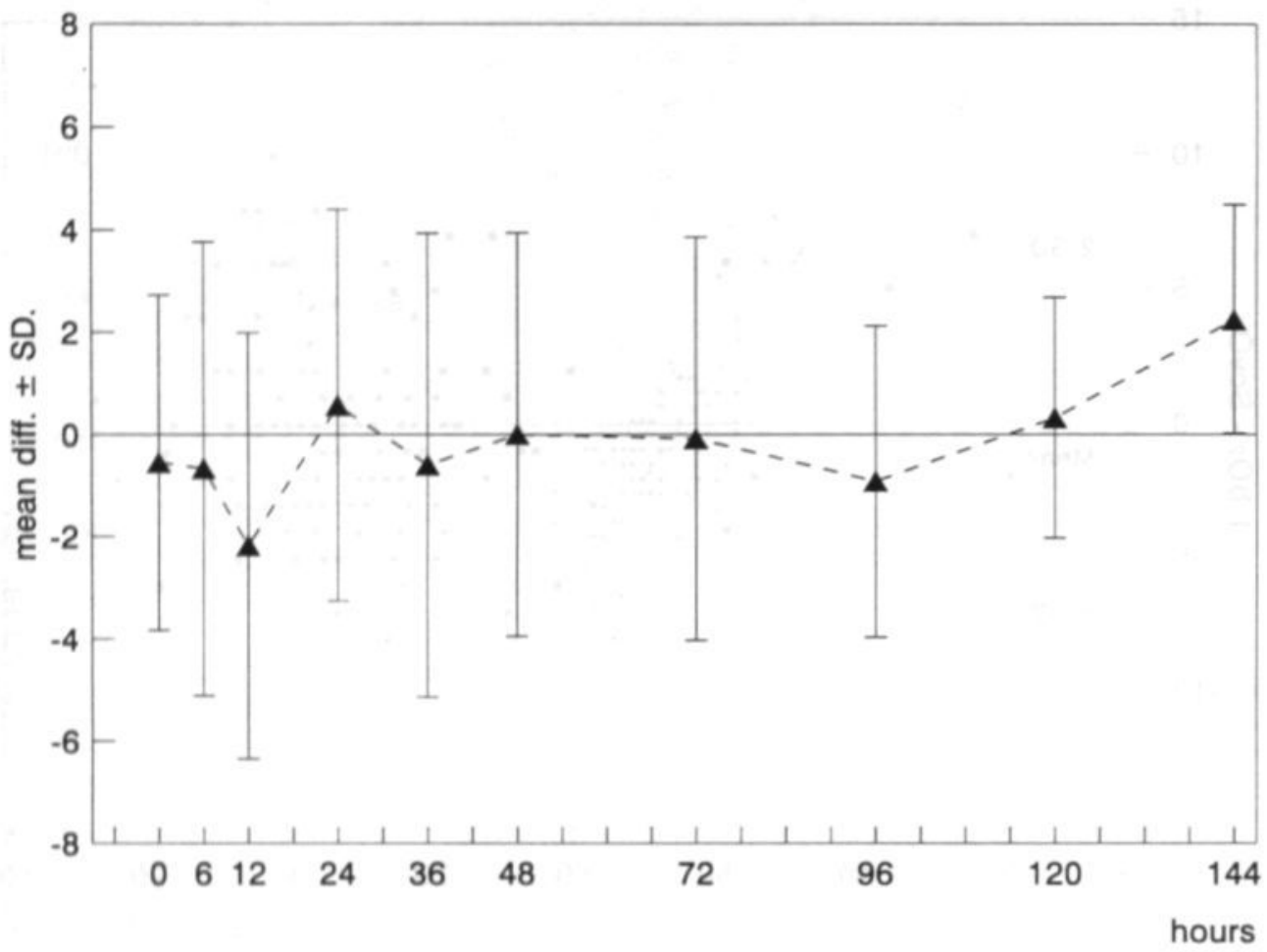

figure 3: Mean difference and $\mathrm{SD}$ between the fiberoptic catheter $\left(\mathrm{SvO}_{2}\right)$ and the hemoximeter $\left(\mathrm{HbO}_{2}\right)$ values with time (note that there was no drift with time).

The fiberoptic catheter did not differ in its usefulness from the standard umbilical catheters regarding administration of fluid, medication and monitoring central venous blood pressure. The catheters were left in place as long as was necessary for clinical management.

This study is the first report on the accuracy of venous oxygen saturation readings in the right atrium in a population of neonatal intensive care patients. The accuracy of the fiberoptic catheter has been demonstrated previously in the umbilical and pulmonary artery, for which the fiberoptic catheter originally was designed.

Previous studies on accuracy in adult intensive care medicine reported that $\mathrm{SvO}_{2}$, analyzed using the least squares method, was significantly correlated with hemoximeter values ${ }^{[16,17]}$. In our study the same correlation coefficient and regression equation were found as in those previous reports ${ }^{[16-18]}$. The correlation coefficient and regression analysis must be used with caution when it is used to compare two methods measuring the same parameter ${ }^{[10,19]}$.

Another possibility and perhaps more appropriate is the use of a plot of the difference between the two values against their mean, with calculation of the mean difference and SD (see Fig. 2). The limits of agreement (mean \pm 2 SD) $(+7.28$ and -8.00$)$ were small enough to consider the readings of venous oxygen saturation reliable. These limits of agreement were comparable with previous reports using this statistical method ${ }^{[20,21]}$.

Because of the similar mean difference in the first blood sample, the oxygen saturation readings after preinsertion calibration can be considered to have been accurate and reliable and facilitated the proper location of the catheter during the insertion procedure. Spectrophotometric measurement of oxygen saturation may be biased by 
changes in $\mathrm{pH}$ of blood ${ }^{[2]}$. The direct effect of the $\mathrm{pH}$ on the absorption spectrum of the oxyhemoglobin has been described at $\mathrm{pH} 6.8$ and 7.6 with dissimilar absorption peaks at $535 \mathrm{~nm}, 577 \mathrm{~nm}$ and $600 \mathrm{~nm}$. No effect was observed on the absorption spectrum of deoxyhemoglobin. However, in the $\mathrm{pH}$ range (median 7.34: 5th and 95th percentile 7.19 and 7.47 , respectively) we have encountered, measurement of oxygen saturation in the hemoximeter may reflect an inaccuracy of up to $1 \%$, which is acceptable ${ }^{[22]}$. Moreover, the fiberoptic catheter measures absorbance at wavelengths that are not influenced by these extreme $\mathrm{pH}$ values.

The multiwave length spectrophotometer Radiometer OSM (3) showed very high accuracy and precision in the measurement of oxygen saturation. A potential small inaccuracy due to the high sensitivity of the presence of fetal hemoglobin may occur [2] Although we did not measure fetal hemoglobin, we assumed that the fraction of fetal hemoglobin in the samples was variable due to the intensive care practice of giving blood transfusions after sampling a definite amount of blood.

The saturation values $>88 \%$ shown in Figs 1 and 2, were from samples taken before the catheter was withdrawn from the left atrium. In this study we described the correlation between values obtained from the catheter system and samples analyzed by the hemoximeter; therefore we decided to include these values in the study.

Other reports ${ }^{[16,1]}$ have shown a tendency for $\mathrm{SvO}_{2}$ measurement to drift with time and become increasingly inaccurate. In our study no significant change in the difference and SD with time was found (Fig. 3).

Measurements in our study were performed in the right atrium in contrast with previous reports in adults where venous oxygen saturation was measured in the pulmonary artery. No evidence was found for a systematic difference between right atrial and pulmonary arterial oxygen saturations over a wide range of hemodynamic conditions both in an animal model and in adults ${ }^{[24,25,26]}$. Other reports have described a poor correlation between right atrial and pulmonary arterial oxygen saturations when absolute numerical values were compared ${ }^{[2]}$. However, a better correlation was observed when subsequent changes of the right atrial and pulmonary arterial saturations were compared ${ }^{[2]}$. Therefore venous oxygen saturation monitoring in the right atrium is useful for following trends and changes in oxygenation status ${ }^{[28]}$. Intracardiac left-to-right shunting through the foramen ovale is common in premature infants, but it is not responsible for differences in right atrial and pulmonary arterial saturations. However, variable shunting across the foramen ovale and/or incomplete mixing of blood in the right atrium can be a problem and is another argument for cautions with the use of exact numerical values of venous saturation.

This study demonstrated the feasibility of the use of a fiberoptic catheter for measurement of venous oxygen saturation in the right atrium with a low incidence of complications. The oxygen saturation readings using this system represented accurately and reliably blood oxygen saturation over a wide range.

In neonatal medicine, knowledge of real tissue oxygen needs is very important because hypoxia, as well as hyperoxia, have their deleterious effects. The current clinical parameters $\left(\mathrm{paO}_{2}\right.$ and $\left.\mathrm{SaO}_{2}\right)$ represent only partially the availability of oxygen to the tissues, and disregard other parameters as blood flow, hemoglobin and tissue oxygen consumption. $\mathrm{ScrO}_{2}$, however, reflects the residual oxygen after tissue oxygen extraction and represents the adequacy of all the above-mentioned parameters of the oxygen transport system.

$\mathrm{ScvO}_{2}$ is measured after mixing of venous blood from all organs in the right heart and reflects global oxygen extraction. Therefore, normal $\mathrm{ScvO}_{2}$ cannot exclude regional tissue ischaemia or hypoxia. Despite these known limitations $\mathrm{ScrO}_{2}$ measurement in the right atrium could be useful as a complementary monitor of tissue oxygen needs in the 
newborn infant.

The results of this study encouraged us to consider this fiberoptic catheter for measuring continuously the venous oxygen saturation in critically ill newborn infants. We are now testing for clinical relevance and describing the "safe ranges" for $\mathrm{ScvO}_{2}$ in neonates requiring intensive care.

\section{References}

Kandel G, Aberman A. Mixed Venous Oxygen Saturation; its role in the assessment of the critically ill patient. Arch Intern Med 1983;143:1400-1402

Baele PL, McMichan JC, Marsh HM, Sill JC, Southorn PA. Continuous monitoring of mixed venous oxygen saturation in critically ill patients. Anesth Analg 1982;61:513-517

Divertie MB, McMichan JC. Continuous monitoring of mixed venous oxygen saturation. Chest $1984 ; 85: 423-428$

Shenaq SA, Casar G, Chelly JE, Ott H, Crawford ES. Continuous monitoring of mixed venous oxygen saturation during aortic surgery. Chest 1987;92:796-799

Magilligan DJ, Taesdall R, Eisinminger R, Peterson E. Mixed venous oxygen saturation as a predictor of cardiac output in the postoperative cardiac surgical patient. Ann Thorac Surg 1987;44:260. 262

Dudell G, Cornisch JD, Bartlett RH. What constitutes adequate oxygenation? Pediatrics 1990;85:39. 41

Kitterman JA, Phibbs RH, Tooley WH. Catheterization of umbilical vessels in newborn infants. Ped Clin of North America 1970;17:895-912

Ewing CK, Durand DJ. Use of umbilical catheters: A study of 100 patients. Pediatr Res $1989 ; 25: 214$ A

Brown EG, Krouskop RW, McDonnel FE, Monge CC, Winslow RE. A technique to continuously measure arteriovenous oxygen content difference and $p_{s_{0}}$ in vivo. J Appl Physiol 1985;58(4):13831389

Bland JM, Altman DG. Statistical methods for assessing agreement between two methods of clinical measurement. Lancet 1986; ; 307-317

Baker DH, Berdon MD, James LS. Proper localization of umbilical arterial and venous catheters by lateral roentgenogram. Pediatrics 1969;43:34-39

Rosen MS. Reich SB. Umbilical venous catheterization in the newborn: Identification of correct positioning. Radiology 1970;95:335-340

Oski FA, Allen DM, Diamond LK. Portal hypertension; a complication of umbilical vein catheterization. Pediatrics 1963;39:297-302

Wigger HJ, Bransilver BR, Blanc WA. Thromboses due to catheterization in infants and children. J Pediatr 1970;76:1-12

15 Dorand RD, Cook LN, Andrews BF. Umbilical vessel catheterization; The low incidence of complications in a series of 200 newborn infants. Clin Pediatr 1977; 16:569-572

Reinhart K, Moser N, Rudolph T, Bredle D, Specht M, Gramm H.J, et al. Accuracy of two mixed venous saturation catheters during long term use in critically ill patients. Anesthesiology 1988;69:769-773

Gettinger A, De Traglia MC, Glass D. In vivo comparison of two mixed venous saturation catheters. Anesthesiology 1987;66:373-375

Vaughn S, Puri VK. Cardiac output changes and continuous mixed venous oxygen saturation measurement in the critically ill. Crit Care Med 1988;16:495-498 
Scuderi PE, Bowton DL, Meredith JW, Harris LC, Brockschmidt J. Clinical evaluation of three mixed-venous oxygen saturation catheters. Anesthesiology 1990;73:A484

21 Boeden G, Spies C, Zaune U, Gabriel H, Martin E. Longterm-accuracy of continuous fiberoptic $\mathrm{SvO}_{2}$ monitoring. Anesthesiology 1990;73:A495

22 Wimberley PD, Fogh-Andersen N, Siggaard-Andersen O, Lundsgaard FC, Zijlstra WG. Effect of $\mathrm{pH}$ on the absorption spectrum of human oxyhemoglobin: a potential source of error on the measuring the oxygen saturation of hemoglobin. Clin Chem 1988;34:750-754

Wimberley PD, Helledie NR, Friis-Hansen B, Siggaard-Andersen O, Fogh-Andersen N. Some problems involved in using hemoglobin oxygen saturation in arterial blood to detect hypoxemia and hyperoxemia in newborn infants. Scand J Clin Lab Invest 1988; 48, Suppl 189: 45-48

24 Barratt-Boyes BG, Wood EH. The oxygen saturation of blood in the venae cavae, right-heart chambers and pulmonary vessels of healthy subjects. J Lab Clin Med 1957;50:93-106

Reinhart K, Rudolph T, Bredle DL, Hannemann L, Cain SM. Comparison of central-venous to mixed-venous oxygen saturation during changes in oxygen supply/demand. Chest 1989;95:12161221

Davies GG, Mendenhall J, Symreng T. Measurement of right atrial oxygen saturation by fiberoptic oximetry accurately reflects mixed venous oxygen saturation in swine. J Clin Monit 1988;4:99-102 Auffray JP, Martin C, Prima F, et al. Venous oxygen saturation: Central venous (CV) or Pulmonary artery (PA) catheter? Anesthesiology 1991;75:A455

Tahvanainen J, Meretoja O, Nikki P. Can central venous blood replace mixed venous blood samples? Crit Care Med 1982;10:758-761

\section{Acknowledgments}

This study was supported by Abbott Inc., the Netherlands. 


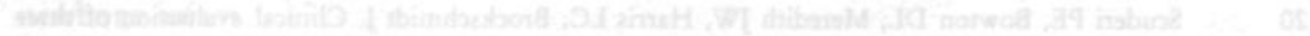

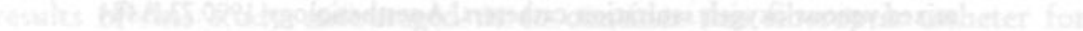

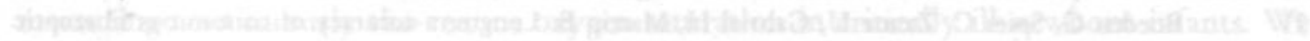

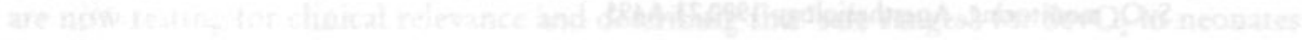

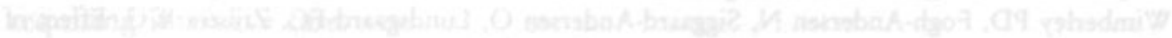

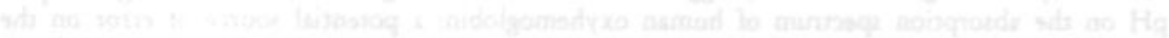

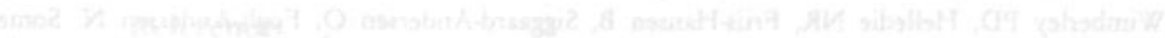

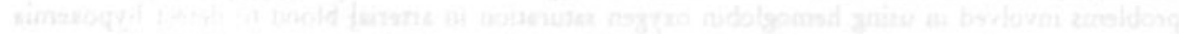

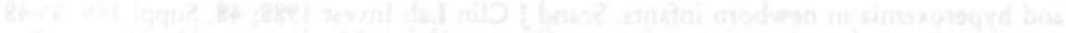




\section{Chapter 6}

\section{Continuous Central Venous Oxygen Saturation $\left(\mathrm{ScvO}_{2}\right)$ measurement by a fiberoptic catheter in newborn infants.}

Mark A.H.B.M. van der Hoeven, Wiel J. Maertzdorf, Carlos E. Blanco.

Archives of Diseases in Childhood; Fetal and Neonatal Edition 1996;74:F177-F188 


\section{Abstract}

Background: Central venous oxygen saturation $\left(\mathrm{ScvO}_{2}\right)$ can be a valuable monitor, reflecting residual oxygen after tissue oxygen extraction and indicating the combined sufficiency of tissue oxygen supply and demand.

Objective: a) To describe the range of $\mathrm{ScvO}_{2}$ values in stable newborn infants breathing room air. b) To examine the relationship between $\mathrm{ScvO}_{2}$ and arterial oxygen saturation $\left(\mathrm{SaO}_{2}\right)$ c) to describe fractional oxygen extraction (F.O.E.) and d) the shunt index, an estimate of the venous admixture.

Study Design: a prospective clinical observational study

Patients: 10 preterm infants breathing room air after the acute phase of respiratory distress syndrome and with an umbilical venous catheter in situ. A fiberoptic catheter remained in the right atrium for continuous measurement of oxygen saturation.

Measurements and Main Results: $\mathrm{ScvO}_{2}, \mathrm{SaO}_{2}$, bloodpressure and heart rate were registered every 15 minutes. F.O.E. and shunt index were calculated. $\mathrm{SaO}_{2}$ and $\mathrm{ScvO}_{2}$ were $93.4 \% \pm$ 3.7 and $73.56 \% \pm 5,25$ (mean $\pm \mathrm{SD}$.), respectively. In seven patients $\mathrm{ScvO}_{2}$ values correlated significantly with $\mathrm{SaO}$ 2. F.O.E was $0.21 \pm 0.04$ (mean $\pm \mathrm{SD}$.) and was significantly correlated with $\mathrm{ScvO}_{2}$. The shunt index was $24 \% \pm 12$ (mean $\pm \mathrm{SD}$ ) and was significantly correlated with $\mathrm{SaO}_{2}$.

Conclusions: Stable preterm infants, breathing room air had a $\mathrm{ScvO}_{2}$ range from $65 \%$ to $82 \%$ (5th and 95th percentile), which corresponded to $\mathrm{SaO}_{2} \geq 86 \%$. ScvO 2 values were significantly correlated with $\mathrm{SaO}_{2}$ in most patients. 


\section{Introduction}

The optimal level of oxygenation in sick newborn infants is not well established. Hyperoxia has been associated with oxygen toxicity related cell injury [1], retinopathy of prematurity ${ }^{[2]}$ and bronchopulmonary dysplasia ${ }^{[3]}$, while hypoxia has been associated with vasoconstriction of the pulmonary vascular bed ${ }^{[4,5]}$, redistribution of the cardiac output ${ }^{[6]}$ and oxygen insufficiency at tissue level with anaerobic metabolism leading to cell damage.

Arterial partial pressure of oxygen $\left(\mathrm{paO}_{2}\right)$ and/or arterial oxygen saturation $\left(\mathrm{SaO}_{2}\right)$ are widely used in judging oxygen needs. These are limited because they do not measure other factors that determine tissue oxygenation such as hemoglobin concentration, cardiac output, local tissue blood flow and oxygen consumption.

Central venous oxygen saturation $\left(\mathrm{ScvO}_{2}\right)$ reflects residual oxygen after tissue oxygen extraction and accounts for all the mentioned variables ${ }^{[7]}$. Measuring the $\mathrm{ScvO}_{2}$ in newborn babies may help minimize unnecessary oxygen administration, and thus decreasing long term morbidity associated with oxygen injury ${ }^{[n]}$. $\mathrm{ScvO}_{2}$ measurement could define insufficient oxygen delivery to tissues when arterial oxygen content and cardiac output are decreased or when oxygen consumption is increased.

In this study we attempted to define the normal range of $\mathrm{ScvO}_{2}$ values in stable newborn infants, breathing room air after a period of respiratory insufficiency.

The measurement of both $\mathrm{SaO}_{2}$ and $\mathrm{ScvO}_{2}$ (dual oximetry) made it possible to calculate fractional oxygen extraction (F.O.E.) and the shunt index ${ }^{[9]}$. F.O.E. is an estimation of the peripheral tissue oxygen extraction coefficient. As oxygen delivery falls, oxygen consumption can be maintained by an increase in the extraction of oxygen delivered to the tissues ${ }^{[10]}$. Shunt index represents an estimate of the venous admixture. Pulmonary venous admixture reflects the degree of mixture of arterial blood and mixed venous blood. We examined the range of these two variables and their relation with $\mathrm{SaO}_{2}$ and $\mathrm{ScvO}_{2}$.

\section{Materials and Methods}

This study was approved by the ethics committee of the Academic Hospital of Maastricht.

We used a 4 Fr. fiberoptic catheter (Oximetrix System, Abbott Lab. Chicago Ill.), which allowed both a continuous measurement of oxygen saturation at the tip of the catheter and infusion of fluids and medication. The continuous measurement of oxygen saturation is based on reflection spectrometry. The light source, consisting of three diodes, emits light at three different wavelengths through a fiberoptic bundle. The back scattered light from the oxygenated and unoxygenated blood is transmitted by the receiving fiberoptic bundle to a photodetector in the optical module. The oximeter computes percent of oxygen saturation values based on the electrical signals from the optical module. The average value for oxygen saturation over a five second period is displayed digitally, and the value updated each second.

The fiberoptic catheter was placed in the right atrium via the umbilical vein in infants who needed a central venous line for clinical management. The catheter was positioned at the midatrial level or at the transition of the inferior vena cava to the right atrium. The position was confirmed by X-ray and ultrasound. Heparinized saline $(0.5$ $\mathrm{U} . / \mathrm{cc}$.) was infused continuously $(0.1 \mathrm{cc} / \mathrm{hr}$.) to avoid fibrin formation over the catheter. Bloodsamples were withdrawn through the catheter at least every twelve hours, immediately analyzed with a hemoximeter (Radiometer OSM3, Copenhagen) and compared 
with simultaneously recorded fiberoptic catheter values. A correction was made when oxygen saturation in correlated samples showed a discrepancy of $\geq 5 \%$. We have previously reported the feasibility and accuracy of the fiberoptic device in newborn infants ${ }^{[1]}$.

The values of $\mathrm{ScvO}_{2}$ were obtained from preterm patients breathing room air after the acute phase of RDS. Infants were allowed to breathe room air when $\mathrm{SaO}_{2}$ monitored by pulse oximetry was $\geq 86 \%{ }^{[12,13]}$. $\mathrm{ScvO}_{2}$ values were accepted when hemoglobin $(\mathrm{Hb})$ was $\geq 7.0 \mathrm{mmol} / \mathrm{L}$, with normal arterial $\mathrm{pH}(7.30-7.45)$ and $\mathrm{pCO}_{2}(4.5-8 \mathrm{kPa})$, and arterial bloodpressure ${ }^{[14]}$

$\mathrm{SaO}_{2}$ was continuously measured by pulse oximetry (Hewlett Packett). Each value is the average of samples taken every 12 seconds over one minute. Arterial blood pressure was monitored through an umbilical or radial artery catheter; these catheters were also used for sampling arterial $\mathrm{pH}, \mathrm{PaCO}_{2}, \mathrm{paO}_{2}$, and base excess for clinical purposes.

$\mathrm{ScvO}_{2}, \mathrm{SaO}_{2}$ values, bloodpressure and heart rate were registered every 15 minutes. Arterial oxygen content $\left(\mathrm{caO}_{2}\right)$ and central venous oxygen content $\left(\mathrm{ccrO}_{2}\right)$ were calculated using the equations:

and

$$
-\mathrm{caO}_{2}(\mathrm{ml} / \mathrm{dl})=\mathrm{SaO}_{2} \times \mathrm{Hb}(\mathrm{mmol} / \mathrm{L}) \times 1.61 \times 1.36
$$

$-\mathrm{ccvO}_{2}(\mathrm{ml} / \mathrm{dl})-\mathrm{ScvO}_{2} \times \mathrm{Hb}(\mathrm{mmol} / \mathrm{L}) \times 1.61 \times 1.36$, respectively.

Fractional oxygen extraction (F.O.E.) was calculated using the equation

- F.O.E. - $\left(\mathrm{SaO}_{2}-\mathrm{ScvO}_{2}\right) / \mathrm{SaO}_{2}$. The shunt index was calculated using the equation:

- shunt index $=100 \times\left\{\left(100-\mathrm{SaO}_{2}\right) /\left(100-\mathrm{ScvO}_{2}\right)\right\}$.

Oxygen saturation and $\mathrm{pcvO}_{2}$ were determined from samples withdrawn from the central venous fiberoptic catheter and the $\mathrm{p}_{50}$ was calculated as described previously ${ }^{[15]}$.

\section{Statistics}

The paired Student's $t$ test was used to compare the hemoximeter values with the simultaneously recorded fiberoptic catheter readings. For each patient we determined mean value and standard deviation (mean $\pm \mathrm{SD}$ ) for $\mathrm{SaO}_{2}$ and $\mathrm{ScvO} 2$. The range was defined by the 5th and 95th percentile. To compare $\mathrm{SaO}_{2}$ with $\mathrm{ScvO}_{2}$, a separate linear regression analysis within each individual was performed to avoid erroneous combining of observations from different individuals ${ }^{[16]}$. A slope (the regression coefficient) for each individual was calculated to obtain an average slope for the group ${ }^{[16]}$. To compare F.O.E and shunt index with $\mathrm{SaO}_{2}$ and $\mathrm{ScvO}_{2}$ the same statistical analysis was performed. Tests were considered to be significant when $p<0.05$.

\section{Results}

In 10 preterm infants breathing room air, $\mathrm{ScvO}_{2}$ could be monitored continuously. They are described in table 1 . The monitoring time ranged from 10-82 hrs. The mean age of the infants when $\mathrm{ScvO}_{2}$ was monitored was $52 \mathrm{hrs}$. (range 18-168 hrs.). A total of 1061 $\mathrm{ScvO}_{2}$ and $\mathrm{SaO}_{2}$ values were obtained simultaneously with bloodpressure and heart rate. The validity of the $\mathrm{ScvO}_{2}$ values was confirmed, since hemoximeter values and simultaneously recorded fiberoptic catheter readings were not significantly different: $(74.7 \% \pm$ 6.8 vs. $73.8 \% \pm 6.3$ ). $\mathrm{SaO}_{2}$ and $\mathrm{ScvO}_{2}$ were $93.4 \% \pm 3.7$ and $73.56 \% \pm 5,25$ (mean \pm SD.), respectively. The $\mathrm{SaO}_{2}$ and $\mathrm{ScvO}_{2}$ values ranged respectively from 87 to $99 \%$ and 65 $\%$ to $82 \%$ (5th and 95 th percentile). When analyzed for each patient separately, $\mathrm{ScvO}_{2}$ ( lowest 5 th and highest 95 th percentile) ranged from $60.1 \%$ to $83.5 \%$ (table 2 ). 
table 1. Patient characteristics, physiological parameters, arterial $\mathrm{pH}, \mathrm{paCO}_{2} \mathrm{paO}_{2}$ and base excess and oxygen saturation, calculated arterial and venous oxygen content.

\begin{tabular}{|c|c|c|c|c|c|}
\hline \multirow{3}{*}{$\begin{array}{l}\text { birthweight (grams) } \\
\text { gestational age (weeks) }\end{array}$} & \multirow{2}{*}{$\begin{array}{l}\text { Mean } \\
938\end{array}$} & \multirow{2}{*}{$\frac{(\mathrm{SD})}{(246)}$} & \multicolumn{3}{|c|}{ Range (5th..95th perc) } \\
\hline & & & & & \\
\hline & 27.0 & $(1.3)$ & & & \\
\hline hemoglobin $(\mathrm{mmol} / \mathrm{L})$ & 8.4 & (1.8) & 7.0 & . & 10.2 \\
\hline $\mathrm{MAP}(\mathrm{mm} \mathrm{Hg})$ & 41.5 & $(7.4)$ & 30 & . & 54.7 \\
\hline heart rate (bpm) & 165 & (15) & 144 & . & 192 \\
\hline $\mathrm{P}_{\mathrm{so}}(\mathrm{kPa})$ & 3.1 & $(0.4)$ & 2.7 & . & 3.9 \\
\hline $\mathrm{pH}$ & 7.36 & $(0.04)$ & 7.30 & - & 7.41 \\
\hline $\mathrm{pCO}_{2}$ & 5.5 & $(1.0)$ & 4.4 & . & 7.8 \\
\hline $\mathrm{pO}_{2}$ & 6.6 & $(0.1)$ & 3.5 & . & 10.2 \\
\hline Base Excess $(\mathrm{mmol} / \mathrm{L})$ & -2.8 & (2.3) & -7.3 & . & 0.1 \\
\hline $\mathrm{caO}_{2}(\mathrm{ml} / \mathrm{dl})$ & 16.9 & (2.2) & 12.6 & . & 20.0 \\
\hline $\mathrm{cvO}_{2}(\mathrm{ml} / \mathrm{dl})$ & 13.2 & $(2.0)$ & 9.6 & - & 16.1 \\
\hline
\end{tabular}

table 2. Mean $\pm \mathrm{SD}$, range (5th and 95th percentile), correlation coefficient and slope of $\mathrm{SaO}_{2}$ and $\mathrm{ScvO} 2$. $\because p<0.05$

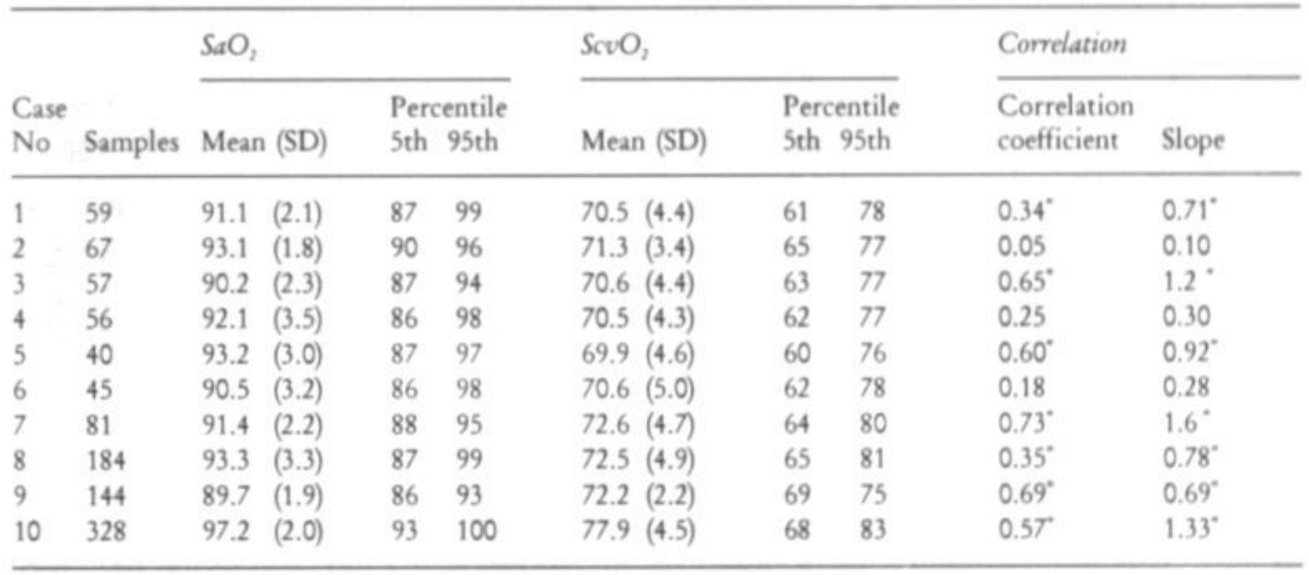

Linear regression analysis comparing $\mathrm{SaO}_{2}$ and $\mathrm{ScvO}_{2}$ for each patient yielded a slope (regression coefficient) and a correlation coefficient $\mathrm{r}$. (table 2, figure 1). In seven patients a significant correlation was found (see figure 1). F.O.E was $0.21 \pm 0.04$ (mean \pm SD.). The 5 th and 95 th percentile were 0.15 and 0.29 , respectively. When analyzed for each patient separately, a range was found (lowest 5 th and highest 95 th percentile) from 0.13 to 0.33 . Figure 2 shows the relation between F.O.E. and $\mathrm{ScvO}_{2}$. F.O.E. and $\mathrm{ScvO}_{2}$ were significantly correlated in all patients. $\mathrm{SaO}_{2}$ and F.O.E. were significantly correlated in only 6 patients with a lower range of correlation coefficients (range $\mathrm{r}:-0.28 \ldots-0.48$ ). Analysis of the relation between F.O.E and $\mathrm{Hb}$ yielded a correlation coefficient $r--0.14 .(p<0.01)$.

The shunt index was $24 \% \pm 12$ (mean $\pm \mathrm{SD}$ ). A range was found (lowest 5 th and highest 95 th percentile) from $7 \%$ to $53 \%$ (table 2 ). When analyzed for each patient separately, we found a significant negative correlation with the $\mathrm{SaO}_{2}$ value in all patients (range r: $-0.72 . .-0.95$; see figure 3). Analysis of the relation with $\mathrm{ScvO}_{2}$ showed a significant correlation in five patients (range $\mathrm{r}:-0.37 .0 .36$ ). 


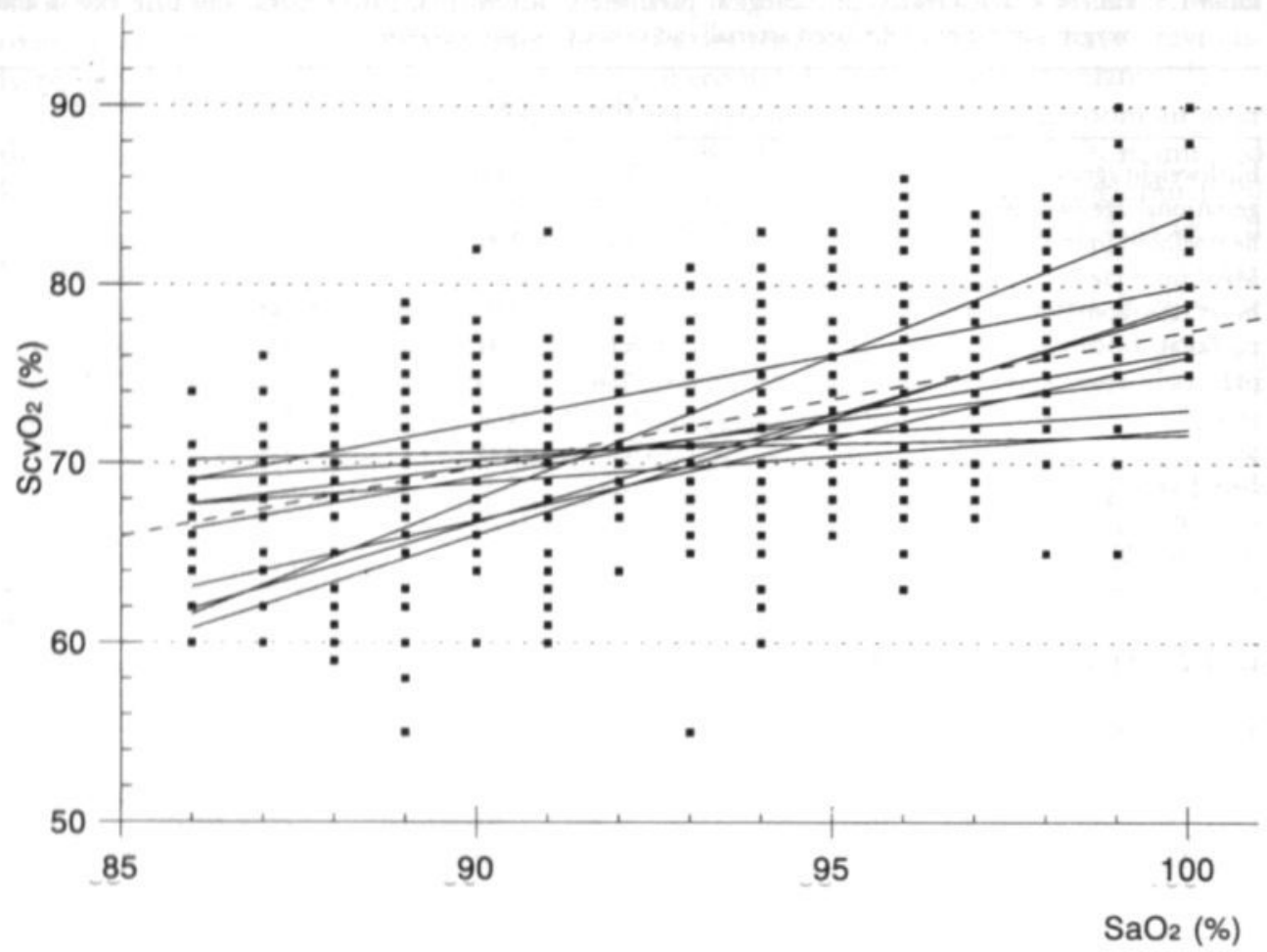

figure 1. Central venous oxygen saturation $\left(\mathrm{ScvO}_{2}\right)$ values corresponding to simultaneously obtained arterial oxygen saturation $\left(\mathrm{SaO}_{2}\right)$ values. Linear regression lines are drawn for each patient. In seven patients a significant correlation was found. An average regression equation was obtained: $\mathrm{ScvO}_{2}=$ $0.46+0.77 \times \mathrm{SaO}_{2}$.

\section{Discussion}

Continuous monitoring of mixed venous oxygen saturation $\left(\mathrm{ScvO}_{2}\right)$ has been used in critically ill adult patients as a valuable alarm signal, reflecting the residual oxygen after tissue oxygen extraction and indicating the combined sufficiency of the tissue oxygen supply and demand ${ }^{[1,18,19]}$. Venous oxygen saturation is used very frequently during extracorporeal life support to determine pump blood flow ${ }^{[20]}$ and has been advocated in the care for sick preterm infants ${ }^{[8]}$. In neonatal medicine the use of $\mathrm{ScvO}_{2}$ could allow to minimize unnecessary oxygen administration and hence to decrease long term morbidity associated with oxygen toxicity related injury ${ }^{[8]}$. However, normal and safe values have not been defined for newborn infants.

In our study we observed a range from $60.1 \%$ to $83.5 \%$ (5th and 95th percentile) in 10 stable preterm infants breathing room air, while $\mathrm{SaO}_{2}$ was $\geq 86 \%$, hemoglobin was $\geq 7.0 \mathrm{mmol} / \mathrm{L}$. Arterial $\mathrm{pH}$ and arterial blood pressure were in normal range. $\mathrm{T} \mathrm{h}$ i s $\mathrm{ScvO}_{2}$ range is similar to the normal range defined for adults; however, oxygen consumption in newborn infants is $5-8 \mathrm{ml} / \mathrm{kg} / \mathrm{min}$, whereas in resting adults oxygen consumption is $3-5 \mathrm{ml} / \mathrm{kg} / \mathrm{min}{ }^{[20]}$. Increased oxygen consumption is not compensated for by increased extraction within tissues, since $\mathrm{ScvO}_{2}$ does not apparently differ from adult values. 


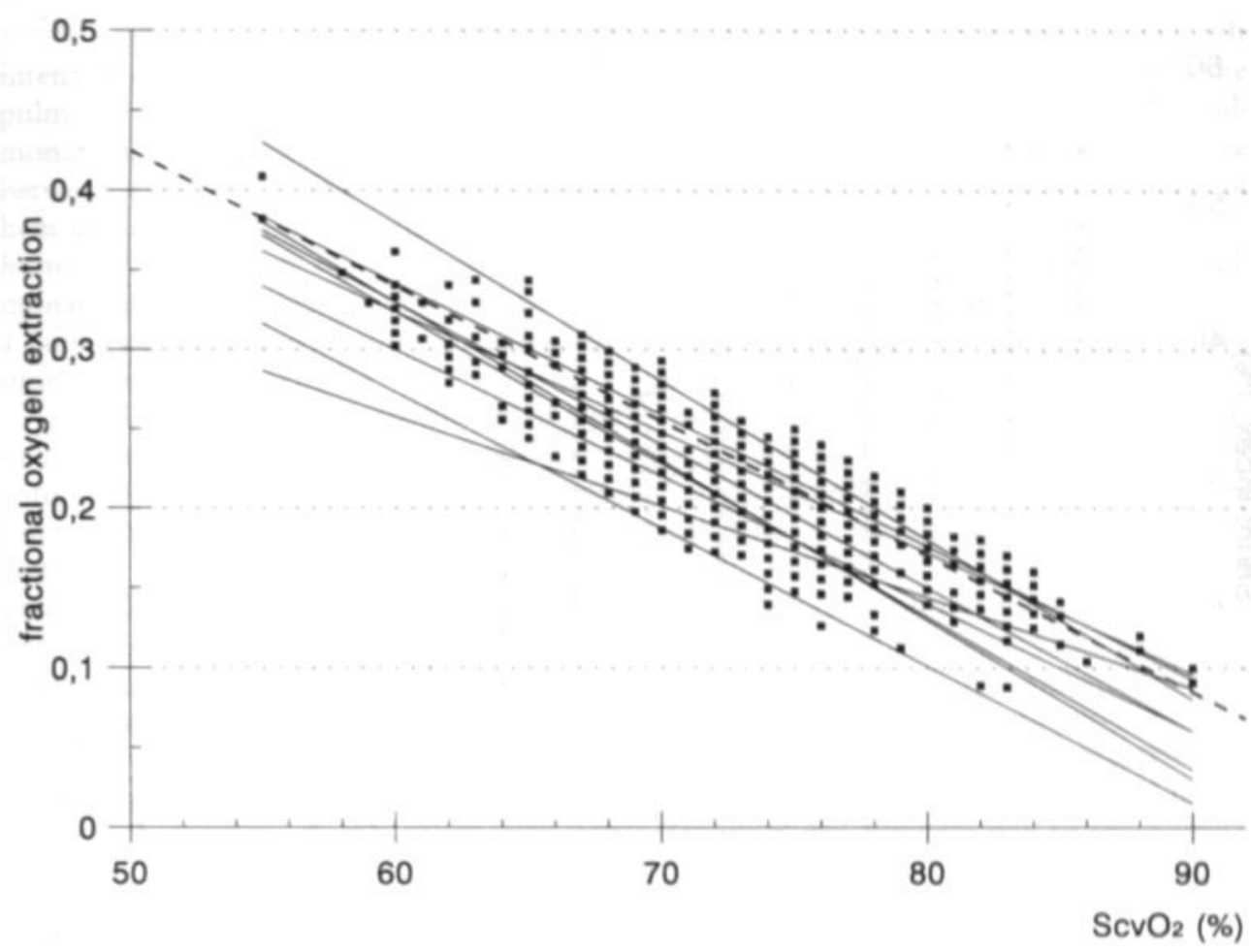

figure 2. Fractional Oxygen Extraction (F.O.E) corresponding to central venous oxygen saturation ( $\left.\mathrm{ScvO}_{2}\right)$. Linear regression lines are drawn for each patient. F.O.E. was significantly correlated with the $\mathrm{ScvO}_{2}$ in each patient. An average regression equation was obtained: F.O.E. $=0.83 \cdot 0.0085 \times$ $\mathrm{ScvO}_{2}$

The oxygen delivery is determined by cardiac output and $\mathrm{caO}_{2}$, which in turn is determined by hemoglobin concentration $(\mathrm{Hb}), \mathrm{O}_{2}$ carrying capacity, oxygen saturation $\left(\mathrm{SaO}_{2}\right)$ and $\mathrm{paO}_{2}$. Cardiac output and hemoglobin concentration in the newborn compensates for higher oxygen consumption. Indeed, hemoglobin concentration and $\mathrm{caO}_{2}$ are higher in newborn babies than in adults ${ }^{[21]}$. Cardiac output in newborn infants determined by various methods is $230 \pm 70 \mathrm{ml} / \mathrm{kg} / \min { }^{[22]}$, whereas cardiac output in adults is $70-90$ $\mathrm{ml} / \mathrm{kg} / \mathrm{min}{ }^{[23]}$. Therefore, the increased oxygen consumption in the newborn infant is counterbalanced by an increased oxygen delivery.

In seven patients a significant correlation was found between $\mathrm{SaO}_{2}$ and $\mathrm{ScvO}_{2}$. This indicates that, when $\mathrm{SaO}_{2}$ is reduced, oxygen consumption is preserved by a fixed oxygen extraction. In three patients $\mathrm{SaO}_{2}$ and $\mathrm{ScvO}_{2}$ were not significantly correlated. We might speculate, that in these babies oxygen consumption was preserved by increased cardiac output. It is unlikely that oxygen consumption was decreased by $\mathrm{SaO}_{2}$ reduction, because in stable patients with a normal blood pressure, normal hemoglobin level and normal oxygen saturation oxygen consumption is independent of oxygen delivery [24]. Oxygen delivery is normally four to five times oxygen consumption as shown the normal fractional oxygen extraction (F.O.E.) of $0.20-0.25$. In adults, a normal range of 0.22 to 0.30 of the F.O.E. has been described ${ }^{[25]}$. An increased F.O.E. can partly compensate for imbalance of oxygen consumption and delivery. Increased oxygen consumption, low hemoglobin and a low cardiac output could explain the high F.O.E. found in our study. 


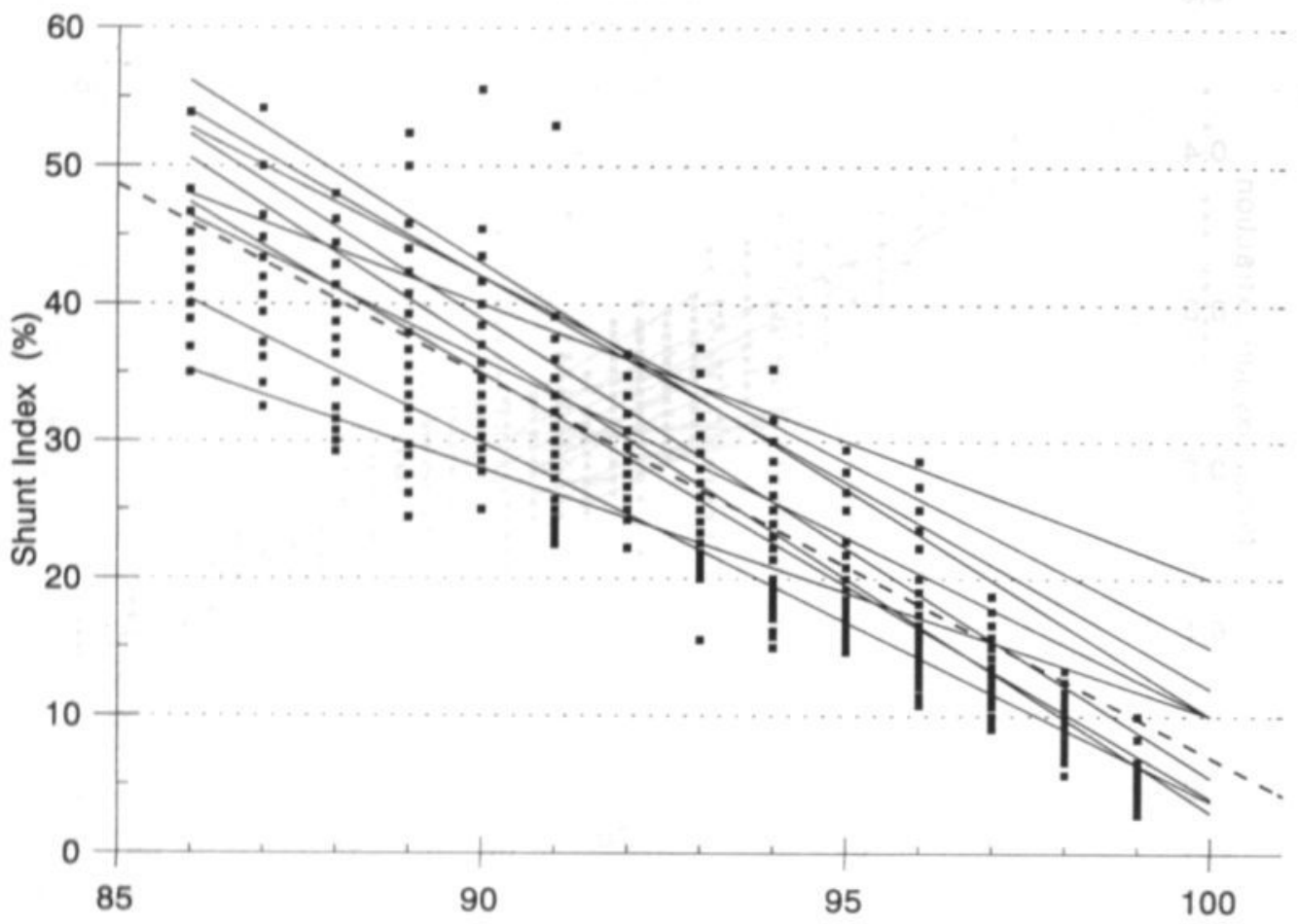

$\mathrm{SaO}_{2}(\%)$

Figure 3. The shunt index, an estimate for the venous admixture corresponding to the arterial oxygen saturation $\left(\mathrm{SaO}_{2}\right)$. Linear regression lines are drawn for each patient. Shunt index and $\mathrm{SaO}_{2}$ were correlated in each patient. An average regression equation was obtained: shunt index $=2.85$. $0.0278 \times \mathrm{SaO}_{2}$

Indeed, we found a significant negative correlation between $\mathrm{Hb}$ and F.O.E. The highly significant correlation between F.O.E. and $\mathrm{ScvO}_{2}$ in all patients confirms that $\mathrm{ScvO}_{2}$ is an excellent monitor of the balance between oxygen delivery and tissue oxygen consumption.

The shunt index is an estimate of venous admixture and can be calculated when both $\mathrm{SaO}_{2}$ and $\mathrm{ScvO}_{2}$ (dual oximetry) are available. It is a derived formula, $(100 \times(100$. $\left.\left.\mathrm{SaO}_{2}\right) /\left(100-\mathrm{ScvO}_{2}\right)\right)$. Dissolved oxygen is discounted, and it is assumed that pulmonary end capillary blood is fully saturated.

Bongard et al. ${ }^{[26]}$ demonstrated a linear relation between this index and venous admixture; when $\mathrm{paO}_{2}$ was low, it was largely accurate but with some overestimation of the value. Concomitantly with F.O.E. it has been used to titrate continuous positive airway pressure in adult intensive care ${ }^{[2]}$. In our patients the shunt index was significantly correlated with $\mathrm{SaO}_{2}$ with values up to $50 \%$ in the lower $\mathrm{SaO}_{2}$ range (fig. 3). Recently, Schultze et al. ${ }^{[2]}$ described approximately similar values of venous admixture of $31 \% \pm 9$ at a $\mathrm{SaO}_{2}$ range between $89 \%$ and $92 \%$ in premature infants. Obviously an increased venous admixture is present when lower $\mathrm{SaO}_{2}$ values are encountered. As can be expected and was demonstrated in a computermodel ${ }^{[2]}$, changes in $\mathrm{SaO}_{2}$ alter the value of the shunt index to a greater extent than changes in $\mathrm{ScvO}_{2}$. 
The measurement site of venous oxygen saturation is still in debate ${ }^{[20]}$. In adult intensive care medicine venous oxygen saturation has been monitored continuously in the pulmonary artery. Measurement of the $\mathrm{ScvO}_{2}$ in the right atrium instead of in the pulmonary artery has been reported ${ }^{10.31]}$. No evidence was found for a systematic difference between right atrial and pulmonary arterial oxygen saturations over a wide range of hemodynamic conditions both in the animal model and in the adult

human $[0,31,32]$. Other reports describe a poor correlation between right atrial and pulmonary arterial oxygen saturation when comparing absolute numerical values ${ }^{[3]}$. However, a better correlation was observed comparing subsequent changes of right atrial and pulmonary arterial saturations ${ }^{[3+]}$.

In neonatal medicine the use of a pulmonary artery catheter is difficult and hazardous, but umbilical venous catheters have been used frequently with a low incidence of complications. Hence, measurements of venous oxygen saturation in newborn infants are limited to the right atrium. Intracardiac left-to-right shunting through the foramen ovale is common in preterm infants, and can be a reason for the higher $\mathrm{ScvO}_{2}$ values found in preterm infants compared with adults. However, intracardiac shunting at the right atrium does not produce a difference in right atrial and pulmonary arterial oxygen saturations, and ,therefore, is not an argument for questioning the validity of the right atrium as measurement site.

$\mathrm{ScvO}_{2}$ measurement has some drawbacks: since it reflects global oxygen extraction, normal values cannot exclude tissue hypoxia in individual organs ${ }^{[3]}{ }^{[3]}$. In sepsis and multiorgan failure normal $\mathrm{ScvO}_{2}$ values may occur despite global hypoxia due to precapillary shunting and the incapacity of tissues to extract enough oxygen ${ }^{[0]}$. These drawbacks do not imply, that measuring $\mathrm{ScrO}_{2}$ is not useful, but that normal and abnormal values must be interpreted together with other physiologic variables in conditions such as perfusion disturbances and sepsis ${ }^{[8]}$.

In summary, we have defined a range of $\mathrm{ScvO}_{2}$ values in preterm newborn infants when breathing room air with a $\mathrm{SaO}_{2} \geq 86 \%$. Whether these values can be used in sick newborn infants to evaluate tissue oxygenation and whether this range can be used to regulate oxygen administration remains to be established. Further study is needed to determine the clinical utility of $\mathrm{ScvO}_{2}$ measurements in neonatal intensive care.

\section{References}

1 Frank L, Bucher JR, Roberts RJ. Oxygen toxicity in neonatal and adult animals of different species. J Appl Physiol 1978;45:699-704

Flynn JT, Bancalari E, Snyder EM, Goldberg RN, Feuer W, Cassady J. A cohort study of transcutaneous oxygen tension and the incidence and severity of retinopathy of prematurity. $\mathrm{N}$ Engl J Med 1992;326:1050-1054

3 Goetzman BW. Understanding bronchopulmonary dysplasia. AJDC 1986;140: 332-334

Fishman AP. Respiratory gases in the regulation of the pulmonary circulation. Physiol Rev $1961 ; 41: 214-280$

Huage A. Hypoxia and pulmonary resistance. The relative effects of pulmonary arterial and alveolar $\mathrm{pO}_{2}$. Acta Physiol Scand 1969; 76: 121-130

Sheldon R, Peeters LLH, Jones Jr. MD, Makowski EL, Meschia G. Redistribution of cardiac output and oxygen delivery in the hypoxemic fetal lamb. Am J Obstet Gynecol 1979;135:1071-1078

O'Connor TA, Hall RT. Mixed venous oxygenation in critically ill neonates. Crit Care Med 1994:22:343-346 
Dudell G, Cornisch JD, Bartlett RH. What constitutes adequate oxygenation? Pediatrics 1990;85:3941

Räsänen J. Role of dual oximetry in the assessment of pulmonary function. In: Reinhart K, Eyrich K. Eds. Clinical aspects of $\mathrm{O}_{2}$ transport and tissue oxygenation. Berlin: Springer Verlag, 1989; pp 193-211

Little RA, Edwards JD. Applied physiology. In: Edwards JD, Shoemaker WC, Vincent JL. Oxygen transport. principles and practice. Philadelphia: Saunders, 1993; pp 21-40

van der Hoeven MA, Maertzdorf WJ, Blanco CE. Feasibility and accuracy of a fiberoptic catheter for the measurement of venous oxygen saturation in newborn infants. Acta Paed 1995;84:122-127 Wasunna A, Whitelaw AG. Pulse oximetry in preterm infants. Arch Dis Child 1987;62:882-888

Joint working group of the British Association of Perinatal Medicine and the Research Unit of the Royal College of Physicians. Development of audit measures and guidelines for good practice in the management of neonatal respiratory distress syndrome. Arch Dis Child 1992;67:1221-1227

Shortland DB, Evans DH, Levene MI. Blood pressure measurements in very low birth weight over the first week of live. J Perinat Med 1988;16:93-97

Brown EG, Krouskop RW, McDonnel FE, Monge CC, Winslow RE. A technique to continuously measure arteriovenous oxygen content difference and $p_{s o}$ in vivo. J Appl Physiol 1985;58(4):13831389

Smith EO. Analysis of repeated measures designs. J Pediatr 1987;111:723-725

Kandel G, Aberman A. Mixed Venous Oxygen Saturation; Its role in the assessment of the critically ill patient. Arch Intern Med 1983;143:1400-1402

Baele PL, McMichan JC, Marsh HM, Sill JC, Southorn PA. Continuous monitoring of mixed venous oxygen saturation in critically ill patients. Anesth Analg 1982;61:513-517

Divertie MB, McMichan JC. Continuous monitoring of mixed venous oxygen saturation. Chest $1984 ; 85: 423-428$

Bartlett RH, Cilley RE. Physiology of extracorporeal life support. In: Arensman RM. Cornish JD. editors. Extracorporeal life support. Boston: Blackwell, 1993: pp 89-102

Delivoria-Papadopolous M, Wagerle LC. Oxygen diffusion and transport. In: Scarpelli EM. editor. Pulmonary Physiology. Philadelphia: Lea \& Febiger, 1990: pp 281-305

Hudson I, Houston A, Aitchison T, Holland B, Turner T. Reproducibility of measurements of cardiac output in newborn infants by doppler ultrasound. Arch Dis Chidh 1990;65:15-19

Guyton AC. Cardiac output, venous return, and their regulation. In: Textbook of medical physiology. Philadelphia: Saunders, 1986: pp 272-284

Seear M, Wensley D, MacNab A. Oxygen consumption-oxygen delivery relationship in children. J Pediatr 1993; 123:208-214

Shoemaker WC. Haemodynamic and oxygen transport in shock: Pathophysiology, monitoring, outcome prediction and therapy. In: Edwards JD, Shoemaker WC, Vincent JL. eds. Oxygen transport. principles and practice. Philadelphia, Saunders, 1993: pp 70-98

Bongard FS, Leighton TA. Continuous dual oximetry in surgical critical care. indications and limitations. Ann Surg 1992;216:60-68

Räsänen J, Downs JB, Malec DJ, Seidman P. Estimation of oxygen utilization by dual oximetry. Ann Surg 1987:206:621-623

Schultze A, Whyte RK, Clifton Way R, Sinclair JC. Effect of the arterial oxygenation level on cardiac output, oxygen extraction and oxygen consumption in low birth weight infants receiving mechanical ventilation. J Pediatr 1995;126:777-784

Vincent JL. Does central venous oxygen saturation accurately reflect mixed venous oxygen saturation? Nothing is simple, unfortunately. Int Care Med 1992;18:386-387

Reinhart K, Rudolph T, Bredle DL, Hannemann L, Cain SM. Comparison of central-venous to mixed-venous oxygen saturation during changes in oxygen supply/demand. Chest 1989;95:12161221 
31 Davies GG, Mendenhall J, Symreng T. Measurement of right atrial oxygen saturation by fiberoptic oximetry accurately reflects mixed venous oxygen saturation in swine. J Clin Monit 1988;4:99-102

32 Barratt-Boyes BG, Wood EH. The oxygen saturation of blood in the venae cavae, right-heart chambers and pulmonary vessels of healthy subjects. J Lab Clin Med 1957;50:93-106

33 Martin C, Auffray JP, Badetti C, Perrin G, Papazian L, Gouin F. Monitoring of central venous oxygen saturation versus mixed venous oxygen saturation in critically ill patients. Int Care Med 1992;18:101-104

34 Tahvanainen J, Meretoja O, Nikki P. Can central venous blood replace mixed venous blood samples? Crit Care Med 1982;10:758-761

35 Reinhart K. Monitoring $\mathrm{O}_{2}$ transport and tissue oxygenation in critically ill patients. In: Reinhart $\mathrm{K}$, Eyrich K. Editors. Clinical aspects of $\mathrm{O}_{2}$ transport and tissue oxygenation. Berlin: Springer Verlag, 1989; pp 193-211

36 Shah DM, Weil MH, Gazmuri RJ, Rackow EC. $\mathrm{O}_{2}$ transport in low flow states of circulatory shock and cardiac arrest. In: Reinhart K, Eyrich $\mathrm{K}$. Editors. Clinical aspects of $\mathrm{O}_{2}$ transport and tissue oxygenation. Berlin: Springer Verlag, 1989; pp 445-461

\section{Acknowledgements}

This study was supported by Abbott Inc. the Netherlands. 


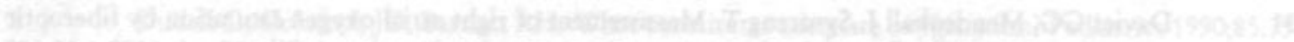

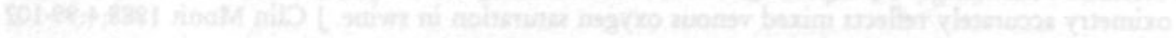

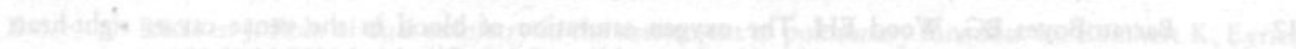

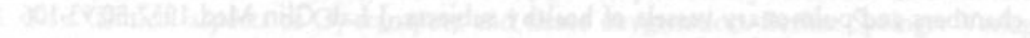

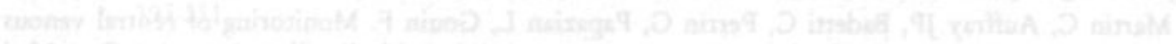

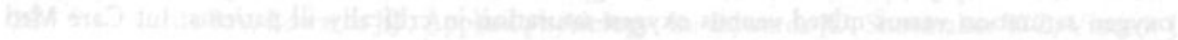

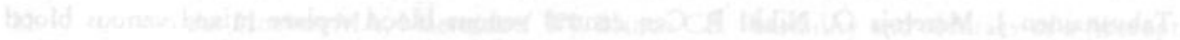

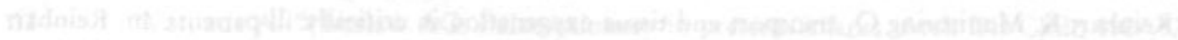

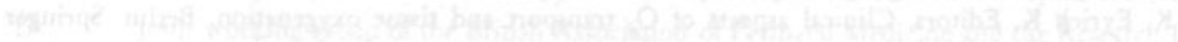

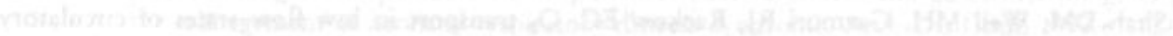

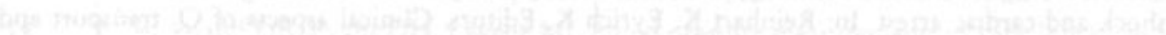




\section{Chapter 7}

Central venous oxygen saturation $\left(\mathrm{ScvO}_{2}\right)$ and derived variables at different ranges of arterial oxygenation in newborn infants with respiratory insufficiency.

Mark A. van der Hoeven, Wiel J. Maertzdorf, Carlos E. Blanco.

Submitted for publication 


\section{Abstract}

Aims: To observe $\mathrm{ScvO}_{2}$ values at different $\mathrm{SaO}_{2}$ values $<86 \%$, at the lower end $(86-90$ $\%)$ and higher (91- $96 \%$ ) end of the recommended range of $\mathrm{SaO}_{2}$ values measured by pulse oximetry in newborn infants with respiratory insufficiency. Other variables as arterial oxygen content $\left(\mathrm{caO}_{2}\right)$ and venous oxygen content $\left(\mathrm{crO}_{2}\right)$, fractional oxygen extraction and the shunt index, an estimate of the venous admixture were calculated.

Design: A non-randomized clinical observational study.

Setting: Level III neonatal intensive care unit of a university hospital.

Patients: 12 (pre)term newborn infants with mechanical ventilation and oxygen need. Birthweight: $1130 \mathrm{gm}(830,1355)$; Gestational age: 28 wks $(26.4,30)$.

Measurements and main results: On line continuous $\mathrm{ScvO}_{2}$ measurement in the right atrium by an umbilical venous fiberoptic catheter. $\mathrm{ScvO}_{2}, \mathrm{SaO}_{2}$ and $\mathrm{FiO}_{2}$ were registered every 15 minutes. F.O.E. and shunt index were calculated. $\mathrm{ScvO}_{2}$ was significantly reduced in the $\mathrm{SaO}_{2}$ range of $86-90 \%$ in nine of the twelve patients. Linear regression analysis yielded a significant correlation between $\mathrm{SaO}_{2}$ and $\mathrm{ScvO}_{2}$ in all but one of the patients. The slope of the regression line between the two levels of oxygenation were not different in any of the infants. $\mathrm{ScvO}_{2}$ values in $\mathrm{SaO}_{2}$ values $<86 \%$ were significantly reduced compared with the values between $86 \%$ and $96 \%$. The shunt index, an estimate of the venous admixture, increased significantly in the lower level of oxygenation in all the patients. In four of the five patients with $\mathrm{SaO}_{2}$ values $<86 \%$ the slope of the regression line was significantly reduced compared to that obtained at $\mathrm{SaO}_{2}$ values $>86 \%$.

Conclusions: On line measurement of $\mathrm{ScvO}_{2}$ at different levels of $\mathrm{SaO}_{2}$ values showed a significant reduction of $\mathrm{ScvO}_{2}$. This reduction of $\mathrm{ScvO}_{2}$ seems to be the primary compensatory mechanism to stabilize tissue oxygenation. 


\section{Introduction}

The optimal level of oxygenation in sick newborn infants is not well established. The currently measured parameters of oxygenation include arterial oxygen tension $\left(\mathrm{paO}_{2}\right)$ and arterial oxygen saturation $\left(\mathrm{SaO}_{2}\right)$.

Attempts have been made to define the limits of the normal range of $\mathrm{paO}_{2}$ and $\mathrm{SaO}_{2}$. For this, values of $\mathrm{paO}_{2}$ and $\mathrm{SaO}_{2}$ were correlated to other variables.

$\mathrm{PaO}_{2}$ levels between 2.5 to $4 \mathrm{kPa}\left(\mathrm{SaO}_{2}\right.$ between 46 to $\left.82 \%\right)$ in newborn infants breathing $13 \%$ oxygen were associated with a rise in pulmonary arterial pressure and resistance ${ }^{[1]}$. Additionally, it was found that visual evoked responses in preterm infants with idiopathic respiratory distress syndrome (IRDS) were more affected, when $\mathrm{PaO}_{2}$ decreased below $7.5 \mathrm{kPa}{ }^{[2]}$. On the other hand Émond et al. ${ }^{[3]}$ demonstrated that approximately $90 \%$ of the hemoglobin of preterm newborn infants is bound to oxygen ( $\mathrm{p}_{\mathrm{x}}$ ) at a level of $\mathrm{paO}_{2}$ of $5.5 \pm 0.5 \mathrm{kPa}$. Furthermore, it was shown, that decreasing $\mathrm{SaO}_{2}$ from $95 \%$ to $90 \%$, corresponding to $\mathrm{paO}_{2}$ values decreasing from $13 \mathrm{kPa}$ to $6.6 \mathrm{kPa}$, did not have any effect on pulmonary hemodynamics, ductus arteriosus, oxygen consumption and cardiac output ${ }^{[0,5]}$. These data have led to different recommendations ${ }^{[6,7]}$ and debate ${ }^{[8,9]}$.

The current clinical parameters of oxygenation, $\mathrm{PaO}_{2}$ and $\mathrm{SaO}_{2}$, are rather poor indicators of tissue oxygenation, because they represent only the availability of oxygen to the tissues. Tissue oxygenation is also determined by other variables as hemoglobin, cardiac output and oxygen uptake of the tissues. Venous oxygen saturation reflects the residual oxygen after tissue oxygen extraction and indicates the combined sufficiency of all these variables ${ }^{[10,11,12]}$. In a previous study we have determined the feasibility and the accuracy of a fiberoptic catheter system in the newborn, providing a continuous central venous oxygen saturation $\left(\mathrm{ScvO}_{2}\right)$ measurement in the right atrium ${ }^{[1]]}$. We have also described a "normal" range of $\mathrm{ScvO}_{2}$ values between $58 \%$ to $85 \%$ in 1-7 days old (pre)term infants breathing room air ${ }^{[14]}$.

The aim of the present work was to describe the $\mathrm{ScvO}_{2}$ values at three levels of $\mathrm{SaO}_{2}$ values: below $86 \%$, between 86 to $90 \%$ and between 91 to $96 \%$; these last two values are the lower and the higher end of the recommended range of $\mathrm{SaO}_{2}$ values in newborn infants with respiratory insufficiency, respectively. Other oxygen transport variables, as arterial $\left(\mathrm{caO}_{2}\right)$ and venous oxygen content $\left(\mathrm{crO}_{2}\right)$, fractional oxygen extraction, an estimate of the venous admixture: the shunt index, $p_{50}$ and $p_{90}$ are described.

\section{Patients and methods}

This study was approved by the ethics committee of the Academic Hospital of Maastricht.

Patients included 12 newborn infants with respiratory insufficiency, oxygen need and endotracheal mechanical ventilation. Umbilical catheters were placed for clinical management.

\section{measurements}

$\mathrm{ScvO}_{2}$ was continuously measured by a $4 \mathrm{Fr}$. fiberoptic catheter (Oximetrix System, Abbott Lab. Chicago Ill.), which allowed both a continuous measurement of oxygen saturation at the tip of the catheter and infusion of fluids and medication. The continuous measurement of oxygen saturation is based on reflection spectrometry. The light source, consisting of three diodes, emits light at three different wavelengths through a fiberoptic bundle. The back scattered light from the oxygenated and unoxygenated red cells is transmitted by the receiving fiberoptic bundle to a photodetector in the optical module. 
The oximeter computes percent of oxygen saturation values based on the electrical signals from the optical module. The average value for oxygen saturation over a five second period is displayed digitally, and the value updated each second.

The fiberoptic catheter was placed in the right atrium via the umbilical vein. The catheter was positioned at the midatrial level or at the transition of the inferior vena cava to the right atrium. The position was confirmed by X-ray and ultrasound. Routinely, heparinized saline $(0.5 \mathrm{U} . / \mathrm{cc}$.) was infused continuously $(0.1 \mathrm{cc} / \mathrm{hr}$.) to avoid fibrin formation over the catheter. Bloodsamples were withdrawn through the catheter at least every twelve hours and immediately analyzed with a hemoximeter (Radiometer OSM3, Copenhagen) and compared with simultaneously recorded fiberoptic catheter readings. When oxygen saturation in correlated samples showed a discrepancy of $\geq 5 \%$, a correction was made.

$\mathrm{SaO}_{2}$ was monitored continuously by pulse oximetry (Hewlett Packard). Each value is the average of samples taken every 12 seconds over one minute.

Arterial blood pressure was monitored through an umbilical or radial artery catheter; these catheters were also used for sampling arterial $\mathrm{pH}, \mathrm{PaCO}_{2}, \mathrm{PaO}_{2}$, and base excess for clinical purposes.

\section{calculations}

Arterial oxygen content $\left(\mathrm{caO}_{2}\right)$ and central venous oxygen content $\left(\mathrm{ccrO}_{2}\right)$ were calculated using the equation:

$-\mathrm{caO}_{2}(\mathrm{ml} / \mathrm{dl})=\mathrm{SaO}_{2} \times \mathrm{Hb}(\mathrm{mmol} / \mathrm{L}) \times 1.61 \times 1.36$

- $\mathrm{ccvO}_{2}(\mathrm{ml} / \mathrm{dl})-\mathrm{ScvO}_{2} \times \mathrm{Hb}(\mathrm{mmol} / \mathrm{L}) \times 1.61 \times 1.36$, respectively.

Fractional oxygen extraction (F.O.E.) was calculated using the equation: F.O.E. - $\left(\mathrm{SaO}_{2}-\mathrm{ScvO}_{2}\right) / \mathrm{SaO}_{2}$.

The venous admixture was estimated using the equation for the shunt index:

- $100 \times\left(100-\mathrm{SaO}_{2}\right) /\left(100-\mathrm{ScvO}_{2}\right)$, assuming that the pulmonary end-capillary blood was fully saturated with oxygen.

The alveolar $\mathrm{pO}_{2}\left(\mathrm{p}_{\mathrm{Alv}} \mathrm{O}_{2}\right)$ was calculated using a simplified alveolar air equation:

- $\mathrm{p}_{\mathrm{Al}} \mathrm{O}_{2}-$ ( $\left.\mathrm{p}_{\text {(barometric) }}-\mathrm{p}_{\text {(HoO) }}\right) . \mathrm{FiO}_{2}-\mathrm{paCO}_{2} / 0.8$

The $\mathrm{pO}_{2}$ at an oxygen saturation of $50 \%\left(\mathrm{p}_{50}\right)$ and of $90 \%\left(\mathrm{p}_{90}\right)$ were estimated using the oxygen status algorithm ${ }^{[16]}$.

\section{Data analysis}

$\mathrm{SaO}_{2}, \mathrm{ScvO}_{2}$, arterial blood pressure, heart rate and the related calculated variables as venous admixture and fractional oxygen extraction were registered every 15 minutes. Arterial blood gas measurements and hemoglobin values were determined when appropriate and related variables as $\mathrm{caO}_{2}, \mathrm{ccvO}_{2}, \mathrm{p}_{\mathrm{Av}} \mathrm{O}_{2}, \mathrm{p}_{50}$ and $\mathrm{p}_{90}$ were calculated. These different parameters were compared for the different levels of oxygenation based on whether the actual $\mathrm{SaO}_{2}$ value did belong to the lower $(86-90 \%)$ or higher $(91-96 \%)$ end of the recommended range of pulse oximetry. In patients with sufficient $\mathrm{SaO}_{2}$ values below $86 \%$, the comparison included this low level of oxygenation.

Data are reported as median values with the 10 th and 90th percentile range. $\mathrm{ScvO}_{2}$ values were compared with the described normal range in infants breathing room air. Data were compared for the different level of oxygenation using the Mann-Whitney U test when data were not normally distributed. To describe the relation between $\mathrm{SaO}_{2}$ and $\mathrm{ScvO}_{2}$ a linear regression analysis was performed in every patient. The slope (regression coefficient) of the regression line was compared for the two levels of oxygenation within each patient using covariant analysis. The identical analysis was performed for the relation between $\mathrm{SaO}_{2}$ and venous admixture and $\mathrm{ScvO}_{2}$ and fractional oxygen extraction. 


\section{Results}

In 12 newborn infants the $\mathrm{ScvO}_{2}$ could be monitored continuously by a fiberoptic catheter in the right atrium confirmed by X-ray or ultrasound and reliable oxygen saturation readings were obtained confirmed by correlated blood samples. Birthweight and gestational age are given in table 1. Diagnoses in all but one patients included idiopathic respiratory distress syndrome (IRDS). One patient (4) had oligohydramnion sequence and lung hypoplasia.

table 1. Gestational age (GA), birth weight (BW) and oxygen transport variables. median (10th, 90th percentile)

\begin{tabular}{lllllll}
\hline $\begin{array}{l}\text { Patient } \\
\text { No }\end{array}$ & $\begin{array}{l}\mathrm{GA} \\
\text { (weeks) }\end{array}$ & $\begin{array}{l}\mathrm{BW} \\
(\mathrm{gram})\end{array}$ & $\mathrm{FiO} 2$ & $\begin{array}{l}\mathrm{P}_{\mathrm{Al}} \mathrm{O}_{2} \\
(\mathrm{kPa})\end{array}$ & $\begin{array}{l}\mathrm{P}_{\infty} \\
(\mathrm{kPa})\end{array}$ & $\begin{array}{l}\mathrm{P}_{*} \\
(\mathrm{kPa})\end{array}$ \\
\hline 1 & 26 & 920 & $0.30(0.25,0.50)$ & $28(18,43)$ & $3.1(2.8,3.5)$ & $6.9(6.3,7.6)$ \\
2 & 27 & 720 & $0.39(0.21,0.65)$ & $31(13,48)$ & $3.9(3.5,4.9)$ & $8.5(7.5,10.3)$ \\
3 & 28.6 & 940 & $0.40(0.32,0.68)$ & $32(22,56)$ & $3.0(2.5,3.8)$ & $6.8(5.7,8.3)$ \\
4 & 39 & 3400 & $1.00(1.00,1.00)$ & $90(85,92)$ & $3.0(1.9,3.5)$ & $6.8(4.8,7.7)$ \\
5 & 30 & 1000 & $0.40(0.29,0.57)$ & $34(17,54)$ & $4.1(3.6,4.9)$ & $8.8(7.8,10.3)$ \\
6 & 28 & 1355 & $0.38(0.21,0.60)$ & $22(13,31)$ & $3.2(2.7,4.0)$ & $7.1(6.2,8.6)$ \\
7 & 28 & 1180 & $0.25(0.21,0.35)$ & $14(13,20)$ & $3.2(2.7,4.0)$ & $7.1(6.2,8.7)$ \\
8 & 29 & 1350 & $0.31(0.24,0.37)$ & $21(16,27)$ & $3.7(2.7,4.2)$ & $8.0(6.2,9.1)$ \\
9 & 25 & 840 & $0.26(0.21,0.33)$ & $18(14,29)$ & $3.2(2.5,4.2)$ & $8.1(6.0,9.0)$ \\
10 & 28.3 & 1130 & $0.33(0.21,0.56)$ & $30(14,54)$ & $2.9(2.8,3.2)$ & $6.6(6.4,7.2)$ \\
11 & 26.4 & 840 & $0.26(0.21,0.30)$ & $16(14,32)$ & $3.4(3.3,3.8)$ & $7.7(7.4,8.3)$ \\
12 & 26.4 & 830 & $0.25(0.21,0.45)$ & $19(13,25)$ & $3.3(2.8,3.7)$ & $7.4(6.3,8.8)$ \\
\hline
\end{tabular}

Oxygen transport variables as $\mathrm{p}_{\mathrm{Alv}} \mathrm{O}_{2}, \mathrm{p}_{5_{0}}$ and $\mathrm{p}_{90}$ are shown in table 1 . In none of the infants a difference between the two levels of oxygenation with regard to the $\mathrm{p}_{\mathrm{Al}} \mathrm{O}_{2}, \mathrm{p}_{50}$ and $\mathrm{p}_{90}$ values was found. The plot of the $\mathrm{paO}_{2}$ and $\mathrm{HbO}_{2}$ values is shown in figure 1 . The median $\mathrm{paO}_{2}$ values for each level of oxygenation $5.6 \mathrm{kPa}(4.6,7.3)$ and $6.8 \mathrm{kPa}(5.8,8.4)$ vs. $8.1 \mathrm{kPa}(6.6,11.0)$ are significantly different $(p<0.001)$. The different values of the $\mathrm{SaO}_{2}$ at the levels of oxygenation resulted in eight patients to a significant difference of the $\mathrm{caO}_{2}$. In all but three patients $\mathrm{ScvO}_{2}$ values were significantly reduced in the lower compared to the higher level of oxygenation. Linear regression analyses comparing $\mathrm{SaO}_{2}$ and $\mathrm{ScvO}_{2}$ yielded a slope (regression coefficient) and a correlation coefficient $\mathrm{r}$ (table 2, figure 2). In all but one patient a significant correlation was found. Comparing the slope of the regression line between the two levels of oxygenation did not yield a significant difference in any of the infants. In five patients sufficient $\mathrm{SaO}_{2}$ values below $86 \%$ could be registered to include the data in table 2 and to perform a regression analysis. $\mathrm{ScvO}_{2}$ values were significantly reduced in this low level of oxygenation compared to higher levels. In two of these five patients linear regression analysis showed a significant increase of the slope in the oxygenation level below $86 \%$ compared with the level between $86 \%$ and $96 \%$ (figure 2).

The shunt index, an estimate of the venous admixture, increased significantly in the lower level of oxygenation in all the patients. In the five patients with $\mathrm{SaO}_{2}$ values below $86 \%$ the shunt index increased additionally. 
table 2. Arterial oxygen saturation $\left(\mathrm{SaO}_{2}\right)$, oxygen content $\left(\mathrm{caO}_{2}\right)$ and central venous oxygen saturation $\left(\mathrm{ScvO}_{2}\right)$, oxygen content $\left(\mathrm{ccvO} \mathrm{O}_{2}\right)$ at different levels of oxygenation defined by $\mathrm{SaO}_{2}$ measured by pulse oximetry. Slope and correlaion coefficient (r) between $\mathrm{SaO}_{2}$ and $\mathrm{ScvO}_{2}$ at the oxygenation level below 86 and above $86 \%$." : the slope increased significantly at the oxygenation evel below $86 \%$. Median values (10th, 90th percentile).

Oxygen transport variables

Arterial

Patients

No

$\mathrm{SaO}_{2}$

(\%)

$\mathrm{CaO}_{2}$

(ml/dl)

$$
\begin{aligned}
& 13.3(9.5,14.3) \\
& 14.7(13.6,15.1) \\
& 15.2(13.4,16.2) \\
& 17.6(11.8,19.9) \\
& 15.6(12.4,20.4) \\
& 17.1(14.4,21.3) \\
& 17.3(15.7,23.2) \\
& 19.4(16.3,24.0) \\
& 17.2(11.2,19.8) \\
& 17.3(16.5,20.9) \\
& 18.1(16.6,21.3) \\
& 18.1(16.9,19.5) \\
& 19.3(17.6,20.6) \\
& 15.3(14.9,25.0) \\
& 16.8(15.7,23.0) \\
& 14.4(14.1,14.5) \\
& 20.2(12.2,20.9) \\
& 18.5(14.2,22.7) \\
& 16.9(14.8,23.9)
\end{aligned}
$$

$88(86,90)$

$93(91,95)$

$88(86,90)$

$92(91,94)$

$89(86,90)$

$93(91,95)$

$89(88,90)$

$93(95,96)$

$88(86,90)$

$93(91,95)$
Central venous

$\mathrm{ScvO}_{2}$

(\%)

$\mathrm{ccvO}_{2}$

(ml/dl)

$10.7(7.8,12.6)$

$12.0(11.2,12.7)$

$12.4(10.9,13.9)$

$72(65,78)$

$77(69,82)$

$12.4(10.0,15.8)$

$75(65,80)$

$75(67,85)$

$13.3(9.6,15.9)$

$70(64,78)$

$78(72,84)$

$78(71,86)$

$69(19,78)$

$77(66,81)$

$80(71,83)$

$76(67,83)$

$79(63,84)$

$67(58,73)$

$75(69,80)$

$66(58,76)$

$75(66,80)$

$69(64,73)$

$73(69,78)$

$15.6(10.4,17.3)$

$16.0(13.1,20.9)$

$20.4(14.5,22.1)$

$11.6(8.6,15.6)$

$15.5(11.7,16.8)$

$15.8(13.8,16.6)$

$16.5(13.2,17.5)$

$11.8(9.9,18.1)$

$14.3(12.1,17.9)$

$11.7(11.3,12.1)$

$16.3(8.5,16.7)$

$13.9(10.8,18.5)$

$13.4(11.6,19.4)$

\section{Correlation}

between $\mathrm{SaO}_{2}$ and $\mathrm{SuO}_{2}$

coefficient slope

(r)

0.63

0.72

$0.68(0.38,0.98)$

$0.97(0.69,1.15)$

0.17

$0.33(0.02,0.63)$

0.75

$0.98(0.59,1.38)$

0.16

$0.35(0.07,0.63)$

0.95

$1.62(1.46,1.78)^{\circ}$

0.35

$0.69(0.49,0.89)$

0.12

$0.23(-0.09,0.56)$

0.79

$1.40(1.27,1.53)$

0.59

$0.96(0.82,1.08)$ 
$15.1(13.9,16.4)$ $18.8(17.9,20.6)$ 
tabel 3. Arterial oxygen saturation $\left(\mathrm{SaO}_{2}\right)$, fractional oxygen extraction (FOE) and shunt index at different levels of oxygenation defined by $\mathrm{SaO} \mathrm{O}_{2}$ measured by pulse oximetry. Correlation coefficient $\left(\mathrm{r}\left(\mathrm{ScvO}_{2}\right)\right.$ between $\mathrm{ScvO}_{2}$ and $\mathrm{FOE}$ at the oxygenation level below 86 and above $86 \%$. Correlation coefficient ( $\mathrm{r}$ $\left(\mathrm{SaO}_{2}\right)$ between $\mathrm{SaO}_{2}$ and shunt index at the oxygenation level below 86 and above $86 \%$. "* : $\mathrm{r}$ increased significantly at the oxygenation level above 86 $\%$. Median values (10th, 90 th percentile).

\begin{tabular}{|c|c|c|c|c|c|c|}
\hline & Oxygenation level & Fractional axygen & tion & Shunt index & & \\
\hline $\begin{array}{l}\text { patient } \\
\text { No }\end{array}$ & $\begin{array}{l}\mathrm{SaO}_{2} \\
(\%)\end{array}$ & $\begin{array}{l}\text { median } \\
(10 \mathrm{th}, 90 \mathrm{th})\end{array}$ & $\begin{array}{l}\mathbf{r} \\
\left(\mathrm{ScvO}_{2}\right)\end{array}$ & $\begin{array}{l}\text { Median (\%) } \\
(10 \text { th , 90th) }\end{array}$ & $\begin{array}{l}\mathbf{r} \\
\left(\mathrm{SaO}_{2}\right)\end{array}$ & slope $(95 \% \mathrm{Cl})$ \\
\hline 1 & $\begin{array}{l}78(67,84) \\
89(86,90) \\
93(91,95)\end{array}$ & $\begin{array}{l}0.17(0.10,0.24) \\
0.19(0.13,0.26) \\
0.17(0.12,0.25)\end{array}$ & 0.63 & $\begin{array}{l}60(47,79) \\
42(31,52) \\
30(10,40)\end{array}$ & $\begin{array}{l}0.72 \\
0.73\end{array}$ & $\begin{array}{ll}-1.4 & (-1.9,-0.9)^{*} \\
-2.5 & (-2.9,-2.1)\end{array}$ \\
\hline 2 & $\begin{array}{l}89(87,90) \\
93(91,96)\end{array}$ & $\begin{array}{l}0.16(0.11,0.27) \\
0.20(0.08,0.27)\end{array}$ & 0.91 & $\begin{array}{l}45(33,53) \\
26(15,50)\end{array}$ & 0.77 & $-3.4(-3.8,-3.0)$ \\
\hline 3 & $\begin{array}{l}83(72,85) \\
89(97,90) \\
92(91,94)\end{array}$ & $\begin{array}{l}0.12(0.03,0.20) \\
0.11(0.06,0.19) \\
0.12(0.06,0.19)\end{array}$ & 0.82 & $\begin{array}{l}64(48,87) \\
52(39,67) \\
36(23,56)\end{array}$ & $\begin{array}{l}0.29 \\
0.61\end{array}$ & $\begin{array}{ll}-0.6 & (-1.5,0.3)^{\circ} \\
-3.7 & (-4.3,-3.1)\end{array}$ \\
\hline 4 & $\begin{array}{l}83(61,85) \\
88(86,90) \\
93(91,95)\end{array}$ & $\begin{array}{l}0.18(0.08,0.64) \\
0.13(0.09,0.25) \\
0.14(0.10,0.24)\end{array}$ & 0.94 & $\begin{array}{l}60(47,73) \\
47(35,64) \\
35(20,45)\end{array}$ & $\begin{array}{l}0.03 \\
0.74\end{array}$ & $\begin{array}{l}-0.03(-0.16,0.10)^{*} \\
-3.3(-3.7,-2.9)\end{array}$ \\
\hline 5 & $\begin{array}{l}88(86,90) \\
92(91,94)\end{array}$ & $\begin{array}{l}0.14(0.07,0.25) \\
0.15(0.09,0.32)\end{array}$ & 0.89 & $\begin{array}{l}48(32,67) \\
35(19,50)\end{array}$ & 0.73 & $-3.6(-4.1,-3.0)$ \\
\hline 6 & $\begin{array}{l}89(86,90) \\
93(91,95)\end{array}$ & $\begin{array}{l}0.23(0.18,0.34) \\
0.20(0.15,0.26)\end{array}$ & 0.94 & $\begin{array}{l}35(28,40) \\
26(20,34)\end{array}$ & 0.78 & $-1.5(-1.7,-1.4)$ \\
\hline 7 & $\begin{array}{l}89(88,90) \\
93(95,96)\end{array}$ & $\begin{array}{l}0.26(0.15,0.34) \\
0.21(0.16,0.28)\end{array}$ & 0.89 & $\begin{array}{l}31(25,48) \\
20(15,27)\end{array}$ & 0.87 & $-2.1(-2.3,-2.0)$ \\
\hline 8 & $\begin{array}{l}88(86,90) \\
93(91,95)\end{array}$ & $\begin{array}{l}0.22(0.17,0.28) \\
0.21(0.16,0.25)\end{array}$ & 0.87 & $\begin{array}{l}37(31,44) \\
28(20,34)\end{array}$ & 0.92 & $-2.7(-2.8,-2.6)$ \\
\hline
\end{tabular}




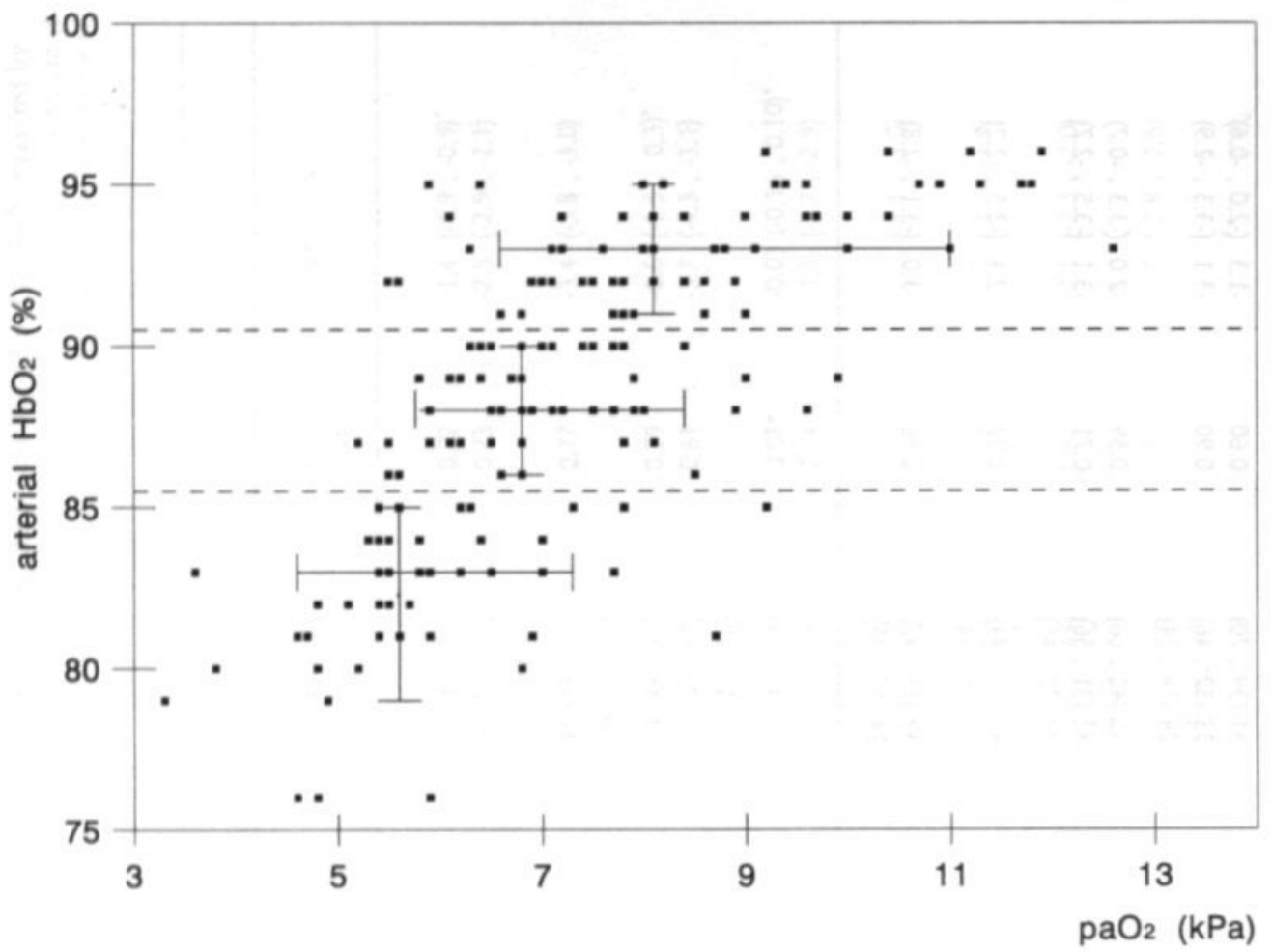

figure 1. Arterial $\mathrm{pO}_{2}\left(\mathrm{paO}_{2}\right)$ corresponding to arterial oxygen saturation $\left(\mathrm{HbO}_{2}\right)$. The $\mathrm{paO}_{2}$ values: $5.6 \mathrm{kPa}$ $(4.6,7.3), 6.8 \mathrm{kPa}(5.8,8.4)$ vs. $8.1 \mathrm{kPa}(6.6,11.0)$ for each level of oxygenation: $83 \%(79,85)$, $88 \%(86,90)$ and $93 \%(91,95)$ are significantly different $(p<0.001)$.

Linear regression analyses for each patient separately showed a negative correlation with $\mathrm{SaO}_{2}$ in all patients (table 3, figure 4).

No differences were found in the slope of the regression lines between the two recommended $\mathrm{SaO}_{2}$ levels above and below $90 \%$. In four of the five patients with $\mathrm{SaO}_{2}$ values below $86 \%$ the slope of the regression line was significantly reduced in comparison with the slope of the regression line obtained at $\mathrm{SaO}_{2}$ values above $86 \%$.

Fractional oxygen extraction (FOE) was significantly increased in five of the twelve patients in the lower level of oxygenation. Linear regression analysis yielded only a significant correlation in six patients with a low range of correlation coefficients: $r: 0.25$ $(0.04,0.42)$. However, linear regression analysis between $\mathrm{ScvO}_{2}$ and fractional oxygen extraction showed a significant correlation in all patients (table 3, figure 4). Comparing the three $\mathrm{SaO}_{2}$ levels fractional oxygenation remained stable, when $\mathrm{ScvO}_{2}$ decreased.

\section{Discussion}

In this study we report on line monitoring $\mathrm{ScvO}_{2}$ by an umbilical fiberoptic catheter in 12 newborn infants with moderate to severe respiratory failure. $\mathrm{ScvO}_{2}$ values and derived variables, as the shunt index and fractional oxygen extraction were compared at low values $\left(\mathrm{SaO}_{2}\right.$ below $\left.86 \%\right)$ and the lower $(86-90 \%)$ and the higher $(91-96 \%)$ end of the recommended range of $\mathrm{SaO}_{2}$ values. 


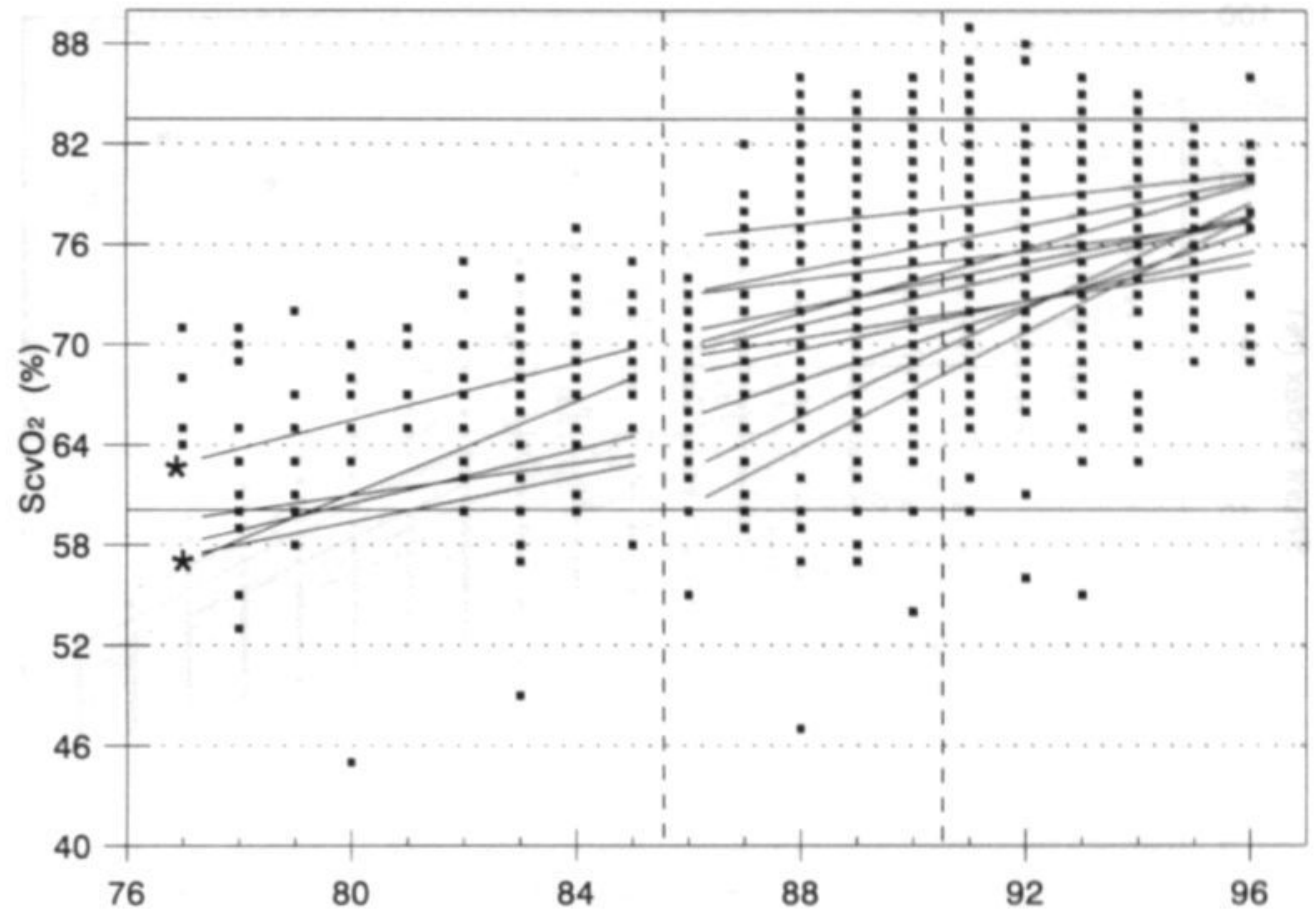

$\mathrm{SaO}_{2}(\%)$

figure 2. Arterial oxygen saturation values obtained by pulse oximetry $\left(\mathrm{SaO}_{2}\right)$ corresponding to central venous oxygen saturation values simultaneously obtained by fiberoptic catheter readings $\left(\mathrm{SevO}_{2}\right)$. Linear regression lines are drawn for each patient and regression analysis showed in all but one patient a significant correlation in at $\mathrm{SaO}_{2}$ values above $86 \%$. "': In two of the five patients the slope of the regression line at $\mathrm{SaO}_{2}$ values below $86 \%$ was significantly different from the slope at $\mathrm{SaO}_{2}$ values above $86 \%$. The arcerated area is the normal range of $\mathrm{ScvO}_{2}$ values as defined in infants breathing room air.

$\mathrm{ScvO}_{2}$ was significantly reduced in the lower level of the recommended range of oxygenation in nine of the twelve patients. Linear regression analysis yielded a significant correlation between $\mathrm{SaO}_{2}$ and $\mathrm{ScvO}_{2}$ in all but one of the patients. However, it must be recognized that changes in $\mathrm{ScvO}_{2}$ values may not only be due to changes in $\mathrm{SaO}_{2}$ but also to changes in cardiac output, $\mathrm{O}_{2}$ uptake, hemoglobin, shift of the oxyhemoglobin dissociation curve or a combination of these variables ${ }^{[15]}$. For example, since in our present study the different $\mathrm{SaO}_{2}$ value in the different levels of oxygenation did not always resulted in a different $\mathrm{caO}_{2}$, due to differences in hemoglobin concentration, $\mathrm{ScvO}_{2}$ values may not not be affected by changes in $\mathrm{SaO}_{2}$.

In addition, $\mathrm{ScvO}_{2}$ value may also be affected by cardiac output and tissue oxygen uptake. $\mathrm{ScvO}_{2}$ monitoring does not yield specific information regarding any individual oxygen transport variable. But in prospective studies in newborn infants ${ }^{[4,5]}$ it was reported that the cardiac output and oxygen consumption did not change neither in the low nor in the high level of the recommended range of oxygenation. 


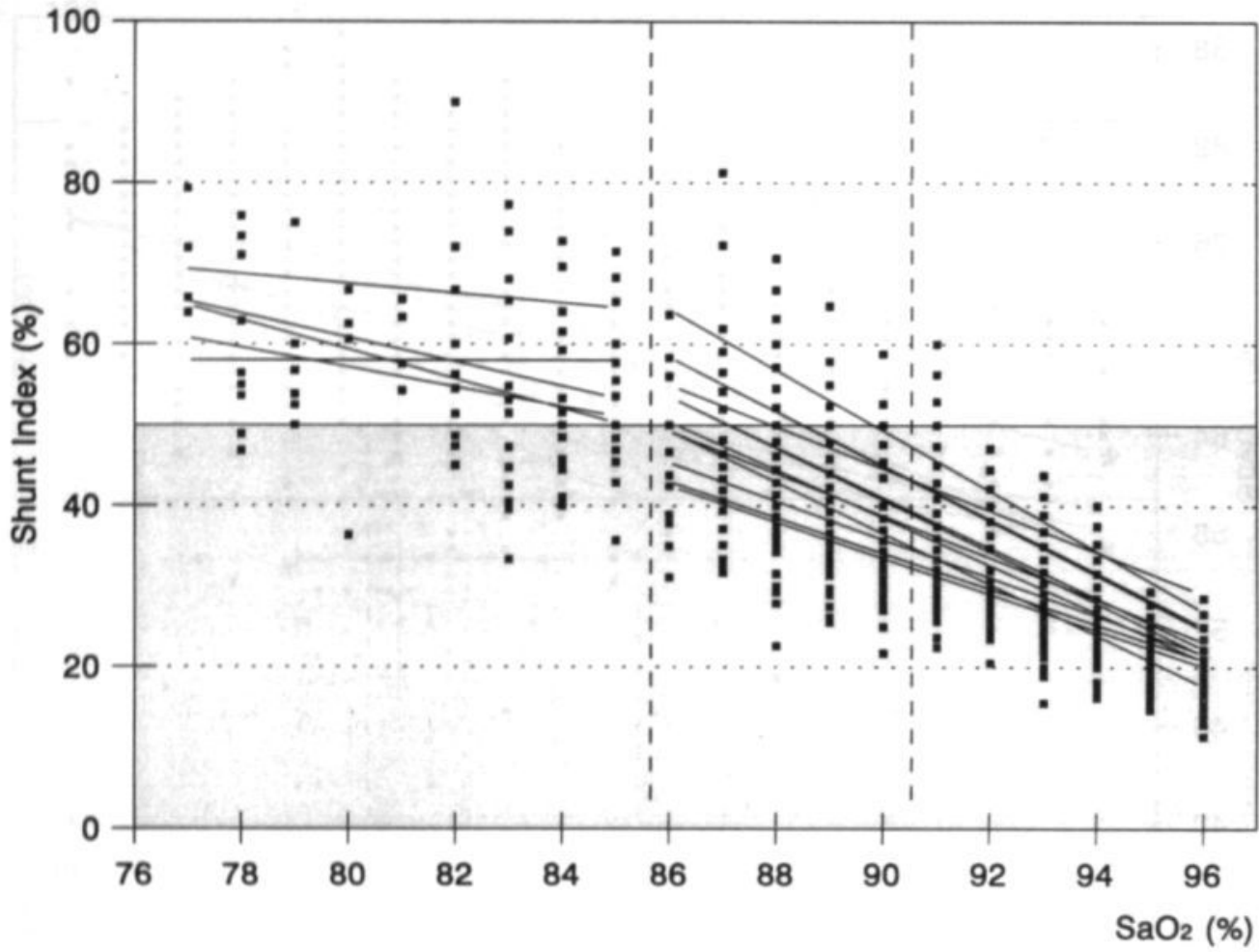

figure 3. Arterial oxygen saturation values obtained by pulse oximetry $\left(\mathrm{SaO}_{2}\right)$ corresponding to the shunt index, an estimate of the venous admixture. Linear regression lines are drawn for each patient. Regression analysis showed a significant correlation in all patients. "': in four of the five patients with $\mathrm{SaO}_{2}$ values below $86 \%$ the slope of the regression line at $\mathrm{SaO}_{2}$ values below $86 \%$ was significantly different from the slope of the regression line obtained at $\mathrm{SaO}_{2}$ values above $86 \%$

Consequently, the reduction of $\mathrm{ScvO}_{2}$ reported in our study seemed at these levels of oxygenation the primary compensatory mechanism to stabilize the tissue oxygenation at lower $\mathrm{SaO}_{2}$ values. This is in agreement with our animal study in which moderate reductions of $\mathrm{ScvO}_{2}$ were not associated with a reduced oxygen consumption or an increased lactate concentration ${ }^{[19]}$. The amount of $\mathrm{ScvO}_{2}$ reduction did not change since the slope of the regression line did not differ between the two levels of oxygenation in any of the infants. In two of the five patients with $\mathrm{SaO}_{2}$ values below $86 \%$ the rate of $\mathrm{ScvO}_{2}$ reduction was significantly increased compared with the change in the recommended range of $\mathrm{SaO}_{2}$ values. Apparently, in these two patients oxygen uptake increased whereas other factors which determine oxygen delivery as cardiac output failed to counterbalance the reduced oxygen saturation. When the present $\mathrm{ScvO}_{2}$ values were compared with the "normal range" defined in infants breathing room air ${ }^{[14]}$, most $\mathrm{ScvO}_{2}$ values in both recommended levels were included within this range. Lower $\mathrm{ScvO}_{2}$ values were mainly encountered with $\mathrm{SaO}_{2}$, values below $86 \%$.

The shunt index is an estimate of the venous admixture that refers to the degree of admixture of mixed venous blood with pulmonary end-capillary blood. The venous admixture is a calculated percentage of blood, which would be required to produce the observed difference between the arterial and the pulmonary end-capillary $\mathrm{pO}_{2}$, which is 


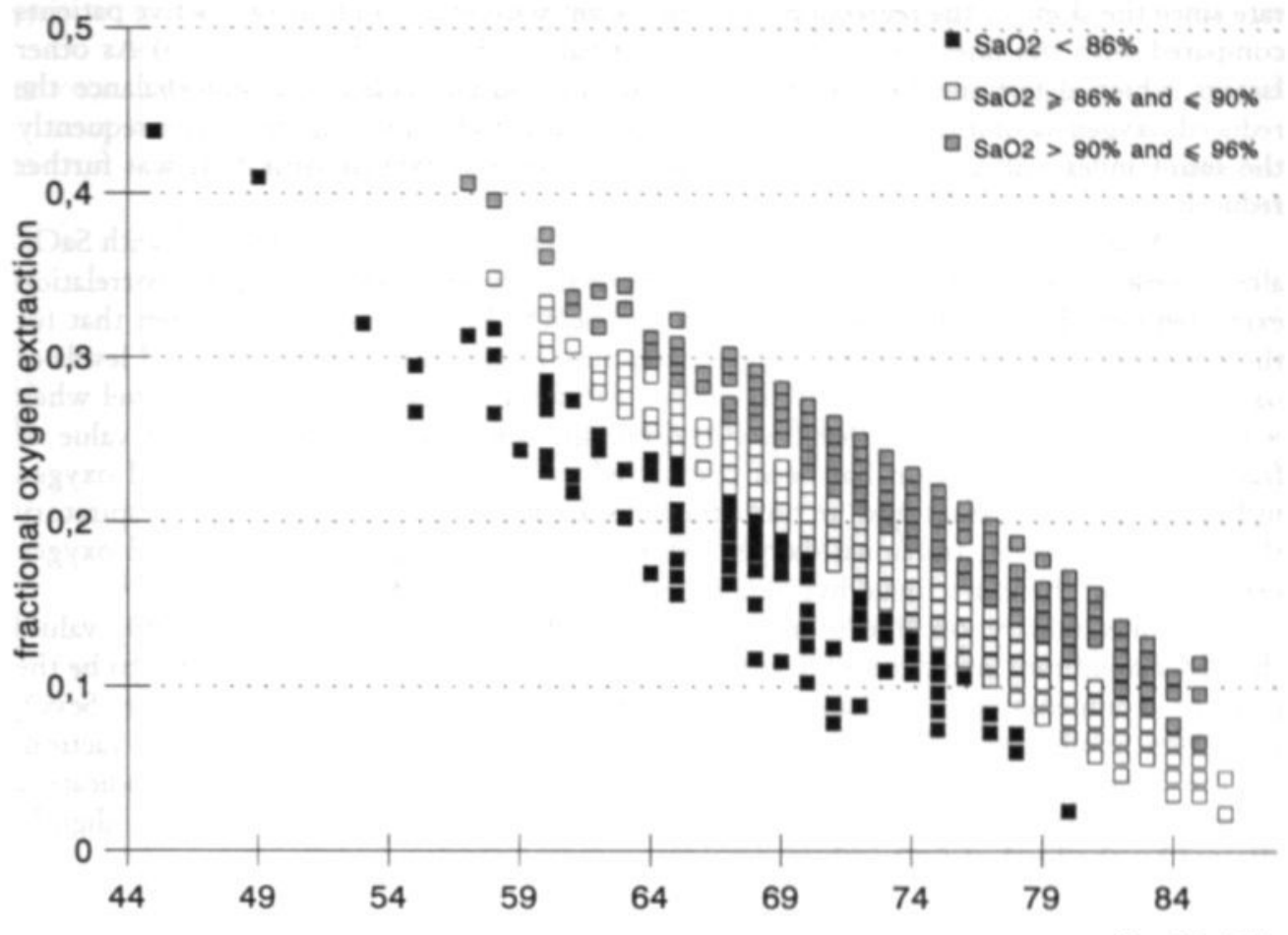

$\mathrm{ScvO}_{2}(\%)$

figure 4. Central venous oxygen saturation $\left(\mathrm{ScvO}_{2}\right)$ values obtained by fiberoptic catheter readings corresponding to the fractional oxygen extraction.

usually taken to equal ideal alveolar $\mathrm{P}_{\text {alv }} \mathrm{O}_{2}{ }^{[20]}$. The calculated $\mathrm{palv}_{2} \mathrm{O}_{2}$ values in our study (table 1) are such that the assumptions of the shunt index, that the pulmonary end-capillary blood is fully saturated and that the dissolved oxygen can be discounted, are warranted. In our study we found an increased shunt index in the lower end of the recommended range of oxygenation, which even further increased in the patients in whom $\mathrm{SaO}_{2}$ values below $86 \%$ were obtained. Linear regression analysis yielded a significant correlation in all the patients.

The shunt index as an estimate of the venous admixture obtained by continuous pulse and venous oximetry (dual oximetry) has been suggested and studied in adult intensive care medicine ${ }^{[21,22,23]}$. It was used to titrate rapidly continuous positive pressure (CPAP) in adults [24]. In neonatal medicine the association between venous admixture and biochemical lung maturity was determined ${ }^{[25]}$ and after administration of surfactant a rapid fall of venous admixture was described [26]. In agreement with our study Schultze et al. [5] found an increased venous admixture in the low level of oxygenation in preterm infants targeting different levels of oxygenation. Although it has been shown, that decreasing $\mathrm{SaO}_{2}$ from $95 \%$ to $90 \%$ corresponding to $\mathrm{paO}_{2}$ values of $11.6 \pm 0.7 \mathrm{kPa}$ and $7.5 \pm 0.4 \mathrm{kPa}$, respectively, did not have any effect on pulmonary circulatory hemodynamics ${ }^{[4]}$, a certain grade of intrapulmonary shunting, ventilation perfusion mismatch or pulmonary vasoconstriction must be assumed to explain the increased venous admixture in the lower levels of oxygenation. At $\mathrm{SaO}_{2}$ values below $86 \%$ the shunt index increased at a reduced 
rate since the slope of the regression lines significantly decreased in four of the five patients compared with the lines obtained at $\mathrm{SaO}_{2}$ values above $86 \%$. (table 3, figure 3) As other factors which determine oxygen delivery as cardiac output failed to counterbalance the reduced oxygen saturation, $\mathrm{ScvO}_{2}$ starts to decrease at a higher rate (figure 2). Consequently the shunt index will increase at a lower rate when arterial oxygen saturation was further reduced.

Fractional oxygen extraction was in six patients significantly correlated with $\mathrm{SaO}_{2}$, albeit weak. ( $r=0.18$ to 0.39 ). Mathematically it can be expected that a good correlation exists between fractional oxygen extraction and $\mathrm{ScvO}_{2}$. In figure 4 it can be seen that for the same level of $\mathrm{ScvO}_{2}$ fractional oxygen extraction increased facing the increased levels of oxygenation. In other terms fractional oxygen extraction remained at the same level when with a reducing oxygenation level $\mathrm{ScvO}_{2}$ decreased concomitantly. The clinical value of fractional oxygen extraction has been considered as an estimate of the peripheral oxygen utilization by the tissues and an instantaneous feedback on circulatory and respiratory therapy ${ }^{[2]}$. However, fractional oxygen extraction based on $\mathrm{ScvO}_{2}$ reflects global oxygen extraction and therefore tissue hypoxia in individual organs cannot be excluded [28].

In summary on line measurement of $\mathrm{ScvO}_{2}$ at different levels of $\mathrm{SaO}_{2}$ values showed a significant reduction of $\mathrm{ScvO}_{2}$. Moreover, this reduction of $\mathrm{ScvO}_{2}$ seems to be the primary compensatory mechanism to stabilize tissue oxygenation. On line $\mathrm{ScvO}_{2}$ measurement allowed an estimate of the venous admixture and fractional oxygen extraction. At the lower level of $\mathrm{SaO}_{2}$ values an increased venous admixture seems to indicate a decreased effectiveness in gas exchange. Fractional oxygen extraction was only slightly affected by the level of $\mathrm{SaO}_{2}$ values.

\section{References}

Moss AF, Emmannouilliedes GC, Adams FH. Response of ductus arteriosus and pulmonary and systemic arterial pressures to changes in oxygen environment in the newborn infant. Pediatrics 1964;33:937-944

Hrbek A, Karlberg P, Kjellmer I, Olsson T, Riha M. Clinical application of evoked EEG responses in newborn infants II: Idiopathic respiratory distress syndrome. Develop Med Child Neurol $1978 ; 20: 619-626$

Émond D, Lachance C, Gagnon J, Bard H. Arterial partial pressure of oxygen required to achieve $90 \%$ saturation of hemoglobin in very low birth weight newborns. Pediatrics 1993;91:602-604

Bard H, Belanger S, Fouron JC. Comparison of effects of $95 \%$ and $90 \%$ oxygen saturations in respiratory distress syndrome. Arch Dis Child 1996;75:F94-F96

Schultze A, Whyte RK, Clifton Way R, Sinclair JC. Effect of the arterial oxygenation level on cardiac output, oxygen extraction and oxygen consumption in low birth weight infants receiving mechanical ventilation. J Pediatr 1995;126:777-784

Joint working group of the British Association of Perinatal Medicine and the Research Unit of the Royal College of Physicians. Development of audit measures and guidelines for good practice in the management of neonatal respiratory distress syndrome. Arch Dis Child 1992;67:1221-1227

American Academy of Pediatrics and American College of Obstetricians and Gynecologists. Guidelines for perinatal care. 3rd ed. Washington, DC. 1992:197-203

Southall DP, Samuels MP, Poets CF. Neonatal respiratory distress syndrome [letter]. Arch Dis Child 1993;69:330

Cochran DP, Shaw NJ. Neonatal respiratory distress syndrome [letter]. Arch Dis Child 1994;70:F230

O'Connor TA, Hall RT. Mixed venous oxygenation in critically ill neonates. Crit Care Med $1994 ; 22: 343-346$ 
Dudell G, Cornisch JD, Bartlett RH. What constitutes adequate oxygenation? Pediatrics 1990;85:39. 41

White RK. Mixed venous oxygen saturation in the newborn: can we and should we measure it? Scand J Clin Lab Invest Suppl 1990;203:203-211

van der Hoeven MAHBM, Maertzdorf WJ, Blanco CE. Feasibility and accuracy of a fiberoptic catheter for the measurement of venous oxygen saturation in newborn infants. Acta Paediatr 1995;584:122-127

van der Hoeven MAHBM, Maertzdorf WJ, Blanco CE. Continuous central venous oxygen saturation $\left(\mathrm{ScvO}_{2}\right)$ measurement using a fiberoptic catheter in newborn infants. Arch Dis Child 1996;74:F177-F181

Nelson LD. Continuous venous oximetry in surgical patients. Ann Surg 1986;203:329-333

Siggaard-Andersen O, Fogh-Andersen N, Gethgen IH, Højkjxr Larsen V. Oxygen status of arterial and mixed venous blood. Crit Care Med 199523:1284-1293

Bartlett RH, Cilley RE. 1993 Physiology of extracorporeal life support. In: Arensman RM, Cornish JD (eds). Extracorporeal life support. Blackwell, Boston, pp 89-104

Wasunna A, Whitelaw AG. Pulse oximetry in preterm infants. Arch Dis Child 1987;62:882-888

van der Hoeven MA, Maertzdorf WJ, Blanco CE. Mixed venous oxygen saturation $\left(\mathrm{SvO}_{2}\right)$ and biochemical parameters of hypoxia during progressive hypoxemia in 10-14 day old piglets. Pediatr Res 1997;42:878-884

Nunn JF. Distribution of pulmonary ventilation and perfusion. In: Nunn's applied respiratory physiology. Oxford, Butterworth, Heinemann. 1993, pp 156-197

Bongard FS, Leighton TA. Continuous dual oximetry in surgical critical care. Indications and limitations. Ann Surg 1992;216:60-68

Räsänen J, Downs JB, Malec DJ, Seidman P. Estimation of oxygen utilization by dual oximetry. Ann Surg 1987;206:621-623

Carrol GC. A continuous monitoring technique for management of acute pulmonary failure. Chest 1987;92:467-469

Räsänen J, Downs JB, Dehaven B. Titration of continuous positive airway pressure by real time dual oximetry. Chest 1987;92:853-856

de Winter JP, Egberts J, Merth IT, Peerdeman A, van Bel F, Bakker GC, Quanjer PH. Biochemical lung maturity static respiratory compliance, and pulmonary gas transfer in intubated preterm infants with and without respiratory distress syndrome. Pediatr Pulmonol 1995;20:152-159

de Winter JP, Merth IT, van Bel F, Egberts J, Brand R, Quanjer PH. Changes of respiratory system mechanics in ventilated lungs of preterm infants with two different schedules of surfactant treatment. Pediatr Res 1994;35: 541-549

Räsänen J. Role of dual oximetry in the assessment of pulmonary function. In: Reinhart K, Eyrich K. (Eds) Clinical aspects of $\mathrm{O}_{2}$ transport and tissue oxygenation. Springer Verlag, Berlin, 1989; 230. 240

Reinhart K. Monitoring $\mathrm{O}_{2}$ transport and tissue oxygenation in critically ill patients. In: Reinhart $\mathrm{K}$, Eyrich K. Editors. Clinical aspects of $\mathrm{O}_{2}$ transport and tissue oxygenation. Berlin: Springer Verlag, 1989; pp 193-211

\section{Acknowledgements}

This study was supported by Abbott Inc. the Netherlands. 


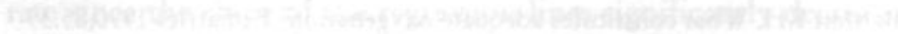

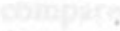

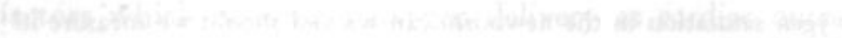

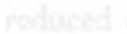

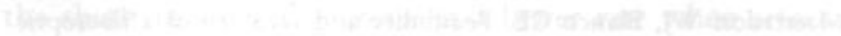

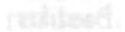


Chapter 8

Summary and Conclusions 


\section{Summary and Conclusions}

In the introduction in this thesis it was stated that it is the objective of intensive care to preserve the human organism by supporting gasexchange with the environment, by improving oxygen transport to the tissues and by monitoring and promoting oxygen uptake by the tissues. It is not astonishing, therefore, that the measurement of $\mathrm{SvO}_{2}$ raised so much interest among intensive care physicians, since $\mathrm{SvO}_{2}$ is an integrated value of all these objectives together.

In neonatal medicine oxygen monitoring and oxygen supply has remained a topic during the history of this discipline. Since both hyperoxia and hypoxia have their damaging effects, the questions, how much oxygen the tissues really need, and how to monitor these oxygen needs, are still not answered completely.

We performed five studies to investigate whether the measurement of $\mathrm{SvO}_{2}$ may give some answers on these issues. The main questions related to these studies were formulated in the introduction and are subsequently discussed in the following paragraphs:

1. What is the relation between tissue oxygenation and the $\mathrm{SvO}_{2}$ value?

2. Is this relation between tissue oxygenation and $\mathrm{SvO}_{2}$ different when oxygen delivery to the tissues is reduced by different manners?

To examine the clinical possibilities of the $\mathrm{SvO}_{2}$ measurement in the newborn period, the following questions were addressed:

3. Is it possible to measure $\mathrm{SvO}_{2}$ continuously in a newborn infant? Where? Are the $\mathrm{SvO}_{2}$ values reliable and accurate?

4. What is the normal range of $\mathrm{SvO}_{2}$ values in stable newborn infants breathing room air? What is the relation between $\mathrm{SaO}_{2}$ and $\mathrm{SvO}_{2}$ values?

5. What is the range of $\mathrm{SvO}_{2}$ values during the acute phase of IRDS during mechanical ventilation and oxygen administration? What is the relation between $\mathrm{SaO}_{2}$ and $\mathrm{SvO}_{2}$ values and derived calculations as venous admixture and fractional oxygen extraction? What is the value of $\mathrm{ScvO}_{2}$ in clinical neonatal medicine?

\section{1. $\mathrm{SvO}_{2}$ and tissue oxygenation}

We have assessed the relationship between $\mathrm{SvO}_{2}$ and tissue oxygenation in an acute neonatal piglet model during hypoxic hypoxia. During the graded steps of hypoxic hypoxia $\mathrm{SvO}_{2}$ decreases parallel to $\mathrm{SaO}_{2}$, oxygen extraction increases and consequently a stable $\mathrm{VO}_{2}$ can be preserved during a rather prolonged period of graded hypoxia. The reduction of $\mathrm{SvO}_{2}$ and the concomitant increase of oxygen extraction seem to be one of the mechanisms to preserve $\mathrm{VO}_{2}$ during moderate hypoxia. Other mechanisms to compensate are an increased cardiac output and a redistribution of blood flow between different (parts of) organs. A redistribution of blood flow was not measured in our experiments. In fact, the value of $\mathrm{SvO}_{2}$ and the distribution of blood flow are related entities, since by a redistribution of blood to high extraction organs the average oxygen extraction will increase and $\mathrm{SvO}$, will decrease.

This finding means that a reduced $\mathrm{SvO}_{2}$ value in itself is not a sign of anaerobic metabolism but is a sign that an organism is calling on its compensatory mechanisms. When more severe hypoxic hypoxia is induced, the decrease of $\mathrm{SaO}_{2}$ is not any more parallelled by $\mathrm{SvO}_{2}$, oxygen consumption is reduced and anaerobic metabolism and lactic acidosis will develop.

At what $\mathrm{SvO}_{2}$ value exactly anaerobic metabolism will develop was determined in 
this study: When the $\mathrm{SvO}_{2}$ value decreased below $15 \%$, tissue oxygen consumption decreased and anaerobic metabolism developed. A value of $\mathrm{SvO}_{2}$ above $40 \%$ excluded anaerobic metabolism. $\mathrm{SvO}_{2}$ values between $15 \%$ and $40 \%$ were rarely a marker for anaerobic metabolism.

Some remarks have to be made to delineate these findings before they can be extrapolated to clinical medicine:

The time aspect in this acute study must be taken into consideration. The above mentioned values could become different in experiments with a more prolonged duration. Secondly, the experiments were performed in anesthetized piglets with mechanical ventilation and pancuronium infusion and consequently a stable and rather low $\mathrm{VO}_{2}$. In clinical medicine in conditions with a more variable and higher $\mathrm{VO}_{2}$, critical values of $\mathrm{SvO}_{2}$ could become different. Thirdly, one must be cautious to use $\mathrm{SvO}_{2}$ to monitor exclusively tissue oxygenation, as this latter is only one of the many variables, that can modify the $\mathrm{SvO}_{2}$ value. Fourth, the $\mathrm{SvO}_{2}$ is a concept defined by the averaged value of the venous oxygen saturations and of the averaged blood flow from all the different organs. This means that normal $\mathrm{SvO}_{2}$ values do not exclude an imbalance between $\mathrm{DO}_{2}$ and $\mathrm{VO}_{2}$ in one or two organs. Finally, the relation between $\mathrm{SvO}_{2}$ values and tissue oxygenation can be even more complex in conditions as sepsis and ARDS, when tissue oxygen uptake is impaired and lactic acidosis exists together with normal or even high $\mathrm{SvO}_{2}$ values.

Probably because of all these reasons aiming at normal $\mathrm{SvO}_{2}$ values was shown not to affect mortality and other oxygen variables in prospective clinical trials in critical ill adult patients, as was discussed in the review on $\mathrm{SvO}_{2}$ and $\mathrm{DO}_{2} / \mathrm{VO}_{2}$ relationship. However, it must be recognized that in these trials patients with complex hemodynamic problems were studied. With respect to the question on the relation between tissue oxygenation and $\mathrm{SvO}_{2}$ during hypoxic hypoxia more direct answers could be given.

Summarizing, reduced $\mathrm{SvO}_{2}$ values during hypoxic hypoxia in itself are not an sign for a reduced $\mathrm{VO}_{2}$ and for anaerobic metabolism. As long as a reduction of $\mathrm{SaO}_{2}$ is parallelled by a equivalent reduction of $\mathrm{SvO}_{2}$, a stable $\mathrm{VO}_{2}$ can be preserved. When severe hypoxic hypoxia is induced, the difference between $\mathrm{SaO}_{2}$ and $\mathrm{SvO}_{2}$ will decrease and $\mathrm{VO}_{2}$ will reduce. Consequently, the relation between $\mathrm{SvO}_{2}$ and tissue oxygenation during hypoxic hypoxia is characterized by a low threshold $\mathrm{SvO}_{2}$ value, below which anaerobic metabolism will ensue. In addition, the above mentioned considerations and remarks must be taken into account, when the relation between $\mathrm{SvO}_{2}$ and tissue oxygenation is evaluated.

\section{The relation between tissue oxygenation and $\mathrm{SvO}_{2}$ during anemic hypoxia compared to hypoxic hypoxia.}

Another study, assessing the relation between $\mathrm{SvO}_{2}$ and tissue oxygenation, was performed to compare the range of $\mathrm{SvO}_{2}$ values during hypoxic hypoxia with the $\mathrm{SvO}_{2}$ values during anemic hypoxia. As different types of hypoxia could have other patterns of circulatory adjustments and compensations, tissue oxygen uptake and consequently $\mathrm{SvO}_{2}$ may be affected.

The critical range of $\mathrm{DO}_{2}$ and oxygen extraction, however, showed no difference between the two types of hypoxia. Hemodynamic responses differed between hypoxic and anemic hypoxia, consisting of an unaltered and increased cardiac output, respectively. We found higher and more variable $\mathrm{SvO}_{2}$ values during anemic hypoxia than during hypoxic hypoxia within and below the critical $\mathrm{DO}_{2}$ range. In our opinion, the most important reasons for this finding include a) the use of the whole range of the oxygen dissociation curve in anemic hypoxia, $b$ ) the induced expansion of the plasma phase with its very low 
oxygen solubility, limiting the ability to transfer oxygen from the red cells to the tissues and c) the increased red cell velocity with a reduced residence time during anemic hypoxia decreasing precapillary oxygen release and diffusional oxygen transfer to other microvessels.

Summarizing, the relation between $\mathrm{SvO}_{2}$ and tissue oxygenation seems to be even more complex than initially was considered, since a critical $\mathrm{SvO}_{2}$ range, below which anaerobic metabolism develops, is shown to be dependent upon the type of hypoxia. However, it can be concluded that during both types hypoxia $\mathrm{VO}_{2}$ could be preserved as long as a stable difference between arterial and venous oxygen content was maintained. Consequently, a threshold $\mathrm{ScvO}_{2}$ value, below which $\mathrm{VO}_{2}$ decreased, could only be discerned at quite low $\mathrm{ScvO}_{2}$ values.

\section{3a. The continuous measurement of $\mathrm{SvO}_{2}$ in newborn infants.}

It has been suggested to measure $\mathrm{SvO}_{2}$ in clinical neonatal medicine to monitor the oxygen needs of the tissues and, consequently, to minimize on one hand oxygen toxicity related diseases as retinopathy of prematurity, bronchopulmonary dysplasia and necrotizing enterocolitis and on the other hand hypoxia related diseases such as cerebral palsy. Since the $\mathrm{SvO}_{2}$ measurement in the pulmonary artery is difficult and hazardous, $\mathrm{SvO}_{2}$ measurements were performed in the right atrium (central venous oxygen saturation: $\mathrm{ScvO}_{2}$ ) by a catheter capable of measuring oxygen saturation by fiberoptic oximetry continuously.

3b. The feasibility of the fiberoptic catheter. The reliability and accuracy of the $\mathrm{ScvO}_{2}$ values. The position of the catheter.

We tested the feasibility and accuracy of the continuous $\mathrm{ScvO}_{2}$ measurement with a $4 \mathrm{Fr}$. fiberoptic catheter, inserted into the right atrium via the umbilical vein to measure $\mathrm{ScvO}_{2}$, continuously.

With regard to feasibility, we conclude that the success rate and complications of the fiberoptic catheter are similar to previously published results. In $67 \%$ of the patients the fiberoptic catheter could be placed in the correct position, i.e. at the mid-atrial level or at the transition of the vena cava inferior and the right atrium. In some infants at the end of the indwelling period, the signal was affected by unusually small light reflectance at the catheter tip and saturation readings were not considered to be reliable any more. Complications such as pericardial effusions, cardiac tamponade, cardiac arrhythmias or perforations were not seen.

With regard to the accuracy it was concluded that the oxygen saturation readings accurately and reliably represented oxygen saturation in the right atrium of newborn infants. The mean difference $( \pm 2 \mathrm{SD})$ between the fiberoptic catheter $\mathrm{ScvO}_{2}$ readings and the hemoximeter $\mathrm{HbO}_{2}$ values was $-0.36 \pm 7.64$. This value of difference and SD is comparable with the data mentioned in the review on accuracy of the fiberoptic oximetry used in pulmonary artery catheters.

The position of the catheter was extensively discussed in the review. It was concluded that the drawbacks (incomplete mixing, susceptibility to catheter motion and atrium wall reflection) are probably as valid in neonatal medicine as in adult medicine. However, the measurement of venous oxygen saturation in newborn infants is limited to the right atrium, since the use of a pulmonary artery catheter is difficult and hazardous. The drawbacks of right atrial oxygen saturation measurement must be taken into account 
by consideration of the position of the catheter, frequent in vivo calibration and caution in the calculation of oxygen transport variables based on central venous oxygen saturations.

Some remarks have to be made upon the limitations and drawbacks of the use of a single lumen catheter in practical neonatal intensive care medicine. Recently, in the care of very small newborn infants the use of double lumen or even triple lumen umbilical vein catheters have become a common procedure. The use of these catheters is warranted by a simultaneous use of continuous medications and parenteral nutrition. The use of a single lumen catheter as the $4 \mathrm{Fr}$. fiberoptic catheter seems now to be limited to more stable infants in whom the continuous $\mathrm{ScvO}_{2}$ measurement does not seem directly necessary. Another limitation is the fact that, as was shown in our feasibility study, the positioning of the catheter through the ductus venosus in the right atrium was only successful in $60 \%$ of the cases. The limitation of the measurement of the $\mathrm{ScvO}_{2}$ in the right atrium and the risk of incomplete mixing have been discussed extensively. In conclusion, the limitations of a single lumen umbilical venous catheter makes one reluctant to consider $\mathrm{ScvO}_{2}$ measurement as a standard procedure in neonatal intensive care medicine. On the other hand the fiberoptic catheter readings do accurately represent $\mathrm{ScvO}_{2}$ values reflecting the residual oxygen after tissue oxygen extraction.

4.

The normal range of $\mathrm{ScvO}_{2}$ values in stable newborn infants breathing room air. The relation between $\mathrm{SaO}_{2}$ and $\mathrm{ScvO}_{2}$ values. The value of fractional oxygen extraction (F.O.E.) and the shunt index.

In a prospective clinical observational study the range of $\mathrm{ScvO}_{2}$ was described in 10 stable newborn infants breathing room air. In this study a $\mathrm{ScvO}_{2}$ range from $60.1 \%$ to $83.5 \%$ (5th and 95th percentile) was observed, when other variables affecting oxygen transport were in the normal range. i.e. $\mathrm{SaO}_{2}: \geq 86 \%$; hemoglobin: $\geq 7.0 \mathrm{mmol} / \mathrm{L} ; \mathrm{pH}$ and blood pressure: normal. This $\mathrm{ScvO}_{2}$ range is similar to the normal range defined for adults, whereas $\mathrm{VO}_{2}$ in newborn infants is increased. Increased $\mathrm{VO}_{2}$ is apparently compensated for by an increased $\mathrm{DO}_{2}$. And indeed both cardiac output and hemoglobin concentration are increased in the newborn period.

The relationship between $\mathrm{ScvO}_{2}$ and $\mathrm{SaO}_{2}$ was examined. In seven patients $\mathrm{ScvO}_{2}$ values correlated significantly with $\mathrm{SaO}$ 2. This indicates that, when $\mathrm{SaO}_{2}$ is reduced, $\mathrm{VO}_{2}$ is preserved by a fixed oxygen extraction. In three patients $\mathrm{SaO}_{2}$ and $\mathrm{ScvO}_{2}$ were not correlated. We might speculate, that in these babies $\mathrm{VO}_{2}$ was preserved by increased cardiac output. It is unlikely that $\mathrm{VO}_{2}$ was decreased by $\mathrm{SaO}_{2}$ reduction, because in stable patients with a normal blood pressure, normal haemoglobin level and normal oxygen saturation $\mathrm{VO}_{2}$ is independent of $\mathrm{DO}_{2}$ over a wide range.

$\mathrm{DO}_{2}$ is normally four to five times $\mathrm{VO}_{2}$ as shown by the normal fractional oxygen extraction (F.O.E.) of $0.20-0.25$, as described in adults. When analyzed for each patient separately, a range ( 5 th and 95th percentile) was found between 0.13 to 0.33 . The highly significant correlation between F.O.E. and $\mathrm{ScvO}_{2}$ in all patients confirms that $\mathrm{ScvO}_{2}$ is an excellent monitor of the balance between oxygen delivery and tissue oxygen consumption.

In addition, the measurement of $\mathrm{ScvO}_{2}$ enables the calculation of the shunt index, an estimate of the venous admixture. A range of the shunt index was found between $7 \%$ and $53 \%$. We found a significant negative correlation between the shunt index and $\mathrm{SaO}_{2}$ in all patients. Obviously, an increased shunt index is present when lower $\mathrm{SaO}_{2}$ values are encountered. 
5. The range of $\mathrm{ScvO}_{2}$ values during the acute phase of IRDS during mechanical ventilation and oxygen supply at different levels of oxygenation. The relation between $\mathrm{SaO}_{2}$ and $\mathrm{ScvO}_{2}$ values and derived calculations as shunt index and F.O.E. The value $\mathrm{ScvO}_{2}$ in clinical neonatal medicine.

A non-randomized clinical observational study was performed in twelve newborn infants with mechanical ventilation and oxygen administration to determine $\mathrm{ScvO}_{2}$ values at different oxygenation levels namely: at $\mathrm{SaO}_{2}$ values below $86 \%$ and at the lower $(86-90$ $\%$ ) and higher ( $91-96 \%$ ) end of the recommended range of $\mathrm{SaO}_{2}$ values measured by pulse oximetry.

The $\mathrm{ScvO}_{2}$ values in both recommended levels are not beyond the "normal range" defined in infants breathing room air. Lower $\mathrm{ScvO}_{2}$ values are mainly encountered in the lowest oxygenation level with a $\mathrm{SaO}_{2}$ below $86 \%$.

A significant correlation between $\mathrm{SaO}_{2}$ and $\mathrm{ScvO}_{2}$ was found in all but one of the patients. The slope of the regression lines did not show a significant difference between the two levels of oxygenation in any of the infants. In the $\mathrm{SaO}_{2}$ level below $86 \% \mathrm{ScvO}_{2}$ values were significantly reduced compared with the level between $86 \%-96 \%$. In two patients the rate of $\mathrm{ScvO}_{2}$ reduction (the slope) was significantly increased compared with the change in the $\mathrm{SaO}_{2}$ level between $86 \%-96 \%$. Apparently, these two patients tried to increase oxygen uptake whereas other factors which determine oxygen delivery as cardiac output failed to counterbalance the reduced oxygen saturation.

An increased shunt index was found in our study in the lower end of the recommended range of oxygenation, which even further increased in the patients in whom $\mathrm{SaO}_{2}$ values below $86 \%$ were obtained. Linear regression analysis yielded a significant correlation in all the patients. It may be assumed that a certain grade of intrapulmonary shunting or ventilation / perfusion mismatch and pulmonary vasoconstriction must exists to explain the increased venous admixture in the lower levels of oxygenation. On the other hand it can be questioned, whether a calculated item as the shunt index really reflects these clinical problems, although the assumptions were not violated.

Fractional oxygen extraction was in six patients significantly correlated with $\mathrm{SaO}_{2}$, albeit weak. $(r-0.18$ to 0.39$)$. When F.O.E.was compared for the different levels of oxygenation, F.O.E. remained at the same level when $\mathrm{ScvO}_{2}$ decreased concomitantly with a reducing oxygenation level.

In conclusion, on line measurement of $\mathrm{ScvO}_{2}$ at decreasing levels of $\mathrm{SaO}_{2}$, showed a significant reduction of $\mathrm{ScvO}_{2}$. The $\mathrm{ScvO}_{2}$ values were not beyond the range described in infants breathing room air. This reduction of $\mathrm{ScrO}_{2}$ seems to be the primary compensatory mechanism to stabilize oxygen extraction and tissue oxygenation. Referring to the debate on $\mathrm{SaO}_{2}$ alarm limits in oxygen therapy in the newborn period the measurement of $\mathrm{ScvO}_{2}$ may introduce a new element in this debate. Since $\mathrm{ScvO}_{2}$ decreased parallel with the reduction of $\mathrm{SaO}_{2}$, we have shown that even at the lowest $\mathrm{SaO}_{2}$ levels tissue oxygen uptake is preserved. Consequently, it can be concluded that the difference between $\mathrm{SaO}_{2}$ and $\mathrm{ScvO}_{2}$ is more important than the absolute value of $\mathrm{ScvO}_{2}$.

On the question whether it is of interest to know the $\mathrm{ScvO}_{2}$, value, three cases will be presented as examples that continuous $\mathrm{ScvO}_{2}$ measurement could be a valuable complimentary monitor of oxygenation:

case 1. A preterm infant with a gestational age of 28 weeks and a birth weight of 890 gram. Diagnoses: IRDS and E. Coli sepsis and meningitis. The infant required positive pressure ventilation, later followed by high frequency ventilation and intratracheal surfactant. The clinical course was complicated by an intraventricular hemorrhage. The umbilical 
vein was catheterized with a fiberoptic catheter for central venous access and $\mathrm{ScvO}_{2}$ measurement. The tip of the catheter was located just above the junction of the right atrium and the inferior caval vein. The fiberoptic readings correlated with the hemoximeter values $(77.16 \% \pm 3.25$ vs $76.16 \% \pm 4.41)$. The hemoglobin level decreased from 8.5 $\mathrm{mmol} / \mathrm{L}$ to $7.6 \mathrm{mmol} / \mathrm{L}$ and further to $6.8 \mathrm{mmol} / \mathrm{L}$ due to multiple blood sampling. $\mathrm{SaO}_{2}$ monitored by pulse oximetry did not show any alteration, however, $\mathrm{ScvO}_{2}$ decreased significantly with an increase in fractional oxygen extraction.

case 2. A preterm infant with a gestational age of 27 weeks and a birth weight of 720 gram. The delivery was complicated by a moderate asphyxia. The umbilical vein was catheterized with a fiberoptic catheter for central venous access and $\mathrm{ScvO}_{2}$ measurement. The course was complicated by severe hypotension and respiratory insufficiency. Intermittent positive pressure ventilation and surfactant replacement therapy were required. Blood pressure was supported by volume replacement and the use of dopamine and dobutamine. After increasing dopamine up to a level of $30 \mu \mathrm{g} / \mathrm{kg} / \mathrm{min}$, the $\mathrm{ScvO}_{2}$ level increased from $70.5 \% \pm 5.0$ to $78.6 \% \pm 6.7$ in contrast to the $\mathrm{SaO}_{2}$, which decreased from $91.8 \% \pm 3.4$ to $90.0 \% \pm 2.6$.

case 3. A preterm infant with a gestational age of 28 weeks and a birth weight of 1350 gram. The delivery was complicated by a severe asphyxia: arterial umbilical cord $\mathrm{pH}$ was 6.89. Immediately after delivery ventilator support was initiated. After stabilization, a fiberoptic catheter was inserted into the right atrium for central venous access. The infant stabilized and the ventilatory support could be discontinued. However sudden epileptic spells occurred associated with an elevation of the heart frequency and the blood pressure and a small decrease in the $\mathrm{SaO}_{2}$. The $\mathrm{ScvO}_{2}$ decreased during these episodes from $75 \%$ to $55 \%$. Anticonvulsive therapy was started and these episodes did not repeat.

The three cases here reported illustrate that the continuous monitoring of the $\mathrm{ScvO}_{2}$ allowed to detect an alteration in the balance between $\mathrm{DO}_{2}$ and $\mathrm{VO}_{2}$, while $\mathrm{SaO}_{2}$ did not show changes. The first patient demonstrated a decrease in arterial oxygen content by a low hemoglobin, counterbalanced by an increasing oxygen extraction. The second patient was treated with volume replacement and inotropic support. The improvement of $\mathrm{DO}_{2}$ by increasing heart frequency and cardiac output resulted in a higher $\mathrm{ScvO}_{2}$ value. In the third patient the $\mathrm{ScvO}_{2}$ decreased because of an increased oxygen consumption due to convulsions.

Although we are aware that these cases do not support in a scientific way the clinical utility of the $\mathrm{ScvO}_{2}$ measurement, we think that these cases illustrate the effectiveness of the $\mathrm{ScvO}_{2}$ measurement. These cases illustrate the different variables, that can affect $\mathrm{ScvO}_{2}$. Consequently, the interpretation of abnormal values may be difficult in clinical practice. In addition, one has to consider that even normal $\mathrm{ScvO}_{2}$ values do not exclude disturbances in oxygen transport in individual organs and impairments in tissue oxygen uptake as has been described in sepsis.

In these conclusive remarks we want to touch briefly on some ideas for further research in this field. Future research should be directed to simplifying the interpretation of $\mathrm{ScvO}_{2}$ values, for example, by additional continuous monitoring of other variables that determine $\mathrm{ScvO}_{2}$. It seems that continuous measurement of cardiac output has arrived in adult intensive care medicine. This monitoring tool is not ready yet for neonatal medicine but it is worth to observe closely the results of pending clinical trials. In the same direction is the measurement of the gastric intramucosal $\mathrm{pH}$ to evaluate tissue (an)aerobic 
metabolism. Recently a device is produced suitable for neonatal care medicine.

The review on oxygen transport learns that much of the perinatal development of tissue microvasculature and mitochondria is unknown or only occasionally investigated. Future research should be directed to determine the influence of the development of microvasculature on oxygen uptake by the tissues. Since in newborns and especially in preterm infants vascular system is still in development, oxygen uptake in these infants could be affected by a still less extended tissue vasculature.

The fact that the perinatal period is characterized by a switch from low oxidative metabolism to efficient oxidative phosphorylation by a rapid proliferation and maturation of cellular mitochondria, has raised our interest. Is this switch controlled by an intrinsic cellular clock or triggered by the birth itself and what are the consequences of a preterm birth?

$\mathrm{SvO}_{2}$ is a flow-weighted average of venous oxygen saturation values from all the tissues and reflects the combined sufficiency of all the variables that constitute $\mathrm{DO}_{2}$ and $\mathrm{VO}_{2}$. In neonatal medicine $\mathrm{ScvO}_{2}$ measurement in the right atrium together with $\mathrm{SaO}_{2}$ by pulse oximetry is useful as a complementary monitor of tissue oxygen needs in newborn infants. 
Hoofalstukn 9

Sameryatting on Conclusted 


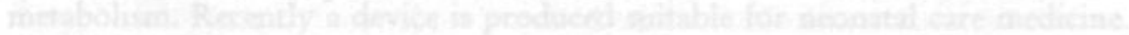

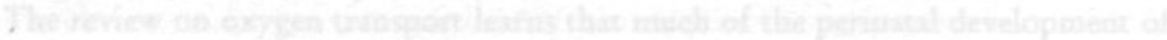

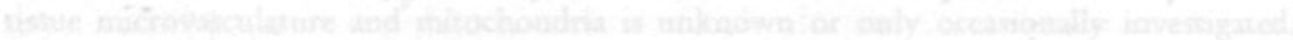

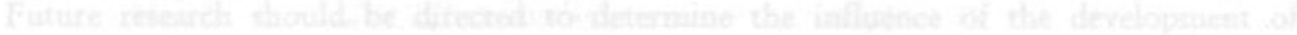

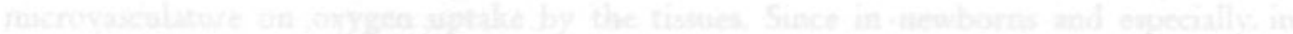

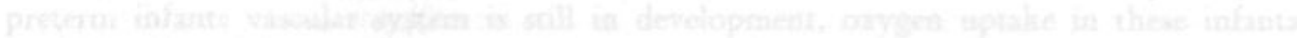

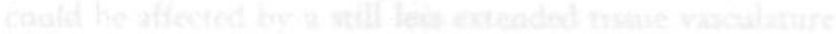

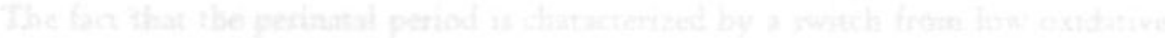

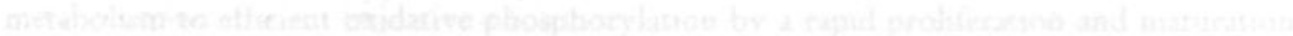

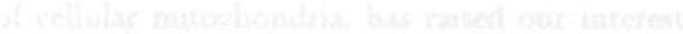


Hoofdstuk 9

Samenvatting en Conclusies 


\section{Samenvatting en Conclusies}

In de inleiding van dit proefschrift is de stelling naar voren gebracht dat het uiteindelijke doel van intensieve medische zorg is om het menselijke organisme in stand te houden door de gasuitwisseling te ondersteunen, door het zuurstoftransport naar de weefsels te verbeteren en door het monitoren en bevorderen van de zuurstofopname door de perifere weefsels. Het is niet verwonderlijk, dat de gemengd veneuze zuurstofsaturatie $\left(\mathrm{SvO}_{2}\right)$ zoveel belangstelling heeft gewekt bij intensieve care artsen, omdat de $\mathrm{SvO}_{2}$ een geïntegreerde waarde is, waarin zowel de gasuitwisseling, als het zuurstoftransport en de zuurstofopname in vertegenwoordigd zijn.

$\mathrm{SvO}_{2}$ geeft namelijk het overblijvende zuurstofgehalte weer nadat de weefsels zuurst of hebben opgenomen. De waarde van de $\mathrm{SvO}_{2}$ wordt dan ook bepaald door de arteriële zuurstofsaturatie, het hemoglobine, de cardiac output en door het zuurstofverbruik van de weefsels.

In de neonatale medische zorg zijn het monitoren van het zuurstofgehalte en het toedienen van zuurst of altijd belangrijke discussiepunten geweest. Omdat zowel een tekort als een overmaat aan zuurstof een schadelijk effect kunnen hebben, zijn vragen over de exacte zuurstofbehoefte en over het meten van deze zuurstofbehoefte nog steeds actueel en niet volledig beantwoord.

Ons onderzoek heeft zich gericht op de meting van $\mathrm{SvO}_{2}$ en op de vraag of $\mathrm{SvO}_{2}$ een antwoord kan geven naar de exacte zuurstofbehoefte van de weefsels. De belangrijkste vragen zijn in de inleiding van dit proefschrift geformuleerd en worden hier kort gememoreerd en de conclusies zullen vervolgens in de volgende paragrafen worden besproken.

waarde?

1. Welke is de relatie tussen het zuurstofverbruik van de weefsels en de $\mathrm{SvO}_{2}$

2. Is deze relatie tussen het zuurstofverbruik van de weefsels en de $\mathrm{SvO}_{2}$ waarde anders wanneer het tekort aan zuurstof op een andere manier tot stand komt?

$\mathrm{Om}$ de klinische mogelijkheden van de continue $\mathrm{SvO}_{2}$ meting in de neonatale periode te onderzoeken, werden de volgende vragen behandeld.

3. Is het mogelijk om de $\mathrm{SvO}_{2}$ continue te meten in een pasgeboren kind? Waar kan de $\mathrm{SvO}_{2}$ gemeten worden? $\mathrm{Zijn}$ de $\mathrm{SvO}_{2}$ waarden betrouwbaar en nauwkeurig?

4. Welke zijn de normale $\mathrm{SvO}_{2}$ waarden in stabiele pasgeboren kinderen, die geen extra zuurstof toegediend krijgen. Welke is de relatie tussen de arteriële en de veneuze zuurstofsaturatie waarden?

5. Wat zijn de $\mathrm{SvO}_{2}$ waarden tijdens de acute fase van de IRDS tijdens kunstmatige beademing en extra zuurstofvoorziening. Welke is de relatie tussen de arteriële en veneuze zuurstofsaturatie en afgeleide waarden als veneuze admixture en fractionele zuurstof extractie? Wat is het belang van $\mathrm{SvO}_{2}$ in de zorg voor ernstig zieke pasgeboren kinderen?

\section{1. $\mathrm{SvO}_{2}$ en het zuurstofverbruik van de weefsels.}

Wij hebben de relatie tussen de zuurstofverbruik van de weefsels en $\mathrm{SvO}_{2}$ onderzocht in een acuut dierenmodel het neonatale varken-, waarbij de zuurstof toediening stapsgewijze werd verminderd. Tijdens de geleidelijke vermindering van de zuurstof verminderden de arteriële en de veneuze zuurstofsaturatie in dezelfde mate, de fractionele zuurstof extractie nam toe en dientengevolge bleef het zuurstofverbruik van de weefsels gedurende lange tijd gelijk. Het verminderen van de $\mathrm{SvO}_{2}$ en de toename in fractionele 
zuurstof extractie zijn mechanismen om het zuurstofverbruik van de weefsels te stabiliseren. Andere mechanismen die een verminderd zuurstofaanbod kunnen compenseren zijn een verhoogde cardiac output en een redistributie van de bloeddoorstroming naar de verschillende (delen van) organen. Een redistributie van de bloeddoorstroming werd in onze experimenten niet gemeten. Maar de waarde van $\mathrm{SvO}_{2}$ en de distributie van de bloeddoorstroming zijn gerelateerde waarden, omdat door een redistributie van bloed naar organen met een hoge extractie de gemiddelde zuurstof extractie zal toenemen en de $\mathrm{SvO}_{2}$ dus zal afnemen.

Deze bevinding betekent dat een lage $\mathrm{SvO}_{2}$ waarde op zich zelf niet een signaal van anaërobe stofwisseling is, maar een signaal dat een organisme een beroep doet op zijn compensatie mechanismen om het zuurstofverbruik gelijk te houden. Wanneer een meer verdergaande hypoxie wordt geïnduceerd, wordt de vermindering van $\mathrm{SaO}_{2}$ niet meer in gelijke mate gevolgd door de $\mathrm{SvO}_{2}$, vermindert het zuurstofverbruik van de weefsels en ontstaat een anaërobe metabolisme.

$\mathrm{Bij}$ welke $\mathrm{SvO}_{2}$ waarden het anaërobe metabolisme ontstaat is ook in ons onderzoek bepaald. Als de $\mathrm{SvO}_{2}$ waarde beneden de $15 \%$ kwam, verminderde het zuurstofverbruik van de weefsels en ontstond er een anaëroob metabolisme met lactaat acidose. Een $\mathrm{SvO}_{2}$ waarde boven de $40 \%$ sloot een anaëroob metabolisme uit. $\mathrm{SvO}_{2}$ waarden tussen de $15 \%$ en $40 \%$ waren zelden geassocieerd met anaëroob metabolisme.

Enkele opmerkingen moeten gemaakt worden om bovenstaande bevindingen te nuanceren. Ten eerste moet het tijdsaspect van dit onderzoek in ogenschouw worden genomen. De bovenvermelde waarden zouden verschillend kunnen zijn in experimenten met een langere tijdsduur. Ten tweede werden de experimenten uitgevoerd in biggetjes onder narcose en met een kunstmatige beademing. Daardoor was er sprake van een constant en tamelijk laag zuurstofverbruik. In de klinische geneeskunde in patiènten met een meer variabel en hoger zuurstofverbruik zou de $\mathrm{SvO}_{2}$ drempelwaarde voor anaëroob metabolisme kunnen veranderen. Ten derde moet men omzichtig zijn om de $\mathrm{SvO}_{2}$ te gebruiken als een parameter exclusief voor het monitoren van één variabele, zoals het zuurstofverbruik van de weefsels. De waarde van $\mathrm{SvO}_{2}$ is afhankelijk van veel verschillende variabelen. Ten vierde is de $\mathrm{SvO}_{2}$ een begrip, gedefinieerd door de gemiddelde waarde van de veneuze saturaties van de verschillende organen en door de bloeddoorstroming door die verschillende organen. Dit betekent dat een "normale" $\mathrm{SvO}_{2}$ waarde een afwijkende verhouding tussen het zuurstofaanbod en het zuurstofverbruik in één bepaald orgaan niet uitsluit. Ten slotte kan de relatie tussen $\mathrm{SvO}_{2}$ en zuurstofverbruik nog complexer zijn in condities zoals sepsis en ARDS, als de opname van zuurstof door de weefsels is verminderd en lactaat acidose ontstaat samen met normale of zelfs hoge $\mathrm{SvO}_{2}$ waarden.

Waarschijnlijk omwille van de bovenvermelde argumenten is men er nooit in geslaagd in prospectief klinisch onderzoek aan te tonen dat het klinisch handelen gericht op het verkrijgen van "normale" $\mathrm{SvO}_{2}$ waarden de uitkomst van ernstig zieke volwassen patiënten heeft beïnvloed of verbeterd. Wel moet gezegd worden dat in deze trials patiënten met zeer complexe hemodynamische problemen bestudeerd werden. In ieder geval kunnen wat betreft de relatie tussen $\mathrm{SvO}_{2}$ en zuurstofverbruik van de weefsels tijdens hypoxische hypoxie de volgende conclusies worden getrokken.

Tijdens hypoxische hypoxie zijn verlaagde $\mathrm{SvO}_{2}$ waarden op zich zelf niet een signaal voor een verminderd zuurstofverbruik van de weefsels of voor een anaëroob metabolisme. Zo lang als een verlaging van de $\mathrm{SaO}_{2}$ gepaard gaat met een evenredige verlaging van de $\mathrm{SvO}_{2}$ kan een constant en stabiel zuurstofverbruik in stand worden gehouden. $\mathrm{Bij}$ een diepere hypoxische hypoxie zal het verschil tussen de $\mathrm{SaO}_{2}$ en $\mathrm{SvO}_{2}$ verminderen en het zuurstofverbruik van de weefsels zal lager worden. Daarom wordt de relatie tussen zuurstofverbruik en $\mathrm{SvO}_{2}$ gekenmerkt door een lage kritische drempel waarde 
van $\mathrm{SvO}_{2}$, beneden welke een anaëroob metabolisme ontstaat. Bovendien moet men rekening houden met bovengenoemde overwegingen en opmerkingen, als men de relatie tussen $\mathrm{SvO}_{2}$ en zuurstofverbruik evalueert.

\section{De relatie tussen zuurstofverbruik van de weefsels en $\mathrm{SvO}_{2}$ vergeleken tijdens enerzijds hypoxische en anderzijds anemische hypoxie.}

Een volgend onderzoek werd gedaan om de relatie tussen zuurstofverbruik van de weefsels en $\mathrm{SvO}_{2}$ vast te stellen tijdens hypoxische en anemische hypoxie. Omdat verschillende soorten van hypoxie kunnen verschillen in circulatoire compensatie mechanismen, kan de opname van zuurstof door de weefsels verschillen en dus ook de $\mathrm{SvO}_{2}$. Ons belangrijkste resultaat was dat er hogere en meer variabele $\mathrm{SvO}_{2}$ waarden tijdens de anemische hypoxie werden gevonden in vergelijking met de hypoxische hypoxie. De drempelwaarde van het zuurstofaanbod en van de zuurstof extractie, beneden welke een anaëroob metabolisme ontstaat, liet geen verschillen zien tussen de hypoxische en anemische hypoxie. Naar onze mening zijn de belangrijkste oorzaken voor deze bevinding a) het ten dienste staan van de volledige zuurst of dissociatie curve tijdens de anemische hypoxie, b) de relatieve toename van het plasma met zijn lage zuurstof oplosbaarheid tijdens de anemische hypoxie beperkt de mogelijkheid voor het transport van zuurstof van de erythrociet naar de weefsels en c) de toegenomen snelheid van de bloeddoorstroming tijdens anemische hypoxie met een kortere verblijfstijd in de weefsel capillairen vermindert de precapillaire zuurstof afgifte naar andere weefselvaten.

Samenvattend lijkt de relatie tussen $\mathrm{SvO}_{2}$ en zuurstofverbruik van de weefsels nog complexer, omdat de $\mathrm{SvO}_{2}$ drempelwaarde blijkbaar ook beinvloed wordt door het soort hypoxie. Maar de conclusie kan getrokken worden, dat tijdens beide soorten hypoxie het zuurstofverbruik van de weefsels in stand gehouden kan worden, zolang als een bestendig verschil tussen de arteriële en het veneuze zuurstofgehalte kan worden gehandhaafd. Daarom werd een $\mathrm{SvO}_{2}$ drempelwaarde, waar beneden het zuurstofverbruik van de weefsels verminderde, alleen gevonden bij relatief lage $\mathrm{SvO}_{2}$ waarden.

\section{De continue meting van $\mathrm{SvO}_{2}$ in pasgeboren kinderen}

Het voorstel om de $\mathrm{SvO}_{2}$ te meten in de klinische zorg voor ernstig zieke pasgeboren kinderen was naar voren gebracht om de precieze zuurstofbehoefte van pasgeboren kinderen te kunnen bepalen. Men hoopte dan aandoeningen te verminderen samenhangend met de toxiciteit van zuurstof, zoals retinopathie van de prematuriteit, bronchopulmonale dysplasie en necrotiserende enterocolitis. Ook aandoeningen samenhangend met een tekort aan zuurstof, zoals cerebraal bepaalde spasticiteit en mentale schade hoopte men zo te kunnen voorkomen. Omdat de $\mathrm{SvO}_{2}$ meting in de arteria pulmonalis in kleine pasgeboren kinderen moeilijk en gevaarlijk is, werden de $\mathrm{SvO}_{2}$ metingen verricht in het rechteratrium (centraal veneuze zuurstofsaturatie; $\mathrm{ScvO}_{2}$ ) met een fiberoptic catheter, die een continue meting van zuurstofsaturatie mogelijk maakt.

De toepasbaarheid van de fiberoptic catheter. De betrouwbaarheid en de nauwkeurigheid van de $\mathrm{ScvO}_{2}$ waarden. De positie van de catheter.

Wij hebben de toepasbaarheid en de nauwkeurigheid van de continue $\mathrm{ScvO}_{2}$ meting getest zoals die gerealiseerd werd door een 4 French fiberoptic catheter, die inge- 
bracht was in het rechteratrium via de navelvene.

Ten eerste wat betreft de toepasbaarheid van deze catheter, hebben wij geconcludeerd dat het percentage met succes ingebrachte catheters en het aantal complicaties niet verschilden van de routinematig gebruikte catheters. In $67 \%$ van de patiënten kon de fiberoptic catheter geplaatst worden in de juiste positie d.w.z. in het midden van het rechteratrium of op de overgang van de vena cava inferior en het rechteratrium. In een paar kinderen was het signaal aan het einde van de periode, dat de catheters in situ waren, verminderd door een lage reflectie aan de tip van de catheter en de weergave van de zuurstofsaturatie kon niet meer als betrouwbaar worden beschouwd. Ernstige complicaties zoals pericardiale effusies, cardiale tamponades, perforaties en aritmieën hebben zich niet voorgedaan.

Ten tweede wat betreft de nauwkeurigheid van de $\mathrm{ScvO}_{2}$ weergave werd door ons geconcludeerd, dat de zuurstofsaturaties van het bloed in het rechteratrium van pasgeboren kinderen nauwkeurig en betrouwbaar werden weergegeven. Het gemiddelde verschil $( \pm S D)$ tussen de weergave van de fiberoptic catheter en de laboratorium hemoximeter zuurstofsaturatie waarden bedroeg $-0.36 \pm 7.64$. Deze waarde van het gemiddelde verschil en de standaard deviatie is vergelijkbaar met de gegevens uit de "volwassen" literatuur over de nauwkeurigheid van de fiberoptic oximetrie in de arteria pulmonalis.

De positie van de catheter is uitgebreid bediscussieerd in het literatuur overzicht inzake de oximetrie. Hierin werd geconcludeerd, dat de nadelen (niet volledige menging van het bloed, grotere gevoeligheid voor catheter bewegingen en reflectie van de atrium wand) waarschijnlijk even geldig zijn in de neonatalogie als in de volwassen klinische zorg. Maar men moet zich bedenken, dat de meting van de gemengd veneuze zuurstofsaturatie $\left(\mathrm{SvO}_{2}\right)$ in de neonatologie alleen mogelijk is in het rechteratrium, omdat het gebruik van een arteria pulmonalis catheter in een (prematuur) pasgeboren kind moeilijk en gevaarlijk is. Wel dient men te anticiperen op de genoemde nadelen van de $\mathrm{ScvO}_{2}$ meting in het rechteratrium door a) frequent een in vivo calibratie uit te voeren en $b$ ) door bedachtzaam te zijn bij het berekenen van zuurstoftransport variabelen gebaseerd op centraal veneuze zuurstofsaturatie metingen.

Enkele opmerkingen dienen nog gemaakt te worden over de beperkingen en nadelen van het gebruik van een "single" lumen navelvene catheter in de praktische neonatale intensieve zorg. Sinds kort is het in de neonatale intensieve zorg routine geworden om dubbel of zelfs triple lumen navelvene catheters te gebruiken. Het routinematig toepassen van deze catheters wordt gerechtvaardigd door het gelijktijdig en continue toedienen van medicijnen en parenterale voeding. Het gebruik maken van een "single" lumen catheter zoals de door ons gebruikte $4 \mathrm{Fr}$. catheter lijkt zich nu te beperken tot meer stabiele kinderen, in wie nu juist de meting van de veneuze saturatie niet direct noodzakelijk is. Een andere beperking van een navelvene catheter is het feit dat slechts in twee derde van de patiënten een catheter correct via de ductus venosus in het rechteratrium gepositioneerd kon worden.

Samenvattend zal men aan de ene kant met een zekere terughoudendheid de $\mathrm{ScvO}_{2}$ meting in overweging nemen gezien de beperkingen van een "single" lumen catheter terwijl men aan de andere kant zich dient te realiseren dat de fiberoptic catheter betrouwbaar en nauwkeurig de $\mathrm{ScvO}_{2}$ waarde van pasgeboren kinderen weergeeft. 

extra zuurstofbehoefte. De relatie tussen $\mathrm{SaO}_{2}$ en $\mathrm{ScvO}_{2}$ waarden. De waarde van de fractionele zuurstof extractie en de "shunt index".

We hebben in een prospectief klinisch observationeel onderzoek de reeks van $\mathrm{ScvO}_{2}$ waarden beschreven van 10 stabiele pasgeboren kinderen die geen extra zuurstof (meer) nodig hadden. Hierbij werd een reeks $\mathrm{ScvO}_{2}$ waarden gevonden van $60 \%$ tot $83 \%$ ( 5 e en 95 ste percentiel). Andere variabelen, die het zuurstoftransport kunnen beïnvloeden waren normaal: $\mathrm{SaO}_{2}:>86 \%$; hemoglobine: $>7.0 \mathrm{mmol} / \mathrm{L} ; \mathrm{pH}$ en bloeddruk:normaal. Deze reeks $\mathrm{ScvO}_{2}$ waarden in stabiele niet zieke kinderen is gelijk aan de waarden beschreven bij volwassenen, hoewel het zuurstofverbruik bij pasgeborenen duidelijk hoger is dan bij volwassenen. Het hogere zuurstofverbruik wordt kennelijk gecompenseerd door een toegenomen zuurstofaanbod aan de weefsels. En inderdaad zowel de cardiac output als de hemoglobine concentratie zijn hoger in de neonatale periode in vergelijking met de volwassen leeftijd.

De relatie tussen $\mathrm{ScvO}_{2}$ en $\mathrm{SaO}_{2}$ werd eveneens onderzocht. In zeven patiënten vertoonden de $\mathrm{ScvO}_{2}$ waarden een significante correlatie met de $\mathrm{SaO}_{2}$ waarden. Dit toont aan dat, wanneer $\mathrm{SaO}_{2}$ vermindert, $\mathrm{ScvO}_{2}$ in evenredige mate vermindert, zodat een stabiel zuurstofverbruik in stand kan worden gehouden. In drie patiënten waren de $\mathrm{SaO}_{2}$ en $\mathrm{ScvO}_{2}$ niet met elkaar gecorreleerd. Speculerend kunnen wij aannemen dat het zuurstofverbruik bij deze kinderen in stand werd gehouden door een toename van de cardiac output, omdat in stabiele patiënten het zuurstofverbruik onafhankelijk is over een groot traject van het zuurstofaanbod.

Het zuurstofaanbod is gewoonlijk vier tot vijf keer zo groot als het zuurstofverbruik, zoals naar voren komt in de normale waarde van de fractionele zuurstof extractie van 0.20 tot 0.25 . In ons onderzoek geanalyseerd voor iedere patiënt afzonderlijk werd een reeks $\left(5^{\circ}\right.$ en $95^{\text {te }}$ percentiel) van waarden tussen de 0.13 en 0.33 werd gevonden. Er bestond een zeer goede correlatie tussen de fractionele zuurst of extractie en de $\mathrm{ScvO}_{2}$. Hierin wordt nogmaals het opmerkelijke belang van de $\mathrm{ScvO}_{2}$ angetoond als een monitor van de balans tussen het zuurstofaanbod en zuurstofverbruik.

Verder maakt de $\mathrm{ScvO}_{2}$ het mogelijk om de shunt index te berekenen: de shunt index is een vereenvoudigde bepaling van de veneuze admixture. Wij vonden in deze 10 stabiele pasgeborenen een reeks waarden tussen $7 \%$ en $53 \%$. Er was sprake van een duidelijke negatieve correlatie tussen de shunt index en $\mathrm{SaO}_{2}$ in alle patiënten: in andere woorden bij lagere $\mathrm{SaO}_{2}$ waarden was er sprake van een toegenomen shunt index.

5.

De reeks van $\mathrm{ScvO}_{2}$ waarden tijdens de acute fase van respiratoire problemen in pasgeboren kinderen met kunstmatige beademing en extra zuurstofbehoefte. De relatie tussen $\mathrm{SaO}_{2}$ en $\mathrm{ScvO}_{2}$ waarden. Fractionele zuurstof extractie en shunt index. Het belang van de $\mathrm{ScvO}_{2}$ meting in de neonatale klinische zorg.

$W_{i j}$ hebben tot slot een observationele studie verricht in twaalf pasgeboren kinderen met kunstmatige beademing en extra zuurstof om de $\mathrm{ScvO}_{2}$ waarden te bepalen op verschillende niveaus van oxygenatie gedefinieerd door de $\mathrm{SaO}_{2}$, waarde: $\mathrm{SaO}_{2}$ waarden onder $86 \%, \mathrm{SaO}_{2}$ waarden tussen 86 en $90 \%$ en $\mathrm{SaO}_{2}$ waarden tussen 91 en $96 \%$. Deze laatste twee niveaus behoren, respectievelijk, tot het lage en hoge gedeelte van de in de literatuur anbevolen reeks van $\mathrm{SaO}_{2}$ waarden, zoals die gemeten wordt door de polsoximetrie.

De $\mathrm{ScvO}_{2}$ waarden in het lage en in het hoge gedeelte van de aanbevolen $\mathrm{SaO}_{2}$ 
waarden komen overeen met de "normale" $\mathrm{ScvO}_{2}$ waarden zoals deze door ons zijn beschreven in kinderen, die geen extra zuurstof nodig hadden. Lagere $\mathrm{ScvO}_{2}$ waarden worden meestal gevonden in het laagste oxygenatie niveau bij $\mathrm{SaO}_{2}$ waarden onder $86 \%$.

Een significante correlatie tussen $\mathrm{SaO}_{2}$ en $\mathrm{ScvO}_{2}$ werd in alle kinderen op één na gevonden. De helling van de regressielijnen vervaardigd voor ieder kind afzonderlijk toonde geen significant verschil tussen de twee gedeelten van de aanbevolen oxygenatie waarden. In het laagste oxygenatie niveau bij $\mathrm{SaO}_{2}$ waarden onder de $86 \%$ waren de $\mathrm{ScvO}_{2}$ waarden duidelijk verminderd ten opzichte van het oxygenatie niveau met $\mathrm{SaO}_{2}$ waarden tussen 86 $\%$ en $96 \%$. In twee patiënten was de mate van de $\mathrm{ScvO}_{2}$ vermindering (de helling van de regressielijn) significant toegenomen in vergelijking met de $\mathrm{ScvO}_{2}$ vermindering in de hogere oxygenatie niveaus. Blijkbaar was er in deze patiënten sprake van een toegenomen zuurstof extractie, terwijl andere compensatie mechanismen zoals cardiac output niet in staat waren om de verminderde zuurstofsaturatie te compenseren.

In ons onderzoek werd een toegenomen shunt index gevonden in het lagere gedeelte van de aanbevolen $\mathrm{SaO}_{2}$ waarden. $\mathrm{Bij} \mathrm{SaO}_{2}$ waarden onder de $86 \%$ was de shunt index verder toegenomen tot zelfs waarden van $60 \%$ tot $80 \%$. Aangenomen moet worden dat er een zekere mate van een intrapulmonale shunting of een minder goed op elkaar afgestemd zijn van long perfusie en ventilatie moet bestaan om deze toegenomen veneuze admixture te kunnen verklaren in de lagere niveaus van oxygenatie. Aan de andere kant kan men zich afvragen of een berekend item als de shunt index werkelijk een betrouwbare afspiegeling is van klinische problemen, hoewel aan de voorwaarden en vooronderstellingen om de shunt index te gebruiken wel voldaan was.

Fractionele zuurstof extractie was, al was het in geringe mate $(r-0.18$ tot 0.39$)$ in zes patiënten significant gecorreleerd met $\mathrm{SaO}_{2}$.

Samenvattend liet de "on line" monitoring van $\mathrm{ScvO}_{2}$ zien dat $\mathrm{ScvO}_{2}$ daalde bij afnemende niveaus van oxygenatie. $\mathrm{De} \mathrm{ScvO}_{2}$ waarden waren niet buiten de reeks van waarden, zoals die beschreven is bij kinderen, die geen extra zuurstof nodig hadden. Deze vermindering van $\mathrm{ScvO}_{2}$ waarden lijkt het eerste compensatiemechanisme te zijn om het zuurstofverbruik van de weefsels in stand te houden. Betreffende de discussie over de alarmgrenzen van $\mathrm{SaO}_{2}$ inzake de neonatale zuurstof therapie kan de meting van de $\mathrm{ScvO}_{2}$ een nieuw element in deze discussie brengen: Een lagere grenswaarde voor $\mathrm{SaO}_{2}$ zou eventueel geaccepteerd kunnen worden, wanneer gelijktijdige gemeten $\mathrm{ScvO}_{2}$ waarden in evenredige mate verminderd zijn, en dus het zuurstofverbruik van de weefsels stabiel is gebleven. Men kan dan ook concluderen, dat het verschil tussen de $\mathrm{SaO}_{2}$ en $\mathrm{ScvO}_{2}$ waarden van groter belang lijkt te zijn dan de absolute waarde van $\mathrm{ScvO}_{2}$ alleen.

Aangaande de vraag welke het klinisch belang is om de $\mathrm{ScvO}_{2}$ waarde te kennen, zullen hier in het kort drie klinische casus worden gepresenteerd als voorbeelden dat de continue meting van $\mathrm{ScvO}_{2}$ een waardevolle complementaire monitor van de oxygenatie kan zijn:

Casus 1. Prematuur kind; zwangerschapsduur: 28 weken; geboortegewicht: 890 gram. Diagnose: IRDS en E Coli sepsis, meningitis. Behandeling: positieve druk beademing; hoge frequentie beademing; intratracheale surfactant suppletie. Het klinisch beloop werd gecompliceerd door een intraventriculaire bloeding. De navelvene werd gecatheteriseerd met een fiberoptic catheter voor centraal veneuze toegang en de meting van de $\mathrm{ScvO}_{2}$. De punt van de catheter was gelegen op de overgang van het rechteratrium naar de vena cava inferior. De zuurstofsaturatie weergave van de fiberoptic catheter kwam overeen met de waarden van de hemoximeter $(77.16 \% \pm 3.25$ vs $76.16 \% \pm 4.41)$ Het hemoglobine daalde van $8.5 \mathrm{mmol} / \mathrm{L}$ tot $7.6 \mathrm{mmol} / \mathrm{L}$ en verder tot $6.8 \mathrm{mmol} / \mathrm{L}$, waarschijnlijk vanwege veel bloedafnames. $\mathrm{De} \mathrm{SaO}_{2}$ waarden lieten geen enkele verandering zien, maar de $\mathrm{ScvO}_{2}$ 
verminderde significant met een stijging van de fractionele zuurstof extractie.

Casus 2. Prematuur kind; zwangerschapsduur: 27 weken; geboortegewicht: 720 gram. De bevalling werd gecompliceerd door een matig ernstige asphyxie. De navelvene werd gecatheteriseerd met een fiberoptic catheter voor centraal veneuze toegang en de meting van de $\mathrm{ScvO}_{2}$. Het klinisch beloop werd gecompliceerd door een respiratoire insufficiëntie en ernstige hypotensie. Positieve drukbeademing en intratracheale surfactant suppletie waren noodzakelijk. De bloeddruk werd ondersteund door middel van volume therapie en dopamine en dobutamine. Na de dopamine medicatie opgevoerd te hebben tot een dosering van $30 \mu \mathrm{g} / \mathrm{kg} / \mathrm{min}$ nam de $\mathrm{ScvO}_{2}$ toe van $70.5 \% \pm 5.0$ tot $78.6 \% \pm 6.7$ in tegenstelling tot de $\mathrm{SaO}_{2}$ die zelfs iets verminderde van $91.8 \% \pm 3.4$ tot $90.0 \% \pm 2.6$.

Casus 3. Prematuur kind; zwangerschapsduur: 28 weken; geboortegewicht: 1350 gram. De bevalling werd gecompliceerd door een ernstige asphyxie. Arteriële navelstreng $\mathrm{pH}$ : 6.89. Onmiddellijk na de bevalling werd begonnen met kunstmatige beademing. $\mathrm{Na}$ stabilisatie werd de navelvene gecatheteriseerd met een fiberoptic catheter voor een centraal veneuze toegang en de meting van de $\mathrm{ScvO}_{2}$. Het beloop liet een respiratoire verbetering zien, zodanig dat de kunstmatige beademing gestopt kon worden. Maar er ontstonden epileptische trekkingen die geassocieerd waren met een verhoging van de hartfrequentie en de bloeddruk en een kleine vermindering van de $\mathrm{SaO}_{2}$. De $\mathrm{ScvO}_{2}$ daalde gedurende deze episodes van $75 \%$ tot $55 \%$. Antiepileptische medicatie werd begonnen en deze episodes deden zich niet meer voor.

Deze drie casus illustreren dat de continue meting van de $\mathrm{ScvO}_{2}$ ons in staat stelde om veranderingen in de balans tussen het zuurstofaanbod en het zuurstofverbruik waar te nemen, terwijl $\mathrm{SaO}_{2}$ geen grote veranderingen liet zien. De eerste patiënt laat een vermindering zien van het zuurstofgehalte in het arteriële bloed door een laag hemoglobine, hetgeen wordt gecompenseerd door een toegenomen zuurstof extractie. De tweede patiënt werd behandeld met een volumetherapie en inotropica ondersteuning. De verbetering van het zuurstofaanbod door een toegenomen cardiac output leidde tot een verhoogde $\mathrm{ScvO}_{2}$ waarde. In de derde patiënt verminderde de $\mathrm{ScvO}_{2}$ vanwege het toegenomen zuurstofverbruik door de epileptische convulsies.

Ofschoon wij ons realiseren dat deze casus niet op een wetenschappelijke manier de klinische bruikbaarheid van de $\mathrm{ScvO}_{2}$ meting aantonen, denken we dat zij wel de effectiviteit illustreren van deze meting. Tevens laten deze casus de verschillende variabelen zien, die de waarde van $\mathrm{ScvO}_{2}$ bepalen. De interpretatie van abnormale waarden kan daarom soms moeilijk zijn. Bovendien kunnen ook normale waarden stoornissen in het zuurstoftransport niet volledig uitsluiten bij voorbeeld in organen afzonderlijk of in het geval van sepsis.

In dit afsluitend hoofdstuk willen wij nog kort ingaan op enkele ideeën voor toekomstig onderzoek in deze richting. Toekomstig onderzoek kan gericht worden naar het vereenvoudigen van de interpretatie van de $\mathrm{ScvO}_{2}$ waarden in de klinische praktijk. Bijvoorbeeld door het continue monitoren van ander variabelen, die de $\mathrm{ScvO}_{2}$ meebepalen. Het lijkt erop, dat de continue meting van de cardiac output tot de mogelijkheden van de volwassen intensive care kan gaan behoren. Hoewel deze meting nog niet klaar is voor de neonatale intensieve care is het de moeite waard om de vooruitgang en de klinische trials in dezen goed in de gaten te houden. In dezelfde richting ligt de meting van de intramucosale $\mathrm{pH}$ meting in de maag voor het evalueren van het (an)aërobe weefsel metabolisme. Onlangs is er een maagsonde op de markt gekomen, die ook geschikt is voor kleine pasgeboren 
kinderen.

Het literatuuroverzicht in dit proefschrift leerde ons dat er nog veel over de perinatale ontwikkeling van de microvasculatuur nog onbekend of onvoldoende onderzocht is. Ook de laat foetale en de perinatale ontwikkeling van het eind-orgaan van het zuurstoftransport, het mitochondrion is nog onvoldoende onderzocht. Het feit dat de perinatale ontwikkeling wordt gekarakteriseerd door een "switch" van een metabolisme met een lage zuurstofverbruik naar een efficiënte oxidatieve phosphorilatie en dat deze "switch" gepaard gaat met een snelle proliferatie en maturatie van de mitochondria heeft onze interesse gewekt. Wordt deze "switch" gecontroleerd door een intrinsieke klok in de cel of wordt hij getriggerd door de geboorte zelf. En welke zijn dan de consequenties bij een premature geboorte?

$\mathrm{ScvO}_{2}$ is gedefinieerd als de gemiddelde waarde van de veneuze saturaties afkomstig van alle organen, en is mede bepaald door de bloeddoorstroming door die verschillende organen. De $\mathrm{ScvO}_{2}$ weerspiegelt alle factoren die het zuurstofaanbod en het zuurstofverbruik bepalen. In de neonatologie is de $\mathrm{ScvO}_{2}$ meting in het rechteratrium samen met de $\mathrm{SaO}_{2}$ meting door middel van de pols oximetrie bruikbaar als een aanvullende monitor van het zuurstoftransport bij pasgeboren kinderen. 


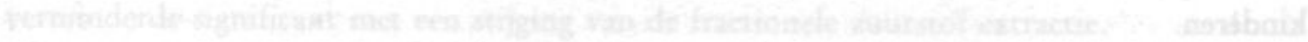

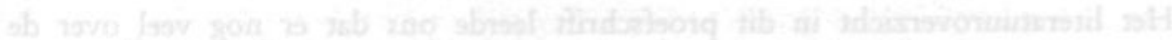

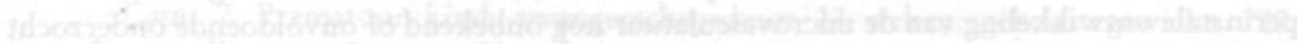

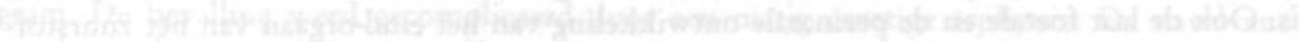

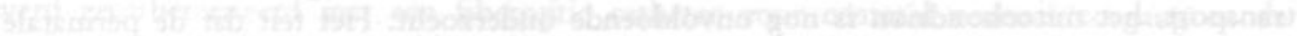

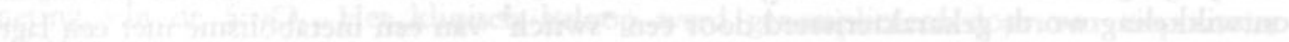

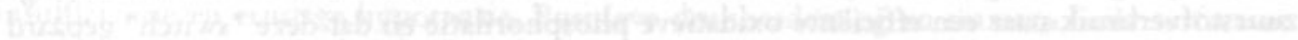

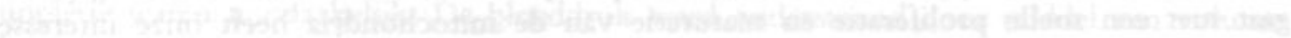

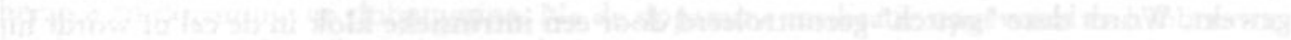

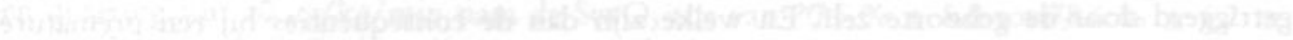
watactar

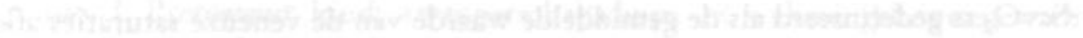

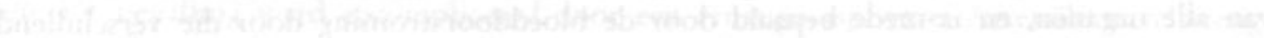

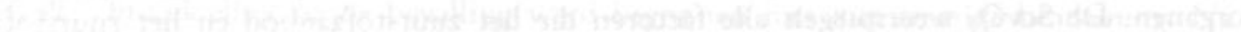

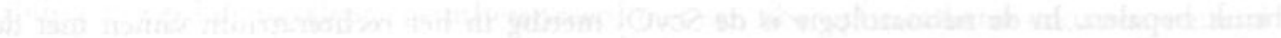

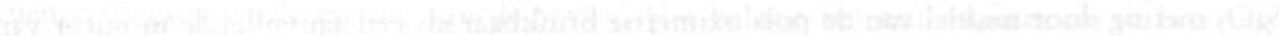

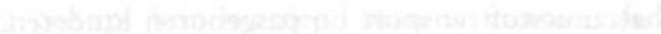




\section{Dankwoord}

Carlos Blanco bedank ik voor zijn ideeën bij het opzetten en uitvoeren van het onderzoek. Zijn kritische kanttekeningen (letterlijk en figuurlijk) bij de manuscripten van de artikelen waren van grote waarde en bovendien erg leerzaam. Kortom, ik ben hem dankbaar voor het "leren onderzoek te doen". Ik ben er trots op door hem tot neonatoloog te zijn opgeleid en ik beschouw het als een voorrecht om met hem dit vak uit te kunnen oefenen.

Wiel Maertzdorf ken ik vanaf mijn sollicitatie in Maastricht. Hij is dan ook nadrukkelijk verbonden met mijn vorming tot kinderarts, neonatoloog en "import Maastrichtenaar". Ik ben hem dankbaar voor het meedenken, meediscussiëren en meelezen met dit proefschrift.

Ik dank mijn collega's neonatologen Pieter Degraeuwe, jarenlang mijn kamergenoot, Danilo Gavilanes, Twan Mulder en Eduardo Villamor voor de goede en vriendelijke sfeer en voor de belangstelling naar de vorderingen van het boekje.

Ik dank de verpleegkundigen van de neonatologie afdeling E2 voor hun geïnteresseerde, soms wat ongelovige vragen naar het proefschrift. Ja, het is echt waar, ik ga promoveren op "die catheters".

Theo Hoorntje wil ik bedanken voor zijn hulp en betrokkenheid bij de biggetjesexperimenten.

Ik wil mijn ouders bedanken voor hun vertrouwen en ondersteuning tijdens de studiejaren. Ik ben blij, dat zij deze afsluiting van de studie kunnen meemaken.

Tot slot bedank ik Brigitte: aan haar en aan onze kinderen is dit boek opgedragen. 


\section{Curriculum Vitae}

De schrijver van dit proefschrift werd geboren in 's-Gravenhage op 18 november 1954. In 1973 werd op het Aloysius college te 's-Gravenhage het Gymnasium B eindexamen behaald.

Van 1973 tot 1981 studeerde hij geneeskunde aan de Rijksuniversiteit Leiden. Het doctoraal examen werd behaald in 1980 . Op 18 september 1981 behaalde hij zijn artsexamen.

Van 1982 tot 1986 volgde hij de opleiding kindergeneeskunde bij Prof.dr. LHJ. Ramaekers in het Annadal ziekenhuis in Maastricht. De datum van inschrijving in het register als kinderarts is 1 februari 1986. Hierna was hij werkzaam tot maart 1988 als chef de clinique in het De Weverziekenhuis en de St. Elisabeth kliniek, de vroedvrouwenschool, te Heerlen. Van 1988 tot 1990 volgde hij de opleiding tot kinderarts-neonatoloog bij Prof.dr. CE. Blanco in het Academisch Ziekenhuis Maastricht.

Vanaf maart 1990 is hij werkzaam als kinderarts-neonatoloog bij de capaciteitsgroep kindergeneeskunde in het Academisch Ziekenhuis Maastricht.

Binnen de Universiteit Maastricht is hij werkzaam als blokcoördinator van het blok 2.6 (Geboren en getogen).

Hij is getrouwd met Brigitte van Wijk en zij hebben drie kinderen. 

